Technische Universität München

Lehrstuhl für Ernährungsphysiologie

\title{
Amino acid absorption and homeostasis in mice lacking the intestinal peptide transporter PEPT1
}

Anna-Maria NäßI

Vollständiger Abdruck der von der Fakultät Wissenschaftszentrum Weihenstephan für Ernährung, Landnutzung und Umwelt der Technischen Universität München zur Erlangung des akademischen Grades eines

Doktors der Naturwissenschaften

genehmigten Dissertation.

Vorsitzender:

Univ.-Prof. Dr. D. Haller

Prüfer der Dissertation:

1. Univ.-Prof. Dr. H. Daniel

2. Univ.-Prof. Dr. M. Klingenspor

Die Dissertation wurde am 24.08.2011 bei der Technischen Universität München eingereicht und durch die Fakultät Wissenschaftszentrum Weihenstephan für Ernährung, Landnutzung und Umwelt am 06.02.2012 angenommen. 

Meinen Eltern 



\section{Table of Content}

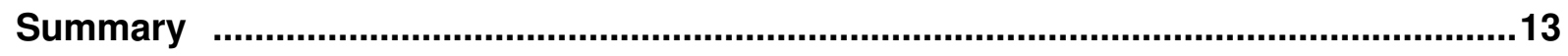

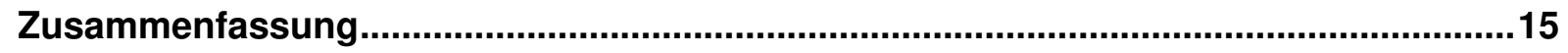

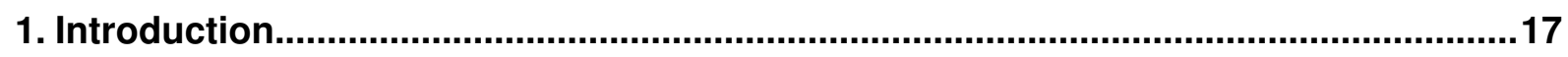

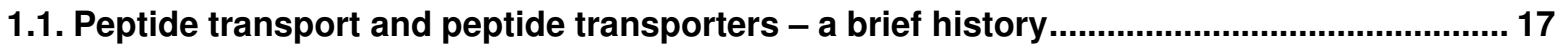

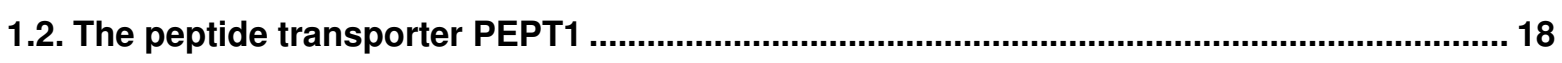

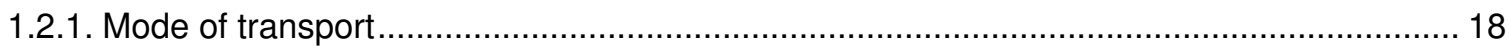

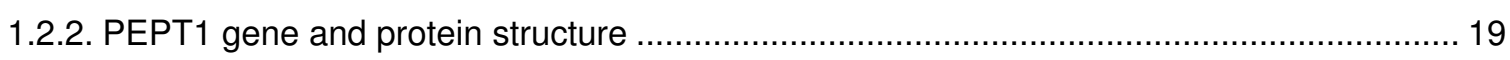

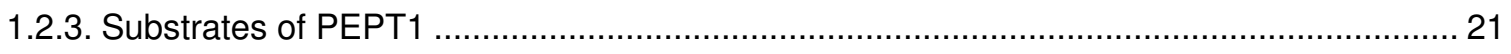

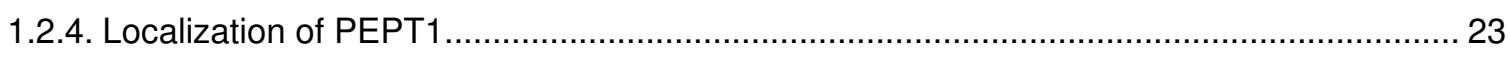

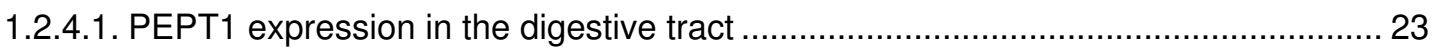

1.2.4.2. Expression of PEPT1 in extra-intestinal tissue ................................................. 24

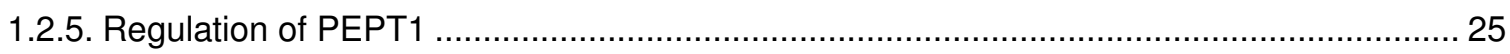

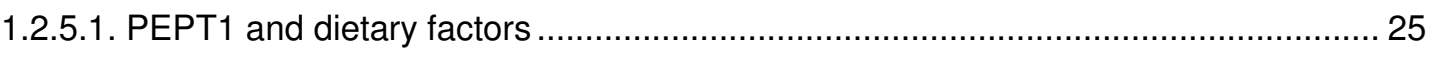

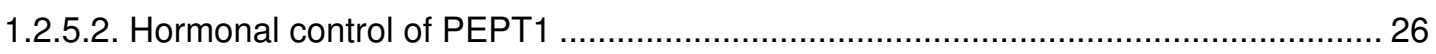

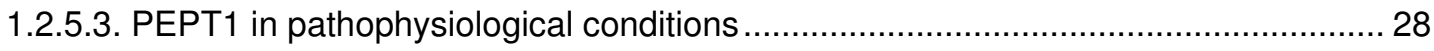

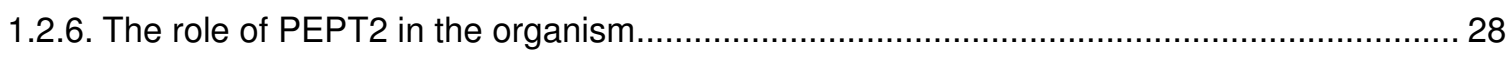

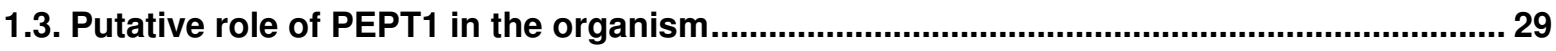

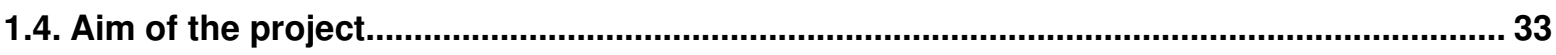

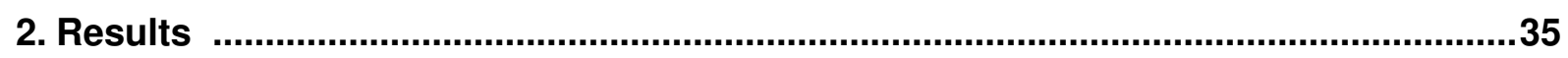

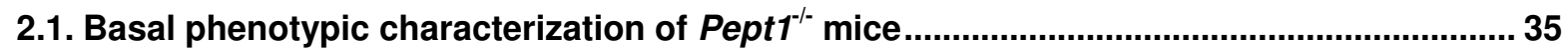

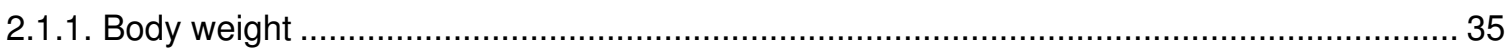

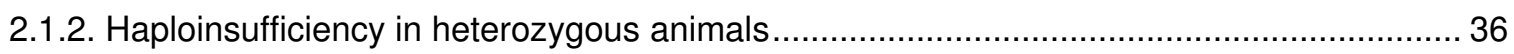

2.1.3. Characterization of tissue samples by profiling techniques.............................................. 37

2.1.4. Amino acid transport and peptide transporter expression in kidney tissue ....................... 40

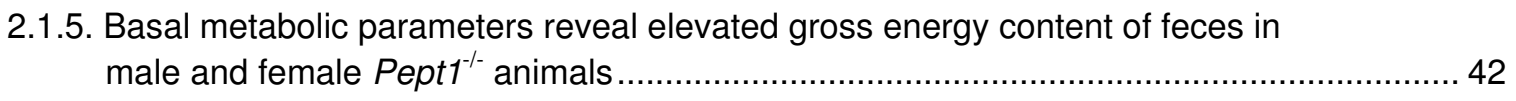

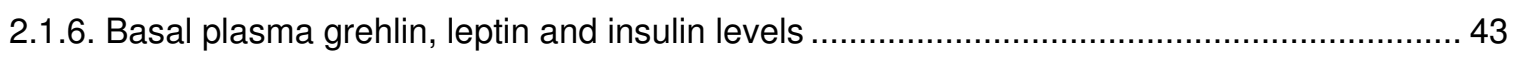


2.2.1. Clinical chemical parameters

2.2.2. Basal amino acid levels in plasma, urine and tissue in male mice

2.2.3. Enzyme and urea levels in liver. 49

2.3. Effects of dietary protein intake on phenotypic changes in PEPT1-deficient mice. 49

2.3.1. Subtle effects after administration of a low-protein diet. 49

2.3.2. Effects of feeding a high-protein diet on Pept $1^{-/-}$mice 51

2.3.2.1. Metabolic parameters 51

2.3.2.2. Energy content of feces in Pept $1^{-/-}$mice is elevated when fed a HP diet....... 53

2.3.2.3. Energy assimilation differences 54

2.3.2.4. Clinical chemistry plasma and urine parameters in animals fed a HP diet....... 54

2.3.2.5. High-protein diet alters plasma amino acid levels .................................... 56

2.3.2.6. Liver tissue amino acid levels and enzyme activities in $P e p t 1^{-/-}$animals................. 60

2.3.2.7. Decreased leptin levels in Pept $1^{-/}$animals ............................................... 63

2.3.3. Gender aspects in the effects of a high-protein diet ........................................... 64

2.3.3.1. Modified clinical chemistry plasma parameters in female Pept ${ }^{-/}$mice ................. 65

2.3.3.2. Alterations in plasma and liver amino acids of female Pept $1^{-/-}$mice on a

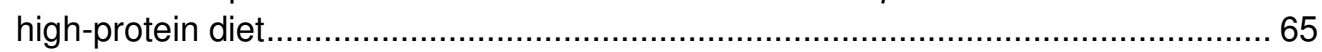

2.3.3.3. Enzyme activities and urea concentration in liver tissue .............................. 68

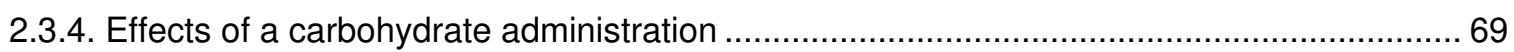

2.3.4.1. Administration of a high-protein diet and water enriched with glucose.................69

2.3.4.2. Blood glucose and insulin secretion after an oral glucose tolerance test............... 71

2.4. Effects of an acute protein administration by gavage ................................................... 72

2.4.1. Changes in plasma amino acids after administration of a low dose of ${ }^{15} \mathrm{~N}$-labeled protein

2.4.2. Effects of a high intragastric protein load on plasma and liver amino acid levels in $P$ ept $1^{+/+}$and Pept $1^{-/-}$animals

3. Discussion

3.1. Basal phenotypic characterization. 


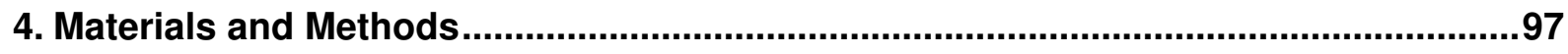

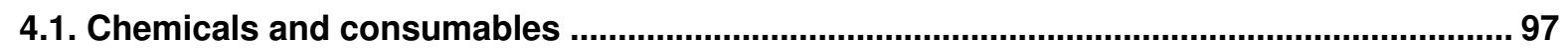

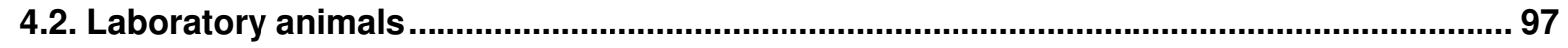

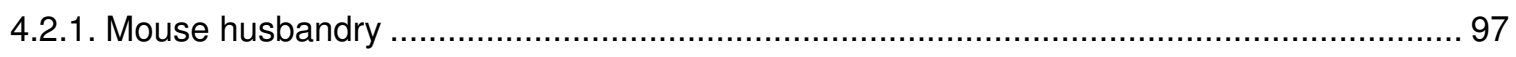

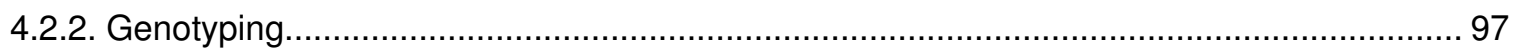

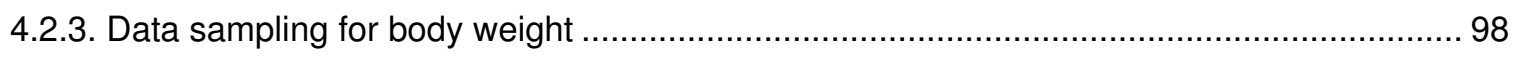

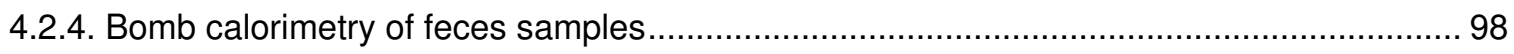

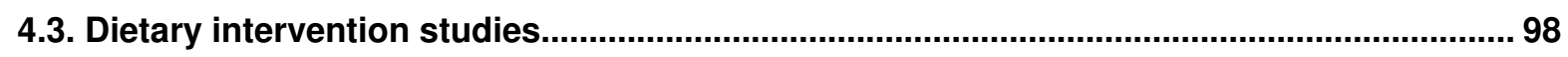

4.3.1. Dietary intervention study with low, medium and high protein content for 5 days

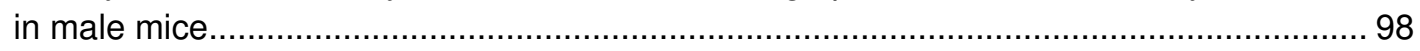

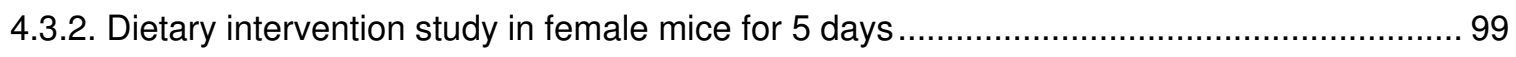

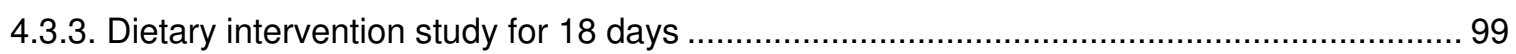

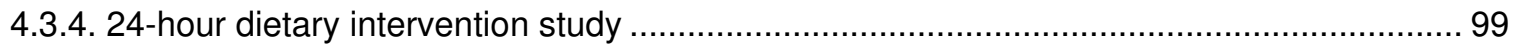

4.4. High protein load and administration of low $15 \mathrm{~N}$-labeled protein load by

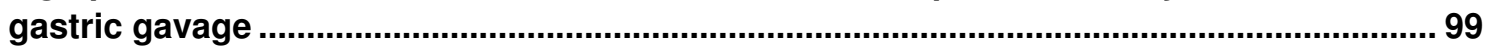

4.5. Analysis of selected metabolites in body fluids and tissue .......................................... 100

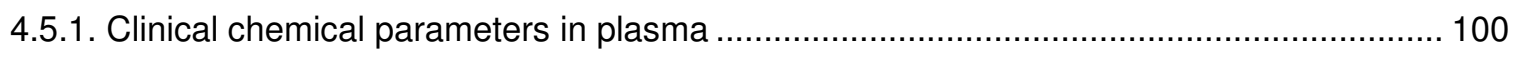

4.5.2. Amino acid analysis in plasma, urine and tissue ....................................................... 100

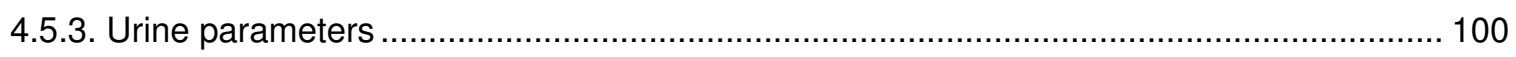

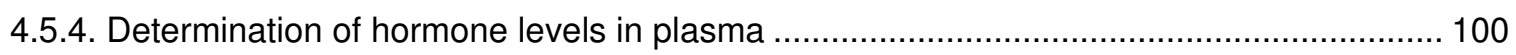

4.5.5. Measurement of enzyme activites in liver and kidney tissue........................................ 101

4.5.6. Oral glucose tolerance test (OGTT) and insulin measurement ...................................... 101

4.6. Characterization of tissue samples by profiling techniques............................................ 101

4.6.1. Proteome analysis of intestinal tissue by 2D-PAGE and MALDI-TOF-MS ...................... 101

4.6.2. Transcriptome analysis of mucosal samples by cDNA microarrays................................ 102

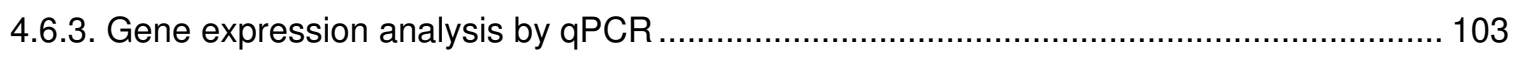

4.7. Western blot analysis and uptake studies in BBMV and everted gut sacs ...................... 103

4.7.1. Intestinal brush border membrane vesicles (BBMV) .................................................... 103

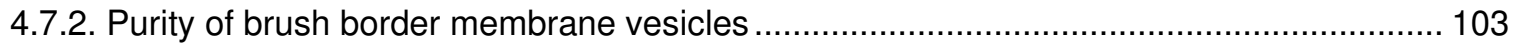

4.7.3. Preparation of BBMV from kidney tissue and uptake studies ......................................... 104

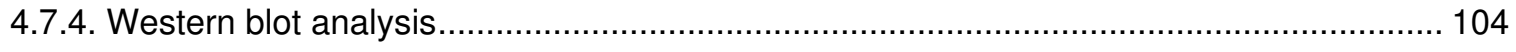

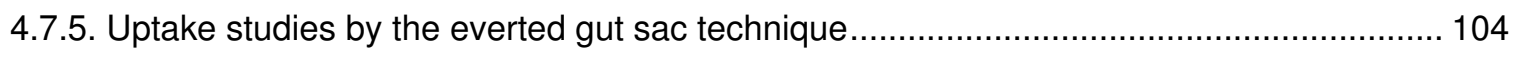




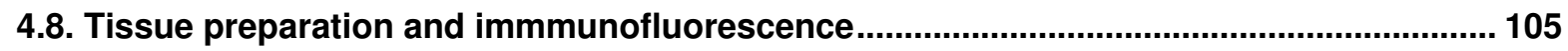

4.9. Detection of B-galactosidase activity via X-gal staining................................................ 105

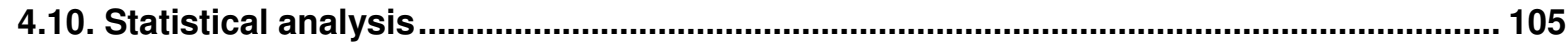

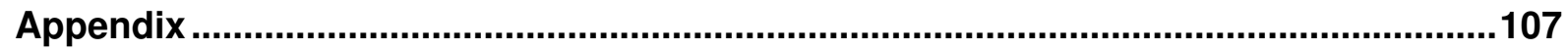

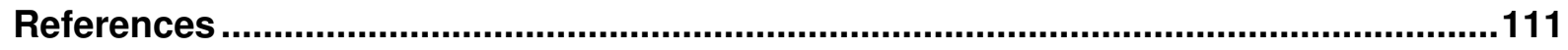

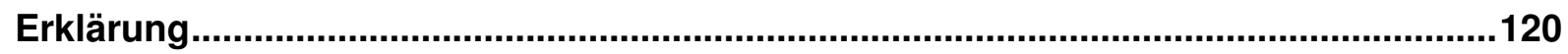

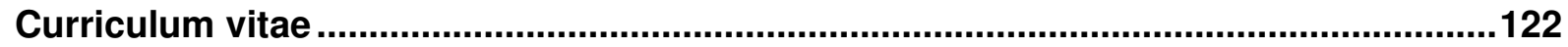

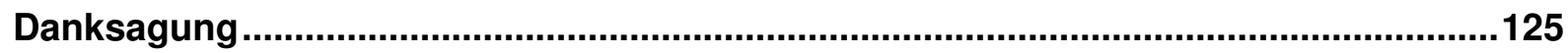




\section{List of Tables}

Table 1: Changes in protein levels in mucosal tissues of PEPT1-deficient animals. 37

Table 2: Microarray analysis of mucosal tissue of Pept1-deficient animals.

Table 3: Basal clinical chemical parameters in plasma of female and male $\mathrm{Pept}^{+/+}$and Pept1//- mice.

Table 4: Basal plasma amino acid concentrations in male mice

Table 5: Basal urinary amino acids in male mice (corrected for creatinine)

Table 6: Liver amino acid concentrations of male mice on control diet

Table 7: Basal enzyme activities in liver tissue of male Pept ${ }^{-\%}$ animals 49

Table 8: Metabolic parameters in response to a low-protein diet for 5 days in male mice 50

Table 9: Metabolic parameters of Pept1+/+ and Pept1-/- mice in response to high-protein intake for 18 days

Table 10: Metabolic parameters of $P e p t 1^{+/+}$and Pept $1^{-/-}$animals in response to high-protein intake for 24 hours.

Table 11: Energy assimilation in Pept $1^{+/+}$and Pept $1^{-/}$animals on low-protein (8\%), control $(21 \%)$ or high-protein $(45 \%)$ diet over a period of 5 days.

Table 12: Clinical chemistry parameters in plasma of mice after 5 days on high-protein diet 55

Table 13: Clinical chemistry parameters in plasma of mice after 18 days on high-protein diet...... 55

Table 14: Plasma amino acid levels of $\mathrm{Pept}^{+/+}$and $P e p t 1^{-/-}$animals after 24 hours on high-protein diet.

Table 15: Plasma amino acid levels of $P e p t 1^{+/+}$and Pept $1^{-/}$animals after 5 days on high-protein diet.....

Table 16: Plasma amino acid levels of $P e p t 1^{+/+}$and $P e p t 1^{-/}$animals after 18 days on high-protein diet.

Table 17: Liver amino acid concentrations of $P e p t 1^{1 /+}$ and Pept $1^{-/}$mice after 24 hours on high-protein diet.

Table 18: Liver amino acid concentrations of $P e p t 1^{+/+}$and $P e p t 1^{-1 /}$ mice after 18 days on high-protein diet.....

Table 19: Enzyme activities in liver tissue after 24 hours and 18 days on high-protein diet......

Table 20: Clinical chemistry parameters in plasma of female mice after 5 days on high-protein diet.

Table 21: Plasma amino acid levels of female mice after 5 days on high-protein diet

Table 22: Liver amino acid concentrations in female $\mathrm{Pept}^{+/+}$and $\mathrm{Pept1^{-/ }}$ animals

Table 23: Enzyme activities and urea concentration in liver tissue of female mice after 5 days on high-protein diet. 
Table 24: Metabolic parameters and calculations for energy supply 69

Table 25: Amino acid concentrations of samples from heart and portal vein 15 and 30 minutes after administration of ${ }^{15} \mathrm{~N}$-labeled protein

Table 26: Amino acid concentrations in intestinal tissue samples from JJ, DD and IL after gavage with ${ }^{15} \mathrm{~N}$-labeled protein

Table 27: Amino acid concentrations in plasma after intragastric administration of a high-protein load... 76

Table 28: Enzyme activities in liver tissue 60 minutes after a high-protein load by gavage........ 78

Table 29: Liver amino acids 60 minutes after intragastric administration of a high-protein load 78 


\section{List of Figures}

Fig. 1: PEPT1-mediated uptake of peptides in the context of the epithelial cell .............................. 19

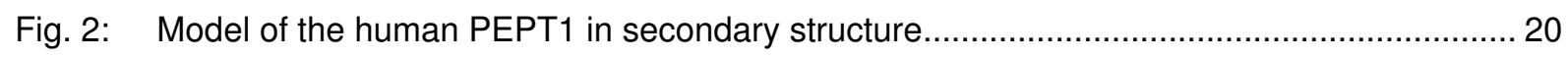

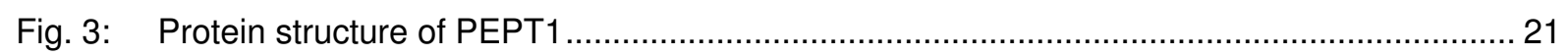

Fig. 4: Molecular structures of selected pharmacologically important compounds that serve as substrates of PEPT1 (from [46]) ........................................................................ 23

Fig. 5: Proposed regulation of PEPT1 promotor activity by Cdx2 and Sp1 (from [69])................... 27

Fig. 6: Schematic of the mouse wild-type allele, the targeting construct and the Pept1 knockout (Pept1 ${ }^{\text {LacZ Neo }}$ ) allele.

Fig. 7: Body weight changes in wildtype animals and mice heterozygote and homozygote for a PEPT1-deficiency

Fig. 8: Protein expression levels in intestinal BBMV 36

Fig. 9: Gly-Sar uptake by everted gut sacs 37

Fig. 10: 2D-PAGE analysis of proteins from mucosal scrapings. 38

Fig. 11: Immunolocalization of PEPT1 in kidney tissue 40

Fig. 12: PEPT1 protein expression levels in kidney BBMV. 40

Fig. 13: X-Gal staining in kidney tissue 41

Fig. 14: Protein expression level of PEPT2 in kidney tissue 41

Fig. 15: Uptake studies with L-proline and D-glucose in BBMV of kidney tissue 42

Fig. 16: Basal metabolic parameters in male and female mice on standard diet. 42

Fig. 17: Gross energy content of excreted feces in male and female mice on control diet ...... 43

Fig. 18: Determination of hormones in plasma of fed and fasted animals. 43

Fig. 19: Urine osmolarity and urea and creatinine levels in female and male $P e p t 1^{+/+}$and Pept $1^{-1-}$ animals.

Fig. 20: Metabolic parameters of $\mathrm{Pept}^{+{ }^{+/}}$and Pept $1^{-/}$animals on HP diet for 5 days. 51

Fig. 21: Metabolic parameters of $\mathrm{Pept}^{+/+}$and Pept $1^{-/-}$animals on HP diet for 18 days. 52

Fig. 22: Gross energy content of mice during the 5 day dietary intervention study 53

Fig. 23: Urea concentrations in $P e p t 1^{+/+}$and $P e p t 1^{-1-}$ animals on a high-protein diet 56

Fig. 24: Changes in plasma amino acid levels after 1, 5 and 18 days on high-protein diet in $P$ ept $1^{-1-}$ animals.

Fig. 25: Determination of leptin, insulin and ghrelin plasma levels in fed and fasted animals after $24 \mathrm{~h}$ on a high protein diet.

Fig. 26: Metabolic parameters of female $P e p t 1^{+/+}$and $P e p t 1^{-/}$animals fed a HP diet for 5 days...... 64 
Fig. 27: Metabolic parameters in mice on HP diet with glucose substitution in the drinking water .... 70

Fig. 28: Oral glucose tolerance test (2 g glucose per $\mathrm{kg} \mathrm{BW}$ ) in $P e p t 1^{+/+}$and $P e p t 1^{-/}$animals.

Fig. 29: Insulin concentration in response to intragastric administration of glucose $(2 \mathrm{~g} / \mathrm{kg})$ in wildtype and $P$ ept $1^{-1 /}$ mice 71

Fig. 30: Amino acid concentrations of isoleucine and proline in plasma of portal vein and heart after administration of ${ }^{15} \mathrm{~N}$-labeled protein by gavage.

Fig. 31: Amino acid appearance in plasma after administration of a low dose

of ${ }^{15} \mathrm{~N}$-labeled protein 74

Fig. 32: Intestinal tissue amino acid levels after administration of ${ }^{15} \mathrm{~N}$-labeled protein 76 


\section{Summary}

All living organisms possess the capability to take up di- and tripeptides from their environment and this is mediated by dedicated integral membrane proteins. In mammals cellular uptake of di- and tripeptides is mediated by the peptide transporters PEPT1 and PEPT2. PEPT2 shows widespread expression within the organism and its dominant role is in the reabsorption of filtered di- and tripeptides in the kidney as shown in a mouse model lacking PEPT2.

The intestinal peptide transporter PEPT1 mediates uptake of di- and tripeptides derived from dietary protein break-down into enterocytes and shows highest expression levels in the small intestine. Whereas the transporter was proven to be essential for amino acid delivery in patients with mutations in amino acid transporter genes such as in Cystinuria or Hartnup disease, its physiological role in overall amino acid absorption is still not known.

To assess the quantitative importance of PEPT1 in amino acid absorption and metabolism a Pept1-knockout mouse strain was comprehensively phenotyped. Analyses comprised brush border membrane vesicles, everted gut sacs and Ussing chambers as well as transcriptome and proteome analysis of intestinal tissue samples. Neither gene expression and proteome profiling nor functional analysis revealed evidence for any compensatory changes in the levels and/or function of transporters for free amino acids in the intestine. However, plasma amino acid levels were increased in Pept $1^{-/}$as compared to Pept $1^{+/+}$animals, suggesting that absorption and/or renal excretion of amino acids is impaired. Plasma appearance rates of ${ }^{15} \mathrm{~N}$-labeled amino acids, determined after intragastric administration of a low-dose of ${ }^{15} \mathrm{~N}$-labeled protein extract, remained unchanged whereas administration of a large protein load via gavage revealed marked differences in plasma appearance of selected amino acids.

To determine whether the protein content in the diet determines the phenotype of the Pept1-knockout mice, wildtype animals and mice lacking PEPT1 were given a highprotein diet (45\% of energy) for 5 days and this led to a markedly reduced food consumption, decreased feces excretion and reduced body weight. When mice were given the diets for 18 days, food intake increased again after the marked reduction 
over the first 5 days but animals did, in contrast to controls, not regain any body weight. The increased fecal energy loss observed in $P e p t 1^{-/}$animals indicates significantly impaired energy assimilation in the intestine. A possible explanation for the effects on food intake might be that hypothalamic control loops with a cross-talk of leptin and the arginine-dependent cerebral NO system are affected as the PEPT1deficient mice have a constitutively increased plasma arginine level but low plasma leptin when fed the high protein diet.

In summary, PEPT1 seems of importance for overall amino acid absorption only when large quantities of dietary protein are provided - either acute via gavage or by feeding a high-protein diet. In addition, when intestinal amino acid transport processes are saturated, PEPT1 can provide additional absorption capacity. Elevated basal plasma concentrations of amino acids in PEPT1-deficient animals seem to arise mainly from alterations in hepatic and renal amino acid metabolism. 


\section{Zusammenfassung}

Alle lebenden Organismen können Di- und Tripeptide aus ihrer Umwelt aufnehmen, was durch die entsprechenden Membranproteine gewährleistet wird. In Säugetieren wird die zelluläre Aufnahme dieser Di- und Tripeptide durch die beiden Peptidtransporter PEPT1 und PEPT1 vermittelt. PEPT2 zeigt eine weit verbreitete Expression im gesamten Organismus, wobei die vorherrschende Rolle in der renalen Reabsorption der gefilterten Di- und Tripeptide liegt, was bereits im Mausmodell gezeigt werden konnte.

Der intestinale Peptidtransporter PEPT1 hingegen, der höchste Expressionspiegel im Dünndarm aufweist, vermittelt die Aufnahme der Di- und Tripeptide in die Enterozyten. Obwohl in Patienten mit Mutationen in Aminosäuretransporter-Genen, wie z.B. bei Cystinurie oder der Hartnup-Krankheit, die essentielle Bedeutung des Transporters für die Aminosäurenzufuhr gezeigt werden konnte, ist die generelle physiologische Rolle bezogen auf die gesamte Aminosäurenabsorption immer noch unklar.

Um die quantitative Bedeutung von PEPT1 in der Absorption und im Metabolismus der Aminosäuren zu analysieren, wurde eine umfassende Phänotypisierung einer Pept1-Knockout Mauslinie durchgeführt. Neben Bürstensaummebranvesikeln, der „Everted Gut Sac“-Technik und Ussing Kammer Versuchen wurde auch eine Transkriptom und Proteomanalyse von intestinalem Gewebe durchgeführt. Jedoch konnte weder durch die Genexpression bzw. Proteomanalyse noch durch funktionelle Studien gezeigt werden, dass es zu kompensatorischen Veränderungen bezogen auf die Menge und/oder die Funktion von Transportern freier Aminosäuren im Darm kommt. Allerdings zeigten Pept $1^{-/}$verglichen mit Pept $1^{+/+}$Tieren erhöhte PlasmaAminosäurespiegel, was auf eine veränderte Absorption und/oder renale Exkretion von Aminosäuren hinweist. Nachdem per Schlundsonde eine geringe Menge an ${ }^{15} \mathrm{~N}$ markiertem Protein verabreicht wurde, zeigten sich keinerlei Veränderungen in der Menge von ${ }^{15} \mathrm{~N}$-markierten Aminosäuren im Plasma. Hingegen wiesen eine Reihe von Aminosäuren, nach Gabe einer großen Proteinmenge, beachtliche Unterschiede im Plasma auf.

Um herauszufinden ob der Proteingehalt einer Diät Einfluss auf den Phänotyp der Pept1-Knockout Mäuse hat, wurden Wildtyp und Pept1-Knockout Mäuse für 5 Tage 
einer Diät mit hoher Proteinzufuhr (45 Energie\%) unterzogen. Diese Diät führte zu einer merklich reduzierten Futteraufnahme, verringertem Gewicht aber auch stark reduzierter Fäzes Exkretion. Wurde diese Diät für 18 Tage verabreicht zeigte sich nach den ersten 5 Tagen, mit extremer Futter, Fäzes und Gewichts Reduktion, ein Wiederanstieg der Futteraufnahme, allerdings blieb das Gewicht der Pept1-Knockout Mäuse, im Gegensatz zu dem der Kontrolltiere, unter dem Ausgangsgewicht. Die erhöhten fäkalen Energieverluste bei PEPT1-defizienten Mäusen könnten auf eine signifikant veränderte Energieassimilation im Darm hinweisen. Eine mögliche Erklärung für die Veränderungen der Futteraufnahme wäre, dass die hypothalamische Regelung und die Interaktion von Leptin mit dem Argininabhängigen zerebralen NO-System betroffen sind, da Pept1-Knockout Mäuse nach der Diät mit hoher Proteinzufuhr gleichbleibend hohe Arginin-Spiegel, jedoch niedrige Leptin-Spiegel im Plasma zeigen.

Zusammenfassend konnte gezeigt werden, dass PEPT1 nur dann für die Aminosäuren-Absorption wichtig zu sein scheint, wenn große Mengen an Nahrungsprotein vorliegen - entweder im akuten Fall durch eine Schlundsonde verabreicht oder durch eine Diät mit hohem Proteinanteil. Zudem kann PEPT1, wenn die intestinalen Prozesse des Aminosäuretransports gesättigt sind, zusätzliche Absorptionskapazitäten bereit stellen. Die erhöhten basalen Aminosäurekonzentrationen im Plasma in PEPT1-defizienten Mäusen scheinen dagegen v.a. durch Veränderungen im hepatischen und renalen Aminosäuremetabolismus begründet. 


\section{Introduction}

\subsection{Peptide transport and peptide transporters - a brief history}

The uptake of nutrients is pivotal to life and occurs in all living organisms. As the cell membrane serves as a barrier for permeation of nutrients and xenobiotics, cellular uptake of nutrients is a critical step in nutrient homeostasis. The maintenance of an intracellular environment, which is markedly different from an extracellular milieu, is essential to life. Thus in the course of evolution a large number of membrane proteins with highly specialized transport functions have emerged to satisfy the needs of the organism in nutrient supply.

Transporters control uptake and efflux of compounds (e.g. amino acids, sugars, drugs) and there are two groups of transporters existing - uniporters and rheogenic transporters. The latter use different energy-coupling mechanisms by coupling of nutrient transport to ion/solute gradients across membranes [1]. Rheogenic, active systems, that mediate nutrient influx into mammalian cells, often use electrochemical $\mathrm{Na}^{+}$gradients. In contrast uptake of nutrients in bacteria, plants or yeast is mainly energized by a transmembrane electrochemical proton gradient [2].

For mammals the small intestine and the kidney are the main sites of absorption and reabsorption, respectively. Solute carrier (SLC) genes, which encode for uniporters as well as ion-coupled transporters and exchangers, mediate uptake of nutrients, like amino acids and peptides. So far at least 362 putatively functional protein coding genes in 55 gene families are known/identified that act in solute transport [3].

The history of research into cellular uptake of peptides and thus of absorptive and digestive processes of protein in the gut starts in the 1970's. There was a highly controversial discussion about the existence and importance of peptide transport in mammalian intestine because it was believed that only free amino acids but not oligopeptides can be absorbed. For a comprehensive review it may be referred to David Matthews - one of the pioneers in this field [4].

In brief, already in the 1950's in prokaryotes uptake of peptide-bound amino acids was described [5, 6]. However it took until 1971, when studies in humans demonstrated the uptake of intact dipeptides [7, 8] and Adibi and colleagues were able to functionally characterize a transport system for di- and tripeptides $[9,10]$. It was the general belief in these times, that the $\mathrm{Na}^{+}$-gradient provides the energy source for uptake of all nutrients against a concentration gradient. Thus it was 
surprising that transport of di- and tripeptides was found to be $\mathrm{H}^{+}$-coupled and $\mathrm{Na}^{+}$independent but stimulated by a pH gradient [11-13]. More detailed studies also indicated the existence of two systems for the transport of peptides - one with a high and one with a low substrate affinity [14]. In addition by Daniel et al. it was shown that the proton dependence was assigned to the cotransport of $\mathrm{H}^{+}$with the substrate [15]. By determination of the substrate affinities of peptide transporters [16] it could be demonstrated that in addition to di- and tripeptides, various peptidomimetics are also translocated by the peptide transport systems [17].

In 1994 PEPT1 was cloned from rabbit small intestine [18, 19] and PEPT2 followed later [20, 21]. PEPT1 (SLC15A1) and PEPT2 (SLC15A2) were the first two members of the mammalian solute carrier family 15, which also includes two other related sequences, namely PHT1 (SLC15A4) and PHT2 (SLC15A3). These peptide/histidine transporters were cloned later but not much information is available until now [22, 23].

\subsection{The peptide transporter PEPT1}

\subsubsection{Mode of transport}

Almost 30 years ago by studies using brush border membrane vesicles of small intestine and kidney it was demonstrated that uptake of dipeptides is independent of $\mathrm{Na}^{+}, \mathrm{K}^{+}$or $\mathrm{Cl}^{-}$-ions. Finally, Ganapathy et al. were able to show that an inwardly directed $\mathrm{pH}$ gradient serves as driving force for uptake of peptides [11-13, 24]. However, dipeptide uptake is indirectly coupled to the $\mathrm{Na}^{+}$-gradient via the apical $\mathrm{Na}^{+}-\mathrm{H}^{+}$exchanger, generating and maintaining the inwardly directed $\mathrm{H}^{+}$gradient via a $1: 1 \mathrm{Na}^{+}$exchange in conjunction with the basolateral $\mathrm{Na}^{+}, \mathrm{K}^{+}-\mathrm{ATPase}$ (see Fig. 1). Using Caco-2 cells, loaded with a pH-sensitive dye, it was demonstrated that PEPT1 in intestinal epithelial cells has an acid-loading activity and that the apical $\mathrm{Na}^{+} / \mathrm{H}^{+}$ exchanger activity is required for the recovery from the acid load [25]. Studies using selective NHE3 inhibitors also illustrated the importance of NHE3 transport for PEPT1-mediated $\mathrm{H}^{+}$-dipeptide cotransport [25-29]. Any maneuvers which alter the $\mathrm{pH}$ and subsequently change the membrane potential can therefore also result in changes in the uptake of substrates by PEPT1 [29, 30]. However as shown by Chen et al. at high substrate concentrations solely the membrane potential, but not the $\mathrm{pH}$ gradient, determines the transport rate of PEPT1 [30]. 


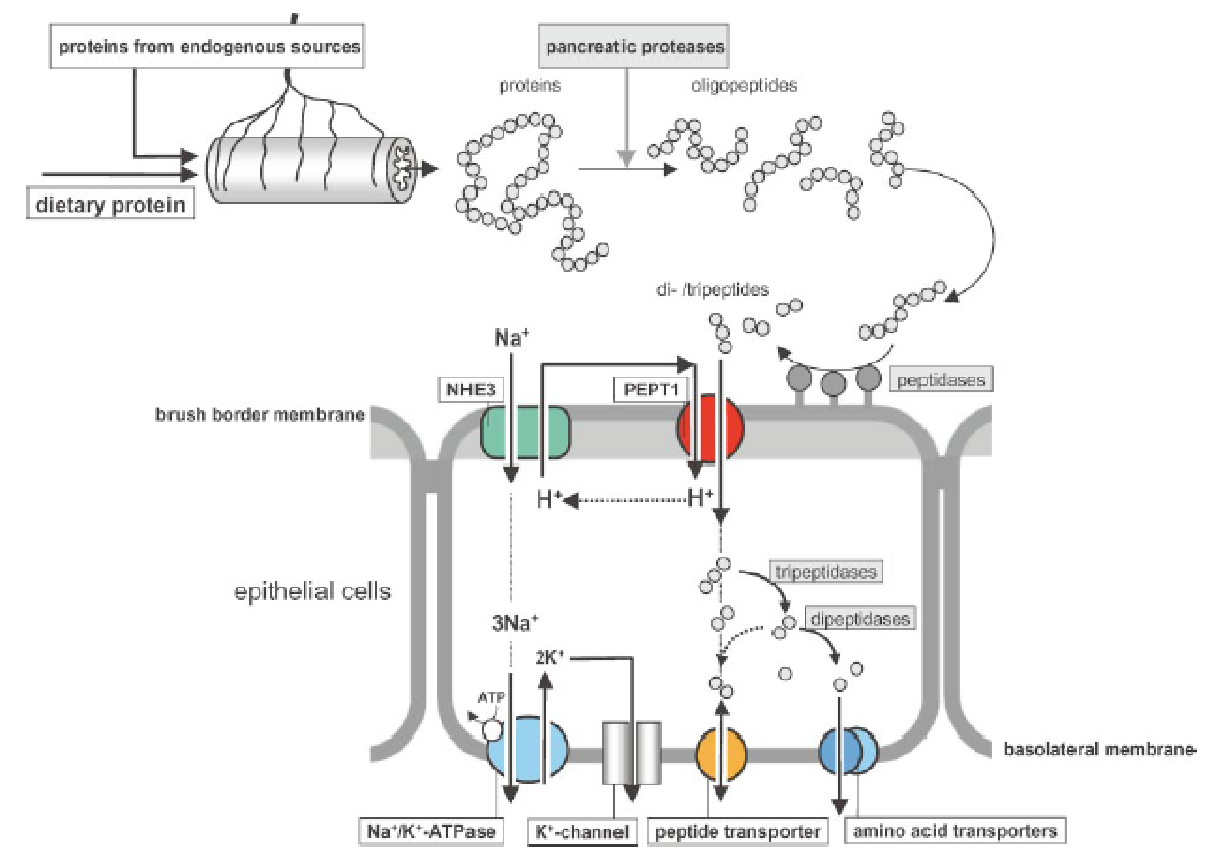

Fig. 1: PEPT1-mediated uptake of peptides in the context of the epithelial cell

Uptake of di-and tripeptides as derived from the intestinal protein breakdown. After uptake of di- and tripeptides via PEPT1 multiple hydrolases in the cytosol hydrolyze the peptides to release the free amino acids. These leave the cell via various amino acid transporters in the basolateral membrane Also shown is the apical $\mathrm{Na}^{+} / \mathrm{H}^{+}$exchanger $\mathrm{NHE}$, which maintains the transmembrane proton gradient (from [31]).

\subsubsection{PEPT1 gene and protein structure}

In humans the gene, which encodes hPEPT1 (see Fig. 2) maps to the chromosome 13q33-34, whereas in mice it can be found on chromosome 14 [32]. Analyses revealed that Pept1 consists of 23 exons and 22 introns [33]. By Urtti et al. it was shown that each exon codes for one of the 12 predicted transmembrane domains (TMD) and for one of the intracellular and extracellular loops respectively [34]. Both the carboxy and the amino termini face the cytoplasmic side. A big extracellular loop is located between TMD 9 and 10 [31]. Comparison of human (707 amino acids) and murine (709 amino acids) PEPT1 showed an identity of $83 \%$ and a similarity of $86 \%$. Furthermore for both, human and murine Pept1, TATA boxes were found about 520 bp (511 bp for human and $517 \mathrm{bp}$ for murine) upstream from the transcription start side. The GC boxes are also included in the putative regulatory region (one of them $29 \mathrm{bp}$ upstream and some others within $300 \mathrm{bp}$ from the transcription site) [34]. Therefore regulation of Pept 1 seems to be influenced more via GC boxes than TATA boxes, resulting in a probable TATA box-deficient promoter. The transcription factor 
Sp1 (Specifity factor 1) binds to 2 GC-rich sites and thus plays a significant role in the basal transcriptional regulation of PEPT1 [35].

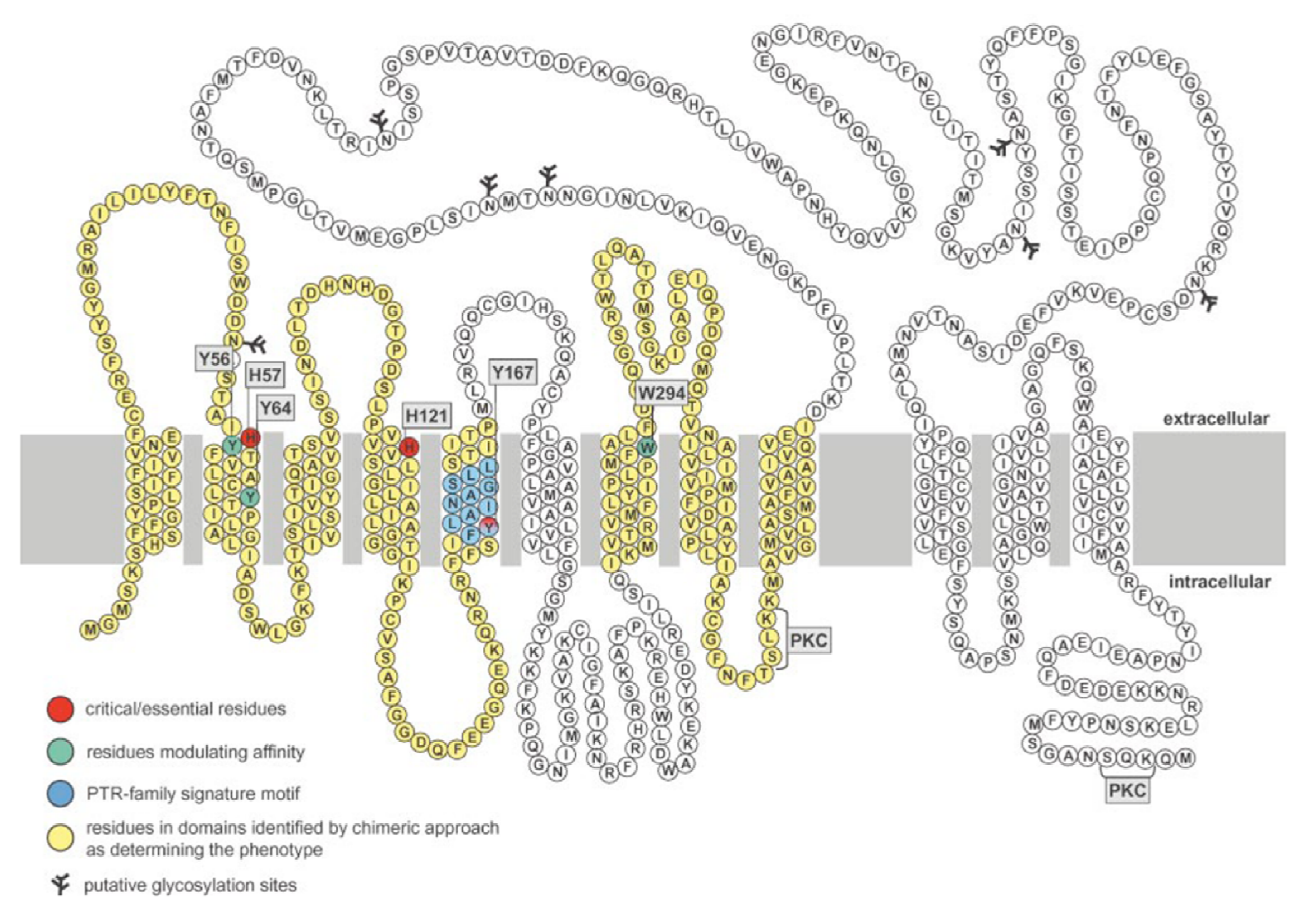

Fig. 2: Model of the human PEPT1 in secondary structure

Shown are protein domains and amino acid residues important for the transport process.(from [31]).

Functionality of PEPT1 depends on different regions within the protein. Functional analysis of chimeric transporters of PEPT1 and PEPT2 showed that the aminoterminal region with TMD 1-4 and 7-9 are essential for substrate binding and affinity $[36,37]$. Relevant or essential for activity of PEPT1 are several amino acid residues. Among them especially the histidine residue ( $\mathrm{H} 57)$ is important. Mutations of $\mathrm{H} 57$, which is located on the interface of TMD 2 and the extracellular side, abolish PEPT1 function [38-40]. Other histidine residues like $\mathrm{H} 111$ and $\mathrm{H} 260$ do not seem to be crucial for PEPT1 activity, whereas H121 appears to be involved in substrate binding [39]. Also important are tyrosine residues, like Y56, which is nearby $\mathrm{H} 57$, and mutating to phenylalanine decreases the affinity for differently charged dipeptides. Alike Y64 seems to be involved in substrate translocation [40]. Tyrosine residues Y167 and other amino acid residues like W294, E595, R282 are essential for PEPT1 activity as well [41, 42].

As far as overall protein structure and membrane topology are concerned, those have not been studied systematically and crystallization of mammalian PEPT1 was 
not yet achieved. The role of the large extracellular domain between TMD 9 and 10 and of the carboxy-terminal regions is still unknown.

By computer-based models, an alignment of the TMD was calculated $[41,43]$ and other model proteins with crystallized structures such as the bacterial transporters LacY and GIpT, which contain 12 TMD [44], were used to provide a protein-template (Fig. 3).

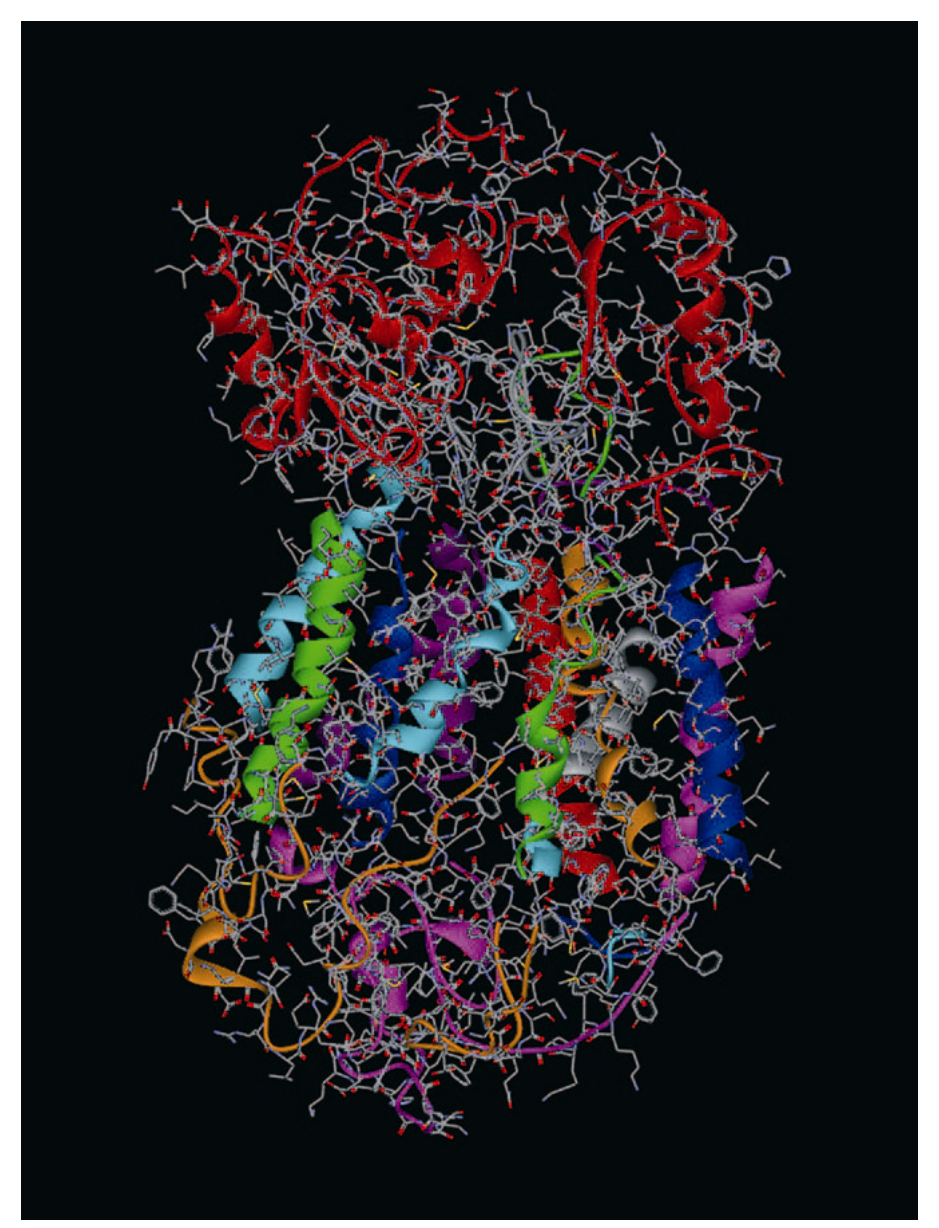

Fig. 3: Protein structure of PEPT1

Shown is the ribbon structure of the hPepT1 protein model. In red the very large EL5 loop, which fully covers the extracellular side, is visualized (from [45]).

\subsubsection{Substrates of PEPT1}

PEPT1 transports almost all possible di- and tripeptides and peptidomimetics. Considering a number of 20 proteinogenic amino acids reveals around 400 di- and 8000 possible tripeptides [46]. It was shown that two oppositely charged head groups (amino and carboxy groups), which are separated by a carbon backbone with a distance of 5.5 to $6.3 \AA$ between the centers of the head groups, are the minimal and 
necessary structural features that allow binding and electrogenic transport via PEPT1 [47]. Thus transport or binding of peptides containing more than 3 amino acids or free amino acids is not possible.

Concerning substrate affinity huge differences exist. Transport of peptides occurs stereoselective, with those containing only L-amino acids, showing higher affinity than peptides containing $\mathrm{D}$ - and L-enantiomers. Important is also the position (either amino- or carboxy-terminal position) of the D-amino acid residues. Affinity of peptides with D-enantiomers in amino-terminal position is higher than when placed in the carboxy-terminal position. Peptides which contain only D-enantiomers of amino acids are not transported by PEPT1 [31].

PEPT1 is a low-affinity and high-capacity transporter, whereas PEPT2 is the highaffinity and low-capacity transporter. Substrate affinities of PEPT1 are in the range of 200 $\mu \mathrm{M}-10 \mathrm{mM}[46]$.

Simple omega fatty acids, which do not contain a peptide bond, can also be transported by PEPT1. Affinities for these fatty acids are comparable to those of normal dipeptides. This suggests that the peptide bond can either be methylated or that the peptide bond can also be replaced by an isosteric thioxo bond, both only with a minor reduction in substrate affinity $[47,48]$. By Brandsch et al. it was shown that peptides, which contain proline residues, display distinct differences in the mesomeric structure of the peptide bond [49]. Thus the trans-conformation of the peptide bond alone is responsible for transport. Proline containing peptides are ticklish substrates, which is mainly due to two factors - the conformation of the peptide bond and also other structural constraints. When proline is offered in an amino-terminal position in peptides, the a-amino group is embedded into the pyrrolidine ring system, which in turn impairs interaction with the transporter and leads to decreased substrate affinity [50].

In addition numerous peptidomimetics can be transported by PEPT1. This is mainly due to the high transport rate and the broad substrate specifity, which make PEPT1 a very good drug delivery system. By studies using doses up to $1 \mathrm{~g}$ of selected ACE inhibitors or aminocephalosporins it was shown that the oral availability rates can be as high as $90 \%[51,52]$. Also transported are dopamine receptor antagonists, antivirals such as valacyclovir and sulprides, but also B-lactam antibiotics.

Not yet understood is how ACE-inhibitors are transported. They do not possess an $\alpha-$ amino group, which was shown to be important for translocation and binding affinity 
of substrate. This group is thought to form a salt bridge with either a histidine or an acidic residue, which is located in the substrate binding pocket [31].

Uptake of PEPT1 substrates in the intestine can be altered by structural changes as well. Some substrates were shown to have an increased uptake and thus a better bioavailability after esterification with an amino acid [53, 54]. For PEPT1 a 3D-QSAR (quantitative structure-activity relationship) model was developed using CoMSIA (comparative molecular similarity indices analysis), which was based on 98 compounds (di- and tripeptides and B-lactam antibiotics) [55]. Using this method allowed to create a simple but robust model to explain binding affinities of novel substrates [56]. In Fig. 4 structural elements defining substrate affinity are shown.

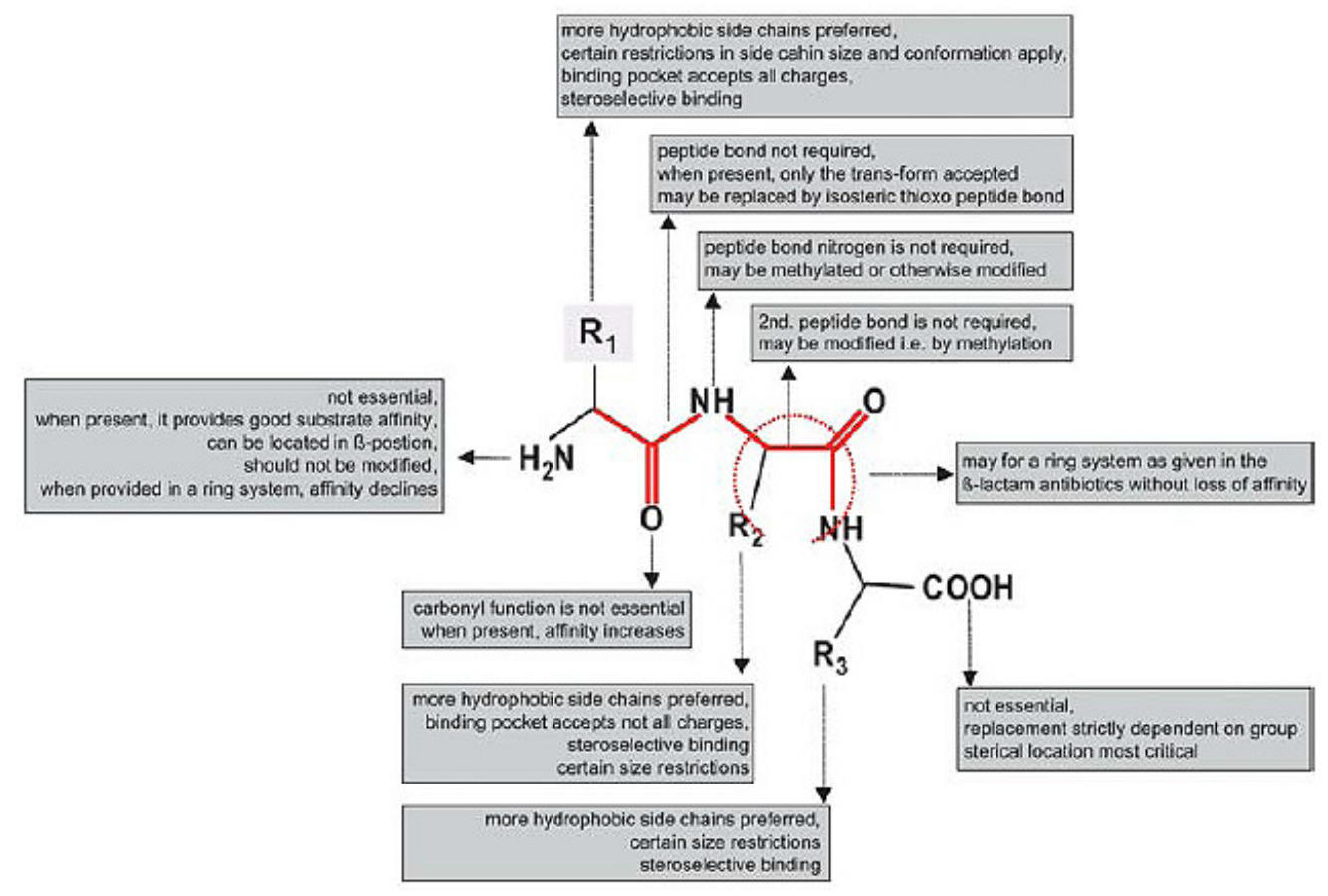

Fig. 4: Molecular structures of selected pharmacologically important compounds that serve as substrates of PEPT1 (from [46])

\subsubsection{Localization of PEPT1}

\subsubsection{PEPT1 expression in the digestive tract}

Highest expression levels of Pept1 were found along the small intestine [18, 57-59], whereas analyses of mRNA expression levels displayed highest expression levels in the jejunum segment [57]. This was further substantiated by analyses of mouse tissue which revealed differences in expression levels between segments of the digestive tract with highest levels in jejunum tissue. Duodenum and ileum displayed 
almost same expression levels, whereas colon tissue showed lowest PEPT1 expression [60]. By immunolocalization Ogihara et al. showed that Pept1 expression is specific to the brush border of the differentiated absorptive epithelial cells [58, 61]. Pept1 expression was also observed in other organs along the digestive tract, albeit in minor concentrations. Using RT-PCR Pept1 expression was found in stomach tissue in humans, rats and mice [57]. However expression in stomach seems to be caused by intestinal metaplasia [62]. Contrary to the findings of Knutter et al. [63], which could localize PEPT1 to the apical membrane of cholangiocytes of mouse extrahepatic biliary duct by immunofluorescence, we were not able to detect PEPT1 expression in the bile duct neither by immunofluorescence nor by X-Gal staining. Furthermore we could not show PEPT1 expression in kidney tissue [60, 64].

In colon, PEPT1 could be detected on mRNA and protein level. However expression in colon is altered by different stages of development and inflammation. In rats PEPT1 was only detectable during days 1-5 after birth. After that and also in adult animals no expression could be found [65]. It was assumed that the higher need for amino acids in the first days of living is responsible for this increased expression. Furthermore inflammatory diseases like ulcerative colitis or Crohn's disease cause higher PEPT1 expressions [66]. In colon of mice and also in colon carcinoma cells increased concentrations of PEPT1 were shown to be induced by inflammatory cytokines (tumor necrosis factor- $\alpha$ and interferon- $-\gamma$ ).

\subsubsection{Expression of PEPT1 in extra-intestinal tissue}

Besides the digestive tract, expression of PEPT1 was also found in other tissue. In kidney, expression seems to vary between species and also differences in expression levels were observed. In rats, PEPT1 expression could be detected by immunofluorescence in the convoluted proximal tubule (S1-segment) [57, 67]. Thereby like PEPT2, PEPT1 seems to be involved in reabsorption of di- and tripeptides [58, 68]. In contrast in rabbit, Pept1 was not detectable via RT-PCR [48]. In humans expression was observed, however expression levels depend on renal diseases [69]. In mice findings are controversial as in some studies Pept1 expression on mRNA and protein level could be shown $[70,71]$ and in other studies no detection was possible [57]. Compared to the digestive tract, kidney tissue shows low expression levels of PEPT1 and its renal function seems to be marginal or negligible $[72,73]$. 
Furthermore expression of PEPT1 was observed in the human bile duct epithelium cell line SK-ChA-1 and in the apical membrane of mouse cholangiocytes [63]. Functional transport was also shown in tumor cells of the extrahepatic biliary duct with $\delta$-ALA [74]. In mice and rats PEPT1 expression was found in the uterus, thymus, male and female gonads and in spleen as well [57, 59, 75, 76]. Again between species rather large differences in expression levels of PEPT1 were observed. In the pineal gland circadian variations in expression were found for a splice variant of PEPT1, consisting of only 150 amino acids of the C-terminus [77].

\subsubsection{Regulation of PEPT1}

\subsubsection{PEPT1 and dietary factors}

\section{Amino acids and peptides}

A high substrate availability appears to increase PEPT1 expression. On mRNA and protein level, exposure of Caco-2 cells to di- and tripeptides induced PEPT1 expression, whereas free amino acids had no such effect $[78,79]$. In rats, Erickson et al. showed in a comparison between a high-protein (50\%) and a low-protein (4\%) diet, that Pept1 mRNA levels in the middle and distal region of rat small intestine were increased 1.5 to 2-fold on a high-protein diet fed for 14 days [80]. Another study confirmed these results, but already after 3 days of feeding the effect was achieved. Furthermore it was shown that an increase in gene expression was also possible with a standard diet by supplementation of a single dipeptide (Gly-Phe) [81]. In this case uptake of Gly-Sar and peptidomimetics via PEPT1 was increased as well [81, 82]. Besides an activation of the Pept1-promotor via selected amino acids and peptides an elevated stability of Pept1-mRNA might be the reason. The increase in Pept1 gene expression after high-protein feeding results from concentrations/levels of diand tripeptides and amino acids in the gut lumen and as shown by Ferraris et al., due to adaptation processes to high-protein diets, peptide transport is increased as well [83].

\section{Other dietary factors regulating PEPT1}

Selected ingredients are also able to influence metabolic pathways of Pept1. The alkaloid capsaicin, found in chili peppers, was shown to block cephalexin absorption from jejunum which may be explained by alterations in PEPT1 activity and changes 
in intracellular calcium [84]. This effect was also observed in Caco-2 cells, which were treated with a $\mathrm{Ca}^{2+}$ blocker [85] and it seems that a reduced cellular $\mathrm{Ca}^{2+}$ concentration stimulates NHE3 activity and thereby increases PEPT1-functions [25]. Other secondary plant compounds like flavonoids, can also influence PEPT1 capacity. In Caco-2 cells, selected flavonoids (e.g. quercetin, genistein and naringin) were shown to increase absorption of the B-lactam antibiotic cefixime, a PEPT1 substrate. By inhibition of epidermal growth factor receptor (EGFR) tyrosine kinase, flavonoids can activate the apical $\mathrm{Na}^{+} / \mathrm{H}^{+}$-exchange with a concomitant increase of the driving force for PEPT1 [86]. By inhibition of NHE3 transport function, PEPT1 activity is reduced. Inhibition of NHE3 leads to reduced uptake of peptides, as the absorptive cells are no longer able to sustain the necessary electrochemical gradient [87]. Furthermore it could be shown that acetaldehyde may affect PEPT1 activity. In rats treated with ethanol and acetaldehyde and similarly in Caco-2 cells treated with acetaldehyde, Gly-Sar uptake was reduced, suggesting a currently unknown mechanism influencing PEPT1 [88].

\section{Fasting}

PEPT1 expression is also influenced by the fasting state and shows diurnal variations. In addition PEPT1 expression seems to be induced by starvation [89]. Also observed were diurnal variations in rats, which showed highest expression levels when animals are in the fasting period at the beginning of the dark cycle, before they start feeding [90]. These variations were related to the fasting period as it was shown that PEPT1 expression is enhanced during short as well as prolonged fasting [61, 91]. Shimakura et al. were able to demonstrate that the fasting induced increase in PEPT1 expression is related to the peroxisome proliferator-activated receptor a (PPARa). PPARa belongs to the nuclear receptor family, with highest expression in tissues that oxidize fatty acids, like heart, liver but also small intestine. Under starvation conditions, PPARa appears to increase PEPT1 expression, resulting in enhanced uptake of peptides [70].

\subsubsection{Hormonal control of PEPT1}

Alterations in Pept1 expression can also be induced by hormones [69]. Very important for protein metabolism is the thyroid hormone. It was shown that renal PEPT1 and PEPT2 mRNA levels were increased by hypothyroidism [92], suggesting 
a more efficient renal reabsorption of peptides and improved protein homeostasis. Contrary, in rats with induced hyperthyroidism, a lowered expression level and transport activity of PEPT1 in small intestine was observed [93]. This might be due to effects of thyroid hormone on transcription and a reduced stabilization of the PEPT1mRNA [93]. Expression of PEPT1 is also closely connected with the growth hormone $(\mathrm{GH})$ axis. Studies with Caco-2 cells revealed that cells treated with recombinant human growth hormone ( $\mathrm{rhGH}$ ) showed increased uptake rates for cephalexin [94]. In contrast, when PEPT1 expression was decreased by oxidative stress, it was elevated again by administration of $\mathrm{GH}$ [95]. How regulation of PEPT1 by GH occurs remains to be determined. It is known that $\mathrm{GH}$ secretion is also indirectly regulated via leptin [96] and therefore the impact of leptin on the peptide transporter could involve GH secretion as well. Leptin and also insulin appear to promote trafficking of PEPT1 to the cell membrane. Leptin acts at the apical membrane whereas insulin binds to the insulin receptors mainly at the basolateral membrane [97]. These findings were in accordance with a rat model of insulin-deficient diabetes that showed lowered transport and expression of PEPT1 [98]. In contrast, PEPT1 showed an increased expression level in a model of hyperinsulinemic type II diabetes [99]. Higher transcription rates and improved mRNA stability of PEPT1 were also found in jejunum of hyperleptinemic rats. Confirmed were these results by Hindlet et al. in leptin-knockout mice [100]. High leptin concentrations can increase the intracellular cyclic adenosine monophosphate (cAMP) concentration leading to an activation of protein kinase cascade with the cAMP-response element binding protein (Creb) phosphorylated and Cdx2 (Caudal type homeobox transcription factor 2) activation. Phosphorylated CREB (pCreb) and Cdx2 are known to interact in the leptin-induced PEPT1 transcriptional activation, thus Cdx2 binding sites in the PEPT1 promotor appear to be important for the leptin mediated changes in PEPT1 transcription [101] (see Fig. 5).

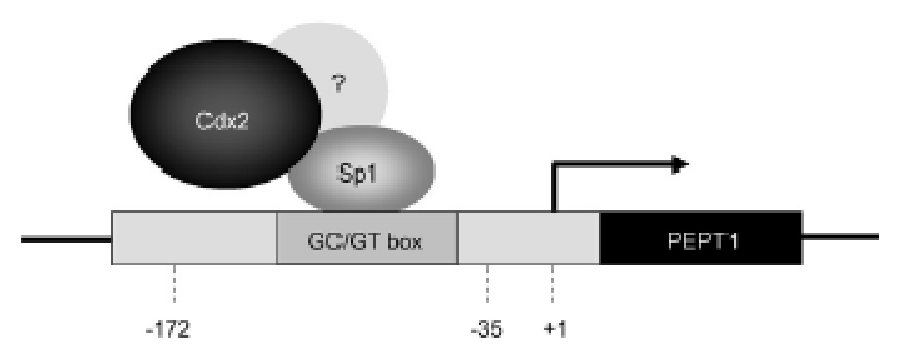

Fig. 5: Proposed regulation of PEPT1 promotor activity by Cdx2 and Sp1 (from [69]) 
Epidermal growth factor (EGF) is also able to alter PEPT1 expression. Short term treatment with EGF in Caco-2 cells revealed elevated peptide (i.e. Gly-Sar) transport activity without an effect on mRNA level [89], whereas long term exposure showed inhibition of PEPT1 mediated absorption and reduced both, mRNA and protein levels [102].

\subsubsection{PEPT1 in pathophysiological conditions}

Expression of PEPT1 after traumatic brain injury was also studied. In the first $24 \mathrm{~h}$ after injury, PEPT1 mediated transport displayed an upregulation and after 7 days it remained at normal levels, although mucosal atrophy was obvious [103] and apoptosis in the mucosal epithelium with markedly reduced crypt depth, surface area and villous heights were observed. PEPT1 expression after intestinal resection has as well been studied and revealed increased expression in the colon [104]. In rat models of chronic renal failure (e.g. uninephroctemy or 5/6 nephroctemy) PEPT1 expression increased in the first 2-4 weeks $[68,105]$.

\subsubsection{The role of PEPT2 in the organism}

Ample information is available for PEPT2 (for reviews see [31, 36, 46, 106-108]). In comparison to PEPT1, PEPT2 is a high-affinity low-capacity transporter with substrate affinities of 5-500 $\mu \mathrm{M}$ [46], but with the same broad substrate specificity. PEPT2 also accepts almost all 400 dipeptides and 8000 tripeptides and many pharmaceutical compounds, like ACE inhibitors or B-lactam antibiotics as well [31]. PEPT1 and PEPT2 share about $70 \%$ sequence similarity and about $50 \%$ sequence identity [109]. Like PEPT1, the transporter is located mainly in the apical membrane of epithelial cells, but compared to PEPT1, PEPT2 shows a wider distribution in the organism. Highest expression levels can be found in the kidney but also in mammary gland, pancreas or in glia cells of the enteric nervous system [110]. In the kidney expression is localized especially to the outer medulla of the proximal tubule (S2 and S3 segment) [67]. Unlike PEPT1, with a developmental expression pattern in the first week of life, PEPT2 expression shows less developmental alterations. However, expression reaches a plateau about 2 weeks after birth [65]. In epithelial cells of glands and ducts of the mammary gland, PEPT2 expression was observed as well [111]. In addition to PEPT1, PEPT2 can be detected in the a-cells of pancreas as 
well [112]. PEPT2 is also found in male and female gonads, prostate, uterus and in the pituitary gland [57]. In lung, PEPT2 is expressed in alveolar type II pneumocytes and in tracheal and bronchial epithelia [113], where it has been proposed as an interesting pharmacological target for drug delivery, with aerosolized formulations [113-115].

The main function of PEPT2 appears to be the reabsorption of filtered di- and tripeptides in the kidney. In combination with amino acid transporters, which are also located in the apical membrane of tubular cells, PEPT2 contributes to amino acid homeostasis and prevents loss of amino acids and peptides via reabsorption [116, 117]. By use of a Pept2 knockout mouse line it could be demonstrated that the uptake of model dipeptides and their renal accumulation was significantly reduced [118]. Particularly renal reabsorption of Cys-Gly, an important break-down product of glutathione was markedly decreased in PEPT2-deficient animals and relates PEPT2 to antioxidative defense mechanism in kidney [73, 119]. Furthermore, Shen et al. demonstrated an important role of PEPT2 in the clearance of dipeptides (and drugs) from the cerebrospinal fluid [120].

A comprehensive phenotyping of male Pept $2^{/-}$mice revealed a lower body weight and also lower relative heart weight. For female knockout mice relative kidney weight was reduced as well. When mice lacking PEPT2 were submitted to dietary intervention studies, using diets with different protein contents $(10 \%, 20 \%$ and $30 \%)$ only subtle but complex phenotypic alterations were observed with adaptations in food intake rates, displaying higher food consumption on a low-protein diet and lower food consumption on a high-protein diet [119].

\subsection{Putative role of PEPT1 in the organism}

Despite all the advances in peptide transporter research, the prime role and relevance of PEPT1 in the mammalian organisms is still unclear. There is a longlasting dispute on the quantitative importance of intestinal transport of di- and tripeptides as compared to that of free amino acids dating back to the original discovery of peptide transport some 40 years ago. Digestion of proteins in the gastrointestinal tract releases free amino acids and small peptides. Numerous amino acid transporter systems have been identified for uptake of the free amino acids. However it has been predicted that up to half of all absorbed amino acids are taken up in peptide form rather than in free form [121]. Since PEPT1 (SLC15A1) is the only 
peptide transporter in the intestinal brush-border membrane [122] it is expected to play a prominent role in overall amino acid absorption.

\section{Release of PEPT1 substrates by digestion}

By hydrolytic cleavage most proteins and oligopeptides are degraded rapidly. However, the velocity of protein breakdown depends on its composition (amino acids) and post-translational modifications. In protein digestion, the primary products of the luminal phase are oligopeptides of medium chain length. At the brush border of intestinal epithelial cells they are further cleaved by membrane anchored peptidases. Huge differences between the hydrolytic activity and the subcellular location of these peptidases were observed, which can be related to the chain length of the peptide substrates [123-125]. Especially for di- and tripeptides a very high activity of intracellular peptidases with a strict specifity for hydrolysis of di- and tripeptides was observed. This suggests that di- and tripeptides may be absorbed in intact form and then intracellular release of free amino acids occurs by cleavage in the cytosol. However, it is still not known to which extent di- and tripeptides are hydrolysed at the brush border membrane and to which extent the peptides are taken up into the cell followed by intracellular hydrolysis. Luminal hydrolysis of normal di- and tripeptides occurs very rapid but dipeptidase activity at the brush border membrane is limited. Therefore a considerable amount of di- and tripeptides may bypass enzymatic cleavage and reach the peptide transporter. In addition certain free amino acids, which are released during hydrolysis, may inhibit the luminal dipeptidases. To which extent peptides can leave the epithelial cell in intact form to reach the circulation is also not known. Thus a basolateral peptide carrier has been proposed [126]. Studies using Caco-2 cells demonstrated the existence of an exit pathway for di- and tripeptides, which is also shared by peptidomimetics [127-129] and displays characteristics not identical but similar to PEPT1. Nevertheless the molecular nature of this basolateral transporter remains to be determined. Prodrugs that are also taken up by the peptide transporters are partially hydrolysed by cellular esterases and the core drug compound can exit the cell by various basolateral drug transporters. One of these transporters is the organic cation transporter OCT1, which was shown to transport drugs and xenobiotics, e.g. acyclovir [130].

Peptide transfer from the gut lumen into peripheral blood was only detectable in humans by use of a large amount of orally administered fairly stable glycyl-peptides 
$[7,10]$. However the relevance of PEPT1 in transferring peptides from the gut lumen into circulation was shown by pharmacokinetic studies of ACE-inhibitors and aminocephalosporins [107, 108]. Both classes of peptidomimetics are transported by PEPT1 and are resistant to hydrolysis. Thus the efficiency of PEPT1 could be shown by their almost complete absorption and their rapid appearance in circulation. The current concept on how peptide and drug transport via PEPT1 occurs in epithelial cells is summarized in Fig. 1.

\section{Amino acid transporters}

Amino acid transport across the apical membrane utilizes sodium-dependent symporters as well as the proton-motive force and also the gradient of other amino acids in exchange for efficient absorption of amino acids from the lumen. In the basolateral membrane uniporters but predominantly antiporters mediate the release of amino acids into circulation [131].

Numerous studies revealed the general properties of mammalian amino acid transporters (for review see [132]), which are on the one hand a broad substrate specificity, with several amino acids sharing a transport system, and on the other hand the stereospecificity, as transport for L-stereoisomers is generally faster [117]. For classification of transporters, functional studies in intestine and kidney as well as urinary amino acid profiles of individuals with different aminoacidurias were consulted resulting in 5 proposed transport activities [133-136]. The 'basic system', which is responsible for the uptake of cationic amino acids together with cystine (system $\mathrm{b}^{0,+}$, system $\mathrm{y}^{+} \mathrm{L}, \mathrm{CAT}-1$ and system $\mathrm{x}_{\mathrm{c}}^{-}$), the 'neutral system' or also called 'methionine preferring system', which transports all neutral amino acids (system $B^{0}, A S C$, system $\mathrm{L}$, system $\mathrm{T}$ and system $\mathrm{A}$ ) and the 'acidic system', mediating the absorption of aspartate and glutamate (system $X_{A G}^{-}$and $A G T 1$ ). Furthermore the 'iminoglycine system', which accounts for transport of proline, hydroxyproline and glycine (PAT1, PAT2, system IMINO and XT2) and the B-amino acid system (TauT and BGT1) were proposed.

\section{Importance of PEPT1 in human genetic disorders}

The importance of PEPT1 has been shown in patients suffering from Hartnup disease and Cystinuria. Hartnup disorder (OMIM 234500) is an autosomal recessive disease first described in the 1950's, which is caused by mutations in the neutral amino acid transporter $\mathrm{B}^{0} \mathrm{AT} 1$ (SLC6A19) [137]. The disorder has an estimated 
prevalence of $\sim 1: 20.000$ [138]. Renal as well as intestinal uptake of neutral amino acids is affected by Hartnup disorder. In vivo an almost complete lack of intestinal tryptophan absorption was observed [139], suggesting that the transporter affected in Hartnup disorder is the major mediator of tryptophan uptake in the intestine. Cystinuria (OMIM 220100), which is caused by genetic defects in the subunits of the heteromeric amino acid tranporter $\mathrm{rBAT} / \mathrm{b}^{0,+} \mathrm{AT}$ (SLC3A1/SLC7A9), is one of the most common genetic disorders, with an overall prevalence of approximately 1 in 7.000 and can cause considerable damage to kidneys. Excessive amounts of arginine, lysine, ornithine and cystine in urine are observed in patients with cystinuria. [140, 141]. Three types of cystinuria are known, namely type I, non-type I (type II) and type III cystinuria. During the last years more than 60 distinct mutations of rBAT have been described (reviewed by [142]). In human perfusion studies of the gastrointestinal tract of patients suffering from both disease it was shown that intestinal absorption of selected amino acids was abolished by the malfunctions of the amino acid transporters, while when the corresponding amino acids were provided in form of dipeptides, normal absorption occurred [143, 144]. Especially for essential amino acids, such as lysine, this compensation of amino acid transporter function via peptide uptake established the essential and life-sustaining role of PEPT1 in the patients [144].

\section{Clinical relevance}

As mentioned before, PEPT1 is also known to transport peptidomimetics. Thus changes of transport activity or expression are also of clinical relevance. Under some pathophysiological and physiological conditions the expression and transport activity of PEPT1 is changed [97], which in turn also affects the pharmacokinetics of substrate drugs. PEPT1 has been identified as a prime target for improving the bioavailability and absorption of peptidomimetics or corresponding pro-drugs [69]. Also in enteral nutrition, by use of peptide solutions PEPT1 gained increasing attention. Especially in patients in severe catabolic states (e.g. trauma, sepsis) or in diseases with a reduced intestinal absorptive area an absorptive advantage may be provided by enteral solutions containing small peptides. In addition amino acids that are unstable or sparingly soluble in free form (e.g. tyrosine, cystine, glutamine) can be provided in more stable forms as di- and tripeptides [145]. 


\subsection{Aim of the project}

To assess the role of PEPT1 in overall amino acid metabolism we performed a comprehensive metabolic phenotyping of mice lacking PEPT1. The project had essentially two phases. Initially a basal characterization of the PEPT1-deficient mouse line concerned analyses of blood, urine and tissues including different profiling techniques such as transcriptome and proteome analysis of intestinal tissue. The second phase included a phenotype analysis when animals were provided diets with different protein contents. 



\section{Results}

\subsection{Basal phenotypic characterization of $P e p t 1^{-1-}$ mice}

The Pept 1 knockout mouse line was obtained from Deltagen and established as described in the 'Materials and Methods' section [71]. In brief the nucleotide sequence of PEPT1 has a length of 3123 bp (see also NCBI: NM_053079) and the gene length is approximately $38 \mathrm{~kb}$ and consists of 23 exons. As shown in Fig. 6 the targeting gene construct (comprising the neomycin resistence and the $\mathrm{B}$ galactosidase gene) was inserted in exon 3 . Thus the nucleotide sequence of bp 78102 on cDNA level was deleted.

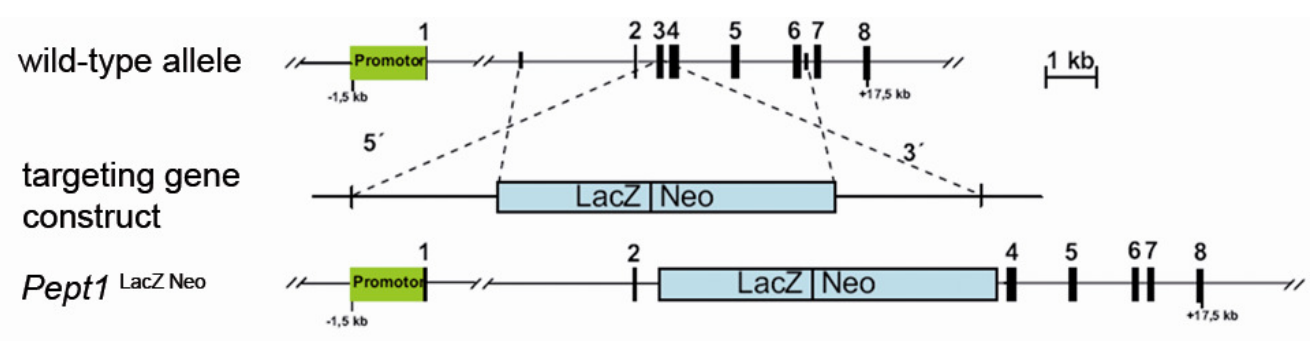

Fig. 6: Schematic of the mouse wild-type allele, the targeting construct and the Pept1 knockout $\left(P e p t 1^{\text {LacZ Neo }}\right.$ ) allele.

\subsubsection{Body weight}

As shown by Meissner et al. the nematode C.elegans, lacking the intestinal peptide transporter, revealed a reduced body and brood size suggesting an overall impaired growth and development by lack of the peptide transporter [146]. To assess whether similar phenotypic alterations can be observed in mice, body weight changes were recorded in male and female littermate animals under standard housing and feeding conditions over 20 weeks (Fig. 7). No significant differences between genotypes could be observed for both male and female mice. 


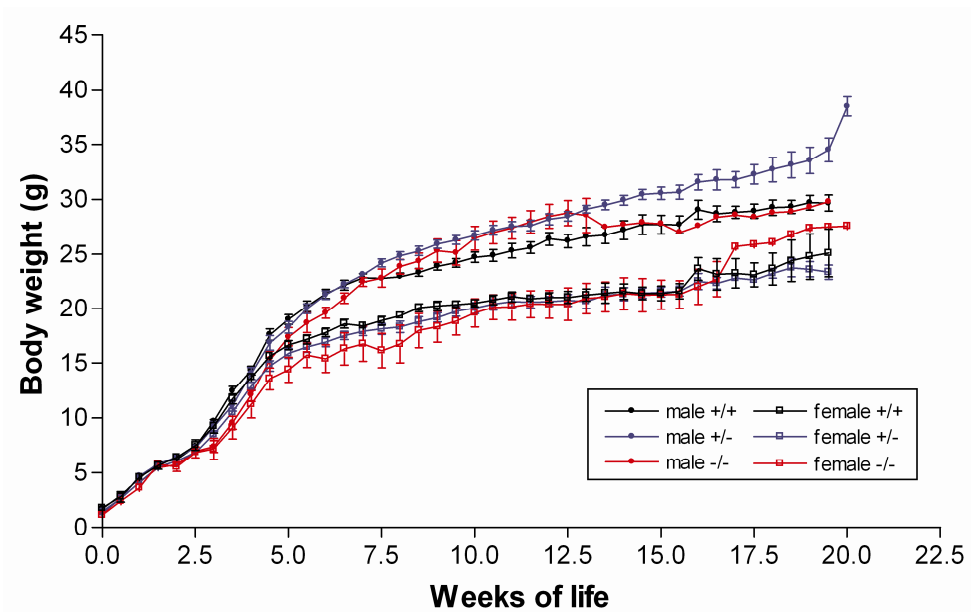

Fig. 7: Body weight changes in wildtype animals and mice heterozygote and homozygote for a PEPT1-deficiency

Body weight of male and female Pept $1^{+/}, P e p t 1^{+/}$and $P e p t 1^{-/}$littermates was monitored over 20 weeks of life. N=7-29 animals per sex and genotype were studied. Data are presented as mean $\pm S E M$. Data from male and female mice were analyzed separately by one way ANOVA.

\subsubsection{Haploinsufficiency in heterozygous animals}

Brush border membrane vesicles (BBMV) were prepared from scraped mucosa samples. The purity of BBMV preparation was assayed by the marker enzyme alkaline phosphatase (EC 3.1.3.1). For all genotypes specific activity of alkaline phosphatase in the final membrane fraction compared with the initial homogenate was increased (Pept $1^{+/+}$animals: 13-fold enrichment, 1704 vs. 132 units/mg protein; Pept $1^{+/}$animals: 10 -fold enrichment, 1394 vs. 134 units/mg protein; Pept $1^{-/}$animals: 10-fold enrichment, 1583 vs. 164 units/mg protein). By Western blot analysis with BBM vesicles we could show that heterozygous animals show haploinsufficiency (Fig. 8).

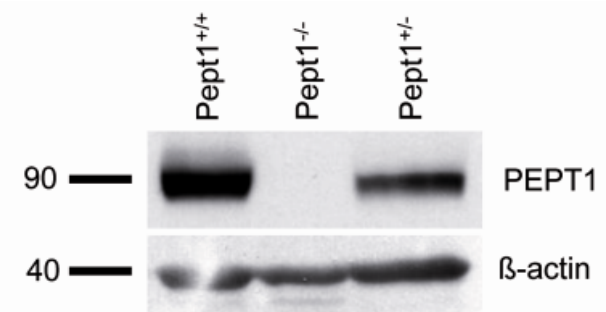

Fig. 8: Protein expression levels in intestinal BBMV

PEPT1 protein density was determined in $P e p t 1^{+/}$, Pept $1^{-/}$and $P e p t 1^{+/}$animals using BBMV prepared from mucosal scrapings. B-actin was used as loading control.

This finding was further confirmed by uptake studies using the everted gut sac technique with Gly-Sar as substrate (Fig. 9). By uptake of $10 \mu \mathrm{M}$ radiolabelled and 
50mM unlabelled Gly-Sar, Pept $1^{+-}$animals displayed only $45 \%$ of uptake activity compared to $\mathrm{Pept}^{+/+}$animals, whereas in Pept $1^{-/-}$animals uptake was reduced by 90\%. Reduced transport function in $P e p t 1^{+/}$animals is due to reduced protein density in membranes.

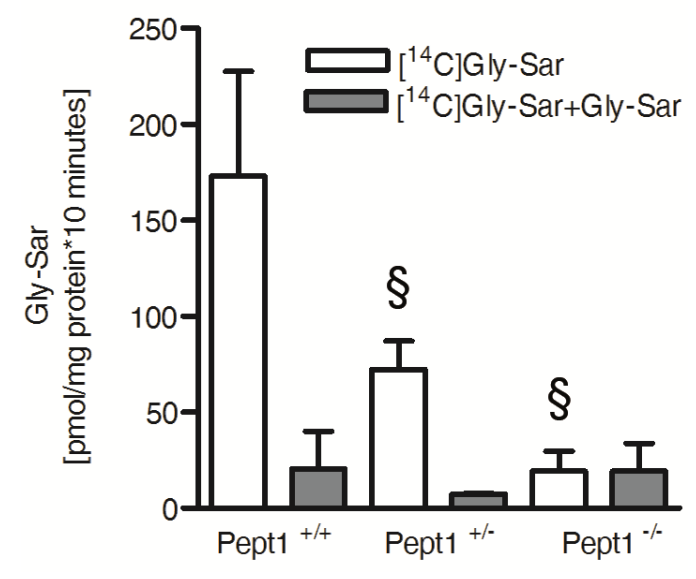

Fig. 9: Gly-Sar uptake by everted gut sacs

All data are presented as mean $\pm \mathrm{SD}$. $\mathrm{N}=6$ male animals per genotype and group were studied.

P-value obtained by two-factor ANOVA analysis and post-hoc analysis (Tukey) when comparing between groups $\left({ }^{*}<0.05\right.$, $\S<0.01, \$<0.001)$.

\subsubsection{Characterization of tissue samples by profiling techniques}

In contrast to C.elegans the transporter-deficient mouse line appears healthy and no alterations in body weight, development and fertility were observed. Therefore we asked whether there is a compensation with changes in amino acid transporter expression and/or increased amino acid transport function that prevents a detectable phenotype. For analysis of changes on transcriptome and proteome level, jejunal sections of the small intestine were removed from Pept $1^{+/+}$and $\mathrm{Pept}^{-1-}$ mice.

\section{Proteome analysis of intestinal tissues}

By 2D-PAGE based proteome analysis of mucosal proteins on average 500 proteins on a gel could be resolved. 7 proteins showed major changes and 6 could be identified by MALDI-TOF-MS based peptide mass fingerprinting (Table 1).

Table 1: Changes in protein levels in mucosal tissues of PEPT1-deficient animals.

\begin{tabular}{|c|c|c|c|c|c|c|c|c|}
\hline $\begin{array}{l}\text { Spot } \\
\text { nr. }\end{array}$ & Protein & $\begin{array}{l}\text { Gene } \\
\text { symbol }\end{array}$ & $\begin{array}{c}\text { MW } \\
(\mathrm{kDa})\end{array}$ & $\begin{array}{c}\text { pl- } \\
\text { value }\end{array}$ & Function & $\begin{array}{c}\% \text { sequence } \\
\text { coverage }\end{array}$ & $\begin{array}{l}\text { Mean ratio } \\
\text { ko/wt }\end{array}$ & $\begin{array}{l}\text { P-value } \\
\text { (t-test) }\end{array}$ \\
\hline 1 & Ribonuclease inhibitor & Rnh1 (Rnh) & 51.5 & 1.83 & protein metabolism & 56 & 0.198 & 6.07E-05 \\
\hline 2 & $\begin{array}{l}\text { Coatomer subunit epsilon } \\
\text { (Epsilon-coat protein) }\end{array}$ & Cope (Cope1) & 34.8 & 2.93 & $\begin{array}{l}\text { protein metabolism/ } \\
\text { transport }\end{array}$ & 61 & 0.259 & 0.0005 \\
\hline
\end{tabular}




\begin{tabular}{|c|c|c|c|c|c|c|c|c|}
\hline $\begin{array}{c}\text { Spot } \\
\text { nr. }\end{array}$ & Protein & $\begin{array}{l}\text { Gene } \\
\text { symbol }\end{array}$ & $\begin{array}{c}\text { MW } \\
(\mathrm{kDa})\end{array}$ & $\begin{array}{c}\text { pl- } \\
\text { value }\end{array}$ & Function & $\begin{array}{l}\% \text { sequence } \\
\text { coverage }\end{array}$ & $\begin{array}{l}\text { Mean ratio } \\
\text { ko/wt }\end{array}$ & $\begin{array}{l}\text { P-value } \\
\text { (t-test) }\end{array}$ \\
\hline 3 & $\begin{array}{c}\text { 14-3-3 protein epsilon } \\
(14-3-3 E)\end{array}$ & Ywhae & 29.3 & 1.84 & metabolism & 54 & 0.385 & 0.0004 \\
\hline 4 & $\begin{array}{l}\text { ATP synthase subunit beta, } \\
\text { mitochondrial precursor } \\
\text { (EC 3.6.3.14) }\end{array}$ & Atp5b & 56.3 & 4.01 & metabolism & 48 & 0.395 & 0.0356 \\
\hline 5 & $\begin{array}{l}\text { Elongation factor 1-beta } \\
\text { (EF-1-beta) }\end{array}$ & Eef1b (Eef1b2) & 24.8 & 1.47 & protein biosynthesis & 47 & 2.105 & 0.0021 \\
\hline 6 & $\begin{array}{c}\text { Peptidyl-prolyl cis-trans } \\
\text { isomerase A } \\
\text { (PPlase A) (EC 5.2.1.8) }\end{array}$ & Ppia & 18.1 & 4.01 & protein metabolism & 57 & 2.540 & 0.0248 \\
\hline
\end{tabular}

Protein extracts from mucosal scrapings of small intestine of $P$ ept $1^{+/+}$(wt) and Pept $1^{-1 /}$ (ko) animals ( $\mathrm{n}=5-6$ per genotype) were analyzed individually by 2D-PAGE on $\mathrm{pH}$ 3-10 strips and MALDI-TOF-MS. Listed are proteins with at least 2-fold changed density of knockout when compared to wildtype animals. Spot numbers correspond to Fig. 10. P-value was obtained by double sided, unpaired Student's $t$-test.

\section{A representative 2D-PAGE gel of mucosal scrapings of a wildtype mouse and} corresponding sections of a representative gel of a Pept1-knockout mouse are shown in Fig. 10.

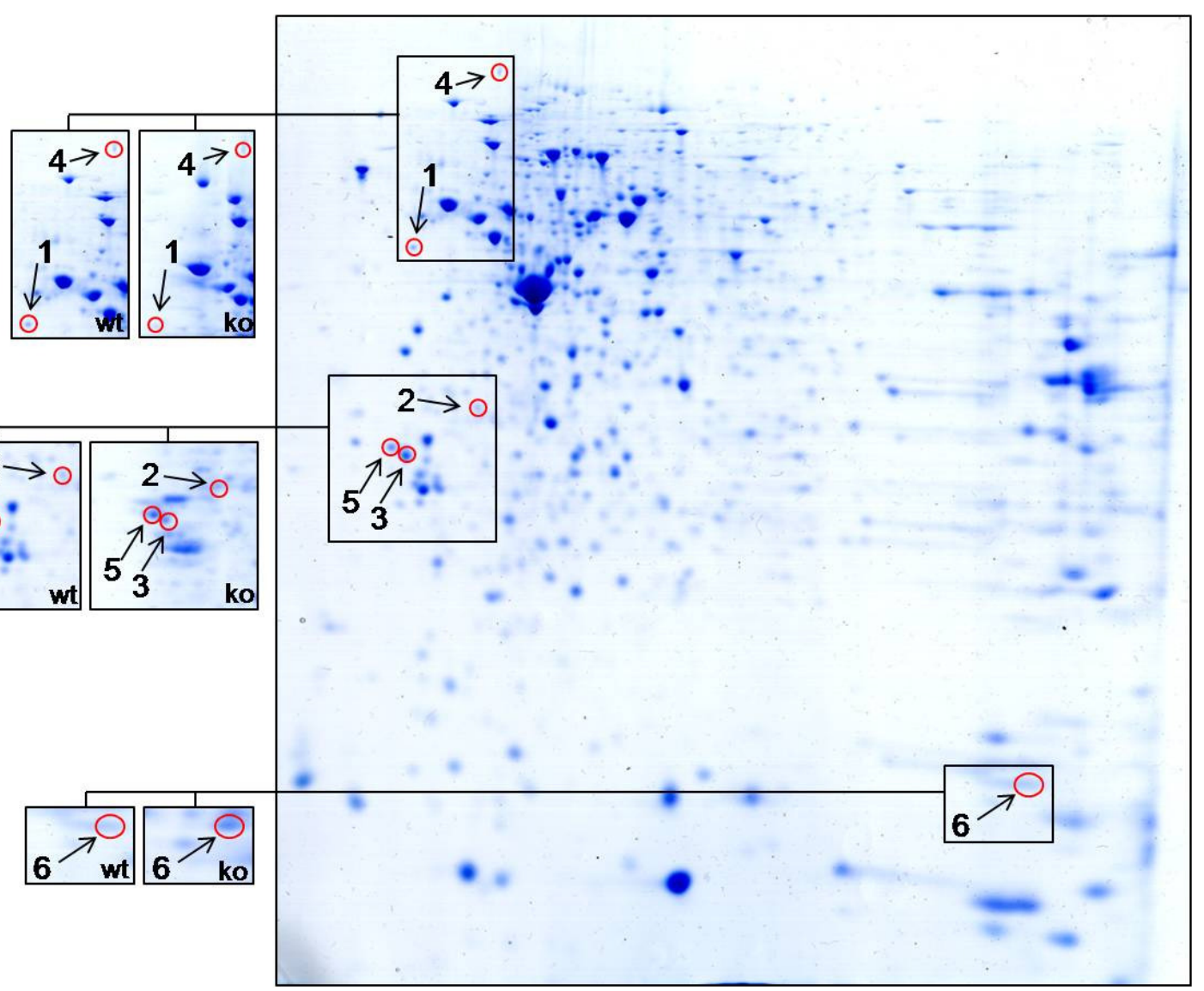

Fig. 10: 2D-PAGE analysis of proteins from mucosal scrapings

Protein extracts from mucosal scrapings of small intestine ( $n=5-6$ per genotype) were analyzed individually by 2D-PAGE. In the first dimension proteins were separated according to their isoelectric point on pH 3-10 strips. In the second dimension separation according to protein mass was performed by electrophoresis on $12.5 \%$ SDS-polyacrylamide gels. A representative Coomassie stained gel of a wildtype protein extract is shown in the middle and enlarged sections of a representative knockout gel in comparison to the wildtype gel are shown for areas that contain protein spots differing significantly in intensity between genotypes. Protein spots which could be identified by MALDI-TOF-MS are indicated by arrows and numbered in Table 1. 
The enzyme peptidylprolyl isomerase A (Ppia) and the translation elongation factor 1beta (Eef1b) showed protein levels elevated by about $50 \%$ in Pept ${ }^{-/}$when compared to $\mathrm{Pept}^{+/+}$animals. The ribonuclease inhibitor 1 (Rnh1) probably involved in controlling mRNA turnover, the coatomer subunit epsilon (Cope) essential for the retrograde Golgi-to-ER transport of dilysine-tagged proteins, the ATP synthase subunit beta (Atp5b) and an adapter protein implicated in the regulation of a large spectrum of signaling pathways (Ywahae) displayed lowered levels in Pept ${ }^{-/}$ animals.

\section{Transcriptome analysis of intestinal tissue}

Differential gene expression analysis was performed by Affymetrix mouse whole genome arrays. Only four genes showed significantly altered mRNA levels in the transporter-deficient mice $(q<0.05)$ (Table 2). Except for Pept1, with a log2-fold change of -58 , only subtle changes of transcript levels could be observed in Pept ${ }^{-/}$ mice. Aldh18a1 and its corresponding protein, $\Delta 1$-pyrroline 5-carboxylate synthase (P5CS) (log2-fold change= -1.5) catalyzes an essential step in pathways by which ornithine, arginine and proline are synthesized from glutamate. The other two transcripts derive from EST clones not yet associated to known proteins (Transcript identifiers: BE648536.1, BM119376.2). No changes in the transcript levels of any of the known amino acid transporters or of PEPT2, expressed in the gut enteric nervous system, were identified in tissues from PEPT1-deficient animals.

Table 2: Microarray analysis of mucosal tissue of Pept1-deficient animals

\begin{tabular}{lcccc}
\hline Transcript & Gene symbol & Function & log 2 fold change & q-value \\
\hline $\begin{array}{l}\text { Solute carrier family 15 (oligopeptide } \\
\text { transporter), member 1 }\end{array}$ & Slc15a1 & peptide transport & -57.77 & $6.22 \mathrm{E}-10$ \\
$\begin{array}{l}\text { RIKEN cDNA B930025B16 gene } \\
\text { (Transcript identifier: BE648536.1) }\end{array}$ & B930025B16Rik & not known & -5.38 & $2.18 \mathrm{E}-07$ \\
$\begin{array}{l}\text { Transcript identifier: BM119376.2 } \\
\begin{array}{l}\text { Aldehyde dehydrogenase 18 family, } \\
\text { member A1 }\end{array}\end{array}$ & Aldh18a1 & metabolism & -1.52 & $2.04 \mathrm{E}-06$ \\
\hline
\end{tabular}

Mucosal scrapings of small intestine ( $n=5-6$ per genotype) were analyzed individually by mouse whole-genome microarrays. After isolation of total RNA, reverse transcription followed and cRNA was biotinylated and fragmented. cDNA samples were then hybridized for $16 \mathrm{~h}$ at $45^{\circ} \mathrm{C}$ on Affymetrix mouse whole-genome arrays. After washing and scanning the arrays, quality control and statistical analysis were performed using a bioconductor and $R$ based method in the NuGO Array Pipeline. Gene expression measures were calculated using GCRMA [147]. 


\subsubsection{Amino acid transport and peptide transporter expression in kidney tissue}

BBMV were prepared from kidney tissue of $\mathrm{Pept}^{+/+}$and $\mathrm{Pept}^{-/-}$animals. The enrichment in the specific activity of alkaline phosphatase in the final membrane fraction compared with the initial homogenate was 18-fold in $P e p t 1^{+/+}$and 20 -fold in Pept $1^{-/}$tissue preparation. Although others reported PEPT1 expression in mouse kidney [71], we were not able to detect PEPT1 in kidney by immunofluorescence staining (Fig. 11) nor by Western blot analysis (Fig. 12), or by LacZ-staining (Fig. 13).

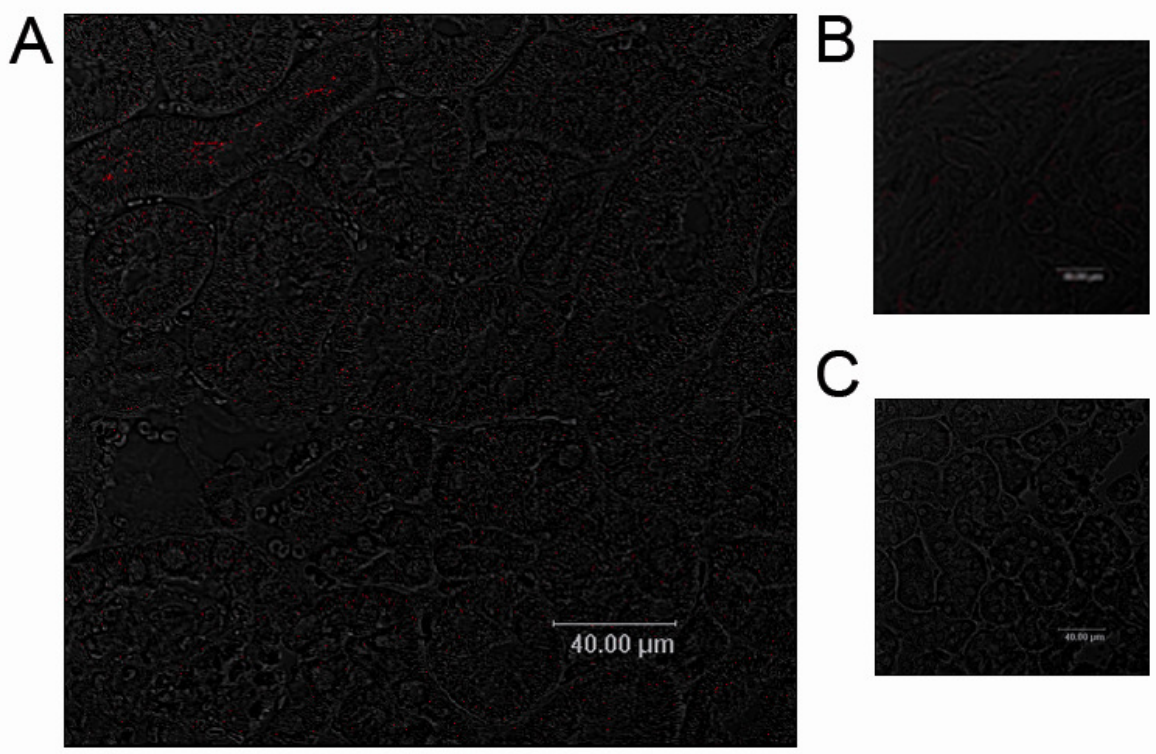

Fig. 11: Immunolocalization of PEPT1 in kidney tissue

Immunolocalization of PEPT1 in renal tissue in wild-type (A) and knockout (B) animals. Also depicted is a negative control, without primary antibody (C). Dilutions of antibodies were: 1:2000 for primary antibody and 1:400 for secondary antibody.

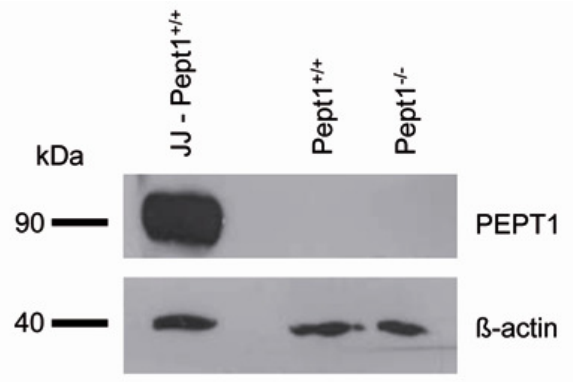

Fig. 12: PEPT1 protein expression levels in kidney BBMV

PEPT1 protein density was determined in $P e p t 1^{+/+}$and $P e p t 1^{-1-}$ animals using kidney BBMV. As a reference wild-type jejeunum samples (marked $\mathrm{JJ}-\mathrm{Pept}^{+/+}$) were used and B-actin was used as loading control. 

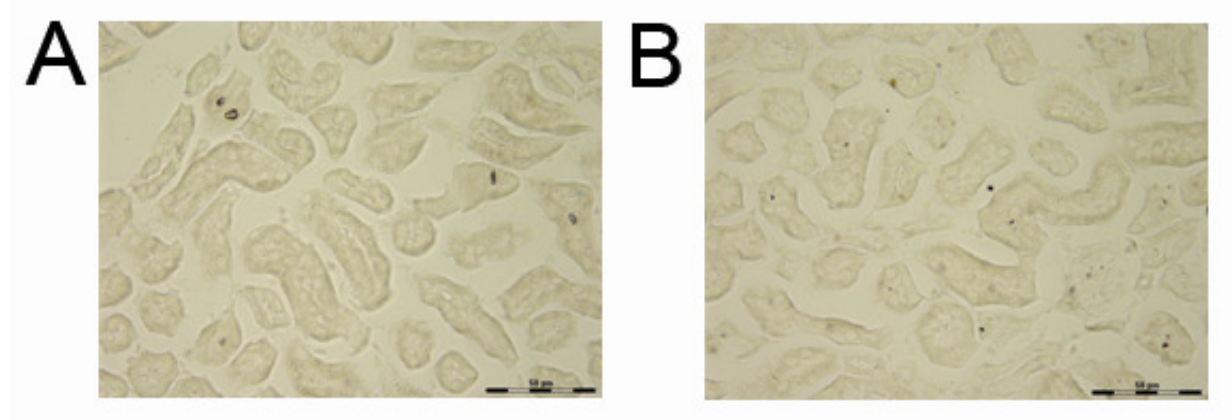

Fig. 13: X-Gal staining in kidney tissue

B-galactosidase activity was determined by X-Gal staining in renal tissue samples of $P e p t 1^{+/+}(\mathrm{A})$ and $P e p t 1^{-/}(\mathrm{B})$ animals.

To assess whether PEPT2 expression in kidney is altered due to lack of PEPT1 in the organism we performed Western blot analysis, but could not observe any differences between wild-type and knockout animals (Fig. 14).

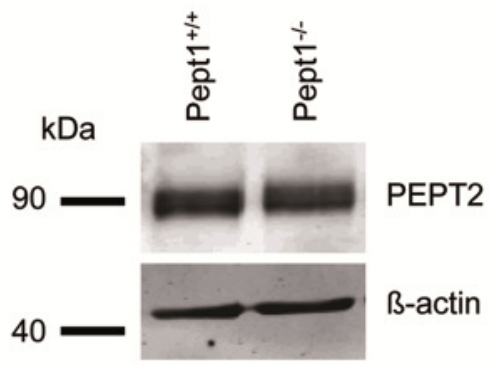

Fig. 14: Protein expression level of PEPT2 in kidney tissue

PEPT2 protein density was determined in wild-type $\left(P e p t 1^{+/+}\right)$and Pept1 knockout $\left(P e p t 1^{-1}\right)$ animals using BBMV prepared from kidney tissue. B-actin was used as loading control.

Since plasma proline levels showed differences between Pept $1^{1 /+}$ and Pept $1^{-1-}$ animals, uptake of L-proline into kidney BBMV was studied, with D-glucose uptake into BBMV serving as a control. In the presence of a $\mathrm{Na}^{+}$-gradient a similar overshoot phenomenon was observed for both L-proline and D-glucose (Fig. 15) independently of genotype. 

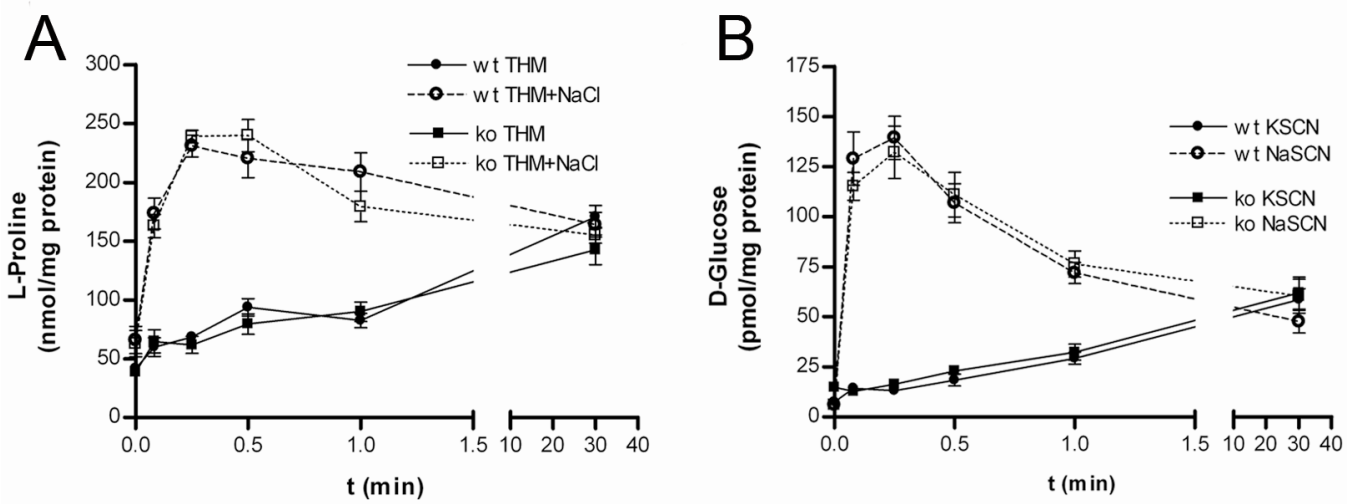

Fig. 15: Uptake studies with L-proline and D-glucose in BBMV of kidney tissue

Uptake of L-proline into BBMV prepared from kidneys of wild-type and Pept1 knockout animals $(\mathrm{A})$ in the presence and the absence of a Na+-gradient. Uptake of $\mathrm{D}$-glucose in the presence and the absence of a $\mathrm{Na}^{+}$-gradient in wild-type and Pept1 knockout (B) animals serving as a control. ( $n=3$ animals)

\subsubsection{Basal metabolic parameters reveal elevated gross energy content of feces in male and female Pept1 ${ }^{-/-}$animals}

Analysis of basal metabolic parameters revealed no differences between genotpyes for male mice. Only female mice displayed significant changes between food intake and feces excretion, whereas for Pept $1^{-1 /}$ mice lower food intake rates $(p<0.013)$ and thus also a lower feces excretion $(p<0.001)$ was observed (Fig. 16). Water consumption did not vary, neither between gender nor genotypes.
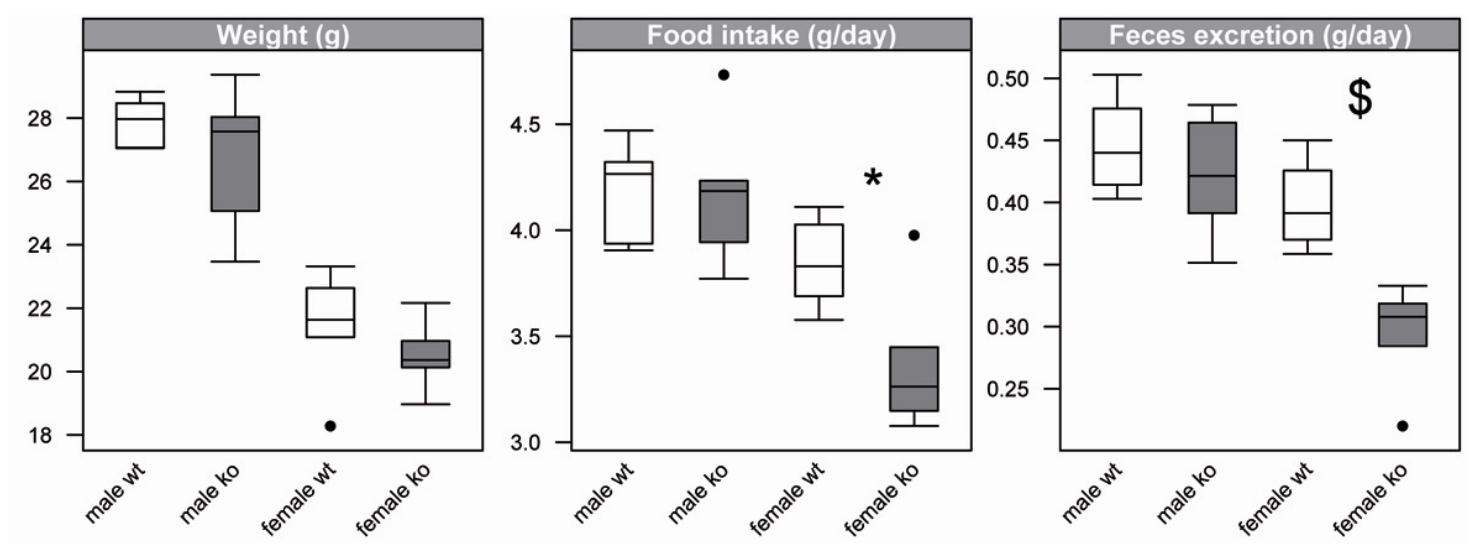

Fig. 16: Basal metabolic parameters in male and female mice on standard diet.

All data are presented as mean $\pm S D$. Data from male and female animals were analyzed separately. $\mathrm{N}=10$ male and female animals per genotype and gender were studied; Pept $1^{+/+}$(wt), Pept $1^{-/ /}$(ko). P-value was obtained by unpaired Student's t-test between genotypes $\left({ }^{*}<0.05, \S<0.01, \$<0.001\right)$.

Most interesting however was the analysis of feces samples using a bomb calorimeter, which revealed that the energy content of feces per gram $(\mathrm{kJ} / \mathrm{g})$ is much 
higher in Pept1 $1^{-/}$than in Pept $1^{+/+}$animals (both $\mathrm{p}<0.001$ ). This effect is independent of gender, as male and female mice display the same effect (Fig. 17).

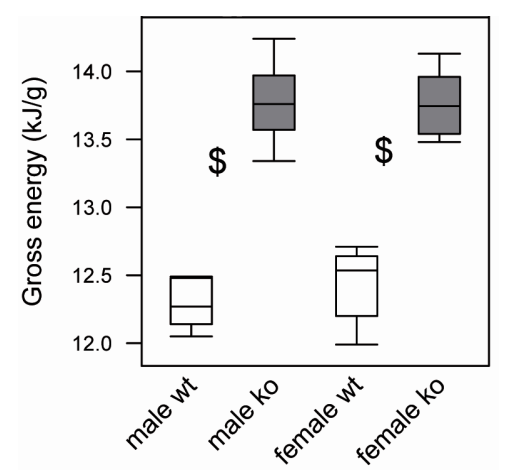

Fig. 17: Gross energy content of excreted feces in male and female mice on control diet

All data are presented as mean $\pm S D$. Data from male and female animals were analyzed separately. $N=10$ male and female animals per genotype and gender were studied; $\operatorname{Pept}^{+{ }^{++}}(\mathrm{wt}), \operatorname{Pept}^{-1 /}(\mathrm{ko})$. P-value was obtained by unpaired Student's t-test between genotypes $\left({ }^{*}<0.05, \S<0.01, \$<0.001\right)$.

\subsubsection{Basal plasma grehlin, leptin and insulin levels}

Hormone levels were determined in male mice $(n=6)$ in fed or fasted ( $6 \mathrm{~h}$ of fasting) state (Fig. 18). Only leptin levels were observed to differ significantly between fasted male Pept $1^{1 /+}$ and Pept $1^{-/}$mice (wt: $5.7 \pm 2.4 \mathrm{ng} / \mathrm{ml}$ vs. ko: $2.5 \pm 1.7 \mathrm{ng} / \mathrm{ml}, \mathrm{p}=0.0013$ ). Pept $1^{-1 /}$ mice in fed state displayed decreased levels when compared to Pept $1^{+/+}$ animals as well (wt: $5.6 \pm 1.6 \mathrm{ng} / \mathrm{ml}$ vs. $2.6 \pm 2.1 \mathrm{ng} / \mathrm{ml}$ ), yet not significant. No significant differences for basal insulin and ghrelin levels, neither in fed nor fasted state could be detected between Pept $1^{+/+}$and Pept $1^{-/}$animals.
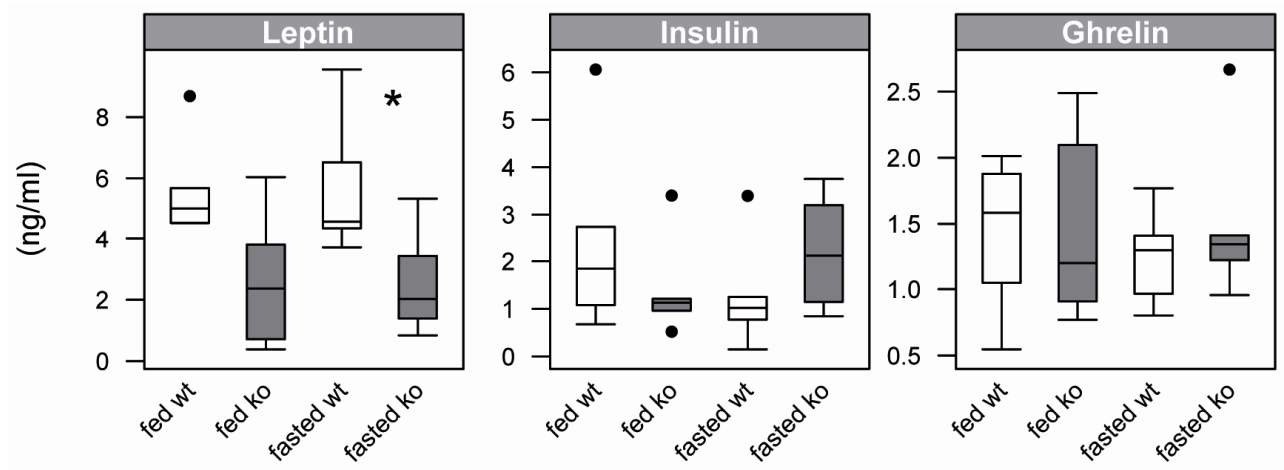

Fig. 18: Determination of hormones in plasma of fed and fasted animals.

All data are presented as mean \pm SD. N=6 male animals per genotype and group were studied; Pept $1^{++}$(wt), Pept $1^{-/}$(ko). P-value was obtained by unpaired Student's t-test between genotypes $\left.{ }^{*}<0.05, \S<0.01, \$<0.001\right)$. 


\subsection{Analysis of selected parameters in body fluids and tissues in basal state}

\subsubsection{Clinical chemical parameters}

\section{Plasma}

Plasma samples of male and female Pept $1^{-/-}$and Pept $1^{+/+}$animals were analyzed using the Piccolo $x$ press $^{\mathrm{TM}}$ chemistry analyzer (Abaxis, California, USA) for 13 parameters (Table 3). However only alkaline phosphatase (ALP) showed significant differences between Pept $1^{-/-}$and Pept $1^{+/+}$animals. As both male and female mice display lowered ALP levels in Pept $1^{-/-}$animals, this effect seems gender independent.

Table 3: Basal clinical chemical parameters in plasma of female and male Pept $1^{+/+}$and Pept1 ${ }^{-/-}$mice

\begin{tabular}{|c|c|c|c|c|c|c|}
\hline \multirow[t]{2}{*}{ Parameter } & \multicolumn{2}{|c|}{ Female } & \multirow[t]{2}{*}{ P-value } & \multicolumn{2}{|c|}{ Male } & \multirow[t]{2}{*}{ P-value } \\
\hline & Pept1 $^{+/+}$ & Pept1 ${ }^{-/-}$ & & Pept $^{+/+}$ & Pept1 ${ }^{-1-}$ & \\
\hline Glucose (mg/dl) & $228.00 \pm 41.09$ & $241.43 \pm 44.28$ & 0.530 & $247.14 \pm 34.09$ & $226.31 \pm 24.24$ & 0.081 \\
\hline Blood urea nitrogen $(\mathrm{mg} / \mathrm{dl})$ & $25.00 \pm 4.14$ & $28.29 \pm 2.93$ & 0.092 & $29.14 \pm 5.20$ & $29.31 \pm 3.73$ & 0.926 \\
\hline Uric acid (mg/dl) & $0.84 \pm 0.17$ & $0.80 \pm 0.28$ & 0.817 & $0.91 \pm 0.36$ & $0.92 \pm 0.41$ & 0.916 \\
\hline Calcium (mg/dl) & $9.86 \pm 0.41$ & $9.80 \pm 0.50$ & 0.791 & $9.19 \pm 0.27$ & $9.15 \pm 0.29$ & 0.667 \\
\hline Total protein (g/dl) & $5.42 \pm 0.22$ & $5.34 \pm 0.15$ & 0.436 & $5.54 \pm 0.25$ & $5.46 \pm 0.18$ & 0.341 \\
\hline $\operatorname{ALT}(\mathrm{U} / \mathrm{I})$ & $32.20 \pm 20.67$ & $32.00 \pm 13.95$ & 0.983 & $23.64 \pm 11.49$ & $22.69 \pm 12.69$ & 0.840 \\
\hline AST(U/I) & $103.20 \pm 48.37$ & $103.14 \pm 62.82$ & 0.998 & $74.21 \pm 14.10$ & $75.00 \pm 19.73$ & 0.906 \\
\hline $\operatorname{ALP}(U / I)$ & $116.20 \pm 18.44$ & $84.86 \pm 21.07$ & 0.005 & $76.14 \pm 8.92$ & $63.92 \pm 12.59$ & 0.007 \\
\hline Total bilirubin (mg/dl) & $0.72 \pm 0.10$ & $0.71 \pm 0.11$ & 0.913 & $0.39 \pm 0.08$ & $0.43 \pm 0.11$ & 0.229 \\
\hline Amylase (U/I) & $835.20 \pm 112.75$ & $734.00 \pm 105.97$ & 0.082 & $1007.50 \pm 241.75$ & $935.85 \pm 219.47$ & 0.429 \\
\hline
\end{tabular}

All data are presented as mean \pm SD. $N=7-10$ female animals and $n=13-14$ male animals per genotype and gender were studied. Male and female data were analyzed separately. P-value was obtained by unpaired Student's t-test.

\section{Urine}

Urea, creatinine and osmolarity of urine samples were determined and for urea and osmolarity no differences neither between genotype nor gender could be determined. Only creatinine concentrations showed significant changes for female mice (Fig. 19), whereas concentrations in male mice were not altered. 


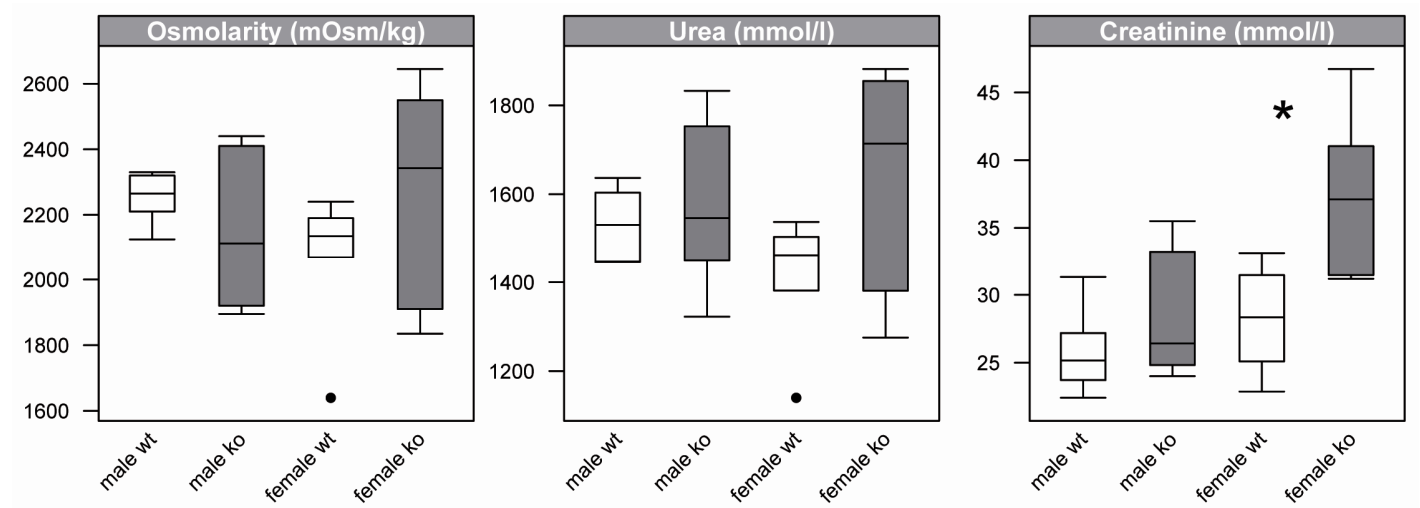

Fig. 19: Urine osmolarity and urea and creatinine levels in female and male Pept1 ${ }^{+/+}$and Pept1 $^{-/ .}$animals.

Osmolarity, urea and creatinine were determined in pooled urine samples of $\mathrm{n}=10$ animals per gender and genotype; $P$ ept $1^{+/+}$ (wt), Pept ${ }^{-1 /}$ (ko). Data of male and female animals were analyzed separately. P-value was obtained by unpaired Student's ttest when comparing between genotypes $\left({ }^{*}<0.05\right)$.

\subsubsection{Basal amino acid levels in plasma, urine and tissue in male mice}

\section{Plasma}

In plasma samples of male Pept $1^{1 /+}$ and Pept $1^{-1 /}$ animals 40 amino acids and derivatives could be quantified by LC-MS/MS. Analysis of basal amino acid levels in plasma demonstrated altered levels in Pept $1^{-1-}$ animals (Table 4). Analysis in male mice revealed that the sum of all measured amino acids and derivatives in plasma increased in Pept $1^{-/}$mice compared to Pept $1^{+/+}$animals. This was attributed to 24 metabolites showing elevated concentrations in plasma whereas none displayed significantly decreased levels. The branched chain amino acids valine, leucine and isoleucine but also aminobutyric acid displayed a tendency to elevated plasma levels in Pept $1^{-1 /}$ mice, yet not significant. Tryptophane, glycine, glutamine, ethanolamine, taurine and ornithine but also the dipeptides anserine and carnosine remained unaltered.

Table 4: Basal plasma amino acid concentrations in male mice

\begin{tabular}{|c|c|c|c|}
\hline Amino acid $(\mu \mathrm{mol} / \mathrm{l})$ & Pept $^{+/+}$ & Pept1 $^{-1-}$ & $P$-value \\
\hline Alanine & $503.83 \pm 43.35$ & $643.83 \pm 122.26$ & 0.025 \\
\hline Alpha-aminoadipic acid & $5.76 \pm 0.81$ & $9.40 \pm 2.12$ & 0.003 \\
\hline Anserine & $1.27 \pm 0.28$ & $1.45 \pm 0.73$ & 0.579 \\
\hline Arginine & $81.55 \pm 16.95$ & $121.33 \pm 18.63$ & 0.003 \\
\hline Argininosuccinase & $0.75 \pm 0.41$ & $0.56 \pm 0.53$ & 0.514 \\
\hline Asparagine & $53.77 \pm 9.42$ & $84.57 \pm 16.91$ & 0.003 \\
\hline Aspartate & $4.38 \pm 1.63$ & $6.81 \pm 1.80$ & 0.034 \\
\hline Beta-Alanine & $6.12 \pm 4.99$ & $14.80 \pm 2.85$ & 0.004 \\
\hline
\end{tabular}




\begin{tabular}{|c|c|c|c|}
\hline Amino acid $(\mu \mathrm{mol} / \mathrm{l})$ & Pept $^{\text {+/+ }^{1+}}$ & Pept1 $^{-1-}$ & $P$-value \\
\hline Carnosine & $1.32 \pm 0.30$ & $1.20 \pm 0.19$ & 0.437 \\
\hline Citrulline & $50.87 \pm 3.48$ & $73.02 \pm 15.77$ & 0.007 \\
\hline Cystathionase & $1.75 \pm 0.45$ & $3.28 \pm 1.11$ & 0.011 \\
\hline Cysteine & $1.63 \pm 0.55$ & $2.45 \pm 0.39$ & 0.013 \\
\hline Ethanolamine & $16.40 \pm 2.58$ & $16.27 \pm 1.17$ & 0.910 \\
\hline Gamma-aminobutyric acid & $1.13 \pm 0.26$ & $1.65 \pm 0.41$ & 0.026 \\
\hline Glutamate & $39.25 \pm 7.71$ & $59.45 \pm 11.00$ & 0.004 \\
\hline Glutamine & $666.17 \pm 102.10$ & $658.17 \pm 61.77$ & 0.873 \\
\hline Glycine & $292.17 \pm 51.70$ & $272.33 \pm 53.06$ & 0.527 \\
\hline Histidine & $59.27 \pm 13.59$ & $82.10 \pm 11.38$ & 0.010 \\
\hline Homocitrulline & $0.60 \pm 0.13$ & $0.78 \pm 0.21$ & 0.104 \\
\hline Homocysteine & $2.99 \pm 0.12$ & $3.01 \pm 0.15$ & 0.769 \\
\hline Hydroxylysine & $0.75 \pm 0.21$ & $1.11 \pm 0.55$ & 0.168 \\
\hline Hydroxyproline & $12.28 \pm 4.22$ & $25.83 \pm 4.30$ & $<0.001$ \\
\hline Isoleucine & $126.05 \pm 36.11$ & $139.70 \pm 27.05$ & 0.476 \\
\hline Leucine & $193.83 \pm 64.48$ & $232.50 \pm 56.69$ & 0.296 \\
\hline Lysine & $301.33 \pm 69.64$ & $491.50 \pm 119.30$ & 0.007 \\
\hline Methionine & $141.53 \pm 39.74$ & $205.50 \pm 42.66$ & 0.023 \\
\hline Ornithine & $61.67 \pm 6.54$ & $69.70 \pm 14.01$ & 0.232 \\
\hline Phenylalanine & $63.47 \pm 11.62$ & $77.05 \pm 6.96$ & 0.034 \\
\hline Phosphoethanolamine & $2.11 \pm 0.86$ & $4.23 \pm 1.30$ & 0.007 \\
\hline Proline & $99.38 \pm 40.92$ & $176.25 \pm 53.06$ & 0.018 \\
\hline Sarcosine & $0.78 \pm 0.27$ & $1.26 \pm 0.21$ & 0.006 \\
\hline Serine & $150.67 \pm 13.37$ & $189.83 \pm 19.49$ & 0.002 \\
\hline Taurine & $369.00 \pm 47.38$ & $410.33 \pm 60.16$ & 0.216 \\
\hline Threonine & $188.50 \pm 62.35$ & $274.67 \pm 52.45$ & 0.027 \\
\hline Tryptophane & $98.32 \pm 16.24$ & $86.32 \pm 9.53$ & 0.150 \\
\hline Tyrosine & $93.32 \pm 23.76$ & $143.07 \pm 35.73$ & 0.018 \\
\hline Valine & $320.17 \pm 110.51$ & $366.83 \pm 70.88$ & 0.404 \\
\hline 2-aminobutyric acid & $8.76 \pm 3.29$ & $9.63 \pm 2.19$ & 0.602 \\
\hline 1-M-Histidine & $3.29 \pm 0.78$ & $4.51 \pm 0.53$ & 0.010 \\
\hline 3-M-Histidine & $2.81 \pm 0.75$ & $4.84 \pm 0.78$ & 0.001 \\
\hline Sum & $4028.97 \pm 469.93$ & $4971.13 \pm 635.16$ & 0.015 \\
\hline
\end{tabular}

All data are presented as mean $\pm \mathrm{SD}$. $\mathrm{N}=6$ male animals per genotype were studied. $\mathrm{P}$-value was obtained by unpaired Student's t-test.

\section{Urine}

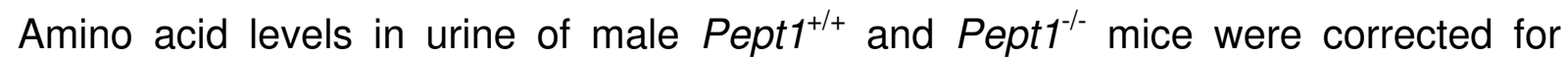
creatinine (Table 5). Argininosuccinate displayed a decrease in Pept $1^{-/}$animals, whereas for glycine an increase could be detected. Most interesting was proline, with an almost 20-fold increase in Pept $1^{-/}$animals. All other amino acids and derivatives did not reveal any significant changes in urine levels of male mice. 
Table 5: Basal urinary amino acids in male mice (corrected for creatinine)

\begin{tabular}{|c|c|c|c|}
\hline Amino acid ( $\mu \mathrm{mol} / \mathrm{mmol}$ creatinine) & Pept1 $^{+++}$ & Pept1 $1^{-/}$ & P-value \\
\hline Alanine & $58.73 \pm 8.58$ & $52.10 \pm 7.91$ & 0.194 \\
\hline Alpha-aminoadipic acid & $15.11 \pm 14.11$ & $24.56 \pm 35.87$ & 0.562 \\
\hline Anserine & $15.68 \pm 4.82$ & $9.59 \pm 6.73$ & 0.102 \\
\hline Arginine & $33.05 \pm 10.57$ & $30.73 \pm 4.61$ & 0.633 \\
\hline Argininosuccinate & $104.15 \pm 10.40$ & $77.95 \pm 21.97$ & 0.025 \\
\hline Asparagine & $21.58 \pm 2.97$ & $19.65 \pm 2.01$ & 0.217 \\
\hline Aspartate & $5.52 \pm 0.93$ & $5.84 \pm 0.93$ & 0.567 \\
\hline Beta-Alanine & $45.94 \pm 7.02$ & $49.58 \pm 3.75$ & 0.289 \\
\hline Beta-aminoisobutyric acid & $36.93 \pm 4.79$ & $38.18 \pm 1.68$ & 0.563 \\
\hline Carnosine & $8.03 \pm 2.24$ & $5.30 \pm 2.94$ & 0.101 \\
\hline Citrulline & $5.25 \pm 4.68$ & $5.30 \pm 5.97$ & 0.987 \\
\hline Cystathionase & $26.44 \pm 9.97$ & $23.66 \pm 12.51$ & 0.679 \\
\hline Cysteine & $103.89 \pm 66.58$ & $79.35 \pm 44.67$ & 0.471 \\
\hline Ethanolamine & $420.55 \pm 52.69$ & $374.86 \pm 5.34$ & 0.061 \\
\hline Gamma-aminobutyric acid & $27.94 \pm 3.10$ & $31.41 \pm 8.32$ & 0.362 \\
\hline Glutamate & $22.68 \pm 2.84$ & $21.16 \pm 3.94$ & 0.460 \\
\hline Glutamine & $200.77 \pm 69.83$ & $174.40 \pm 88.75$ & 0.580 \\
\hline Glycine & $159.28 \pm 5.50$ & $135.53 \pm 9.56$ & $<0.001$ \\
\hline Histidine & $21.16 \pm 7.66$ & $18.87 \pm 6.99$ & 0.599 \\
\hline Homocysteine & $0.84 \pm 0.51$ & $0.89 \pm 1.05$ & 0.919 \\
\hline Hydroxylysine & $0.86 \pm 0.24$ & $0.92 \pm 0.14$ & 0.603 \\
\hline Hydroxyproline & $14.63 \pm 8.93$ & $14.74 \pm 15.71$ & 0.989 \\
\hline Isoleucine & $16.48 \pm 2.50$ & $18.42 \pm 3.60$ & 0.302 \\
\hline Leucine & $57.37 \pm 10.70$ & $49.13 \pm 11.27$ & 0.223 \\
\hline Lysine & $37.05 \pm 5.46$ & $39.69 \pm 6.63$ & 0.468 \\
\hline Methionine & $64.17 \pm 20.53$ & $60.92 \pm 32.37$ & 0.840 \\
\hline Ornithine & $9.35 \pm 1.19$ & $12.42 \pm 4.30$ & 0.122 \\
\hline Phenylalanine & $12.07 \pm 1.66$ & $14.19 \pm 2.44$ & 0.108 \\
\hline Phosphoethanolamine & $14.32 \pm 3.06$ & $12.54 \pm 1.33$ & 0.221 \\
\hline Proline & $21.80 \pm 9.52$ & $429.20 \pm 387.23$ & 0.028 \\
\hline Sarcosine & $3.89 \pm 1.41$ & $4.39 \pm 3.52$ & 0.755 \\
\hline Serine & $26.91 \pm 5.54$ & $22.52 \pm 5.35$ & 0.193 \\
\hline Taurine & $2003.64 \pm 172.34$ & $1768.59 \pm 284.36$ & 0.114 \\
\hline Threonine & $76.48 \pm 28.64$ & $61.05 \pm 24.90$ & 0.343 \\
\hline Tryptophane & $3.54 \pm 0.40$ & $3.63 \pm 0.46$ & 0.751 \\
\hline Tyrosine & $34.39 \pm 10.92$ & $33.09 \pm 14.03$ & 0.861 \\
\hline Valine & $28.87 \pm 4.65$ & $31.83 \pm 6.49$ & 0.385 \\
\hline 1-M-Histidine & $49.27 \pm 6.34$ & $46.87 \pm 3.88$ & 0.448 \\
\hline 3-M-Histidine & $20.16 \pm 3.69$ & $19.96 \pm 2.57$ & 0.915 \\
\hline 2-aminobutyric acid & $1.26 \pm 0.33$ & $1.45 \pm 0.89$ & 0.635 \\
\hline Sum & $3830.03 \pm 486.59$ & $3824.45 \pm 886.61$ & 0.989 \\
\hline
\end{tabular}

All data are presented as mean \pm SD. $N=6$ male animals per genotype were studied. Urine amino acid concentrations were corrected for creatinine. P-value was obtained by unpaired Student's t-test. 


\section{Liver tissue}

For male mice amino acid concentrations in liver tissue were analyzed as well (Table 6). The total concentration of all amino acids (Sum) detected showed no differences depending on genotype. Only citrulline, phosphoethanolamine and ethanolamine showed significantly increased concentrations in Pept $1^{-/-}$compared to Pept ${ }^{+/+}$mice.

Table 6: Liver amino acid concentrations of male mice on control diet

\begin{tabular}{|c|c|c|c|}
\hline Amino acid (nmol/mg protein) & Pept ${ }^{+/+}$ & Pept1 ${ }^{-/}$ & $P$-value \\
\hline Alanine & $117.54 \pm 51.59$ & $102.33 \pm 22.73$ & 0.524 \\
\hline Alpha-aminoadipic acid & $1.29 \pm 0.83$ & $1.22 \pm 0.46$ & 0.864 \\
\hline Asparagine & $3.24 \pm 0.68$ & $3.48 \pm 0.78$ & 0.581 \\
\hline Aspartate & $5.66 \pm 2.44$ & $5.51 \pm 2.22$ & 0.914 \\
\hline Beta-aminoisobutyric acid & $0.25 \pm 0.09$ & $0.24 \pm 0.06$ & 0.852 \\
\hline Citrulline & $1.28 \pm 0.55$ & $2.89 \pm 1.41$ & 0.026 \\
\hline Cystathionase & $1.30 \pm 1.44$ & $0.72 \pm 0.62$ & 0.387 \\
\hline Ethanolamine & $0.31 \pm 0.09$ & $0.56 \pm 0.18$ & 0.013 \\
\hline Gamma-aminobutyric acid & $0.41 \pm 0.14$ & $0.64 \pm 0.41$ & 0.229 \\
\hline Glutamate & $22.38 \pm 3.41$ & $33.52 \pm 13.65$ & 0.081 \\
\hline Glutamine & $78.72 \pm 7.33$ & $67.18 \pm 27.95$ & 0.351 \\
\hline Glycine & $54.14 \pm 13.79$ & $49.51 \pm 19.16$ & 0.641 \\
\hline Histidine & $11.95 \pm 4.43$ & $11.62 \pm 2.89$ & 0.883 \\
\hline Hydroxyproline & $0.50 \pm 0.26$ & $0.61 \pm 0.22$ & 0.441 \\
\hline Isoleucine & $5.74 \pm 2.04$ & $5.05 \pm 1.39$ & 0.506 \\
\hline Leucine & $9.05 \pm 2.79$ & $9.03 \pm 2.44$ & 0.987 \\
\hline Lysine & $11.76 \pm 5.81$ & $10.53 \pm 2.60$ & 0.647 \\
\hline Methionine & $4.55 \pm 1.74$ & $5.11 \pm 2.42$ & 0.655 \\
\hline Ornithine & $4.83 \pm 3.30$ & $4.68 \pm 2.48$ & 0.931 \\
\hline Phenylalanine & $2.96 \pm 0.85$ & $3.16 \pm 0.90$ & 0.707 \\
\hline Phosphoethanolamine & $4.00 \pm 0.97$ & $6.87 \pm 2.32$ & 0.019 \\
\hline Proline & $8.29 \pm 5.50$ & $7.71 \pm 1.95$ & 0.812 \\
\hline Sarcosine & $1.66 \pm 1.18$ & $1.85 \pm 0.92$ & 0.753 \\
\hline Serine & $5.17 \pm 1.62$ & $5.55 \pm 3.14$ & 0.802 \\
\hline Taurine & $241.62 \pm 27.70$ & $232.67 \pm 60.53$ & 0.749 \\
\hline Threonine & $6.53 \pm 2.23$ & $6.21 \pm 2.52$ & 0.819 \\
\hline Tryptophane & $0.94 \pm 0.24$ & $0.98 \pm 0.18$ & 0.749 \\
\hline Tyrosine & $3.43 \pm 1.15$ & $3.87 \pm 0.79$ & 0.451 \\
\hline Valine & $11.07 \pm 3.76$ & $12.11 \pm 3.95$ & 0.653 \\
\hline 2-aminobutyric acid & $1.21 \pm 0.67$ & $1.79 \pm 1.08$ & 0.291 \\
\hline Sum & $622.78 \pm 129.34$ & $598.19 \pm 104.78$ & 0.725 \\
\hline
\end{tabular}

All data are presented as mean \pm SD. $N=6$ male animals per genotype were studied. P-value was obtained by unpaired Student's t-test. 


\subsubsection{Enzyme and urea levels in liver}

Analysis of selected enzyme activities in liver tissue of male Pept $1^{+/+}$and Pept $1^{-/-}$did not yield any significant differences (Table 7). Only urea concentration was significantly decreased in $P e p t 1^{-/}$animals.

Table 7: Basal enzyme activities in liver tissue of male Pept $1^{-/-}$animals

\begin{tabular}{lccc}
\hline Parameter & Pept $^{+/+}$ & Pept $^{-/ \text {r }}$ & $\boldsymbol{P}_{\text {-value }}$ \\
\hline GDH $[\mathrm{mU} / \mathrm{mg}]$ & $798.06 \pm 117.93$ & $755.55 \pm 80.39$ & 0.482 \\
AST $[\mathrm{mU} / \mathrm{mg}]$ & $2396.64 \pm 242.47$ & $2128.04 \pm 537.91$ & 0.291 \\
ALT $[\mathrm{mU} / \mathrm{mg}]$ & $785.57 \pm 69.80$ & $700.51 \pm 108.01$ & 0.136 \\
Urea $[\boldsymbol{\mu m o l} / \mathrm{mg}]$ & $18.21 \pm 3.10$ & $12.48 \pm 1.63$ & 0.002 \\
Arginase[U/mg protein] & $450.30 \pm 32.41$ & $430.46 \pm 126.52$ & 0.718 \\
\hline
\end{tabular}

All data are presented as mean \pm SD. $N=6$ male animals per genotype were studied. P-value was obtained by unpaired Student's t-test.

\subsection{Effects of dietary protein intake on phenotypic changes in PEPT1- deficient mice}

To analyze whether transporter-deficient animals respond to changes in protein supply with metabolic changes, wild-type and knockout animals received diets with different protein contents over different periods of time. Either for $24 \mathrm{~h}, 5$ or 18 days mice received diets with high ( $45 \%$ of energy), low ( $8 \%$ of energy) or medium $(21 \%$ of energy) protein content. We monitored food intake, water consumption, body weight and feces excretion. Plasma and urine parameters as well as amino acid concentrations in plasma, urine and tissue were determined and in addition enzyme activities in tissue were analyzed.

\subsubsection{Subtle effects after administration of a low-protein diet}

Adult male mice on a low-protein (LP) diet for 5 days displayed only a few alterations in metabolic parameters when compared to the control group (Table 8) but no changes between genotypes could be detected. 
Table 8: Metabolic parameters in response to a low-protein diet for 5 days in male mice

\begin{tabular}{|c|c|c|c|c|c|}
\hline \multirow[t]{2}{*}{ Parameter } & \multirow[t]{2}{*}{ Day } & \multicolumn{2}{|c|}{ Control } & \multicolumn{2}{|c|}{ Low-protein } \\
\hline & & Pept1 $^{+/+}$ & Pept1 $1^{-/}$ & Pept1 $^{+/+}$ & Pept1 ${ }^{-/}$ \\
\hline \multirow[t]{5}{*}{ Weight (g) } & 0 & $30.28 \pm 2.41^{c}$ & $29.15 \pm 2.29$ & $28.78 \pm 2.19$ & $27.44 \pm 1.23^{\mathrm{c}}$ \\
\hline & 1 & $30.39 \pm 2.60^{c}$ & $29.05 \pm 2.01$ & $28.46 \pm 2.27$ & $27.57 \pm 1.54^{\mathrm{c}}$ \\
\hline & 2 & $30.41 \pm 2.38^{c}$ & $28.75 \pm 2.13$ & $28.35 \pm 2.38$ & $27.61 \pm 1.58^{\mathrm{c}}$ \\
\hline & 3 & $30.70 \pm 2.36^{\mathrm{c}}$ & $29.01 \pm 1.83$ & $28.50 \pm 2.43$ & $27.47 \pm 1.35^{\mathrm{c}}$ \\
\hline & 4 & $30.77 \pm 2.37^{c}$ & $28.97 \pm 1.77$ & $28.75 \pm 2.47$ & $27.45 \pm 1.54^{\mathrm{C}}$ \\
\hline \multirow[t]{5}{*}{ Food intake (g/day) } & 0 & $4.57 \pm 0.70$ & $4.36 \pm 0.42$ & $4.47 \pm 0.81$ & $3.90 \pm 0.48$ \\
\hline & 1 & $4.68 \pm 0.90$ & $4.24 \pm 0.55$ & $4.11 \pm 0.58$ & $4.19 \pm 1.30$ \\
\hline & 2 & $4.38 \pm 0.60$ & $3.91 \pm 0.37$ & $4.16 \pm 0.52$ & $4.43 \pm 0.52$ \\
\hline & 3 & $4.50 \pm 0.63$ & $4.38 \pm 0.51$ & $4.25 \pm 0.60$ & $4.22 \pm 0.43$ \\
\hline & 4 & $4.65 \pm 0.49^{c}$ & $4.34 \pm 0.36$ & $4.17 \pm 0.46$ & $4.00 \pm 0.61^{\mathrm{c}}$ \\
\hline \multirow[t]{5}{*}{ Feces excretion (g/day) } & 0 & $0.60 \pm 0.10^{c}$ & $0.47 \pm 0.15$ & $0.55 \pm 0.08$ & $0.46 \pm 0.10^{c}$ \\
\hline & 1 & $0.49 \pm 0.13$ & $0.47 \pm 0.05$ & $0.40 \pm 0.11$ & $0.43 \pm 0.15$ \\
\hline & 2 & $0.45 \pm 0.08$ & $0.44 \pm 0.07$ & $0.45 \pm 0.06$ & $0.48 \pm 0.07$ \\
\hline & 3 & $0.49 \pm 0.07^{c}$ & $0.46 \pm 0.09$ & $0.43 \pm 0.04$ & $0.39 \pm 0.09^{c}$ \\
\hline & 4 & $0.49 \pm 0.04^{c, d}$ & $0.48 \pm 0.04^{\mathrm{e}}$ & $0.42 \pm 0.05^{\mathrm{c}}$ & $0.41 \pm 0.07^{\mathrm{d}, \mathrm{e}}$ \\
\hline \multirow[t]{5}{*}{ Water consumption (ml/day) } & 0 & $4.71 \pm 1.14$ & $4.77 \pm 0.62$ & $4.53 \pm 0.71$ & $4.14 \pm 0.24$ \\
\hline & 1 & $5.25 \pm 1.35^{\mathrm{c}, \mathrm{d}}$ & $4.82 \pm 0.70^{e, f}$ & $3.64 \pm 0.59^{\mathrm{c}, \mathrm{e}}$ & $3.55 \pm 0.72^{\mathrm{d}, \mathrm{f}}$ \\
\hline & 2 & $5.86 \pm 2.36^{c}$ & $5.24 \pm 1.32$ & $4.07 \pm 1.25$ & $3.95 \pm 0.92^{c}$ \\
\hline & 3 & $5.06 \pm 1.22^{c, d}$ & $4.83 \pm 0.66^{e, f}$ & $3.29 \pm 0.50^{c, e}$ & $3.13 \pm 0.69^{d, f}$ \\
\hline & 4 & $6.25 \pm 1.73^{\mathrm{c}, \mathrm{d}}$ & $5.95 \pm 1.61^{\mathrm{e}, \mathrm{f}}$ & $4.04 \pm 1.24^{\mathrm{c}, \mathrm{e}}$ & $3.83 \pm 1.11^{\mathrm{d}, \mathrm{f}}$ \\
\hline
\end{tabular}

All data are presented as mean \pm SD. $\mathrm{N}=10$ male animals per genotype and group were studied. P-value obtained by two-factor ANOVA analysis and post-hoc analysis (Tukey) when comparing between groups.

${ }^{b} P<0.05$ obtained by post-hoc analysis (Tukey) when comparing between genotypes.

${ }_{c}^{c} d, e, f P<0.05$ obtained by post-hoc analysis (Tukey) when comparing between groups, independent of genotype.

No significant differences could be obtained between genotypes for any of the measured parameters. However some alterations were observed for weight, which in turn resulted in a modified feces exrection. Problems in quantifying water consumption might explain the large variations in water consumption between the individual days. Due to the negliable effects of a low-protein diet and the major effects observed after feeding mice diets with a high-protein content, we subsequently focused on the effects of feeding HP diets or providing acute HP loads. 


\subsubsection{Effects of feeding a high-protein diet on Pept1 ${ }^{-/-}$mice}

\subsubsection{Metabolic parameters}

In order to assess how a high-protein (HP) diet affects mice lacking the Pept1 gene, adult male animals were fed for $24 \mathrm{~h}, 5$ or 18 days with a HP diet ( $45 \%$ of energy) and a control diet $(\mathrm{C})$ with medium protein content (21\% of energy). In the 5 day lasting dietary intervention study, in comparison to mice on control diet, Pept1\% mice on HP diet showed a decreased food intake, which resulted in lower body weight and reduced feces excretion (Fig. 20).
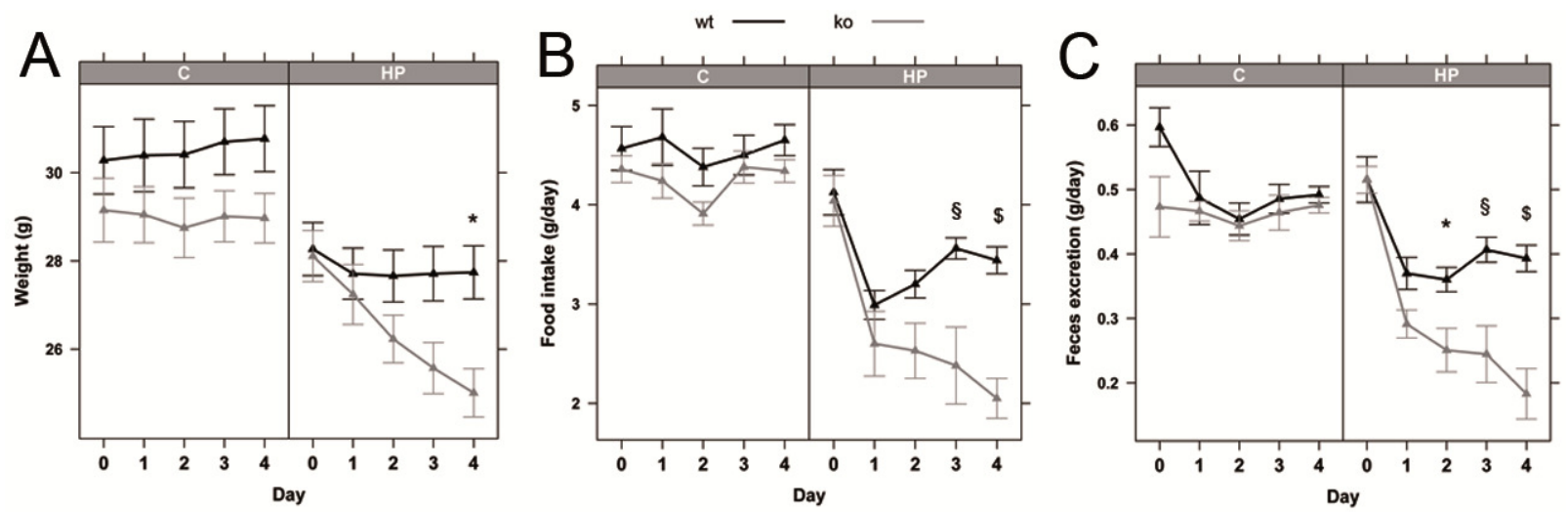

Fig. 20: Metabolic parameters of $P e p t 1^{+/+}$and $P e p t 1^{-/}$animals on HP diet for 5 days.

Weight (A), food intake (B) and feces excretion (C) of male mice on either high-protein (HP) or control (C) diet are shown. All data are presented as mean \pm SD. N=10 male animals per genotype and group were studied; Pept $1^{+/+}(\mathrm{wt})$, Pept $^{-1 /}(\mathrm{ko})$. P-value obtained by two-factor ANOVA analysis and post-hoc analysis (Tukey) when comparing between groups $\left({ }^{*}<0.05\right.$, $\S<0.01, \$<0.001)$.

Like in the 5 day feeding trial, prolonged feeding for 18 days revealed the same results at the beginning of the experiment with a more pronounced reduction in food intake in PEPT1-deficient animals. However, after 5 days Pept $1^{-1-}$ mice on HP diet returned to normal eating habits. Nevertheless, the weight loss persisted and the initial weight was not reached after 18 days (Day 0: $30.7 \pm 1.3 \mathrm{~g}$ vs. Day 18: $28.3 \pm 1.2$ $g, p=0.033$ ). Feces excretion remained lower throughout the whole experiment, with most prominent changes at day 5 (Fig. 21 and Table 9). 

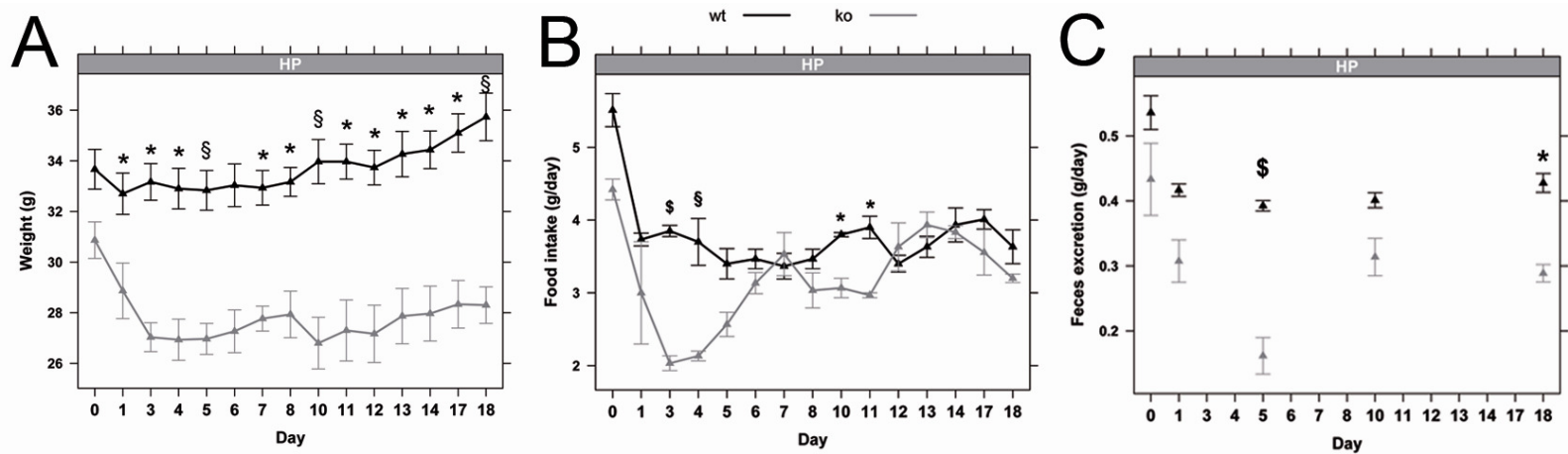

Fig. 21: Metabolic parameters of $P e p t 1^{+/+}$and $P e p t 1^{-/-}$animals on HP diet for 18 days

Weight (A), food intake (B) and feces excretion (C) of male mice on either high-protein (HP) or control (C) diet are shown. All data are presented as mean \pm SD. N=3 male animals per genotype and group were studied; Pept ${ }^{1++}(\mathrm{wt})$, Pept $^{-1 /}$ (ko). P-value obtained by two-factor ANOVA analysis and post-hoc analysis (Tukey) when comparing between groups $\left(^{*}<0.05, \S<0.01, \$<0.001\right)$.

Table 9: Metabolic parameters of $P e p t 1^{+/+}$and $P e p t 1^{-/}$mice in response to high-protein intake for 18 days

\begin{tabular}{|c|c|c|c|c|c|}
\hline \multirow[t]{2}{*}{ Parameter } & \multirow[t]{2}{*}{ Day } & \multicolumn{2}{|c|}{ Control } & \multicolumn{2}{|c|}{ High-protein } \\
\hline & & Pept $1^{+/+}$ & Pept1 $1^{-/}$ & Pept $1^{+/+}$ & Pept1 ${ }^{-/}$ \\
\hline \multirow[t]{3}{*}{ Weight (g) } & 0 & $33.17 \pm 3.52$ & $30.63 \pm 3.86$ & $33.67 \pm 1.36$ & $30.87 \pm 1.25$ \\
\hline & 5 & $34.10 \pm 4.17$ & $30.63 \pm 3.95$ & $32.83 \pm 1.36$ & $26.97 \pm 1.06$ \\
\hline & 18 & $36.67 \pm 4.86$ & $31.37 \pm 5.06$ & $35.73 \pm 1.63$ & $28.30 \pm 1.25$ \\
\hline \multirow[t]{3}{*}{ Food intake (g/day) } & 0 & $5.19 \pm 0.56$ & $4.62 \pm 0.80$ & $5.51 \pm 0.39$ & $4.42 \pm 0.25$ \\
\hline & 5 & $4.30 \pm 0.50^{c}$ & $3.63 \pm 0.35^{d}$ & $3.40 \pm 0.36$ & $2.57 \pm 0.29^{\mathrm{c}, \mathrm{d}}$ \\
\hline & 18 & $3.90 \pm 0.66$ & $3.63 \pm 0.42$ & $3.63 \pm 0.40$ & $3.20 \pm 0.10$ \\
\hline \multirow[t]{3}{*}{ Feces excretion (g/day) } & 0 & $0.53 \pm 0.05$ & $0.48 \pm 0.10$ & $0.54 \pm 0.04$ & $0.43 \pm 0.10$ \\
\hline & 5 & $0.45 \pm 0.02^{c}$ & $0.43 \pm 0.06^{d}$ & $0.39 \pm 0.01^{b}$ & $0.16 \pm 0.05^{\mathrm{b}, \mathrm{c}, \mathrm{d}}$ \\
\hline & 18 & $0.40 \pm 0.02$ & $0.41 \pm 0.09$ & $0.43 \pm 0.02^{b}$ & $0.29 \pm 0.02^{b}$ \\
\hline \multirow[t]{3}{*}{ Gross energy content of feces $(\mathrm{kJ} / \mathrm{g})$} & 0 & $12.28 \pm 0.00$ & $13.23 \pm 0.00$ & $12.18 \pm 0.00$ & $13.75 \pm 0.00$ \\
\hline & 5 & $11.53 \pm 0.15$ & $12.76 \pm 0.34$ & $12.20 \pm 0.23^{b}$ & $15.23 \pm 0.00^{b}$ \\
\hline & 18 & $11.81 \pm 0.17^{b, c, d}$ & $12.95 \pm 0.21^{\mathrm{be}, \mathrm{f}}$ & $12.19 \pm 0.04^{\mathrm{b}, \mathrm{c}, \mathrm{e}}$ & $14.68 \pm 0.04^{b, d, f}$ \\
\hline \multirow[t]{3}{*}{ Water consumption (ml/day) } & 0 & $4.82 \pm 0.36$ & $5.05 \pm 0.52$ & $4.77 \pm 0.57$ & $4.54 \pm 0.40$ \\
\hline & 5 & $4.77 \pm 0.38$ & $5.07 \pm 0.78$ & $5.80 \pm 0.46$ & $5.17 \pm 0.64$ \\
\hline & 18 & $4.40^{c, d} \pm 0.36$ & $5.60 \pm 0.72$ & $6.57 \pm 0.60^{\circ}$ & $6.60 \pm 0.20^{d}$ \\
\hline
\end{tabular}

All data are presented as mean $\pm S D . N=3$ male animals per genotype and group were studied. $\mathrm{P}$-value obtained by two-factor ANOVA analysis and post-hoc analysis (Tukey) when comparing between groups.

${ }^{b} P<0.05$ obtained by post-hoc analysis (Tukey) when comparing between genotypes.

${ }_{c, d, e} P<0.05$ obtained by post-hoc analysis (Tukey) when comparing between groups, independent of genotype.

In a further experiment we confirmed the drastic reduction of food intake just by providing the HP diet for $24 \mathrm{~h}$. In comparison to mice on control diet, Pept $1^{-1 /}$ mice on 
HP diet reduced their food intake by $47.2 \%$ and $P e p t 1^{+/+}$mice by about $35.2 \%$ (wt: $5.4 \pm 0.6$ vs. $3.5 \pm 0.4 \mathrm{~g} /$ day, ko: $5.3 \pm 0.6$ vs. $2.8 \pm 06 \mathrm{~g} /$ day; both $\mathrm{p}<0.001)$. Likewise body weight, feces excretion and water consumption decreased significantly (Table 10).

Table 10: Metabolic parameters of $P e p t 1^{+/+}$and $P e p t 1^{-/-}$animals in response to high-protein intake for 24 hours

\begin{tabular}{|c|c|c|c|c|}
\hline Parameter & Hours & Pept1 $^{+/+}$ & Pept1 $1^{-/}$ & P-value \\
\hline \multirow[t]{2}{*}{ Weight (g) } & 0 & $34.47 \pm 2.96$ & $31.47 \pm 1.56$ & 0.053 \\
\hline & 24 & $33.88 \pm 2.78$ & $30.32 \pm 1.95$ & 0.028 \\
\hline \multirow[t]{2}{*}{ Food intake (g/day) } & 0 & $5.43 \pm 0.60$ & $5.27 \pm 0.61$ & 0.658 \\
\hline & 24 & $3.52 \pm 0.37$ & $2.81 \pm 0.61$ & 0.035 \\
\hline \multirow[t]{2}{*}{ Feces excretion (g/day) } & 0 & $0.32 \pm 0.20$ & $0.45 \pm 0.02$ & 0.153 \\
\hline & 24 & $0.38 \pm 0.05$ & $0.28 \pm 0.10$ & 0.045 \\
\hline \multirow[t]{2}{*}{ Water consumption (ml/day) } & 0 & $4.68 \pm 0.50$ & $4.35 \pm 0.41$ & 0.246 \\
\hline & 24 & $5.95 \pm 0.88$ & $4.42 \pm 1.18$ & 0.029 \\
\hline
\end{tabular}

All data are presented as mean \pm SD. $\mathrm{N}=6$ male animals per genotype and group were studied. P-value obtained by unpaired Student's t-test between genotypes.

\subsubsection{Energy content of feces in Pept $1^{-/ /}$mice is elevated when fed a HP diet}

As observed for animals kept on the standard diet for phenotype analysis in the basal state, Pept $1^{-1 /}$ mice on different diets displayed elevated gross energy contents of feces. After feeding the HP diet this effect became more pronounced with the largest difference on day 2 (wt: 12.3 vs. ko: $14.6 \mathrm{~kJ} / \mathrm{g}, \mathrm{p}=0.002$ ). However as shown in Fig. 22 the difference in energy excretion was also observed for Pept $1^{-1 /}$ mice on control diet with an increase (wt: $11.6 \mathrm{vs.} \mathrm{ko:} 13 \mathrm{~kJ} / \mathrm{g}, \mathrm{p}=0.01$ ).

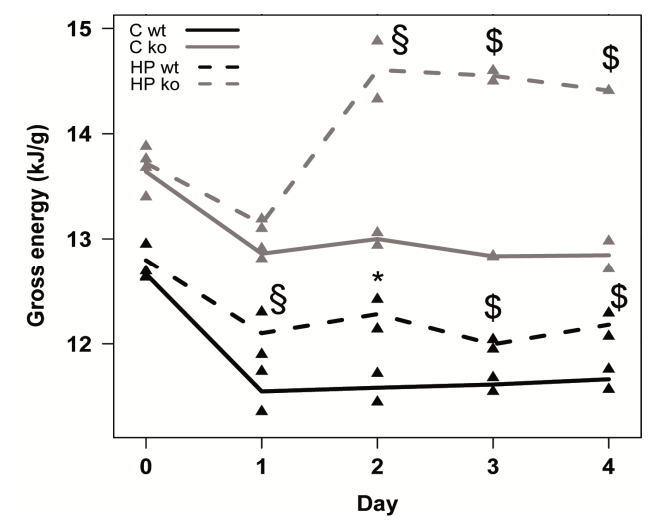

Fig. 22: Gross energy content of mice during the 5 day dietary intervention study

All data are presented as mean $\pm \mathrm{SD}$. $\mathrm{N}=10$ male animals per genotype and group were studied. P-value obtained by twofactor ANOVA analysis and post-hoc analysis (Tukey) when comparing between groups $\left({ }^{*}<0.05, \S<0.01, \$<0.001\right)$. 
After 18 days the energy content of feces of Pept $1^{-/}$animals on HP diet was still significantly higher than in Pept ${ }^{+/+}$animals (14.7 vs. $12.2 \mathrm{~kJ} / \mathrm{g} ; \mathrm{p}<0.001$ ) suggesting no time-dependent compensation.

\subsubsection{Energy assimilation differences}

Based on the data of the 5 day feeding trial, calculations of energy assimilation confirmed the previous findings. With increasing dietary protein content the differences in energy assimilation between Pept $1^{+/+}$and $P e p t 1^{-/}$animals increase (Table 11). The LP diet showed almost no differences and for the control diet only little alterations, with an energy difference after 5 days of $28.36 \mathrm{~kJ} / \mathrm{g}$ could be detected. The HP diet however revealed an increased fecal caloric loss that accounted for a difference of $71 \mathrm{~kJ}$ over 5 days.

Table 11: Energy assimilation in Pept $1^{+/}$and Pept ${ }^{-/}$animals on low-protein (8\%), control (21\%) or highprotein $(45 \%)$ diet over a period of 5 days.

\begin{tabular}{|c|c|c|c|c|c|}
\hline Group & Genotype & $\begin{array}{l}\text { Sum of energy intake } \\
\text { over } 5 \text { days }(k J)\end{array}$ & $\begin{array}{c}\text { Sum of energy } \\
\text { excretion over } 5 \text { days } \\
(\mathrm{kJ})\end{array}$ & $\begin{array}{c}\text { Sum of energy } \\
\text { assimilation over } 5 \text { days } \\
(\mathrm{kJ})\end{array}$ & $\begin{array}{l}\text { Energy difference over } \\
5 \text { days (kJ) }\end{array}$ \\
\hline \multirow{2}{*}{ LP } & Pept $^{+/ /+}$ & 387.23 & 27 & 360.23 & \multirow{2}{*}{7.62} \\
\hline & Pept1 ${ }^{-1 /}$ & 379.6 & 26.66 & 352.61 & \\
\hline \multirow{2}{*}{ C } & Pept1 $^{+/+}$ & 409.98 & 29.83 & 380.15 & \multirow{2}{*}{28.36} \\
\hline & Pept ${ }^{-1 /}$ & 382.08 & 30.29 & 351.79 & \\
\hline \multirow{2}{*}{ HP } & Pept $^{+/ /+}$ & 351.53 & 25.16 & 326.37 & \multirow{2}{*}{71.05} \\
\hline & Pept ${ }^{-1 /}$ & 276.08 & 20.76 & 255.32 & \\
\hline
\end{tabular}

$\mathrm{N}=10$ male animals per genotype and group were studied.

\subsubsection{Clinical chemistry plasma and urine parameters in animals fed a HP diet}

After 5 days on the HP diet 13 plasma parameters were determined. As shown in Table 12, ALP showed significantly reduced levels in Pept $1^{-/}$animals, which were diet-independent. After consumption of a HP diet, amylase and glucose levels in Pept $1^{-/}$mice were significantly decreased. As expected, Pept $1^{+/+}$mice on HP diet showed elevated blood urea nitrogen (BUN) levels when compared to mice on control diet (HP: $41.8 \pm 6.2 \mathrm{mg} / \mathrm{dl}$ vs. C: $31 \pm 4.1 \mathrm{mg} / \mathrm{dl}, \mathrm{p}<0.001)$. Nevertheless, BUN levels in Pept $1^{-/}$animals on a HP diet were comparable to those on control diet (HP: $31.8 \pm 5.6 \mathrm{mg} / \mathrm{dl}$ vs. C: $30.4 \pm 3.8 \mathrm{mg} / \mathrm{dl}$; $\mathrm{p}<0.766)$. Therefore comparison between genotypes on HP diet revealed significant decreased BUN levels for Pept $1^{-/}$animals $(p<0.001)$ most likely as a consequence of lower food and thus protein intake. 
Table 12: Clinical chemistry parameters in plasma of mice after 5 days on high-protein diet

\begin{tabular}{|c|c|c|c|c|}
\hline \multirow[t]{2}{*}{ Parameter } & \multicolumn{2}{|c|}{ Control } & \multicolumn{2}{|c|}{ High protein } \\
\hline & Pept1 $^{+/+}$ & Pept $1^{-/}$ & Pept1 $^{+/+}$ & Pept1 ${ }^{-/-}$ \\
\hline Glucose (mg/dl) & $250.20 \pm 36.50^{c}$ & $229.56 \pm 28.56^{d}$ & $255.33 \pm 20.02^{b}$ & $186.00 \pm 29.17^{b, c, d}$ \\
\hline Blood urea nitrogen $(\mathrm{mg} / \mathrm{dl})$ & $31.00 \pm 4.14^{c}$ & $30.44 \pm 3.84^{d}$ & $41.78 \pm 6.20^{\mathrm{b}, \mathrm{c}, \mathrm{d}}$ & $31.78 \pm 5.61^{b}$ \\
\hline Creatinine (mg/dl) & $0.42 \pm 0.33$ & $0.44 \pm 0.19$ & $0.36 \pm 0.37$ & $0.29 \pm 0.28$ \\
\hline Uric acid (mg/dl) & $1.10 \pm 0.22$ & $1.13 \pm 0.30$ & $1.07 \pm 0.22$ & $1.20 \pm 0.30$ \\
\hline Calcium (mg/dl) & $9.26 \pm 0.21$ & $9.22 \pm 0.29$ & $9.33 \pm 0.44$ & $9.29 \pm 0.23$ \\
\hline Albumine (g/dl) & $0.10 \pm 0.32$ & NA & $0.11 \pm 0.33$ & $0.11 \pm 0.33$ \\
\hline Total protein (g/dl) & $5.58 \pm 0.27$ & $5.49 \pm 0.20$ & $5.60 \pm 0.26$ & $5.53 \pm 0.30$ \\
\hline ALT (U/I) & $19.00 \pm 10.17$ & $16.89 \pm 10.64$ & $12.67 \pm 7.68$ & $9.78 \pm 7.71$ \\
\hline AST (U/I) & $74.00 \pm 13.82$ & $75.33 \pm 20.25$ & $67.56 \pm 12.03$ & $74.89 \pm 17.81$ \\
\hline $\operatorname{ALP}(\mathrm{U} / \mathrm{I})$ & $73.00 \pm 5.91^{b, c}$ & $58.44 \pm 9.21^{b}$ & $68.44 \pm 6.54^{\mathrm{b}}$ & $54.89 \pm 17.15^{\mathrm{b}, \mathrm{c}}$ \\
\hline Total bilirubin (mg/dl) & $0.42 \pm 0.06$ & $0.47 \pm 0.10$ & $0.44 \pm 0.09$ & $0.42 \pm 0.07$ \\
\hline Amylase (U/I) & $1148.00 \pm 84.15^{\mathrm{c}}$ & $1057.78 \pm 126.14^{d}$ & $1007.11 \pm 148.88^{b}$ & $731.33 \pm 128.39^{b, c, d}$ \\
\hline
\end{tabular}

All data are presented as mean \pm SD. $\mathrm{N}=10$ male animals per genotype and group were studied. P-value obtained by two-factor ANOVA analysis and post-hoc analysis (Tukey) when comparing between groups. NA=under detection level.

${ }^{b} P<0.05$ obtained by post-hoc analysis (Tukey) when comparing between genotypes.

${ }^{c, d, e} P<0.05$ obtained by post-hoc analysis (Tukey) when comparing between groups, independent of genotype.

After 18 days on HP diet only BUN levels in plasma were significantly elevated in mice on HP diet compared to control diet, independent of genotype (HP: $44 \pm 4.3$ $\mathrm{mg} / \mathrm{dl}$ vs. C: $26 \pm 3.6 \mathrm{mg} / \mathrm{dl}, \mathrm{p}<0.001)$. ALP, amylase and glucose displayed similar tendencies as on HP diet for 5 days, yet levels did not reach significance (Table 13).

Table 13: Clinical chemistry parameters in plasma of mice after 18 days on high-protein diet

\begin{tabular}{|c|c|c|c|c|}
\hline \multirow[t]{2}{*}{ Parameter } & \multicolumn{2}{|c|}{ Control } & \multicolumn{2}{|c|}{ High protein } \\
\hline & Pept $^{+/+}$ & Pept1 ${ }^{-/ 2}$ & Pept $^{+/+}$ & Pept $^{-/-}$ \\
\hline Glucose (mg/dl) & $278.67 \pm 24.03$ & $216.67 \pm 46.23$ & $282.67 \pm 33.31$ & 212.00 \\
\hline Blood urea nitrogen $(\mathrm{mg} / \mathrm{dl})$ & $26.00 \pm 2.00^{\mathrm{c}, \mathrm{d}}$ & $26.00 \pm 5.29$ & $44.00 \pm 5.29^{c}$ & $44.00^{d}$ \\
\hline Creatinine (mg/dl) & $0.20 \pm 0.35$ & NA & $0.20 \pm 0.35$ & NA \\
\hline Uric acid $(\mathrm{mg} / \mathrm{dl})$ & $1.27 \pm 0.31$ & $1.27 \pm 0.12$ & $1.40 \pm 0.35$ & 1.20 \\
\hline Calcium (mg/dl) & $9.80 \pm 0.35$ & $9.27 \pm 0.58$ & $9.47 \pm 0.42$ & 9.40 \\
\hline Albumine (g/dl) & $2.07 \pm 0.12$ & $0.73 \pm 1.27$ & NA & NA \\
\hline Total protein $(\mathbf{g} / \mathrm{dl})$ & $5.87 \pm 0.23$ & $5.47 \pm 0.31$ & $5.73 \pm 0.12$ & 5.20 \\
\hline $\operatorname{ALT}(\mathrm{U} / \mathrm{I})$ & $42.67 \pm 9.45$ & $32.67 \pm 16.77$ & $24.00 \pm 4.00$ & 38.00 \\
\hline AST(U/I) & $98.67 \pm 26.86$ & $78.67 \pm 13.32$ & $69.33 \pm 3.06$ & 80.00 \\
\hline $\operatorname{ALP}(\mathrm{U} / \mathrm{I})$ & $66.67 \pm 15.53$ & $59.33 \pm 12.70$ & $54.00 \pm 5.29$ & 42.00 \\
\hline Total bilirubin (md/dl) & $0.80 \pm 0.00$ & $0.87 \pm 0.12$ & $0.93 \pm 0.12$ & 0.80 \\
\hline Amylase (U/I) & $1154.67 \pm 114.02$ & $874.67 \pm 251.02$ & $999.33 \pm 84.20$ & 660.00 \\
\hline
\end{tabular}

All data are presented as mean \pm SD. N=1-3 male animals per genotype and group were studied. For knockout animals on highprotein diet only data from one animal was utilizable, thus no SD values could be created. P-value obtained by two-factor ANOVA analysis and post-hoc analysis (Tukey) when comparing between groups. NA=under detection level. ${ }^{b} P<0.05$ obtained by post-hoc analysis (Tukey) when comparing between genotypes.

${ }^{c, d, e} P<0.05$ obtained by post-hoc analysis (Tukey) when comparing between groups, independent of genotype. 
Spot urine samples were analyzed for creatinine and urea. Urea levels were then corrected by creatinine (Fig. 23). Baseline levels revealed no differences between genotypes. After 1 day on HP diet Pept $1^{-/}$animals displayed lowered urea levels compared to Pept $1^{+/+}$mice $(717.8 \pm 265.7$ vs. $1103.2 \pm 116.5 \mathrm{mmol} / \mathrm{mmol}$ creatinine, $\mathrm{p}<0.001)$. After 5 days this difference between genotypes was gone, only between diets these effects were detectable.

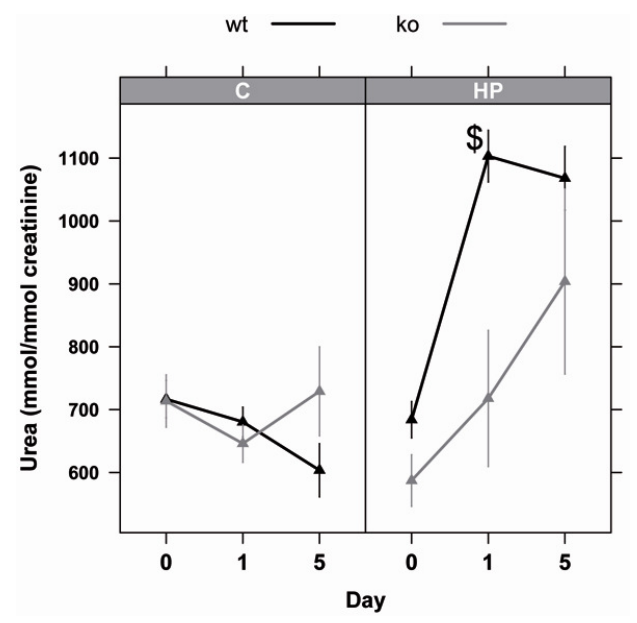

Fig. 23: Urea concentrations in $P e p t 1^{+/+}$and Pept $1^{-1-}$ animals on a high-protein diet

All data are presented as mean \pm SD. Urea concentrations were corrected for creatinine. $\mathrm{N}=4-10$ male animals per genotype and group were studied; Pept1 ${ }^{+/+}$(wt), Pept ${ }^{-1 /}$ (ko). P-value obtained by two-factor ANOVA analysis and post-hoc analysis (Tukey) when comparing between groups $\left({ }^{*}<0.05, \S<0.01\right.$, $\$<0.001)$.

\subsubsection{High-protein diet alters plasma amino acid levels}

7 out of 31 plasma amino acids were significantly changed after $24 \mathrm{~h}$ on HP diet (

Table 14), when the major changes on body weight and food intake were observed in the feeding trials. All amino acids showed decreased levels in plasma of Pept $1^{-/}$ when compared to Pept $1^{+/+}$animals. Among these are glycine and the intermediate and byproduct sarcosine as well as ornithine and beta-alanine. The essential amino acids methionine, threonine and tryptophan displayed lowered levels in Pept $1^{-/}$ compared to Pept $1^{+/+}$animals as well.

Table 14: Plasma amino acid levels of $P e p t 1^{+/+}$and $P e p t 1^{-/-}$animals after 24 hours on high-protein diet

\begin{tabular}{lccc}
\hline Amino acid $(\boldsymbol{\mu m o l} / \mathrm{l})$ & Pept1 $^{+/+}$ & Pept1 $^{- \text {}^{+}}$ & $\boldsymbol{P}_{\text {-value }}$ \\
\hline Alanine & $695.20 \pm 167.87$ & $537.00 \pm 130.06$ & 0.111 \\
Alpha-aminoadipic acid & $8.79 \pm 2.20$ & $7.95 \pm 2.35$ & 0.559 \\
Arginine & $108.76 \pm 40.75$ & $102.58 \pm 21.53$ & 0.754 \\
Asparagine & $101.24 \pm 39.38$ & $93.07 \pm 35.12$ & 0.724 \\
Aspartate & $7.92 \pm 3.12$ & $6.02 \pm 2.53$ & 0.293 \\
Beta-alanine & $10.45 \pm 3.74$ & $4.15 \pm 1.82$ & 0.023 \\
Citrulline & $68.60 \pm 13.29$ & $61.33 \pm 12.15$ & 0.368
\end{tabular}




\begin{tabular}{|c|c|c|c|}
\hline Amino acid $(\mu \mathrm{mol} / \mathrm{l})$ & Pept1 $^{+/+}$ & Pept $^{-/-}$ & $P$-value \\
\hline Cysteine & $95.30 \pm 24.92$ & $74.93 \pm 17.68$ & 0.147 \\
\hline Ethanolamine & $14.46 \pm 3.57$ & $12.16 \pm 3.23$ & 0.292 \\
\hline Glutamate & $47.56 \pm 21.44$ & $34.92 \pm 11.36$ & 0.240 \\
\hline Glutamine & $863.00 \pm 117.90$ & $720.67 \pm 169.26$ & 0.148 \\
\hline Glycine & $252.20 \pm 48.12$ & $184.50 \pm 49.99$ & 0.049 \\
\hline Histidine & $99.10 \pm 22.49$ & $93.17 \pm 19.09$ & 0.647 \\
\hline Hydroxyproline & $17.60 \pm 2.46$ & $14.48 \pm 4.50$ & 0.201 \\
\hline Isoleucine & $263.00 \pm 96.02$ & $172.50 \pm 40.55$ & 0.064 \\
\hline Leucine & $428.60 \pm 176.80$ & $273.67 \pm 60.03$ & 0.073 \\
\hline Lysine & $472.40 \pm 183.11$ & $396.67 \pm 117.28$ & 0.426 \\
\hline Methionine & $124.52 \pm 43.75$ & $65.25 \pm 34.96$ & 0.034 \\
\hline Ornithine & $96.66 \pm 33.55$ & $61.98 \pm 13.54$ & 0.044 \\
\hline Phenylalanine & $102.46 \pm 31.47$ & $83.78 \pm 19.19$ & 0.255 \\
\hline Phosphoethanolamine & $4.95 \pm 1.07$ & $4.77 \pm 1.15$ & 0.789 \\
\hline Proline & $318.32 \pm 156.38$ & $221.25 \pm 107.34$ & 0.254 \\
\hline Sarcosine & $2.83 \pm 1.45$ & $1.36 \pm 0.50$ & 0.044 \\
\hline Serine & $228.40 \pm 61.81$ & $166.17 \pm 37.02$ & 0.068 \\
\hline Taurine & $332.20 \pm 43.73$ & $384.83 \pm 135.84$ & 0.431 \\
\hline Threonine & $364.60 \pm 108.69$ & $241.00 \pm 67.17$ & 0.046 \\
\hline Tryptophane & $107.68 \pm 23.38$ & $74.98 \pm 11.99$ & 0.015 \\
\hline Tyrosine & $152.24 \pm 63.45$ & $96.10 \pm 46.85$ & 0.125 \\
\hline Valine & $660.00 \pm 260.24$ & $429.17 \pm 100.34$ & 0.074 \\
\hline 1-M-Histidine & $2.62 \pm 0.47$ & $2.83 \pm 0.72$ & 0.598 \\
\hline 3-M-Histidine & $3.58 \pm 1.26$ & $3.51 \pm 1.13$ & 0.928 \\
\hline 2-Aminobutyric acid & $13.52 \pm 4.95$ & $10.79 \pm 1.99$ & 0.244 \\
\hline Sum & $5823.73 \pm 1771.76$ & $4628.92 \pm 932.32$ & 0.278 \\
\hline
\end{tabular}

All data are presented as mean \pm SD. $N=4-6$ male animals per genotype were studied. $\mathrm{P}$-value obtained by unpaired Student's ttest between genotypes.

After 5 days on the HP diet, 29 metabolites were in the detection level. When comparing Pept1 $1^{-/}$to Pept1 $1^{+/}$animals only arginine, 3-methyl-histidine and proline showed significant elevated levels (Table 15).

Table 15: Plasma amino acid levels of $P e p t 1^{+/+}$and $P e p t 1^{-/-}$animals after 5 days on high-protein diet

\begin{tabular}{lcccc}
\hline Amino acid $(\mu \mathrm{mol} / \mathrm{l})$ & \multicolumn{2}{c}{ Control } & \multicolumn{2}{c}{ High-protein } \\
\cline { 2 - 5 } & Pept1 $^{+/+}$ & Pept $^{-/-}$ & Pept1 $^{+/+}$ & Pept1 $^{-/}$ \\
\hline Alanine & $478.12 \pm 61.28$ & $481.56 \pm 85.20$ & $489.60 \pm 101.49$ & $441.00 \pm 200.03$ \\
Alpha-aminoadipic acid & $9.27 \pm 2.04$ & $10.81 \pm 2.32$ & $8.04 \pm 1.82$ & $9.97 \pm 4.07$ \\
Anserine & $1.65 \pm 0.22$ & $1.87 \pm 0.17$ & $1.56 \pm 0.13$ & $1.50 \pm 0.07$ \\
Arginine & $44.77 \pm 22.83^{\mathrm{b}, \mathrm{c}}$ & $90.01 \pm 29.77^{\mathrm{b}}$ & $53.08 \pm 19.07^{\mathrm{b}}$ & $96.88 \pm 42.58^{\mathrm{b}, \mathrm{c}}$ \\
Asparagine & $60.98 \pm 18.94$ & $69.13 \pm 32.70$ & $53.07 \pm 29.58$ & $67.23 \pm 36.94$ \\
Beta-Alanine & $8.86 \pm 4.27$ & $4.80 \pm 0.45$ & $6.24 \pm 2.09$ & $7.53 \pm 3.63$ \\
Citrulline & $66.98 \pm 10.49$ & $80.98 \pm 10.90$ & $64.85 \pm 18.05$ & $78.97 \pm 19.79$
\end{tabular}




\begin{tabular}{|c|c|c|c|c|}
\hline \multirow[t]{2}{*}{ Amino acid $(\mu \mathrm{mol} / \mathrm{l})$} & \multicolumn{2}{|c|}{ Control } & \multicolumn{2}{|c|}{ High-protein } \\
\hline & Pept1 $^{+/+}$ & Pept1 ${ }^{-/}$ & Pept1 $^{+/+}$ & Pept1 $1^{-/}$ \\
\hline Ethanolamine & $17.53 \pm 3.70$ & $17.58 \pm 4.72$ & $17.55 \pm 2.59$ & $18.31 \pm 6.81$ \\
\hline Glutamate & $51.65 \pm 12.20$ & $59.34 \pm 16.95$ & $53.41 \pm 18.09$ & $44.63 \pm 14.05$ \\
\hline Glutamine & $558.89 \pm 101.88$ & $529.22 \pm 121.78$ & $607.80 \pm 138.37$ & $668.60 \pm 148.07$ \\
\hline Glycine & $204.46 \pm 35.46$ & $236.33 \pm 124.60$ & $184.60 \pm 42.96$ & $171.40 \pm 55.35$ \\
\hline Histidine & $68.60 \pm 13.73$ & $70.72 \pm 3.82$ & $67.61 \pm 13.83$ & $80.27 \pm 18.10$ \\
\hline Hydroxyproline & $12.46 \pm 2.82$ & $15.77 \pm 4.31^{\mathrm{c}, \mathrm{d}}$ & $9.57 \pm 1.65^{c}$ & $8.71 \pm 4.90^{d}$ \\
\hline Isoleucine & $154.07 \pm 53.29$ & $153.33 \pm 32.65$ & $204.70 \pm 57.70$ & $179.30 \pm 60.76$ \\
\hline Leucine & $234.63 \pm 81.49$ & $216.11 \pm 48.76$ & $308.50 \pm 97.64$ & $288.10 \pm 128.86$ \\
\hline Lysine & $367.83 \pm 84.68$ & $424.44 \pm 125.50^{c}$ & $265.10 \pm 44.01^{\mathrm{c}}$ & $399.40 \pm 178.29$ \\
\hline Methionine & $84.93 \pm 55.05$ & $92.12 \pm 56.43$ & $95.27 \pm 78.26$ & $80.79 \pm 46.86$ \\
\hline Ornithine & $119.41 \pm 43.40$ & $101.17 \pm 24.86$ & $94.72 \pm 26.63$ & $96.26 \pm 26.37$ \\
\hline Phenylalanine & $76.48 \pm 16.27$ & $76.41 \pm 19.24$ & $79.25 \pm 14.50$ & $91.66 \pm 27.46$ \\
\hline Proline & $151.21 \pm 49.46^{\mathrm{b}}$ & $280.33 \pm 59.60^{b, c}$ & $157.10 \pm 46.65^{\mathrm{c}}$ & $222.30 \pm 146.55$ \\
\hline Serine & $139.88 \pm 29.80$ & $149.22 \pm 41.95$ & $124.38 \pm 43.93$ & $142.05 \pm 54.97$ \\
\hline Taurine & $359.89 \pm 91.45$ & $377.22 \pm 201.55$ & $313.60 \pm 90.90$ & $383.40 \pm 195.83$ \\
\hline Threonine & $232.06 \pm 53.12$ & $234.11 \pm 43.84$ & $200.80 \pm 34.40$ & $198.40 \pm 80.66$ \\
\hline Tryptophane & $89.93 \pm 10.97$ & $81.06 \pm 16.24$ & $76.82 \pm 13.16$ & $72.88 \pm 30.87$ \\
\hline Tyrosine & $147.48 \pm 44.97$ & $126.10 \pm 30.04$ & $126.88 \pm 48.02$ & $129.50 \pm 95.61$ \\
\hline Valine & $426.22 \pm 104.29^{c}$ & $408.00 \pm 63.01^{d}$ & $612.40 \pm 152.04^{c, d}$ & $480.10 \pm 142.17$ \\
\hline 1-M-Histidine & $2.82 \pm 0.15$ & $3.29 \pm 1.10$ & $2.58 \pm 0.50$ & $3.66 \pm 0.65$ \\
\hline 3-M-Histidine & $2.62 \pm 0.56$ & $2.90 \pm 0.64$ & $2.01 \pm 0.46^{b}$ & $3.49 \pm 0.69^{b}$ \\
\hline 2-aminobutyric acid & $9.17 \pm 2.10$ & $9.26 \pm 2.54$ & $12.86 \pm 4.61$ & $12.09 \pm 5.52$ \\
\hline Sum & $4182.83 \pm 618.42$ & $4403.21 \pm 588.29$ & $4293.95 \pm 763.83$ & $4478.38 \pm 1123.11$ \\
\hline
\end{tabular}

All data are presented as mean $\pm \mathrm{SD}$. $\mathrm{N}=4-10$ male animals per genotype and group were studied. $\mathrm{P}$-value obtained by twofactor ANOVA analysis and post-hoc analysis (Tukey) when comparing between groups.

${ }^{b} P<0.05$ obtained by post-hoc analysis (Tukey) when comparing between genotypes.

${ }_{c, d, e} P<0.05$ obtained by post-hoc analysis (Tukey) when comparing between groups, independent of genotype.

Independent of genotype, 7 amino acids and derivatives revealed significant changed levels in mice after feeding a HP diet when compared to mice on control diet. Amongst them were the branched chain amino acids valine, leucine and isoleucine, but also alpha-aminobutyric acid and glutamine. All of them showed elevated levels in mice on HP as compared to control diet (valine: $546.3 \pm 158.5 \mu \mathrm{mol} / \mathrm{l}$ vs. $417.6 \pm 85.4$ $\mu \mathrm{mol} / \mathrm{l}, \mathrm{p}=0.003$; leucine: $298.3 \pm 111.8 \mu \mathrm{mol} / \mathrm{l}$ vs. $225.9 \pm 66.8 \mu \mathrm{mol} / \mathrm{l}, \mathrm{p}=0.02$; isoleucine: $192 \pm 59.1 \mu \mathrm{mol} / /$ vs. $153.7 \pm 43.5 \mu \mathrm{mol} / \mathrm{l}, \mathrm{p}=0.028$; 2 -amino butyric acid: $12.5 \pm 5 \mu \mathrm{mol} / \mathrm{l}$ vs. $9.2 \pm 2.3 \mu \mathrm{mol} / \mathrm{l}, \mathrm{p}=0.013$; glutamine: $638.2 \pm 142.9 \mu \mathrm{mol} / \mathrm{l}$ vs. $544.8 \pm 109.6 \mu \mathrm{mol} / \mathrm{l}, \mathrm{p}=0.038)$. Decreased levels in animals on HP diet were found for anserine $(1.5 \pm 0.1 \mu \mathrm{mol} / \mathrm{l}$ vs. $1.8 \pm 0.2 \mu \mathrm{mol} / \mathrm{l}, \mathrm{p}<0.001)$ and hydroxyproline $(9.1 \pm 3.6$ $\mu \mathrm{mol} / / \mathrm{vs} .14 \pm 3.9 \mu \mathrm{mol} / \mathrm{l}, \mathrm{p}<0.001)$. 
31 metabolites could be detected when feeding the HP diet for 18 days (Table 16). Besides 2-aminobutyric acid also the branched chain amino acids leucine and isoleucine were elevated in mice on HP diet when compared to mice on control diet independent of genotpye (alpha-aminobutyric acid: $11.8 \pm 3.2 \mu \mathrm{mol} / \mathrm{l}$ vs. $7 \pm 1.1 \mu \mathrm{mol} / \mathrm{l}$, $\mathrm{p}=0.0057$; leucine: $339.2 \pm 117.1 \mu \mathrm{mol} / \mathrm{l}$ vs. $205.3 \pm 34.8 \mu \mathrm{mol} / \mathrm{l}, \mathrm{p}=0.023$; isoleucine: $216 \pm 79.5 \mu \mathrm{mol} / \mathrm{l}$ vs. $140.7 \pm 22.4 \mu \mathrm{mol} / \mathrm{l}, \mathrm{p}=0.049)$. Contrary, glutamine and ethanolamine levels were higher in animals on control than on HP diet (glutamine: $755.8 \pm 91.8 \mu \mathrm{mol} / / \mathrm{l}$ vs. $661.8 \pm 46.5 \mu \mathrm{mol} / \mathrm{l}, \mathrm{p}=0.049$; ethanolamine: $21.4 \pm 4.2 \mu \mathrm{mol} / / \mathrm{l}$ vs. $16.2 \pm 3 \mu \mathrm{mol} / \mathrm{l}, \mathrm{p}=0.03)$. However, no differences between genotypes were observed in the HP group.

Table 16: Plasma amino acid levels of $P e p t 1^{+/+}$and Pept $1^{-/-}$animals after 18 days on high-protein diet

\begin{tabular}{|c|c|c|c|c|}
\hline \multirow[t]{2}{*}{ Amino acid $(\mu \mathrm{mol} / \mathrm{l})$} & \multicolumn{2}{|c|}{ Control } & \multicolumn{2}{|c|}{ High protein } \\
\hline & Pept1 $^{+/+}$ & Pept1 ${ }^{-/-}$ & Pept1 $^{+/+}$ & Pept1 $^{-/ 2}$ \\
\hline Alanine & $557.67 \pm 166.64$ & $592.67 \pm 225.31$ & $521.67 \pm 103.32$ & $449.67 \pm 52.56$ \\
\hline Alpha-aminoadipic acid & $10.81 \pm 2.77$ & $9.90 \pm 5.02$ & $7.79 \pm 0.74$ & $11.38 \pm 1.44$ \\
\hline Arginine & $29.93 \pm 16.07^{b, c}$ & $76.80 \pm 18.49^{b}$ & $56.30 \pm 12.56$ & $66.97 \pm 3.72^{c}$ \\
\hline Asparagine & $77.37 \pm 25.89$ & $127.17 \pm 58.77$ & $62.50 \pm 14.19$ & $71.23 \pm 12.34$ \\
\hline Aspartate & $4.80 \pm 0.66$ & $8.58 \pm 7.12$ & $7.74 \pm 0.64$ & $6.66 \pm 2.68$ \\
\hline Citrulline & $61.90 \pm 7.83$ & $83.67 \pm 9.01^{\mathrm{c}}$ & $61.10 \pm 18.40$ & $52.27 \pm 2.51^{c}$ \\
\hline Ethanolamine & $20.40 \pm 2.95$ & $22.47 \pm 5.59$ & $16.00 \pm 3.56$ & $16.33 \pm 3.03$ \\
\hline Gamma-aminobutyric acid & $1.73 \pm 0.33$ & $1.52 \pm 0.32$ & $1.55 \pm 0.17$ & $1.46 \pm 0.07$ \\
\hline Glutamate & $79.43 \pm 17.07$ & $94.97 \pm 53.00$ & $78.33 \pm 6.27$ & $68.10 \pm 16.46$ \\
\hline Glutamine & $751.33 \pm 21.94$ & $760.33 \pm 143.27$ & $695.33 \pm 25.50$ & $628.33 \pm 37.17$ \\
\hline Glycine & $283.33 \pm 40.15$ & $285.00 \pm 128.99$ & $209.33 \pm 23.18$ & $215.00 \pm 16.52$ \\
\hline Histidine & $71.87 \pm 5.65$ & $97.93 \pm 18.26$ & $69.30 \pm 9.72$ & $67.70 \pm 9.91$ \\
\hline Homocysteine & $3.19 \pm 0.19$ & $2.94 \pm 0.12$ & $3.05 \pm 0.16$ & $3.06 \pm 0.14$ \\
\hline Hydroxyproline & $13.77 \pm 2.20^{c}$ & $10.25 \pm 2.09$ & $8.86 \pm 0.95^{\mathrm{C}}$ & $12.43 \pm 1.19$ \\
\hline Isoleucine & $143.00 \pm 34.39$ & $138.33 \pm 7.23$ & $264.67 \pm 87.09$ & $167.33 \pm 33.25$ \\
\hline Leucine & $213.33 \pm 51.25^{\mathrm{c}}$ & $197.33 \pm 14.19^{d}$ & $413.67 \pm 124.84^{c, d}$ & $264.67 \pm 45.54$ \\
\hline Lysine & $326.33 \pm 90.14$ & $304.67 \pm 89.63$ & $252.00 \pm 65.21$ & $249.67 \pm 40.67$ \\
\hline Methionine & $49.80 \pm 8.66$ & $63.03 \pm 18.74$ & $50.97 \pm 18.57$ & $31.90 \pm 10.04$ \\
\hline Ornithine & $134.03 \pm 32.99$ & $86.90 \pm 11.76$ & $106.27 \pm 30.64$ & $81.40 \pm 17.87$ \\
\hline Phenylalanine & $83.50 \pm 17.91$ & $100.90 \pm 18.37$ & $97.50 \pm 14.53$ & $77.47 \pm 10.25$ \\
\hline Phosphoethanolamine & $0.36 \pm 0.06$ & $0.39 \pm 0.05$ & $0.37 \pm 0.11$ & $0.56 \pm 0.33$ \\
\hline Proline & $111.93 \pm 49.85$ & $219.00 \pm 88.15$ & $161.63 \pm 84.95$ & $160.33 \pm 50.52$ \\
\hline Serine & $163.00 \pm 46.87$ & $187.33 \pm 78.87$ & $127.67 \pm 21.83$ & $130.67 \pm 30.75$ \\
\hline Taurine & $390.67 \pm 83.99$ & $315.33 \pm 47.61$ & $368.67 \pm 116.14$ & $387.33 \pm 34.53$ \\
\hline Threonine & $221.00 \pm 77.31$ & $179.33 \pm 42.85$ & $205.33 \pm 65.06$ & $184.67 \pm 40.28$ \\
\hline Tryptophane & $104.87 \pm 23.53$ & $95.27 \pm 11.75$ & $89.13 \pm 17.69$ & $72.50 \pm 6.29$ \\
\hline Tyrosine & $99.83 \pm 39.42$ & $153.00 \pm 31.61$ & $129.03 \pm 38.65$ & $73.77 \pm 18.58$ \\
\hline Valine & $341.33 \pm 77.36^{c}$ & $379.67 \pm 37.90$ & $682.33 \pm 213.01^{c}$ & $417.00 \pm 96.89$ \\
\hline 1-M-Histidine & $4.25 \pm 0.82 b$ & $2.71 \pm 0.23^{b}$ & $3.18 \pm 0.08$ & $3.75 \pm 0.38$ \\
\hline
\end{tabular}




\begin{tabular}{lcccc}
\hline Amino acid $(\mu \mathrm{mol} / \mathrm{l})$ & \multicolumn{2}{c}{ Control } & \multicolumn{2}{c}{ High protein } \\
\cline { 2 - 5 } & Pept1 $^{+/+}$ & Pept1 $^{-/}$ & Pept1 $^{+/+}$ & Pept $^{-/}$ \\
\hline 3-M-Histidine & $3.31 \pm 0.60^{\mathrm{b}}$ & $1.94 \pm 0.21^{\mathrm{b}, \mathrm{c}}$ & $2.30 \pm 0.45$ & $3.33 \pm 0.34^{\mathrm{c}}$ \\
2-aminobutyric acid & $7.42 \pm 1.54$ & $6.49 \pm 0.47$ & $11.73 \pm 3.72$ & $11.93 \pm 3.46$ \\
Sum & $4365.51 \pm 891.54$ & $4605.83 \pm 721.49$ & $4765.30 \pm 1019.24$ & $3988.85 \pm 426.01$ \\
\hline
\end{tabular}

All data are presented as mean \pm SD. $\mathrm{N}=4-10$ male animals per genotype and group were studied. P-value obtained by twofactor ANOVA analysis and post-hoc analysis (Tukey) when comparing between groups.

${ }^{b} P<0.05$ obtained by post-hoc analysis (Tukey) when comparing between genotypes.

${ }^{c, d}, e<0.05$ obtained by post-hoc analysis (Tukey) when comparing between groups, independent of genotype.

Fig. 24 displays the concentrations of selected amino acids and their timedependency during the dietary intervention. For all timepoints only the branched chain amino acids (depicted are isoleucine and leucine) showed elevated plasma levels in Pept $1^{+/+}$animals consuming a HP diet, when compared to Pept ${ }^{-/}$animals. Wild-type animals displayed slightly elevated arginine levels after $24 \mathrm{~h}$ consumption of a HP diet. These concentrations were similar to the already higher basal arginine levels in the Pept $1^{-/}$animals. Despite a further consumption of the HP diet for 5 days, arginine returned to the basal levels in wild-type animals, whereas Pept $1^{-/}$animals displayed still elevated levels, independently of diet.
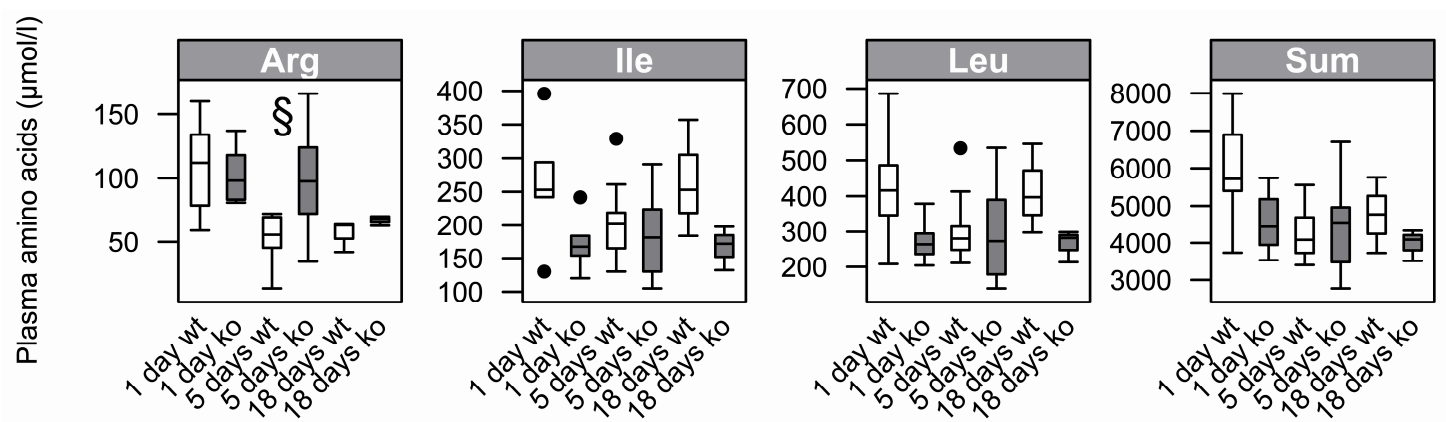

Fig. 24: Changes in plasma amino acid levels after $24 \mathrm{~h}, 5$ and 18 days on high-protein diet in Pept $1^{-/}$animals.

All data are presented as mean \pm SD. N=3-10 male animals per genotype and group were studied; Pept ${ }^{1 /+}$ (wt), Pept $1^{-/ /}(\mathrm{ko})$. P-value obtained by unpaired Student's t-test between genotypes $\left({ }^{*}<0.05, \S<0.01, \$<0.001\right)$.

\subsubsection{Liver tissue amino acid levels and enzyme activities in Pept $1^{-1-}$ animals}

Liver tissue samples of mice on control or HP diet for 24 hours or 18 days were analyzed for amino acid levels and enzyme activities. After 24h on HP diet liver amino acid analysis revealed 2 out of 32 measured metabolites with significant different levels between genotypes (Table 17). Sarcosine displayed lowered levels, whereas methionine levels were elevated in Pept $1^{-1 /}$ mice. 
Table 17: Liver amino acid concentrations of $P e p t 1^{+/+}$and $P e p t 1^{-/-}$mice after 24 hours on high-protein diet

\begin{tabular}{|c|c|c|c|}
\hline Amino acid (nmol/mg protein) & Pept1 $^{+/+}$ & Pept1 ${ }^{-/-}$ & $P$-value \\
\hline Alanine & $128.09 \pm 28.09$ & $111.02 \pm 29.43$ & 0.351 \\
\hline Alpha-aminoadipic acid & $7.42 \pm 7.65$ & $1.38 \pm 0.95$ & 0.116 \\
\hline Asparagine & $9.11 \pm 1.45$ & $9.14 \pm 1.33$ & 0.969 \\
\hline Aspartate & $7.18 \pm 4.82$ & $5.45 \pm 2.08$ & 0.475 \\
\hline Beta-alanine & $2.78 \pm 0.67$ & $2.89 \pm 0.51$ & 0.778 \\
\hline Beta-aminoisobutyric acid & $0.27 \pm 0.11$ & $0.27 \pm 0.07$ & 0.977 \\
\hline Citrulline & $0.64 \pm 0.18$ & $0.66 \pm 0.18$ & 0.890 \\
\hline Cysteine & $0.19 \pm 0.06$ & $0.19 \pm 0.05$ & 0.994 \\
\hline Ethanolamine & $2.08 \pm 0.38$ & $2.08 \pm 0.26$ & 0.991 \\
\hline Gamma-aminobutyric acid & $1.15 \pm 0.54$ & $0.66 \pm 0.11$ & 0.083 \\
\hline Glutamate & $65.35 \pm 25.59$ & $45.78 \pm 9.75$ & 0.143 \\
\hline Glutamine & $91.08 \pm 18.62$ & $81.80 \pm 20.86$ & 0.455 \\
\hline Glycine & $53.75 \pm 7.81$ & $51.57 \pm 10.40$ & 0.700 \\
\hline Histidine & $17.22 \pm 3.52$ & $15.97 \pm 3.89$ & 0.591 \\
\hline Hydroxyproline & $0.75 \pm 0.29$ & $0.52 \pm 0.14$ & 0.147 \\
\hline Isoleucine & $11.06 \pm 2.32$ & $9.78 \pm 2.27$ & 0.382 \\
\hline Leucine & $21.14 \pm 4.10$ & $19.81 \pm 4.17$ & 0.608 \\
\hline Lysine & $26.17 \pm 5.35$ & $25.45 \pm 5.39$ & 0.829 \\
\hline Methionine & $2.50 \pm 0.42$ & $3.59 \pm 0.81$ & 0.018 \\
\hline Ornithine & $9.95 \pm 5.17$ & $8.53 \pm 1.97$ & 0.579 \\
\hline Phenylalanine & $5.85 \pm 1.05$ & $6.62 \pm 1.11$ & 0.271 \\
\hline Phosphoethanolamine & $7.51 \pm 1.20$ & $8.47 \pm 1.45$ & 0.257 \\
\hline Proline & $19.93 \pm 9.19$ & $13.84 \pm 5.59$ & 0.229 \\
\hline Sarcosine & $4.24 \pm 1.69$ & $1.87 \pm 0.78$ & 0.018 \\
\hline Serine & $14.42 \pm 3.92$ & $15.88 \pm 3.16$ & 0.522 \\
\hline Taurine & $259.22 \pm 15.95$ & $248.70 \pm 40.90$ & 0.574 \\
\hline Threonine & $12.83 \pm 3.80$ & $13.90 \pm 4.00$ & 0.660 \\
\hline Tryptophane & $1.55 \pm 0.24$ & $1.48 \pm 0.32$ & 0.718 \\
\hline Tyrosine & $8.51 \pm 2.27$ & $7.50 \pm 1.44$ & 0.411 \\
\hline Valine & $24.42 \pm 5.30$ & $20.24 \pm 3.69$ & 0.172 \\
\hline 1-M-Histidine & $0.93 \pm 0.33$ & $0.63 \pm 0.11$ & 0.075 \\
\hline 2-Aminobutyric acid & $3.31 \pm 2.18$ & $2.35 \pm 1.32$ & 0.412 \\
\hline Sum & $820.58 \pm 118.70$ & $737.98 \pm 106.63$ & 0.260 \\
\hline
\end{tabular}

All data are presented as mean $\pm S D$. $N=5-6$ male animals per genotype were studied. P-value obtained by unpaired Student's $t$ test between genotypes.

When kept 18 days on the HP diet, no differences between genotypes were obtained. However, between diets 4 out of 28 detectable metabolites revealed significant differences (Table 18). Decreased concentrations in mice on HP compared to control diet were observed for methionine, citrulline and glutamine. Elevated concentrations in liver amino acids after 18 days on HP diet were only seen for serine. 
Table 18: Liver amino acid concentrations of $P e p t 1^{+/+}$and $P e p t 1^{-1 /}$ mice after 18 days on high-protein diet

\begin{tabular}{|c|c|c|c|c|}
\hline \multirow[t]{2}{*}{ Amino acid (nmol/mg protein) } & \multicolumn{2}{|c|}{ Control } & \multicolumn{2}{|c|}{ High-protein } \\
\hline & Pept1 $^{+/+}$ & Pept1 $^{-/-}$ & Pept1 $^{+/+}$ & Pept1 ${ }^{-/}$ \\
\hline Alanine & $83.90 \pm 10.28$ & $92.21 \pm 15.87$ & $96.58 \pm 28.53$ & $84.43 \pm 17.13$ \\
\hline Alpha-aminoadipic acid & $0.84 \pm 0.61$ & $1.23 \pm 0.56$ & $0.88 \pm 0.70$ & $0.96 \pm 0.67$ \\
\hline Alpha-aminoisobutyric acid & $0.19 \pm 0.10$ & $0.25 \pm 0.06$ & $0.30 \pm 0.12$ & $0.25 \pm 0.03$ \\
\hline Asparagine & $2.70 \pm 0.45$ & $3.10 \pm 0.98$ & $3.69 \pm 0.43$ & $4.82 \pm 1.73$ \\
\hline Aspartate & $4.25 \pm 1.97$ & $5.74 \pm 3.22$ & $2.78 \pm 0.26$ & $7.25 \pm 4.18$ \\
\hline Citrulline & $1.24 \pm 0.28^{b}$ & $3.64 \pm 1.78^{b, c, d}$ & $0.41 \pm 0.12^{c}$ & $0.39 \pm 0.13^{d}$ \\
\hline Ethanolamine & $0.26 \pm 0.05$ & $0.42 \pm 0.12$ & $1.71 \pm 0.91$ & $1.51 \pm 0.65$ \\
\hline Gamma-aminobutyric acid & $0.28 \pm 0.01$ & $0.32 \pm 0.10$ & $0.44 \pm 0.07$ & $0.56 \pm 0.22$ \\
\hline Glutamate & $20.07 \pm 1.52$ & $35.57 \pm 18.04$ & $19.56 \pm 6.12$ & $25.92 \pm 10.23$ \\
\hline Glutamine & $78.80 \pm 6.35^{\mathrm{b}, \mathrm{c}}$ & $44.98 \pm 3.48^{b}$ & $54.13 \pm 5.42^{c}$ & $62.81 \pm 12.42$ \\
\hline Glycine & $46.90 \pm 3.02$ & $53.05 \pm 27.75$ & $49.59 \pm 2.59$ & $55.48 \pm 11.02$ \\
\hline Histidine & $8.93 \pm 1.37$ & $10.30 \pm 2.07$ & $7.39 \pm 1.27$ & $9.32 \pm 3.12$ \\
\hline Isoleucine & $4.28 \pm 0.62$ & $4.89 \pm 1.75$ & $6.51 \pm 2.34$ & $6.12 \pm 2.64$ \\
\hline Leucine & $6.98 \pm 1.01$ & $8.17 \pm 2.82$ & $11.09 \pm 2.62$ & $11.71 \pm 4.61$ \\
\hline Lysine & $8.18 \pm 1.06$ & $9.61 \pm 2.15$ & $10.46 \pm 2.21$ & $13.64 \pm 5.92$ \\
\hline Methionine & $3.21 \pm 1.36$ & $4.89 \pm 0.69^{c, d}$ & $1.59 \pm 0.19^{c}$ & $1.74 \pm 0.29^{d}$ \\
\hline Ornithine & $2.36 \pm 0.37$ & $2.98 \pm 1.40$ & $5.18 \pm 1.25$ & $7.10 \pm 4.33$ \\
\hline Phenylalanine & $2.29 \pm 0.31$ & $2.47 \pm 0.55$ & $2.69 \pm 0.39$ & $3.42 \pm 1.37$ \\
\hline Phosphoethanolamine & $3.47 \pm 0.57$ & $7.09 \pm 3.38$ & $3.48 \pm 0.79$ & $5.04 \pm 0.53$ \\
\hline Proline & $5.22 \pm 1.63$ & $7.78 \pm 2.54$ & $6.39 \pm 3.67$ & $7.63 \pm 4.24$ \\
\hline Sarcosine & $0.88 \pm 0.44$ & $1.11 \pm 0.34$ & $0.65 \pm 0.55$ & $0.59 \pm 0.47$ \\
\hline Serine & $3.83 \pm 0.05^{\mathrm{c}}$ & $2.83 \pm 0.60^{d}$ & $6.28 \pm 0.67$ & $10.11 \pm 4.16^{\mathrm{c}, \mathrm{d}}$ \\
\hline Taurine & $236.97 \pm 20.45$ & $269.57 \pm 70.91$ & $186.68 \pm 28.41$ & $191.41 \pm 32.30$ \\
\hline Threonine & $4.89 \pm 1.00$ & $4.35 \pm 1.20$ & $4.87 \pm 0.55$ & $8.82 \pm 4.38$ \\
\hline Tryptophane & $0.76 \pm 0.17$ & $0.95 \pm 0.26$ & $1.06 \pm 0.25$ & $0.96 \pm 0.25$ \\
\hline Tyrosine & $2.58 \pm 0.66$ & $3.73 \pm 1.18$ & $4.78 \pm 1.15$ & $5.11 \pm 2.05$ \\
\hline Valine & $8.84 \pm 1.15$ & $13.71 \pm 5.17$ & $14.33 \pm 6.20$ & $13.97 \pm 6.95$ \\
\hline 2-Aminobutyric acid & $0.75 \pm 0.14$ & $2.22 \pm 1.48$ & $2.16 \pm 1.03$ & $2.21 \pm 1.04$ \\
\hline Sum & $543.83 \pm 19.72$ & $597.16 \pm 147.47$ & $505.66 \pm 85.14$ & $543.27 \pm 115.73$ \\
\hline
\end{tabular}

All data are presented as mean \pm SD. $\mathrm{N}=4-10$ male animals per genotype and group were studied. $\mathrm{P}$-value obtained by twofactor ANOVA analysis and post-hoc analysis (Tukey) when comparing between groups.

${ }^{b} P<0.05$ obtained by post-hoc analysis (Tukey) when comparing between genotypes.

${ }^{c, d},{ }^{e} P<0.05$ obtained by post-hoc analysis (Tukey) when comparing between groups, independent of genotype.

Enzyme activities in liver tissue were altered in animals fed a HP diet (Table 19). After $24 \mathrm{~h}$ and 18 days on HP diet, Pept $1^{\%}$ animals showed significant increased GDH activities when compared to Pept $1^{+/+}$animals. Nevertheless GDH activity in Pept $^{+/+}$animals on HP diet was comparable to mice on control diet, where no differences between genotypes were detectable. However in Pept1\% animals on HP diet GDH activity was still increased compared to animals on control diet. 
Table 19: Enzyme activities in liver tissue after 24 hours and 18 days on high-protein diet

\begin{tabular}{|c|c|c|c|c|c|c|}
\hline \multirow[t]{2}{*}{ Parameter } & \multicolumn{2}{|c|}{ 24h - High-protein } & \multicolumn{2}{|c|}{18 days - Control } & \multicolumn{2}{|c|}{18 days - High-protein } \\
\hline & Pept $^{+/+}$ & Pept1 ${ }^{-/-}$ & Pept1 $^{+/+}$ & Pept1 $1^{--}$ & Pept1 $^{+/+}$ & Pept1 ${ }^{-1-}$ \\
\hline $\begin{array}{l}\text { Arginase liver } \\
\text { [U/mg protein] }\end{array}$ & $87.55 \pm 9.24$ & $71.70 \pm 19.62$ & $88.31 \pm 6.55$ & $104.01 \pm 24.63^{\mathrm{b}, \mathrm{c}}$ & $62.43 \pm 8.74^{b}$ & $63.55 \pm 9.25^{c}$ \\
\hline GDH [mU/mg] & $943.42 \pm 113.30^{\mathrm{a}}$ & $1148.14 \pm 98.80^{\mathrm{a}}$ & $752.31 \pm 109.82$ & $738.02 \pm 79.84$ & $708.66 \pm 82.68$ & $955.78 \pm 119.16$ \\
\hline AST [mU/mg] & $2230.56 \pm 187.90$ & $2335.30 \pm 585.22$ & $2422.69 \pm 338.16$ & $2475.13 \pm 560.19$ & $1965.85 \pm 189.94$ & $2141.81 \pm 351.17$ \\
\hline ALT [mU/mg] & $770.02 \pm 168.66$ & $742.93 \pm 203.04$ & $784.33 \pm 45.74^{\mathrm{b}, \mathrm{c}}$ & $797.21 \pm 18.34^{\mathrm{d}, \mathrm{e}}$ & $623.36 \pm 19.38^{\mathrm{b}, \mathrm{d}}$ & $643.19 \pm 65.04^{c, e}$ \\
\hline Urea $[\mu \mathrm{mol} / \mathrm{mg}]$ & $18.43 \pm 3.52$ & $18.33 \pm 2.80$ & $13.88 \pm 0.93$ & $10.01 \pm 0.88$ & $16.10 \pm 2.14$ & $14.99 \pm 3.96$ \\
\hline $\begin{array}{l}\text { Arginase kidney } \\
\text { [U/mg protein] }\end{array}$ & $9.30 \pm 3.02$ & $8.91 \pm 4.32$ & --- & --- & --- & --- \\
\hline
\end{tabular}

All data are presented as mean \pm SD. $N=3-6$ male animals per genotype and group were studied. P-value obtained by unpaired Student's t-test between genotypes or by two-factor ANOVA analysis and post-hoc analysis (Tukey) when comparing between groups.

${ }^{a} P<0.05$ obtained by unpaired Student's t-test between genotypes.

${ }^{b, c, d, e} P<0.05$ obtained by post-hoc analysis (Tukey) when comparing between groups, independent of genotype.

Independent of genotype, comparing only HP to control diet, after 18 days intervention, ALT (633.3 $\pm 44.3 \mathrm{mU} / \mathrm{mg}$ vs. $790.8 \pm 32 \mathrm{mU} / \mathrm{mg} ; \mathrm{p}<0.001)$ and arginase $(63 \pm 8.1 \mathrm{U} / \mathrm{mg}$ protein vs. 96.2 $\pm 18.3 \mathrm{U} / \mathrm{mg}$ protein; $\mathrm{p}=0.002)$ showed decreased activities. Urea concentration was significantly higher in HP fed mice than fed control diet $(15.5 \pm 2.9 \mu \mathrm{mol} / \mathrm{mg}$ vs. $11.9 \pm 3 \mu \mathrm{mol} / \mathrm{mg}, \mathrm{p}=0.037)$, also independently of genotype.

\subsubsection{Decreased leptin levels in Pept1//- animals}

After $24 \mathrm{~h}$ on a HP diet hormone levels were measured. Similar to the findings on standard diet for basal state assessment, leptin levels differed significantly between male Pept $1^{+/+}$and Pept $1^{-/-}$mice. After $24 \mathrm{~h}$ on HP diet Pept $1^{-/}$animals displayed significantly decreased levels when compared to $P$ ept $1^{+/+}$animals $(2.2 \pm 1.4 \mathrm{ng} / \mathrm{ml}$ vs. $7.6 \pm 2.4 \mathrm{ng} / \mathrm{ml}, \mathrm{p}=0.001$ ). After $24 \mathrm{~h}$ on HP diet no significant changes for insulin and ghrelin levels could be observed (Fig. 25). 

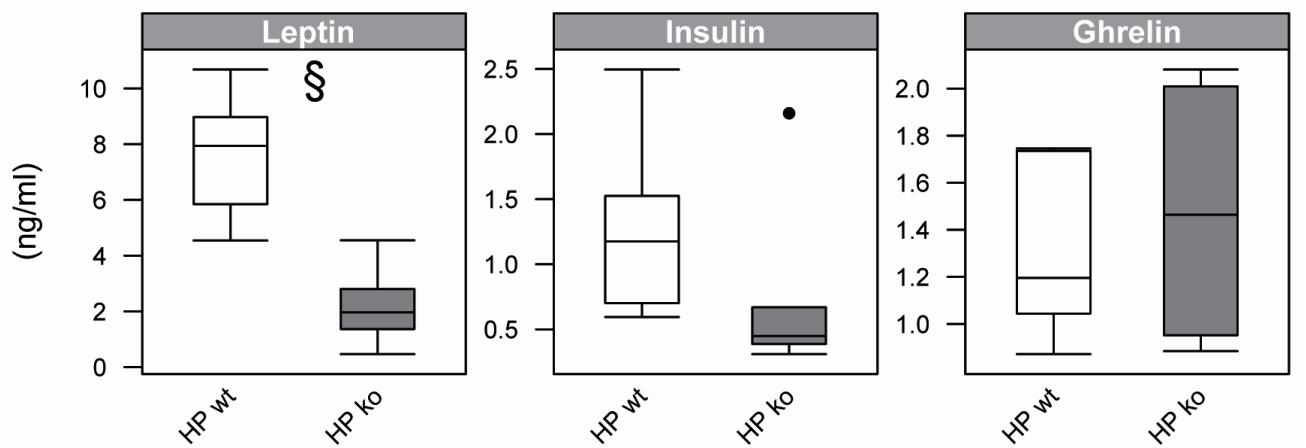

Fig. 25: Determination of leptin, insulin and ghrelin plasma levels in fed and fasted animals after $24 \mathrm{~h}$ on a high protein diet.

All data are presented as mean $\pm \mathrm{SD}$. $\mathrm{N}=6$ male animals per genotype and group were studied. $\mathrm{P}$-value was obtained by unpaired Student's t-test between genotypes ( $\left.{ }^{*}<0.05, \S<0.01, \$<0.001\right)$.

\subsubsection{Gender aspects in the effects of a high-protein diet}

Like for the male mice, we conducted feeding trials with adult female mice $(n=10)$ with a control diet ( $21 \%$ of energy) and a HP diet ( $45 \%$ of energy). Similar to the male mice, female Pept $1^{-/}$mice on HP diet showed a more decreased food intake, resulting in lower body weight and reduced feces excretion as well (Fig. 26). But female mice on HP diet already displayed significant differences between the initial weight at Day 0, which raises difficulties to relate the weight effects explicit to the HP diet. In addition female mice seemed to react with more severe effects to the diet. Water consumption also varied significantly in the HP group between genotypes, displaying lowered water consumption rates in Pept $1^{\text {\% }}$ mice, but only on days 2 and 3 (Day 2: wt $8.56 \pm 1.62 \mathrm{ml} /$ day vs. ko $6.73 \pm 1.02 \mathrm{ml} /$ day, $\mathrm{p}=0.005$; Day3: wt $7.74 \pm$ $1.88 \mathrm{ml} /$ day vs. ko $5.96 \pm 1.41 \mathrm{ml} /$ day, $\mathrm{p}=0.03$ ).
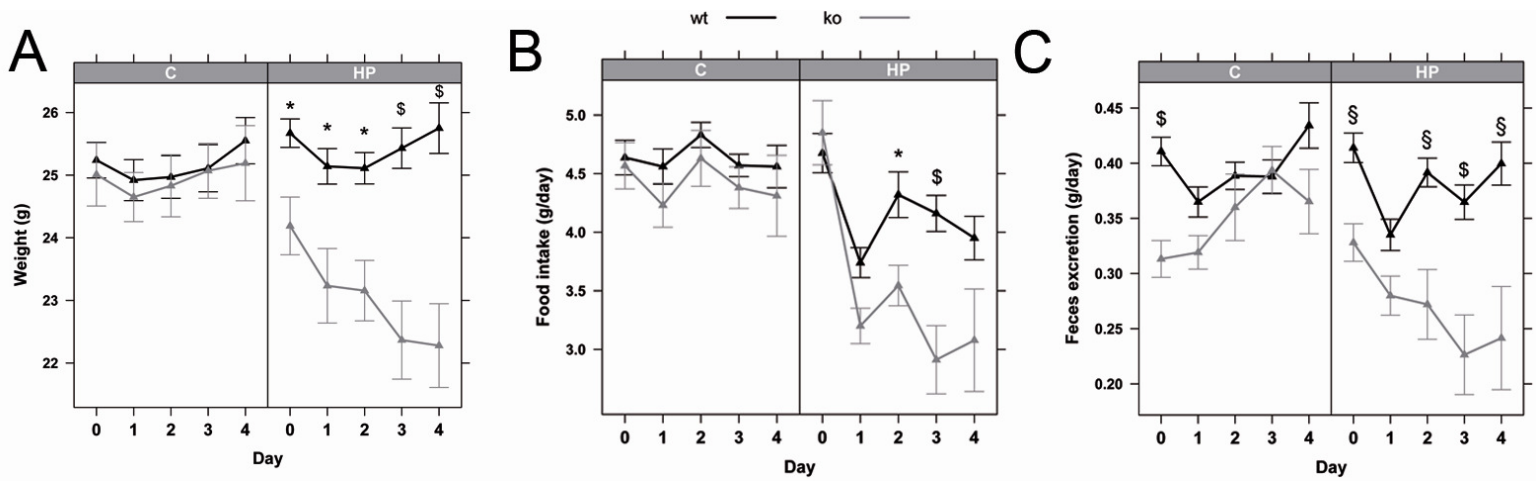

Fig. 26: Metabolic parameters of female Pept $1^{+/+}$and $P e p t 1^{-/}$animals fed a HP diet for 5 days.

Weight (A), food intake (B) and feces excretion (C) of female mice on either HP or control diet are shown

All data are presented as mean \pm SD. N=10 female animals per genotype and group were studied; Pept $1^{+/+}$(wt), Pept $1^{-/-}$(ko). Pvalue obtained by two-factor ANOVA analysis and post-hoc analysis (Tukey) when comparing between groups $\left({ }^{*}<0.05, \S<0.01\right.$, $\$<0.001)$. 


\subsubsection{Modified clinical chemistry plasma parameters in female $P e p t 1^{-/-}$mice}

13 plasma parameters were determined after 5 days on the HP diet (Table 20). As observed for male mice, also female mice display significant lower ALP levels in Pept $1^{-\%}$ animals. In addition alterations between genotypes on HP diet were seen for total protein and calcium.

Table 20: Clinical chemistry parameters in plasma of female mice after 5 days on high-protein diet

\begin{tabular}{lcccc}
\hline Parameter & \multicolumn{2}{c}{ Control } & \multicolumn{2}{c}{ High-protein } \\
\cline { 2 - 5 } & Pept $^{+/+}$ & Pept1 $^{-/}$ & Pept $^{+/+}$ & Pept $^{-/ \cdot}$ \\
\hline Glucose (mg/dl) & $228.00 \pm 41.09$ & $241.43 \pm 44.28$ & $255.60 \pm 40.12$ & $194.33 \pm 53.12$ \\
Blood urea nitrogen (mg/dl) & $25.00 \pm 4.14$ & $28.29 \pm 2.93$ & $35.40 \pm 7.24$ & $40.67 \pm 9.27$ \\
Calcium (mg/dl) & $9.86 \pm 0.41^{\mathrm{c}}$ & $9.80 \pm 0.50^{\mathrm{d}}$ & $9.68 \pm 0.38^{\mathrm{b}}$ & $10.50 \pm 0.33^{\mathrm{b}, \mathrm{c}, \mathrm{d}}$ \\
Total protein (g/dl) & $5.42 \pm 0.22^{\mathrm{c}}$ & $5.34 \pm 0.15^{\mathrm{c}}$ & $5.26 \pm 0.33^{\mathrm{b}}$ & $5.83 \pm 0.34^{\mathrm{b}, \mathrm{c}, \mathrm{d}}$ \\
ALT (U/l) & $32.20 \pm 20.67$ & $32.00 \pm 13.95$ & $34.80 \pm 13.24$ & $40.33 \pm 26.99$ \\
AST (U/l) & $103.20 \pm 48.37$ & $103.14 \pm 62.82$ & $86.00 \pm 15.86$ & $114.67 \pm 76.12$ \\
ALP (U/l) & $116.20 \pm 18.44^{\mathrm{b}, \mathrm{c}}$ & $84.86 \pm 21.07^{\mathrm{b}}$ & $96.40 \pm 10.06^{\mathrm{b}}$ & $67.33 \pm 25.60^{\mathrm{b}, \mathrm{c}}$ \\
Total bilirubin (mg/dl) & $0.72 \pm 0.10$ & $0.71 \pm 0.11$ & $0.72 \pm 0.10$ & $0.70 \pm 0.17$ \\
Amylase (U/l) & $835.20 \pm 112.75$ & $734.00 \pm 105.97$ & $764.80 \pm 45.12$ & $722.00 \pm 112.43$ \\
\hline
\end{tabular}

All data are presented as mean $\pm S D$. $N=10$ female animals per genotype and group were studied. P-value obtained by twofactor ANOVA analysis and post-hoc analysis (Tukey) when comparing between groups.

${ }^{b} P<0.05$ obtained by post-hoc analysis (Tukey) when comparing between genotypes.

${ }^{c, d, e} P<0.05$ obtained by post-hoc analysis (Tukey) when comparing between groups, independent of genotype.

\subsubsection{Alterations in plasma and liver amino acids of female Pept ${ }^{-/ 2}$ mice on a high-protein diet}

In female mice 34 metabolites could be detected after 5 days on HP diet (Table 21). However in the HP diet group only two amino acids displayed alterations between genotypes. Among them was taurine, which displayed significantly elevated levels in $P e p t 1^{-/-}$animals and hydroxyproline with lowered concentrations in Pept $1^{-/-}$animals.

Table 21: Plasma amino acid levels of female mice after 5 days on high-protein diet

\begin{tabular}{|c|c|c|c|c|}
\hline \multirow[t]{2}{*}{ Amino acid $(\mu \mathrm{mol} / \mathrm{l})$} & \multicolumn{2}{|c|}{ Control } & \multicolumn{2}{|c|}{ High-protein } \\
\hline & Pept1 $^{+/+}$ & Pept1 ${ }^{-/-}$ & Pept1 $^{+/+}$ & Pept1 ${ }^{-/-}$ \\
\hline Alanine & $681.70 \pm 223.05$ & $693.30 \pm 266.64$ & $650.30 \pm 158.82$ & $709.56 \pm 437.45$ \\
\hline Alpha-aminoadipic acid & $7.98 \pm 1.47$ & $13.32 \pm 5.59$ & $13.61 \pm 15.27$ & $24.51 \pm 26.05$ \\
\hline Arginine & $126.88 \pm 23.72$ & $168.10 \pm 39.35$ & $114.64 \pm 40.21$ & $149.27 \pm 80.15$ \\
\hline Asparagine & $78.34 \pm 26.59$ & $71.63 \pm 29.79$ & $72.05 \pm 32.04$ & $91.93 \pm 65.59$ \\
\hline Aspartate & $11.51 \pm 3.51$ & $10.47 \pm 3.30$ & $13.60 \pm 3.20$ & $13.08 \pm 6.62$ \\
\hline Beta-Alanine & $27.55 \pm 1.77$ & $26.74 \pm 3.74$ & $26.69 \pm 3.10$ & $26.21 \pm 2.00$ \\
\hline Citrulline & $68.28 \pm 11.07$ & $79.74 \pm 16.04$ & $72.17 \pm 16.20$ & $91.79 \pm 31.44$ \\
\hline Cystationase & $3.54 \pm 1.53$ & $3.59 \pm 0.73$ & $3.88 \pm 1.13$ & $4.33 \pm 1.48$ \\
\hline
\end{tabular}




\begin{tabular}{|c|c|c|c|c|}
\hline \multirow[t]{2}{*}{ Amino acid $(\mu \mathrm{mol} / \mathrm{l})$} & \multicolumn{2}{|c|}{ Control } & \multicolumn{2}{|c|}{ High-protein } \\
\hline & Pept1 ${ }^{+/+}$ & Pept1 ${ }^{1-2}$ & Pept1 $^{+/+}$ & Pept1 ${ }^{-/}$ \\
\hline Cysteine & $44.51 \pm 19.71$ & $50.98 \pm 16.40$ & $44.93 \pm 18.25$ & $75.94 \pm 87.08$ \\
\hline Ethanolamine & $12.48 \pm 3.30$ & $10.02 \pm 2.54$ & $12.55 \pm 1.78$ & $12.65 \pm 6.65$ \\
\hline Glutamate & $45.74 \pm 17.44$ & $38.03 \pm 9.35$ & $51.39 \pm 11.61$ & $44.71 \pm 22.81$ \\
\hline Glutamine & $770.10 \pm 116.48$ & $765.70 \pm 116.08$ & $755.70 \pm 150.44$ & $945.33 \pm 313.44$ \\
\hline Glycine & $299.50 \pm 53.28^{\mathrm{b}, \mathrm{c}}$ & $204.90 \pm 53.33^{b}$ & $249.20 \pm 49.25$ & $183.56 \pm 58.99^{c}$ \\
\hline Histidine & $81.48 \pm 14.44$ & $88.70 \pm 17.03$ & $80.20 \pm 18.60$ & $102.63 \pm 51.88$ \\
\hline Homocysteine & $2.69 \pm 0.21$ & $2.84 \pm 0.16$ & $2.81 \pm 0.23$ & $2.84 \pm 0.26$ \\
\hline Hydroxyproline & $9.83 \pm 2.26^{c}$ & $8.76 \pm 2.65^{d}$ & $7.40 \pm 1.60^{b}$ & $3.75 \pm 1.30^{b, c, d}$ \\
\hline Isoleucine & $170.10 \pm 30.03^{c, d}$ & $172.00 \pm 36.95^{\mathrm{e}, \mathrm{f}}$ & $267.10 \pm 71.80^{\mathrm{c}, \mathrm{e}}$ & $312.89 \pm 123.05^{\mathrm{d}, \mathrm{f}}$ \\
\hline Leucine & $248.90 \pm 42.51^{c, d}$ & $272.90 \pm 76.46^{\mathrm{e}}$ & $419.60 \pm 128.40^{c}$ & $543.56 \pm 220.21^{\mathrm{d}, \mathrm{e}}$ \\
\hline Lysine & $498.20 \pm 183.76$ & $586.60 \pm 193.86$ & $402.80 \pm 166.58$ & $600.78 \pm 244.95$ \\
\hline Methionine & $73.54 \pm 33.04$ & $83.27 \pm 44.49$ & $76.35 \pm 31.06$ & $80.72 \pm 51.43$ \\
\hline Ornithine & $76.69 \pm 15.59^{c}$ & $85.16 \pm 28.56$ & $87.82 \pm 30.33$ & $130.58 \pm 64.12^{c}$ \\
\hline Phenylalanine & $86.32 \pm 10.54^{c}$ & $86.67 \pm 21.00^{d}$ & $102.41 \pm 25.45$ & $140.69 \pm 61.67^{\mathrm{c}, \mathrm{d}}$ \\
\hline Phosphoethanolamine & $7.08 \pm 1.64$ & $7.28 \pm 2.39$ & $7.16 \pm 1.65$ & $9.52 \pm 4.47$ \\
\hline Proline & $168.32 \pm 106.66$ & $217.56 \pm 95.07$ & $238.63 \pm 124.20$ & $288.50 \pm 187.41$ \\
\hline Sarcosine & $1.26 \pm 0.33$ & $1.56 \pm 0.65$ & $2.11 \pm 1.33$ & $2.22 \pm 1.52$ \\
\hline Serine & $208.70 \pm 63.24$ & $183.65 \pm 66.11$ & $201.60 \pm 68.63$ & $205.09 \pm 116.87$ \\
\hline Taurine & $373.90 \pm 104.50$ & $448.50 \pm 171.15$ & $314.80 \pm 39.22^{b}$ & $559.00 \pm 307.87^{b}$ \\
\hline Threonine & $297.90 \pm 121.26$ & $295.30 \pm 105.18$ & $312.50 \pm 117.74$ & $303.22 \pm 94.62$ \\
\hline Tryptophane & $104.66 \pm 20.83$ & $82.93 \pm 23.40$ & $98.79 \pm 24.13$ & $73.39 \pm 32.98$ \\
\hline Tyrosine & $137.45 \pm 53.70$ & $131.05 \pm 55.35$ & $182.99 \pm 82.86$ & $150.31 \pm 109.55$ \\
\hline Valine & $414.10 \pm 75.29^{c, d}$ & $424.70 \pm 97.53^{\mathrm{e}, \mathrm{f}}$ & $635.10 \pm 173.53^{\mathrm{c}, \mathrm{e}}$ & $745.33 \pm 286.02^{d, f}$ \\
\hline 1-M-Histidine & $1.96 \pm 0.40$ & $2.15 \pm 0.48$ & $1.77 \pm 0.61$ & $1.56 \pm 0.54$ \\
\hline 3-M-Histidine & $2.34 \pm 0.57$ & $2.98 \pm 2.11$ & $2.01 \pm 0.46$ & $2.74 \pm 1.60$ \\
\hline 2-aminobutyric acid & $12.46 \pm 2.15^{c}$ & $16.21 \pm 3.06$ & $15.19 \pm 4.42$ & $25.22 \pm 15.87^{c}$ \\
\hline Sum & $5155.99 \pm 989.75$ & $5337.29 \pm 1050.97$ & $5539.85 \pm 1303.99$ & $6657.41 \pm 2044.71$ \\
\hline
\end{tabular}

All data are presented as mean $\pm S D$. N=9-10 female animals per genotype and group were studied. P-value obtained by twofactor ANOVA analysis and post-hoc analysis (Tukey) when comparing between groups.

${ }^{b} P<0.05$ obtained by post-hoc analysis (Tukey) when comparing between genotypes.

$c, d, e, f<0.05$ obtained by post-hoc analysis (Tukey) when comparing between groups, independent of genotype.

Independently of genotype, 8 amino acids and derivatives revealed significant changed levels in plasma of animals on HP diet. Among them were the branched chain amino acids valine, leucine and isoleucine, but also ornithine, sarcosine and phenylalanine. All of them showed elevated levels in mice on HP when compared to control diet (valine HP: $419.40 \pm 84.97 \mu \mathrm{mol} / / \mathrm{l}$ vs.C $687.32 \pm 233.69 \mu \mathrm{mol} / \mathrm{l}, \mathrm{p}<0.001$; leucine HP: $260.90 \pm 61.46 \mu \mathrm{mol} / \mathrm{l}$ vs.C $478.32 \pm 183.95 \mu \mathrm{mol} / \mathrm{l}, \mathrm{p}<0.001$; isoleucine HP: $171.05 \pm 32.78 \mu \mathrm{mol} / \mathrm{l}$ vs.C $288.79 \pm 99.29 \mu \mathrm{mol} / \mathrm{l}, \mathrm{p}<0.001$; ornithine HP: 80.92 $\pm 22.81 \mu \mathrm{mol} / / \mathrm{lvs} . \mathrm{C} 108.07 \pm 52.62 \mu \mathrm{mol} / \mathrm{l}, \mathrm{p}=0.041$; sarcosine HP: $1.41 \pm 0.53 \mu \mathrm{mol} / \mathrm{l}$ vs.C $2.16 \pm 1.38 \mu \mathrm{mol} / \mathrm{l}, \mathrm{p}=0.028$; phenylalanine HP: $86.50 \pm 16.17 \mu \mathrm{mol} / \mathrm{l}$ vs.C $120.54 \pm 48.98 \mu \mathrm{mol} / \mathrm{l}, \mathrm{p}=0.0055)$. Decreased levels in animals on HP diet were 
found for 1-methyl-histidine (C: $2.06 \pm 0.44 \mu \mathrm{mol} / \mathrm{l}$ vs. HP: $1.67 \pm 0.57 \mu \mathrm{mol} / \mathrm{l}$, $\mathrm{p}=0.024)$ and hydroxyproline (C: $9.29 \pm 2.46 \mu \mathrm{mol} / \mathrm{l}$ vs. HP: $5.67 \pm 2.35 \mu \mathrm{mol} / \mathrm{l}$, $\mathrm{p}<0.001)$.

Concentrations of 32 amino acids and derviatives could be determined in liver tissue of female mice after 5 days on HP diet (Table 22). 7 of these 32 amino acids showed alterations between genotypes when fed the HP diet. All of them were increased in Pept $1^{-/}$animals, when compared to wild-type animals. Amongst them were lysine, methionine and ornithine, but also glutamate, 2-aminobutyric acid, 1-methyl-histidine and beta-aminoisobutyric acid.

Table 22: Liver amino acid concentrations in female $P e p t 1^{+/+}$and $P e p t 1^{-/-}$animals

\begin{tabular}{|c|c|c|c|c|}
\hline \multirow[t]{2}{*}{ Amino acid (nmol/mg protein) } & \multicolumn{2}{|c|}{ Control } & \multicolumn{2}{|c|}{ High-protein } \\
\hline & $\mathrm{Pept1}^{+/+}$ & Pept1 $^{-/ 2}$ & Pept1 $^{+/+}$ & Pept1 $^{-/-}$ \\
\hline Alanine & $103.56 \pm 15.01$ & $94.37 \pm 13.47^{c}$ & $125.33 \pm 18.09$ & $128.28 \pm 49.35^{\mathrm{c}}$ \\
\hline Alpha-aminoadipic acid & $2.62 \pm 1.30^{\mathrm{c}}$ & $4.55 \pm 5.78$ & $16.58 \pm 26.49$ & $32.91 \pm 40.61^{\mathrm{c}}$ \\
\hline Asparagine & $4.40 \pm 0.75^{\mathrm{c}}$ & $3.62 \pm 0.53^{\mathrm{d}, \mathrm{e}}$ & $5.57 \pm 1.53^{\mathrm{d}}$ & $6.28 \pm 1.84^{\mathrm{c}, \mathrm{e}}$ \\
\hline Aspartate & $4.69 \pm 1.56^{\mathrm{c}}$ & $4.99 \pm 2.31^{d}$ & $8.41 \pm 3.71$ & $11.68 \pm 7.83^{\mathrm{c}, \mathrm{d}}$ \\
\hline Beta-Alanine & $0.95 \pm 0.79^{c}$ & $0.69 \pm 0.42^{\mathrm{d}, \mathrm{e}}$ & $1.60 \pm 0.88^{d}$ & $1.93 \pm 0.62^{\mathrm{c}, \mathrm{e}}$ \\
\hline Beta-aminoisobutyric acid & $0.35 \pm 0.08^{c}$ & $0.40 \pm 0.11^{d}$ & $0.42 \pm 0.13^{b}$ & $0.59 \pm 0.19^{b, c, d}$ \\
\hline Citrulline & $0.28 \pm 0.10$ & $0.36 \pm 0.09$ & $0.30 \pm 0.05$ & $1.36 \pm 2.46$ \\
\hline Cysteine & $0.11 \pm 0.04$ & $0.14 \pm 0.05$ & $0.11 \pm 0.03$ & $0.23 \pm 0.16$ \\
\hline Ethanolamine & $1.26 \pm 0.41^{\mathrm{c}, \mathrm{d}}$ & $1.28 \pm 0.34^{e, f}$ & $1.97 \pm 0.34^{\mathrm{c}, \mathrm{e}}$ & $2.30 \pm 0.64^{\mathrm{d}, \mathrm{f}}$ \\
\hline Gamma-aminobutyric acid & $0.59 \pm 0.14^{\mathrm{c}, \mathrm{d}}$ & $0.48 \pm 0.13^{e, f}$ & $0.79 \pm 0.16^{c, e}$ & $0.84 \pm 0.23^{\mathrm{d}, \mathrm{f}}$ \\
\hline Glutamate & $28.88 \pm 7.27^{\mathrm{c}}$ & $24.58 \pm 4.98^{\mathrm{d}, \mathrm{e}}$ & $40.30 \pm 12.67^{\mathrm{b}, \mathrm{d}}$ & $60.34 \pm 20.19^{\mathrm{b}, \mathrm{c}, \mathrm{e}}$ \\
\hline Glutamine & $59.66 \pm 13.95$ & $47.39 \pm 8.25$ & $55.01 \pm 14.74$ & $63.14 \pm 14.90$ \\
\hline Glycine & $48.30 \pm 7.54^{b}$ & $36.58 \pm 7.99^{\mathrm{b}, \mathrm{c}}$ & $49.29 \pm 13.14^{c}$ & $40.98 \pm 7.83$ \\
\hline Histidine & $8.63 \pm 1.30^{\mathrm{c}, \mathrm{d}}$ & $7.43 \pm 1.68^{\mathrm{e}, \mathrm{f}}$ & $10.75 \pm 1.41^{c, e}$ & $11.74 \pm 2.38^{\mathrm{d}, \mathrm{f}}$ \\
\hline Homocitrulline & $0.10 \pm 0.02$ & $0.08 \pm 0.02^{c}$ & $0.14 \pm 0.06$ & $0.16 \pm 0.12^{c}$ \\
\hline Isoleucine & $5.94 \pm 1.07^{\mathrm{c}, \mathrm{d}}$ & $4.77 \pm 0.78^{\mathrm{e}, \mathrm{f}}$ & $9.22 \pm 1.82^{\mathrm{c}, \mathrm{e}}$ & $9.98 \pm 3.22^{\mathrm{d}, \mathrm{f}}$ \\
\hline Leucine & $10.70 \pm 1.92^{\mathrm{c}, \mathrm{d}}$ & $9.46 \pm 1.54^{\mathrm{e}, \mathrm{f}}$ & $16.10 \pm 3.39^{\mathrm{c}, \mathrm{e}}$ & $20.02 \pm 6.26^{\mathrm{d}, \mathrm{f}}$ \\
\hline Lysine & $16.51 \pm 1.74^{\mathrm{c}}$ & $14.50 \pm 2.16^{d}$ & $19.97 \pm 3.73^{b}$ & $28.97 \pm 10.62^{b, c, d}$ \\
\hline Methionine & $1.90 \pm 0.38^{\mathrm{c}}$ & $2.24 \pm 0.21^{d}$ & $1.82 \pm 0.56^{\mathrm{b}}$ & $2.89 \pm 0.61^{\mathrm{b}, \mathrm{c}, \mathrm{d}}$ \\
\hline Ornithine & $6.04 \pm 1.32^{c}$ & $6.41 \pm 1.58^{d}$ & $8.02 \pm 2.11^{b}$ & $13.30 \pm 7.66^{\mathrm{b}, \mathrm{c}, \mathrm{d}}$ \\
\hline Phenylalanine & $3.54 \pm 0.59$ & $3.24 \pm 0.52$ & $4.12 \pm 0.87$ & $5.41 \pm 1.55$ \\
\hline Phosphoethanolamine & $6.65 \pm 1.15$ & $6.69 \pm 3.31$ & $6.40 \pm 1.14$ & $9.23 \pm 5.20$ \\
\hline Proline & $6.15 \pm 1.30^{\mathrm{c}, \mathrm{d}}$ & $5.59 \pm 1.17^{\mathrm{e}, \mathrm{f}}$ & $12.52 \pm 3.74^{\mathrm{c}, \mathrm{e}}$ & $17.58 \pm 7.92^{\mathrm{d}, \mathrm{f}}$ \\
\hline Sarcosine & $0.52 \pm 0.19^{c, d}$ & $0.45 \pm 0.26^{\mathrm{e}, \mathrm{f}}$ & $1.58 \pm 0.46^{\mathrm{c}, \mathrm{e}}$ & $1.64 \pm 1.06^{\mathrm{d}, \mathrm{f}}$ \\
\hline Serine & $8.74 \pm 1.73$ & $8.71 \pm 1.84$ & $9.25 \pm 2.15$ & $11.15 \pm 3.51$ \\
\hline Taurine & $211.46 \pm 8.41^{b}$ & $148.90 \pm 58.45^{\mathrm{b}, \mathrm{c}}$ & $200.60 \pm 24.02^{c}$ & $194.41 \pm 42.99$ \\
\hline Threonine & $7.06 \pm 1.28^{\mathrm{c}}$ & $6.03 \pm 1.50^{\mathrm{d}, \mathrm{e}}$ & $9.04 \pm 2.28^{d}$ & $10.77 \pm 3.45^{\mathrm{c}, \mathrm{e}}$ \\
\hline Tryptophane & $1.16 \pm 0.18$ & $1.00 \pm 0.19$ & $1.13 \pm 0.22$ & $1.32 \pm 0.51$ \\
\hline Tyrosine & $5.06 \pm 0.51$ & $4.39 \pm 1.13^{\mathrm{c}}$ & $7.54 \pm 1.18^{\mathrm{c}}$ & $7.10 \pm 4.23$ \\
\hline
\end{tabular}




\begin{tabular}{|c|c|c|c|c|}
\hline \multirow[t]{2}{*}{ Amino acid (nmol/mg protein) } & \multicolumn{2}{|c|}{ Control } & \multicolumn{2}{|c|}{ High-protein } \\
\hline & Pept $^{+/+}$ & Pept1 ${ }^{-2}$ & Pept ${ }^{+/+}$ & Pept1 $^{1-2}$ \\
\hline Valine & $12.02 \pm 2.14^{\mathrm{c}, \mathrm{d}}$ & $9.41 \pm 1.21^{\mathrm{e}, \mathrm{f}}$ & $19.92 \pm 4.99^{\mathrm{c}, \mathrm{e}}$ & $23.67 \pm 7.59^{\mathrm{d}, \mathrm{f}}$ \\
\hline 1-M-Histidine & $0.49 \pm 0.07^{c}$ & $0.40 \pm 0.09^{d, e}$ & $0.66 \pm 0.15^{\mathrm{b}, \mathrm{d}}$ & $0.90 \pm 0.24^{\mathrm{b}, \mathrm{c}, \mathrm{e}}$ \\
\hline 2-aminobutyric acid & $2.36 \pm 1.00^{c}$ & $2.32 \pm 0.70^{d}$ & $4.07 \pm 1.85^{\mathrm{b}}$ & $7.74 \pm 3.87^{\mathrm{b}, \mathrm{c}, \mathrm{d}}$ \\
\hline Sum & $570.72 \pm 46.82^{c}$ & $461.46 \pm 45.41^{\mathrm{d}, \mathrm{e}}$ & $648.54 \pm 75.33^{d}$ & $728.83 \pm 164.32^{\mathrm{c}, \mathrm{e}}$ \\
\hline
\end{tabular}

All data are presented as mean \pm SD. $\mathrm{N}=9-10$ female animals per genotype and group were studied. P-value obtained by twofactor ANOVA analysis and post-hoc analysis (Tukey) when comparing between groups.

${ }^{b} P<0.05$ obtained by post-hoc analysis (Tukey) when comparing between genotypes.

${ }^{c}, d, e, f<<0.05$ obtained by post-hoc analysis (Tukey) when comparing between groups, independent of genotype.

\subsubsection{Enzyme activities and urea concentration in liver tissue}

Enzyme activities in liver tissue of female mice after 5 days on a HP diet did not reveal any genotype-specific effects. Only between diets changes were observed (Table 23) with alterations in arginase (C: $80.31 \pm 15.34 \mathrm{U} / \mathrm{mg}$ protein vs. HP: 115.17 $\pm 30.09 \mathrm{U} / \mathrm{mg}$ protein, $\mathrm{p}<0.001$ ), $\mathrm{GDH}$ (C: $645.92 \pm 159.57 \mathrm{mU} / \mathrm{mg}$ vs. HP: $1137.74 \pm$ $341.39 \mathrm{mU} / \mathrm{mg},<0.001$ ) and AST levels (C: $1954.26 \pm 417.98 \mathrm{mU} / \mathrm{mg}$ vs. HP: $2627.69 \pm 613.87 \mathrm{mU} / \mathrm{mg}, p<0.001$ ), whereas all enzyme acitivities were increased in animals on HP diet.

Table 23: Enzyme activities and urea concentration in liver tissue of female mice after 5 days on highprotein diet

\begin{tabular}{|c|c|c|c|c|}
\hline \multirow[t]{2}{*}{ Parameter } & \multicolumn{2}{|c|}{ Control } & \multicolumn{2}{|c|}{ High-protein } \\
\hline & Pept1 $^{+/+}$ & Pept1 $^{-1-}$ & Pept1 $^{+/+}$ & Pept1 $1^{-/}$ \\
\hline Arginase [U/mg protein] & $87.20 \pm 18.30^{\circ}$ & $73.43 \pm 7.50^{\mathrm{d}, \mathrm{e}}$ & $111.33 \pm 25.03^{d}$ & $119.97 \pm 36.68^{\mathrm{c}, \mathrm{e}}$ \\
\hline GDH $[\mathrm{mU} / \mathrm{mg}]$ & $698.60 \pm 189.15^{\mathrm{c}, \mathrm{d}}$ & $593.24 \pm 108.68^{e, f}$ & $1193.30 \pm 310.49^{\mathrm{c}, \mathrm{e}}$ & $1068.29 \pm 386.23^{\mathrm{d}, \mathrm{f}}$ \\
\hline AST [mU/mg] & $2156.30 \pm 454.78^{c}$ & $1752.23 \pm 267.01^{d}$ & $2859.47 \pm 556.10^{c, d}$ & $2337.95 \pm 587.26$ \\
\hline ALT [mU/mg] & $667.75 \pm 106.30$ & $571.19 \pm 90.62$ & $1256.30 \pm 1383.58$ & $719.61 \pm 241.19$ \\
\hline Urea $[\mu \mathrm{mol} / \mathrm{mg}]$ & $16.19 \pm 3.14$ & $15.43 \pm 2.52$ & $16.37 \pm 4.00$ & $20.36 \pm 7.84$ \\
\hline
\end{tabular}

All data are presented as mean $\pm S D$. N=8-10 female animals per genotype and group were studied. $\mathrm{P}$-value obtained by twofactor ANOVA analysis and post-hoc analysis (Tukey) when comparing between groups.

${ }^{b} P<0.05$ obtained by post-hoc analysis (Tukey) when comparing between genotypes.

${ }_{c, d, e, f} P<0.05$ obtained by post-hoc analysis (Tukey) when comparing between groups, independent of genotype. 


\subsubsection{Effects of a carbohydrate administration}

\subsubsection{Administration of a high-protein diet and water enriched with glucose}

Due to the findings of the 5 day dietary intervention study, demonstrating mice on high-protein diets to reduce their food intake drastically, we tried to determine whether this effect is only due to the diet or is also associated with other factors. Therefore we determined the mean energy supply and water consumption of the 5 day feeding trial and calculated the difference of energy intake between animals on either control or HP diet. To allow mice on HP diet to balance the energy difference compared to mice on control diet, they were offered water containing glucose. The water contained as much glucose as needed to compensate the energy difference between the HP and the control group (Table 24). The amount of glucose was calculated with a surplus of $25 \%$ (in case of lower water consumption rates of mice on HP diet).

Table 24: Metabolic parameters and calculations for energy supply

\begin{tabular}{lccr}
\hline Parameter & Control (mean) & \multicolumn{2}{c}{ High-protein } \\
\cline { 3 - 4 } & & Pept $^{+/+}$ & Pept1 $^{-/-}$ \\
\hline Food intake (g/day) & 4.40 & 3.46 & 2.72 \\
Food intake (kJ/day) & 79.21 & 70.30 & 55.21 \\
Water consumption (ml/day) & 5.27 & 6.10 & 5.94 \\
Difference (g/day) & --- & 0.94 & 1.68 \\
Difference (kJ/day) & --- & 19.03 & 34.12 \\
\hline
\end{tabular}

Mice on high-protein diet with glucose substitution (HPG) did not display such a drastic decrease in weight gain in the first 5 days of the diet, as seen for mice which were only given the HP diet. Although food intake was as drastically reduced, HPG animals gained weight throughout the whole intervention period by the glucose intake from drinking water. Thus the energy intake was larger than that of the control group and no decrease in body weight, as shown for mice on HP diet, could be observed (Fig. 27). 

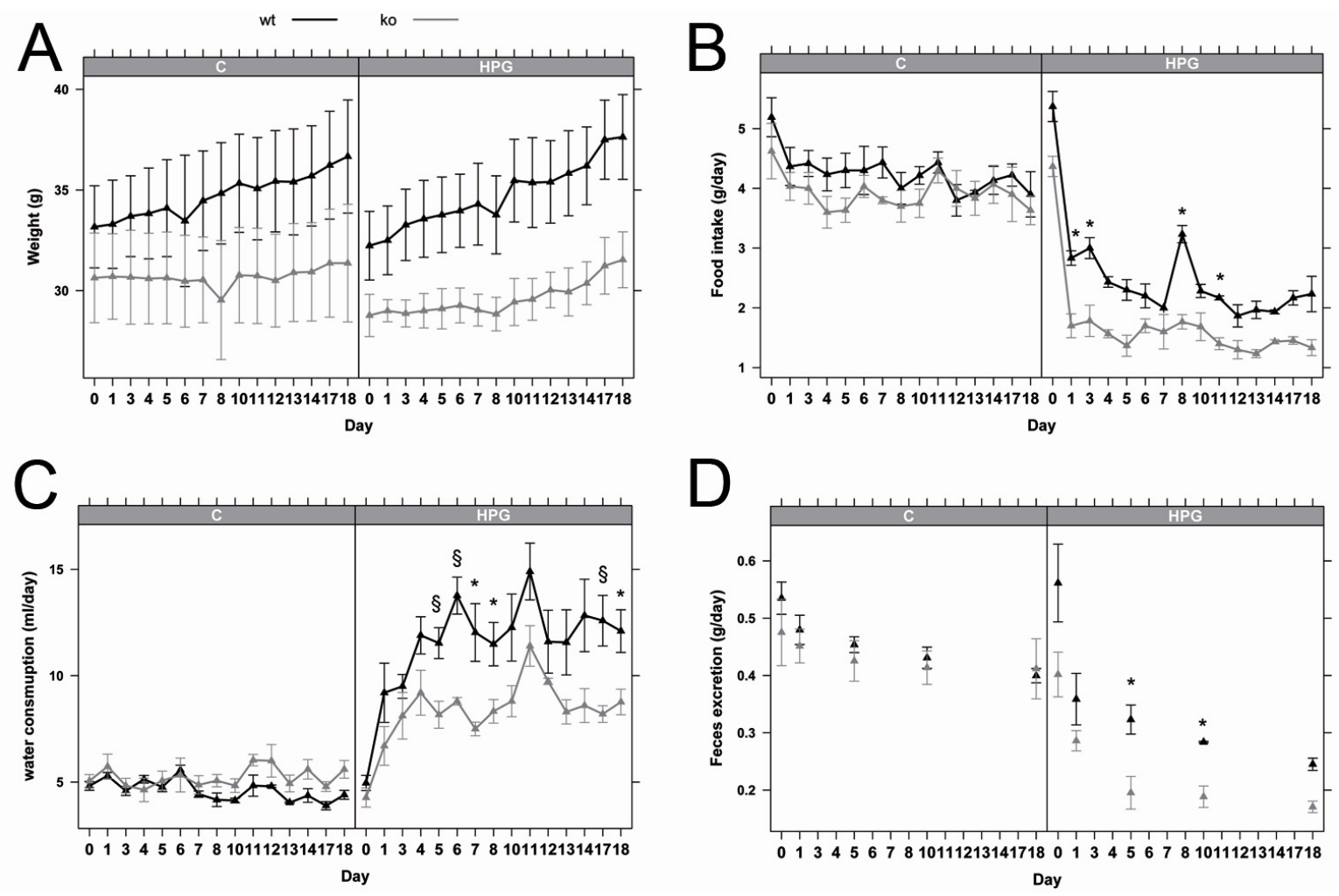

Fig. 27: Metabolic parameters in mice on HP diet with glucose substitution in the drinking water

\begin{abstract}
Weight (A), food intake (B), water consumption (C) and feces excretion (D) of male mice on either control diet or highprotein diet and glucose substitution in the drinking water are shown.

All data are presented as mean \pm SD. N=3 male animals per genotype and group were studied; Pept $1^{+/+}$(wt), Pept ${ }^{-1 /}$ (ko). P-value obtained by two-factor ANOVA analysis and post-hoc analysis (Tukey) when comparing between genotypes $\left({ }^{*}<0.05, \S<0.01, \$<0.001\right)$.
\end{abstract}

However genotype-specific differences were observed in food intake and as a result of that also in feces excretion. Pept $1^{-/-}$mice on HPG did show a more reduced food intake and also reduced feces excretion than wild-type mice. In contrast water consumption rates show an inverse effect with higher consumption rates in wild-type animals as in $\mathrm{Pept1}^{-/-}$mice.

Although wild-type mice on HPG displayed slightly higher food intake and water consumption rates than Pept1/- animals, the mean energy intake of both genotypes on HPG was almost the same with 95,92 kJ/d for wild-type animals and 95,6 kJ/d for Pept ${ }^{-}$animals. Calculating the mean energy intake revealed that $P e p t 1^{+/+}$animals on HPG obtained $50,34 \mathrm{~kJ} / \mathrm{d}$ from food and $45,58 \mathrm{~kJ} / \mathrm{d}$ by the glucose enriched water. On the other hand Pept ${ }^{-1-}$ animals ingested $34,71 \mathrm{~kJ} / \mathrm{d}$ with the food, but $60,89 \mathrm{~kJ} / \mathrm{d}$ by the drinking water. 


\subsubsection{Blood glucose and insulin secretion after an oral glucose tolerance test}

To assess whether Pept $1^{+/+}$and Pept $1^{-/}$animals show differences in glucose absorption we performed an oral glucose tolerance test (OGTT) where animals received $2 \mathrm{~g}$ glucose per $\mathrm{kg}$ bodyweight. As expected, plasma glucose concentrations increased and reached a maximum $15 \mathrm{~min}$ after the glucose load. Differences between genotypes could not be observed at any timepoint (Fig. 28).

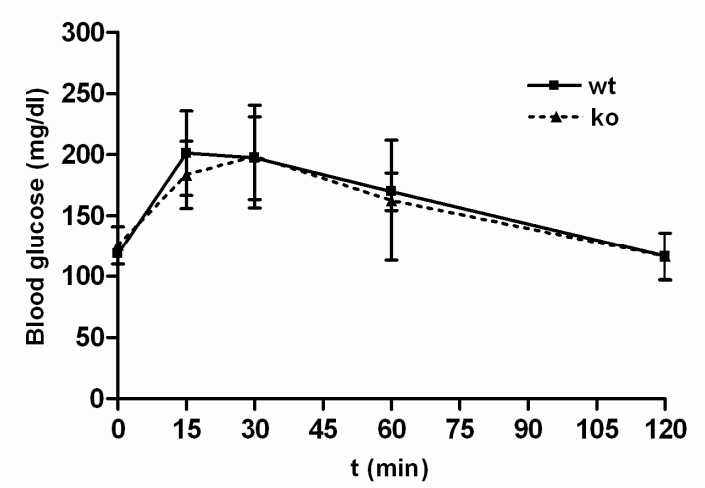

Fig. 28: Oral glucose tolerance test (2 g glucose per kg BW) in Pept $1^{+/+}$and Pept ${ }^{-/}$animals.

All data are presented as mean \pm SEM. N=16 mice per genotype (4 per time point) were studied; $P$ ept $1^{+/+}$(wt), Pept $1^{-1-}$ (ko). $\mathrm{P}$-value obtained by two-factor ANOVA analysis and post-hoc analysis (Tukey) when comparing between groups $\left({ }^{*}<0.05\right.$, $\S<0.01, \$<0.001)$. 2 g glucose per kg bodyweight.

15 min after the gavage a rapid increase in insulin levels in response to glucose was observed (Fig. 29), but together with the glucose profile it can be concluded that glucose homeostasis remains unaltered in $P e p t 1^{-1 /}$ mice.

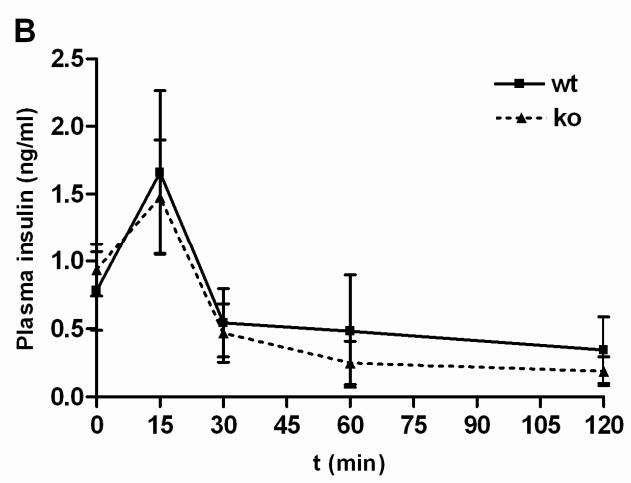

Fig. 29: Insulin concentration in response to intragastric administration of glucose $(2 \mathrm{~g} / \mathrm{kg})$ in wildtype and Pept $1^{-/ /}$mice

All data are presented as mean \pm SEM. N=16 mice per genotype (4 per time point) were studied; Pept ${ }^{+/+}$(wt), Pept $1^{-1 /}$ (ko). $\mathrm{P}$-value obtained by two-factor ANOVA analysis and post-hoc analysis (Tukey) when comparing between groups $\left({ }^{*}<0.05\right.$, $\S<0.01, \$<0.001)$. 


\subsection{Effects of an acute protein administration by gavage}

\subsubsection{Changes in plasma amino acids after administration of a low dose of ${ }^{15} \mathrm{~N}$ - labeled protein}

After $12 \mathrm{~h}$ fasting, a ${ }^{15} \mathrm{~N}$-labeled yeast protein $(8.83 \mathrm{mg})$ was given to $P e p t 1^{+/+}$and Pept $1^{-1}$ animals by gavage. To assess time-dependent changes in amino acid absorption blood samples were collected at 15 and $30 \mathrm{~min}$ from portal vein and heart. 19 amino acids could be quantified (Table 25), however no differences were observed in blood samples from heart in any of the measured amino acids.

Table 25: Amino acid concentrations of samples from heart and portal vein 15 and 30 minutes after administration of ${ }^{15} \mathrm{~N}$-labeled protein

\begin{tabular}{|c|c|c|c|c|c|c|c|c|}
\hline \multirow{3}{*}{$\begin{array}{l}\text { Amino acid } \\
(\mu \mathrm{mol} / \mathrm{l})\end{array}$} & \multicolumn{4}{|c|}{15 minutes } & \multicolumn{4}{|c|}{30 minutes } \\
\hline & \multicolumn{2}{|c|}{ heart } & \multicolumn{2}{|c|}{ portal vein } & \multicolumn{2}{|c|}{ heart } & \multicolumn{2}{|c|}{ portal vein } \\
\hline & Pept1 $^{+/+}$ & Pept1 $^{-/-}$ & Pept $^{+/+}$ & Pept1 $^{-/-}$ & Pept1 $^{+/+}$ & Pept1 $^{-/-}$ & Pept $^{+/+}$ & Pept1 ${ }^{-/-}$ \\
\hline Alanine & $39.94 \pm 9.25$ & $53.33 \pm 38.32$ & $73.58 \pm 17.56$ & $68.65 \pm 28.26$ & $46.43 \pm 17.40$ & $44.09 \pm 16.24$ & $61.61 \pm 10.27$ & $62.45 \pm 11.41$ \\
\hline Arginine & $4.79 \pm 1.25$ & $7.72 \pm 2.83$ & $2.07 \pm 1.05$ & $4.18 \pm 4.52$ & $3.64 \pm 1.45$ & $4.61 \pm 0.69$ & $1.21 \pm 0.64$ & $1.70 \pm 0.42$ \\
\hline Asparagine & $6.69 \pm 0.70$ & $8.60 \pm 6.80$ & $4.73 \pm 0.76$ & $6.47 \pm 7.37$ & $8.05 \pm 2.79$ & $7.73 \pm 1.83$ & $5.50 \pm 0.48$ & $5.03 \pm 0.61$ \\
\hline Aspartate & $1.03 \pm 0.49$ & $0.62 \pm 0.48$ & $1.20 \pm 0.60$ & $1.43 \pm 0.49$ & $1.18 \pm 0.40$ & $1.64 \pm 0.61$ & $1.84 \pm 0.86$ & $1.64 \pm 0.60$ \\
\hline Citrulline & $2.29 \pm 0.44$ & $2.31 \pm 0.43$ & $3.63 \pm 0.90$ & $2.78 \pm 0.33$ & $2.04 \pm 0.40$ & $2.64 \pm 0.47$ & $2.35 \pm 0.83$ & $2.91 \pm 0.71$ \\
\hline Cysteine & $9.33 \pm 2.40$ & $8.65 \pm 1.83$ & $8.19 \pm 3.01$ & $7.55 \pm 2.70$ & $7.17 \pm 4.25$ & $6.97 \pm 4.18$ & $6.95 \pm 2.27$ & $9.48 \pm 2.09$ \\
\hline Glutamate & $3.84 \pm 1.31$ & $4.34 \pm 1.94$ & $20.74 \pm 7.50$ & $15.70 \pm 6.24$ & $5.14 \pm 0.64$ & $5.87 \pm 1.16$ & $21.71 \pm 4.02$ & $17.86 \pm 4.94$ \\
\hline Glutamine & $11.49 \pm 0.93$ & $13.55 \pm 3.80$ & $18.80 \pm 5.71$ & $16.29 \pm 3.49$ & $18.58 \pm 1.45$ & $17.35 \pm 2.91$ & $26.42 \pm 6.04$ & $26.56 \pm 6.75$ \\
\hline Glycine & $20.16 \pm 1.57$ & $20.90 \pm 8.53$ & $13.60 \pm 1.66$ & $14.46 \pm 8.59$ & $25.45 \pm 6.17$ & $21.01 \pm 4.56$ & $18.89 \pm 2.76$ & $16.89 \pm 7.68$ \\
\hline Isoleucine & $16.46 \pm 1.72$ & $19.16 \pm 3.06$ & $36.58 \pm 3.79^{d}$ & $29.78 \pm 4.16^{d}$ & $18.28 \pm 2.39$ & $18.31 \pm 5.22$ & $30.21 \pm 2.85$ & $33.58 \pm 6.37$ \\
\hline Leucine & $33.43 \pm 4.02$ & $43.11 \pm 11.10$ & $72.99 \pm 9.36$ & $69.67 \pm 12.42$ & $38.78 \pm 4.38$ & $39.80 \pm 8.42$ & $68.70 \pm 7.45$ & $70.94 \pm 8.18$ \\
\hline Lysine & $35.30 \pm 9.12$ & $36.92 \pm 11.24$ & $32.68 \pm 9.57$ & $40.14 \pm 6.46$ & $34.28 \pm 8.32$ & $39.62 \pm 7.20$ & $33.87 \pm 3.61$ & $38.22 \pm 7.79$ \\
\hline Methionine & $7.35 \pm 0.58$ & $7.51 \pm 1.87$ & $4.21 \pm 1.09$ & $5.09 \pm 2.68$ & $6.53 \pm 0.65$ & $8.27 \pm 1.60$ & $4.05 \pm 1.00$ & $3.43 \pm 0.68$ \\
\hline Phenylalanine & $18.48 \pm 1.95$ & $22.59 \pm 4.33$ & $38.84 \pm 6.02$ & $35.39 \pm 2.50$ & $21.48 \pm 2.93$ & $22.71 \pm 3.79$ & $32.82 \pm 3.88$ & $36.92 \pm 2.50$ \\
\hline Proline & $18.60 \pm 2.59$ & $15.06 \pm 2.82$ & $18.08 \pm 3.70$ & $14.08 \pm 3.78$ & $15.83 \pm 3.21$ & $14.52 \pm 3.45$ & $12.15 \pm 3.50$ & $11.17 \pm 1.73$ \\
\hline Serine & $12.90 \pm 1.66$ & $16.61 \pm 7.57$ & $8.49 \pm 2.01$ & $11.67 \pm 7.78$ & $17.21 \pm 5.44$ & $14.81 \pm 3.28$ & $9.21 \pm 3.01$ & $8.51 \pm 1.99$ \\
\hline Threonine & $24.18 \pm 2.48$ & $23.43 \pm 1.29$ & $23.60 \pm 3.64$ & $21.63 \pm 4.30$ & $29.97 \pm 5.89$ & $29.14 \pm 5.00$ & $21.89 \pm 6.99$ & $24.75 \pm 3.82$ \\
\hline Tyrosine & $23.95 \pm 2.99$ & $27.79 \pm 5.50$ & $40.89 \pm 8.25$ & $35.61 \pm 6.53$ & $22.91 \pm 3.01$ & $25.12 \pm 3.19$ & $27.28 \pm 3.83$ & $30.73 \pm 4.01$ \\
\hline Valine & $59.41 \pm 6.51$ & $71.11 \pm 16.09$ & $92.11 \pm 10.48$ & $88.95 \pm 15.60$ & $68.76 \pm 6.18$ & $72.67 \pm 15.36$ & $87.93 \pm 7.46$ & $97.62 \pm 17.94$ \\
\hline
\end{tabular}

All data are presented as mean \pm SD. $\mathrm{N}=10$ male animals per genotype and group were studied. Timepoints were analyzed separately. P-value obtained by unpaired Student's t-test when comparing between genotypes.

${ }^{b} P<0.05$ obtained when comparing between genotypes after 15 minutes in heart.

${ }^{c} P<0.05$ obtained when comparing between genotypes after 15 minutes in portal vein.

${ }^{d} P<0.05$ obtained when comparing between genotypes after 30 minutes in heart.

${ }^{e} P<0.05$ obtained when comparing between genotypes after 30 minutes in portal vein.

Isoleucine levels were significantly higher in Pept $1^{+/+}$compared to Pept $1^{-/}$animals after 15 min only in the portal vein, but this difference disappeared after 30 min (Fig. 30). No other amino acid showed differences in plasma appearance when compared 
between genotypes. A total of 10 amino acids (isoleucine, leucine, valine, glutamic acid, tyrosine, phenylalanine, alanine, citrulline, glutamine, tryptophane) showed higher portal blood concentrations than in blood collected from heart, but independently of genotype.
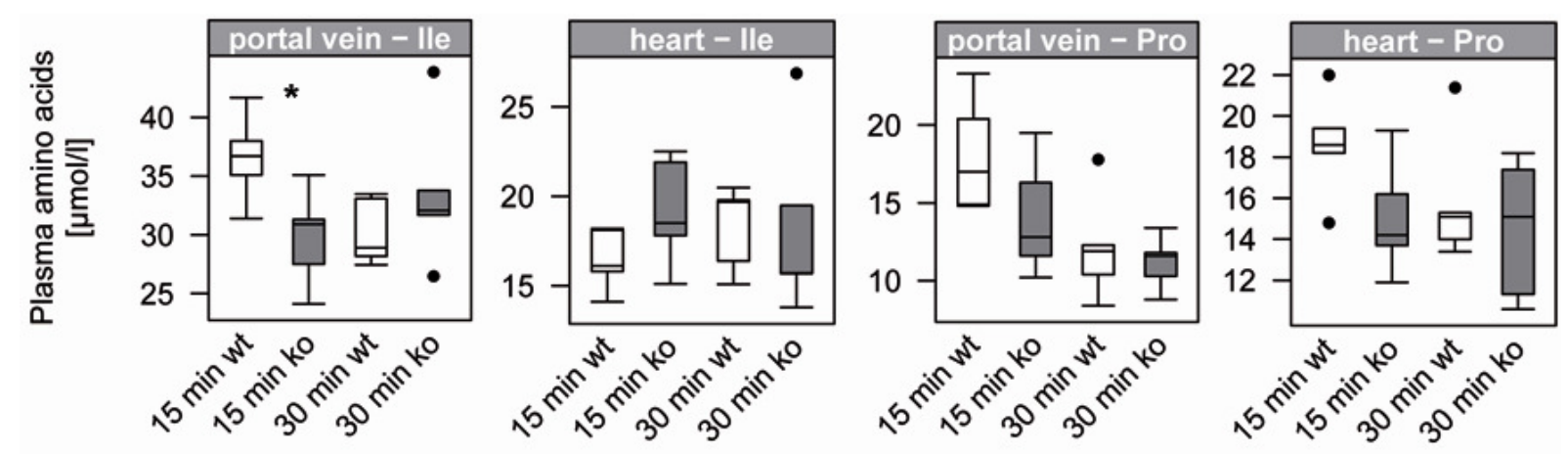

Fig. 30: Amino acid concentrations of isoleucine and proline in plasma of portal vein and heart after administration of ${ }^{15} \mathrm{~N}$-labeled protein by gavage

Analysis of amino acids from plasma of portal vein and heart 15 and $30 \mathrm{~min}$ after administration of ${ }^{15} \mathrm{~N}$-labeled protein in $12 \mathrm{~h}$ fasted wild-type (wt) and Pept1 knockout (ko) animals ( $\mathrm{n}=5$ male animals per timepoint and genotype). $\left({ }^{*}<0.05, \S<0.01\right.$, $\$<0.001)$.

A comparison of the concentrations of ${ }^{14} \mathrm{~N}$ and ${ }^{15} \mathrm{~N}$ labeled amino acids did also not reveal major alterations. For ${ }^{14} \mathrm{~N}$-labeled amino acids differences between genotypes were only detectable for lysine after $15 \mathrm{~min}$ (ko: $294.8 \pm 22.1 \mu \mathrm{mol} / \mathrm{l} \mathrm{vs}$. wt: $197.6 \pm 42.2$ $\mu \mathrm{mol} / \mathrm{l}, P=0.002$ ) and arginine after $30 \mathrm{~min}$ (ko: $36.6 \pm 4.1 \mu \mathrm{mol} / \mathrm{l} \mathrm{vs}$. wt: $25.1 \pm 7.6$ $\mu \mathrm{mol} / \mathrm{l}, P=0.02)$. For ${ }^{15} \mathrm{~N}$-labeled amino acids in portal blood, as mentionend above, only isoleucine showed slightly reduced concentrations with a genotype-specific effect at $15 \mathrm{~min}$ (ko: $29.8 \pm 4.2 \mu \mathrm{mol} / \mathrm{l}$ vs. wt: $36.6 \pm 3.8 \mu \mathrm{mol} / \mathrm{l}, P=0.03$ ) but none of the other amino acids. Taken together, neither levels of ${ }^{14} \mathrm{~N}$ nor ${ }^{15} \mathrm{~N}$-labeled amino acids determined in portal blood of $\mathrm{Pept}^{+/+}$and Pept1\% mice revealed remarkable differences (Fig. 31). 

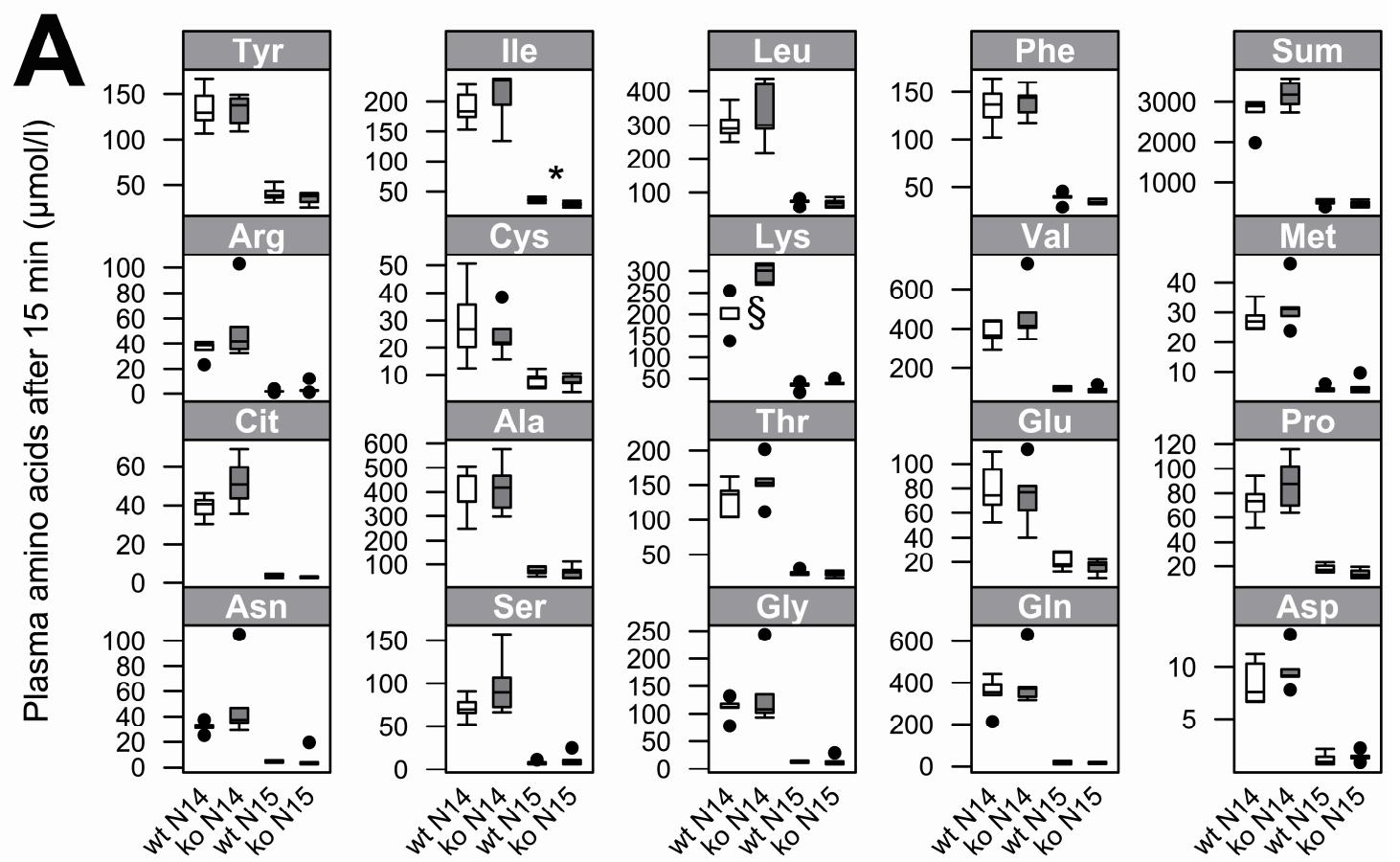

B
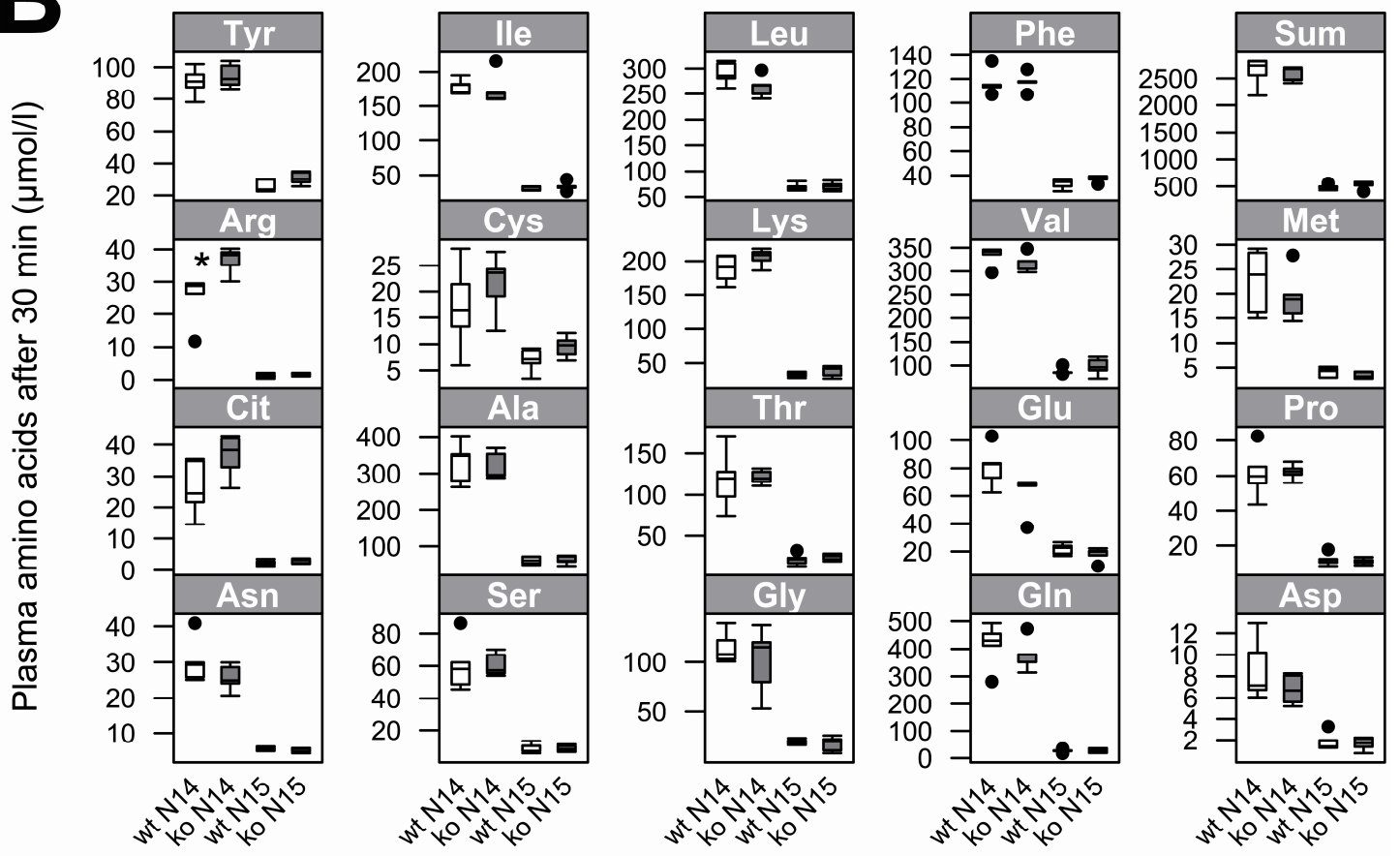

Fig. 31: Amino acid appearance in plasma after administration of a low dose of ${ }^{15} \mathrm{~N}$-labeled protein

Analysis of ${ }^{14} \mathrm{~N}$ and ${ }^{15} \mathrm{~N}$ labeled amino acids from plasma of portal vein $15(\mathrm{~A})$ and $30 \mathrm{~min}(\mathrm{~B})$ after administration of $15 \mathrm{~N}$-labeled protein $\left(8.83 \mathrm{mg}\right.$ ) by gavage in $12 \mathrm{~h}$-fasted $\operatorname{Pept}^{1_{++}}(\mathrm{wt})$ and Pept $1^{-/-}(\mathrm{ko})$ animals $(\mathrm{n}=5$ male animals per timepoint and genotype). (•) indicate outlier. Data are presented as mean \pm SD. $\quad\left({ }^{*}<0.05, \S<0.01, \$<0.001\right)$. 
Administration of the ${ }^{15} \mathrm{~N}$-labeled protein allowed also to assess the prime site of absorption in the intestine. 21 labeled amino acids could be quantified in tissue samples of duodenum (DD), jejeunum (JJ) and ileum (IL) by LC-MS/MS analysis. After 30 minutes levels of almost all amino acids - except for cysteine - were highest in $J J$ as compared to DD and IL segments $(p<0.001)$, but no differences between genotypes could be detected. Concentrations of proline, arginine, isoleucine and cysteine in the different tissue segments are shown exemplary in Fig. 32.

Table 26: Amino acid concentrations in intestinal tissue samples from JJ, DD and IL after gavage with ${ }^{15} \mathrm{~N}$ labeled protein

\begin{tabular}{|c|c|c|c|}
\hline Amino acid $(\mu \mathrm{mol} / \mathrm{l})$ & DD & JJ & IL \\
\hline Alanine & $22.67 \pm 5.94^{\mathrm{c}}$ & $60.13 \pm 17.61^{c, d}$ & $17.32 \pm 7.57^{d}$ \\
\hline Arginine & $0.85 \pm 0.52^{c}$ & $4.69 \pm 2.15^{c, d}$ & $0.89 \pm 0.69^{d}$ \\
\hline Asparagine & $4.15 \pm 1.68^{\mathrm{c}}$ & $18.72 \pm 7.74^{c, d}$ & $4.02 \pm 3.36^{d}$ \\
\hline Aspartate & $3.54 \pm 1.86^{\mathrm{C}}$ & $12.87 \pm 5.40^{c, d}$ & $7.07 \pm 4.73^{d}$ \\
\hline Citrulline & $0.20 \pm 0.08^{c}$ & $0.40 \pm 0.14^{c}$ & NA \\
\hline Cysteine & $1.29 \pm 0.81$ & $1.07 \pm 0.30$ & $1.45 \pm 0.82$ \\
\hline Glutamate & $26.01 \pm 5.97^{\mathrm{c}}$ & $60.44 \pm 16.12^{\mathrm{c}, d}$ & $34.25 \pm 10.69^{d}$ \\
\hline Glutamine & $1.95 \pm 1.16^{\mathrm{C}}$ & $8.39 \pm 3.98^{c, d}$ & $2.37 \pm 1.22^{d}$ \\
\hline Glycine & $14.61 \pm 4.54^{\mathrm{C}}$ & $38.07 \pm 11.85^{c, d}$ & $15.05 \pm 7.19^{d}$ \\
\hline Histidine & $1.43 \pm 0.46^{c}$ & $4.47 \pm 1.69^{c, d}$ & $1.59 \pm 0.75^{d}$ \\
\hline Isoleucine & $4.06 \pm 1.68^{\mathrm{C}}$ & $18.56 \pm 8.06^{\mathrm{c}, \mathrm{d}}$ & $4.11 \pm 2.44^{d}$ \\
\hline Leucine & $9.54 \pm 4.07^{\mathrm{C}}$ & $38.89 \pm 16.93^{c, d}$ & $9.77 \pm 5.67^{d}$ \\
\hline Lysine & $4.46 \pm 1.89^{c}$ & $20.32 \pm 8.23^{c, d}$ & $4.89 \pm 3.17^{d}$ \\
\hline Methionine & $8.30 \pm 3.89^{c}$ & $32.48 \pm 13.24^{\mathrm{c}, d}$ & $2.52 \pm 1.39^{d}$ \\
\hline Phenylalanine & $4.79 \pm 2.21^{\mathrm{c}}$ & $18.13 \pm 8.16^{c, d}$ & $5.82 \pm 3.17^{d}$ \\
\hline Proline & $5.40 \pm 1.67^{c}$ & $18.71 \pm 6.91^{c, d}$ & $5.07 \pm 2.59^{d}$ \\
\hline Serine & $6.95 \pm 3.12^{c}$ & $27.81 \pm 11.97^{c, d}$ & $7.64 \pm 4.68^{d}$ \\
\hline Threonine & $5.93 \pm 2.22^{c}$ & $22.68 \pm 9.28^{c, d}$ & $6.94 \pm 3.47^{d}$ \\
\hline Tryptophane & $0.47 \pm 0.20^{c}$ & $1.98 \pm 0.88^{c, d}$ & $0.63 \pm 0.33^{d}$ \\
\hline Tyrosine & $4.21 \pm 1.81^{\mathrm{C}}$ & $14.60 \pm 6.19^{c, d}$ & $4.82 \pm 2.48^{d}$ \\
\hline Valine & $9.91 \pm 3.57^{c}$ & $39.51 \pm 16.00^{c, d}$ & $10.79 \pm 5.88^{d}$ \\
\hline Sum & $139.43 \pm 45.14^{c}$ & $461.87 \pm 167.16^{c, d}$ & $145.56 \pm 63.41^{d}$ \\
\hline
\end{tabular}

All data are presented as mean $\pm S D$. $N=10$ male animals per genotype and group were studied. P-value obtained by one-factor ANOVA analysis and post-hoc analysis (Tukey) when comparing between groups.

${ }^{\text {c, } d} P<0.05$ obtained by post-hoc analysis (Tukey) when comparing between groups. 

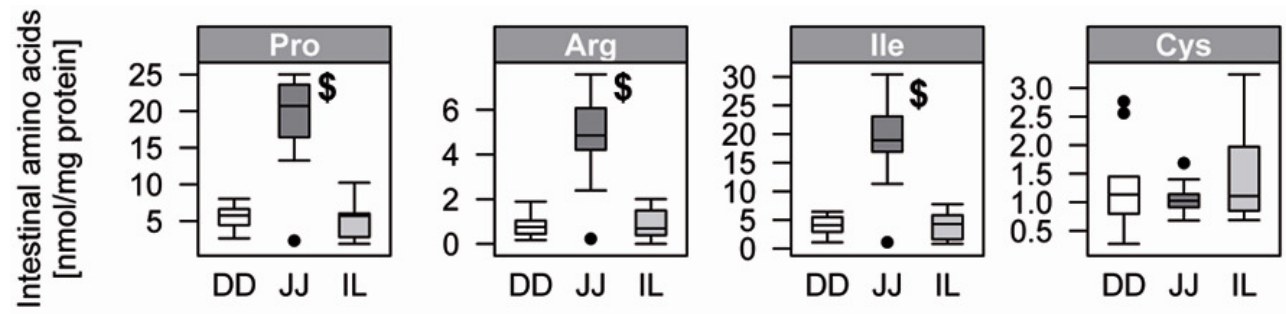

Fig. 32: Intestinal tissue amino acid levels after administration of ${ }^{15} \mathrm{~N}$-labeled protein

Amino acid analysis in tissue samples of duodenum, jejunum and ileum $(n=10)$ collected 30 min after administration of ${ }^{15} \mathrm{~N}$-labeled protein. ${ }^{*} \mathrm{p}<0.05, \S p<0.01, \$ p<0.001$.

\subsubsection{Effects of a high intragastric protein load on plasma and liver amino acid levels in Pept ${ }^{+/+}$and Pept1 ${ }^{-/-}$animals}

After intragastric administration of a high protein load $(178 \mathrm{mg})$ blood samples were collected at 10, 30 and 60 min and 35 amino acids and derivatives were quantified in plasma by LC-MS/MS (Table 27). Already at $10 \mathrm{~min}$ the Pept $1^{+/+}$animals showed an increased concentration in the sum of all 35 plasma amino acids detected, when compared to Pept $1^{-/}$mice. This was mainly due to increased glutamine, taurine and glycine levels with the latter two consistently showing significantly increased levels throughout the experiment. At 30 min after protein administration 5 other amino acids displayed significantly altered levels including the branched chain amino acids valine and isoleucine as well as threonine, proline and phosphoetanolamine. At $60 \mathrm{~min}$ a total of 15 amino acids and derivatives displayed significantly higher plasma concentrations in Pept $1^{+/+}$as compared to Pept $1^{-/-}$animals. Amongst them were, in addition to valine and isoleucine, aminobutyric acid, glutamate and aspartate, their amides glutamine and asparagine as well as serine, threonine, alanine, aminoadipic acid and cystathione. From all amino acids, proline showed the largest concentration difference.

Table 27: Amino acid concentrations in plasma after intragastric administration of a high-protein load

\begin{tabular}{|c|c|c|c|c|c|c|}
\hline \multirow[t]{2}{*}{ Amino acid $(\mu \mathrm{mol} / \mathrm{l})$} & \multicolumn{2}{|c|}{10 minutes } & \multicolumn{2}{|c|}{30 minutes } & \multicolumn{2}{|c|}{60 minutes } \\
\hline & Pept $^{+/+}$ & Pept1 $^{-/-}$ & Pept1 $^{+/+}$ & Pept1 $^{-/-}$ & Pept1 $^{+/+}$ & Pept1 ${ }^{-/-}$ \\
\hline Alanine & $867.67 \pm 413.21$ & $644.83 \pm 85.45$ & $854.33 \pm 279.28$ & $825.17 \pm 283.35$ & $1169.50 \pm 293.33^{d}$ & $809.00 \pm 131.59^{d}$ \\
\hline $\begin{array}{l}\text { Alpha-aminoadipic } \\
\text { acid }\end{array}$ & $6.79 \pm 1.45$ & $6.38 \pm 2.28$ & $12.79 \pm 4.90$ & $13.57 \pm 5.09$ & $58.98 \pm 21.97^{d}$ & $27.50 \pm 12.40^{d}$ \\
\hline Anserine & $2.99 \pm 1.12$ & $2.43 \pm 1.03$ & $1.94 \pm 0.42$ & $1.82 \pm 0.46$ & $2.53 \pm 0.83$ & $1.86 \pm 0.77$ \\
\hline Arginine & $205.17 \pm 44.36$ & $242.67 \pm 53.94$ & $263.83 \pm 75.67$ & $348.50 \pm 78.87$ & $208.17 \pm 48.33$ & $256.33 \pm 86.81$ \\
\hline Asparagine & $128.62 \pm 101.55$ & $71.63 \pm 14.25$ & $152.72 \pm 71.34$ & $110.52 \pm 51.51$ & $187.67 \pm 60.74^{d}$ & $114.83 \pm 39.59^{d}$ \\
\hline
\end{tabular}




\begin{tabular}{|c|c|c|c|c|c|c|}
\hline \multirow[t]{2}{*}{ Amino acid $(\mu \mathrm{mol} / \mathrm{l})$} & \multicolumn{2}{|c|}{10 minutes } & \multicolumn{2}{|c|}{30 minutes } & \multicolumn{2}{|c|}{60 minutes } \\
\hline & Pept $1^{+/+}$ & Pept1 ${ }^{-/-}$ & Pept1 $^{+/+}$ & Pept1 ${ }^{-/}$ & Pept1 ${ }^{+/+}$ & Pept1 ${ }^{-/-}$ \\
\hline Aspartate & $22.43 \pm 19.09$ & $14.32 \pm 7.25$ & $29.00 \pm 16.66$ & $17.32 \pm 13.00$ & $75.83 \pm 37.00^{d}$ & $19.79 \pm 10.13^{d}$ \\
\hline Beta-alanine & $17.65 \pm 0.97$ & $17.30 \pm 1.21$ & $16.35 \pm 0.97$ & $16.22 \pm 1.39$ & $16.85 \pm 2.33$ & $15.83 \pm 2.55$ \\
\hline Carnosine & $1.86 \pm 0.89$ & $1.54 \pm 0.59$ & $1.47 \pm 0.40$ & $1.47 \pm 0.20$ & $1.77 \pm 0.92$ & $1.28 \pm 0.51$ \\
\hline Citrulline & $78.33 \pm 8.79$ & $79.05 \pm 14.05$ & $100.80 \pm 16.19$ & $112.55 \pm 13.49$ & $114.15 \pm 15.45$ & $112.17 \pm 23.84$ \\
\hline Cystathionase & $5.73 \pm 1.59$ & $4.33 \pm 1.78$ & $6.53 \pm 2.95$ & $4.50 \pm 1.55$ & $10.60 \pm 4.77^{d}$ & $4.53 \pm 1.62^{d}$ \\
\hline Cysteine & $88.98 \pm 18.99$ & $92.33 \pm 17.45$ & $108.98 \pm 28.93$ & $102.25 \pm 14.42$ & $101.03 \pm 15.20$ & $97.32 \pm 28.71$ \\
\hline Ethanolamine & $17.45 \pm 4.84$ & $13.07 \pm 1.95$ & $14.10 \pm 1.48$ & $14.90 \pm 4.17$ & $14.49 \pm 2.77^{d}$ & $10.43 \pm 1.42^{d}$ \\
\hline Glutamate & $82.02 \pm 59.40$ & $53.78 \pm 21.68$ & $95.43 \pm 38.47$ & $60.43 \pm 34.95$ & $246.33 \pm 110.35^{d}$ & $63.55 \pm 30.83^{d}$ \\
\hline Glutamine & $1114.17 \pm 197.24^{\mathrm{b}}$ & $817.33 \pm 140.75^{b}$ & $1048.00 \pm 105.61$ & $937.83 \pm 258.11$ & $1167.50 \pm 191.93^{d}$ & $873.33 \pm 220.09^{d}$ \\
\hline Glycine & $340.83 \pm 74.15^{b}$ & $250.33 \pm 40.35^{\mathrm{b}}$ & $305.00 \pm 67.07^{c}$ & $204.33 \pm 61.19^{c}$ & $365.17 \pm 54.27^{d}$ & $222.83 \pm 27.60^{d}$ \\
\hline Histidine & $133.48 \pm 46.73$ & $95.53 \pm 8.98$ & $123.67 \pm 15.17$ & $113.43 \pm 37.27$ & $127.17 \pm 19.47$ & $117.85 \pm 21.01$ \\
\hline Hydroxyproline & $17.48 \pm 2.32$ & $17.48 \pm 4.03$ & $18.75 \pm 4.13$ & $14.98 \pm 3.90$ & $18.17 \pm 4.79$ & $15.79 \pm 4.46$ \\
\hline Isoleucine & $298.17 \pm 110.21$ & $230.17 \pm 32.34$ & $589.50 \pm 163.23^{c}$ & $408.67 \pm 56.32^{c}$ & $555.17 \pm 164.08^{d}$ & $343.33 \pm 65.63^{d}$ \\
\hline Leucine & $514.50 \pm 181.42$ & $408.67 \pm 86.02$ & $961.33 \pm 242.22$ & $846.67 \pm 150.33$ & $832.33 \pm 310.13$ & $636.17 \pm 137.21$ \\
\hline Lysine & $587.17 \pm 223.58$ & $528.50 \pm 99.13$ & $1045.83 \pm 343.62$ & $\begin{array}{c}1162.83 \pm \\
184.75\end{array}$ & $964.33 \pm 236.88$ & $876.83 \pm 179.28$ \\
\hline Methionine & $101.25 \pm 26.66$ & $96.03 \pm 27.97$ & $173.17 \pm 59.64$ & $139.50 \pm 23.28$ & $135.43 \pm 29.94$ & $130.00 \pm 15.92$ \\
\hline Ornithine & $125.75 \pm 56.75$ & $118.25 \pm 24.91$ & $206.67 \pm 65.69$ & $219.67 \pm 59.71$ & $171.32 \pm 40.72$ & $138.05 \pm 40.69$ \\
\hline Phenylalanine & $191.33 \pm 75.42$ & $152.33 \pm 8.57$ & $176.17 \pm 35.47$ & $235.33 \pm 83.16$ & $156.50 \pm 33.73$ & $144.33 \pm 39.91$ \\
\hline Phosphoethanolamine & $10.64 \pm 1.98$ & $8.53 \pm 2.74$ & $10.94 \pm 1.12^{c}$ & $8.27 \pm 2.22^{c}$ & $14.04 \pm 5.55$ & $9.02 \pm 3.45$ \\
\hline Proline & $224.67 \pm 136.15$ & $155.50 \pm 20.25$ & $316.17 \pm 97.06^{c}$ & $112.70 \pm 34.21^{c}$ & $430.17 \pm 86.78^{d}$ & $105.67 \pm 15.43^{d}$ \\
\hline Sarcosine & $2.25 \pm 0.67$ & $2.27 \pm 0.68$ & $4.19 \pm 1.39$ & $2.93 \pm 0.93$ & $5.12 \pm 2.47$ & $3.43 \pm 1.23$ \\
\hline Serine & $274.67 \pm 161.67$ & $182.00 \pm 19.08$ & $291.17 \pm 107.47$ & $246.83 \pm 93.36$ & $325.00 \pm 83.93^{d}$ & $223.83 \pm 52.93^{d}$ \\
\hline Taurine & $735.33 \pm 116.96^{\mathrm{b}}$ & $547.67 \pm 100.56^{b}$ & $760.33 \pm 126.11^{\mathrm{c}}$ & $480.83 \pm 149.33^{c}$ & $1209.83 \pm 448.07^{d}$ & $600.17 \pm 281.40^{d}$ \\
\hline Threonine & $295.67 \pm 85.05$ & $224.17 \pm 30.27$ & $508.00 \pm 161.98^{c}$ & $268.67 \pm 52.88^{c}$ & $567.67 \pm 130.12^{d}$ & $293.83 \pm 45.50^{d}$ \\
\hline Tryptophane & $116.73 \pm 29.48$ & $103.53 \pm 17.75$ & $148.83 \pm 30.37$ & $145.35 \pm 29.19$ & $121.35 \pm 25.29$ & $120.73 \pm 26.79$ \\
\hline Tyrosine & $230.17 \pm 85.71$ & $215.17 \pm 59.18$ & $414.17 \pm 149.18$ & $360.50 \pm 98.48$ & $286.67 \pm 74.34$ & $211.00 \pm 66.34$ \\
\hline Valine & $620.50 \pm 161.33$ & $488.00 \pm 66.22$ & $1038.33 \pm 231.16^{c}$ & $739.00 \pm 76.46^{c}$ & $1192.33 \pm 367.09^{d}$ & $727.00 \pm 121.91^{d}$ \\
\hline 1-M-Histidine & $2.47 \pm 0.87$ & $2.66 \pm 0.73$ & $3.53 \pm 0.70$ & $2.58 \pm 0.84$ & $2.30 \pm 0.41$ & $2.63 \pm 0.79$ \\
\hline 3-M-Histidine & $4.92 \pm 1.43$ & $5.55 \pm 1.88$ & $5.34 \pm 0.86$ & $4.24 \pm 1.52$ & $3.84 \pm 0.77$ & $3.80 \pm 1.23$ \\
\hline 2-Aminobutyric acid & $5.59 \pm 1.40$ & $6.28 \pm 1.78$ & $10.36 \pm 2.87$ & $7.70 \pm 0.94$ & $21.67 \pm 6.96^{d}$ & $10.04 \pm 1.22^{d}$ \\
\hline Sum & $\begin{array}{l}7473.41 \pm \\
2188.69\end{array}$ & $\begin{array}{c}5899.61 \pm \\
469.02\end{array}$ & $\begin{array}{l}9817.72 \pm \\
2391.15\end{array}$ & $\begin{array}{c}8292.06 \pm \\
892.21\end{array}$ & $\begin{array}{c}10880.97 \pm \\
1404.39\end{array}$ & $\begin{array}{c}7344.08 \pm \\
940.72\end{array}$ \\
\hline
\end{tabular}

All data are presented as mean \pm SD. $\mathrm{N}=4-10$ male animals per genotype and group were studied. Timepoints were analyzed separately. P-value obtained by unpaired Student's t-test when comparing between genotypes.

${ }^{b} P<0.05$ obtained when comparing between genotypes after 10 minutes.

${ }^{c} P<0.05$ obtained when comparing between genotypes after 30 minutes.

${ }^{d} P<0.05$ obtained when comparing between genotypes after 60 minutes.

Measurements of enzyme activities and urea concentrations in liver tissue $60 \mathrm{~min}$ after gavage did not reveal major differences between $P_{e p t 1^{+/+}}$and $P e p t 1^{-1-}$ animals (Table 28). 
Table 28: Enzyme activities in liver tissue 60 minutes after a high-protein load by gavage

\begin{tabular}{lccc}
\hline Parameter & Pept $^{+/+}$ & Pept $^{-\boldsymbol{I}^{-}}$ & P-value \\
\hline GDH $[\mathrm{mU} / \mathrm{mg}]$ & $784.18 \pm 92.63$ & $751.10 \pm 40.83$ & 0.480 \\
AST $[\mathrm{mU} / \mathrm{mg}]$ & $1785.52 \pm 410.97$ & $1679.38 \pm 308.84$ & 0.646 \\
ALT $[\mathrm{mU} / \mathrm{mg}]$ & $743.41 \pm 68.11$ & $719.27 \pm 62.22$ & 0.558 \\
Urea $[\boldsymbol{\mu m o l} / \mathrm{mg}]$ & $21.31 \pm 5.44$ & $17.81 \pm 2.39$ & 0.218 \\
Arginase[U/mg protein] & $391.21 \pm 87.78$ & $441.00 \pm 91.83$ & 0.383 \\
\hline
\end{tabular}

All data are presented as mean $\pm S D$. $N=6$ male animals per genotype were studied. P-value obtained by unpaired Student's ttest between genotypes.

However, independent of genotype urea levels increased $(19.7 \pm 3.8 \mu \mathrm{mol} / \mathrm{mg}$ vs. $15.3 \pm 4.5 \mu \mathrm{mol} / \mathrm{mg}, \mathrm{p}=0.02$ ) after the protein load when compared to basal levels whereas AST activities decreased (1737.3 $\pm 354.5 \mathrm{mU} / \mathrm{mg}$ vs. $2262.3 \pm 421.8 \mathrm{mU} / \mathrm{mg}$, $\mathrm{p}=0.004)$.

When assessed 60 min after protein administration, amino acid levels in liver tissues increased significantly for 12 amino acids (Table 29) with proline showing the most prominent change in wild-type animals when compared to knockout animals. Decreased levels in Pept $1^{-/}$compared to Pept $1^{+/+}$animals were also observed for the sum of all measured amino acids and derivatives.

Table 29: Liver amino acids 60 minutes after intragastric administration of a high-protein load

\begin{tabular}{|c|c|c|c|}
\hline Amino acid (nmol/mg protein) & Pept $^{+/+}$ & Pept1 ${ }^{-/}$ & $P$-value \\
\hline Alanine & $133.85 \pm 20.39$ & $98.39 \pm 24.64$ & 0.022 \\
\hline Alpha-aminoadipic acid & $35.40 \pm 11.98$ & $24.39 \pm 8.30$ & 0.094 \\
\hline Alpha-aminoisobutyric acid & $0.36 \pm 0.09$ & $0.21 \pm 0.04$ & 0.005 \\
\hline Asparagine & $3.28 \pm 0.69$ & $2.59 \pm 0.46$ & 0.070 \\
\hline Aspartate & $10.71 \pm 1.74$ & $6.98 \pm 1.45$ & 0.002 \\
\hline Citrulline & $3.11 \pm 1.02$ & $3.37 \pm 0.80$ & 0.642 \\
\hline Cystathionase & $2.12 \pm 1.14$ & $1.33 \pm 0.70$ & 0.177 \\
\hline Ethanolamine & $0.48 \pm 0.04$ & $0.48 \pm 0.03$ & 0.797 \\
\hline Gamma-aminobutyric acid & $0.60 \pm 0.10$ & $0.49 \pm 0.09$ & 0.070 \\
\hline Glutamate & $56.89 \pm 12.30$ & $33.69 \pm 14.98$ & 0.015 \\
\hline Glutamine & $65.06 \pm 15.39$ & $40.99 \pm 8.21$ & 0.007 \\
\hline Glycine & $37.60 \pm 7.16$ & $25.40 \pm 6.72$ & 0.012 \\
\hline Histidine & $9.61 \pm 2.03$ & $9.13 \pm 1.61$ & 0.657 \\
\hline Hydroxyproline & $0.60 \pm 0.12$ & $0.54 \pm 0.11$ & 0.422 \\
\hline Isoleucine & $10.91 \pm 3.61$ & $6.33 \pm 1.33$ & 0.015 \\
\hline Leucine & $17.50 \pm 6.86$ & $12.55 \pm 3.29$ & 0.142 \\
\hline Lysine & $33.92 \pm 11.67$ & $24.30 \pm 5.98$ & 0.102 \\
\hline Methionine & $1.27 \pm 0.54$ & $0.73 \pm 0.26$ & 0.053 \\
\hline Ornithine & $14.75 \pm 6.50$ & $8.32 \pm 2.58$ & 0.048 \\
\hline
\end{tabular}




\begin{tabular}{lccc} 
Phenylalanine & $3.37 \pm 1.12$ & $2.48 \pm 0.69$ & 0.129 \\
Phosphoethanolamine & $4.95 \pm 0.65$ & $4.88 \pm 0.97$ & 0.878 \\
Proline & $14.75 \pm 4.53$ & $4.20 \pm 0.70$ & $<0.001$ \\
Sarcosine & $2.28 \pm 0.79$ & $2.85 \pm 0.73$ & 0.228 \\
Serine & $6.71 \pm 2.99$ & $4.41 \pm 1.47$ & 0.121 \\
Taurine & $203.61 \pm 16.98$ & $196.38 \pm 25.96$ & 0.581 \\
Threonine & $9.83 \pm 4.26$ & $6.02 \pm 1.82$ & 0.072 \\
Tryptophane & $1.01 \pm 0.27$ & $0.76 \pm 0.14$ & 0.073 \\
Tyrosine & $5.11 \pm 1.33$ & $3.53 \pm 0.99$ & 0.042 \\
Valine & $25.08 \pm 8.54$ & $13.98 \pm 2.67$ & 0.012 \\
2-Aminobutyric acid & $4.03 \pm 1.68$ & $1.91 \pm 0.71$ & 0.018 \\
Sum & $718.77 \pm 84.55$ & $541.59 \pm 72.23$ & 0.003 \\
\hline
\end{tabular}

All data are presented as mean $\pm S D$. $N=6$ male animals per genotype were studied. $\mathrm{P}$-value obtained by unpaired Student's $\mathrm{t}$ test between genotypes $(\mathrm{P}<0.05)$. 



\section{Discussion}

The quantitative importance of peptide transport over that of transport of free amino acids has been a subject of controversial discussions after the initial discovery of peptide transport some 40 years ago. Controversy arose from the dogma that only monomers as final degradation products of luminal digestion could be absorbed from the intestine [4]. Early studies in humans on protein digestion revealed that the majority of amino acids in the lumen are found in form of di- and tripeptides [148]. Their uptake into tissues was finally demonstrated and studies in BBMV revealed that the transport process was proton-dependent [149]. After cloning of PEPT1 it was shown to represent a high capacity electrogenic system with the unique feature to transport numerous possible dietary di- and tripeptides. A malfunction of PEPT1 leading to reduced amino acid absorption would thus - when uptake of essential amino acids becomes limited - cause a retardation of growth and development. In BBMV and via heterologous expression of the cloned transporters, PEPT1 has been studied extensively [19] and numerous publications over the last 40 years have been presented. However, only little knowledge exists to which extent PEPT1 contributes to overall amino acid metabolism. To define this role of the transporter, a mouse model deficient of PEPT1 was employed [71], and the present work describes the phenotypic characterization of this mouse line.

\subsection{Basal phenotypic characterization}

Absorption of di- and tripeptides is mediated by the peptide transporter PEPT1 and this has been shown in many studies [150]. With the in vivo model of a PEPT1deficient mouse the physiological importance of PEPT1 and its function in epithelial assimilation of amino acid nitrogen and whole body amino acid metabolism can be studied.

Intestinal tissues of the upper small intestine show highest expression levels of Pept1 [57], and using real-time RT-PCR, expression levels of Pept1 on mRNA level in intestinal tissue of the Pept1 knockout mice were not detectable. Furthermore Western blot analysis revealed that PEPT1 was not detectable in mice lacking Pept1 [60]. These findings were also confirmed by $\mathrm{Hu}$ et al., which were able to show that Pept1 $^{-/}$mice lacked expression of PEPT1 protein in the intestine as well [71]. The 
PEPT1 protein is detected in the brush border membrane of intestinal enterocytes [58] but antibody-based immunofluorescence demonstrated the absence of the protein in Pept1 knockout animals [60]. Although the transporter can be found along the small intestine, little differences in expression levels exist between segments [57, 151]. In comparison to jejunum, duodenum and ileum display lower but almost same expression levels whereas in the ileum this expression may facilitate effective absorption along the small intestine [60].

As far as PEPT1 expression in kidney is concerned, there seems to exist a controversy and species differences. Shimakura et al. demonstrated PEPT1 in mice [70] and also $\mathrm{Hu}$ et al. detected PEPT1 in kidney tissue of wild-type animals [71]. Lu and Klaassen only found very low amounts of PEPT1 in kidney [57]. Due to the localization in the $S 1$ segment of the proximal tubule in rats [67] and its characteristics with high transport capacity and a low affinity PEPT1 has been proposed to mediate the reabsorption of bulk quantities of peptides in the more proximal parts, whereas PEPT2, which is located in the S2 and S3 segment, acts more distal taking care of remaining luminal substrates. Studies on mice lacking PEPT2 revealed that a remaining $30 \%$ in reabsorption of dipeptides may be attributed to PEPT1 $[72,73]$. However we were not able to detect PEPT1 expression in kidney [64]. Yet, we tested whether PEPT2 expression is altered in mice lacking PEPT1 but Western blot analysis revealed no changes in the PEPT2 protein in kidney tubules [64]. Further studies (e.g. with a double-knockout mouse line) may help to define the contribution of the two transporters to renal handling of peptides.

Studies using the model organism C.elegans revealed that a deletion of Pept1 resulted in a severe phenotype, characterized by retarded development, a reduced progeny and reduzed body size, as well as an increased stress tolerance, when compared to wild-type animals [146, 152]. Although amino acid transporters were shown to provide enough amino acids to sustain life they were not able to compensate the loss of PEPT1 [146]. Especially in times of a high amino acid demand, like during growth and development, the pivotal role of PEPT1 in worms becomes obvious. Shen et al., demonstrated in rats higher expression levels of PEPT1 in small intestine and colon shortly after birth [65], suggesting that a high growth rate may be better achieved with high PEPT1 levels in the intestine. 
However, contrary to these findings in worms, the transporter-deficient mouse line appears healthy and no alterations in body weight, development and fertility were observed. Nevertheless deletion of Pept1 markedly reduced the intestinal uptake of GlySar (by at least $80 \%$ ) and its oral absorption after gastric gavage (about 50\%) [71]. In our experiments we could reproduce these findings and furthermore demonstrate that heterozygous animals show an haploinsufficient phenotype. In comparison to wildtype animals uptake studies with everted gut sacs revealed $45 \%$ uptake activity in heterozygous animals, whereas Pept1 knockout animals had only $11 \%$ uptake activity left and this may be attributed to diffusion. These findings were also proven by Western blot analysis. Like Pept $1^{-/-}$animals, Pept $1^{+/-}$mice also did not display altered development, body weight or fertility [64].

Due to these findings, and keeping the severe phenotype of worms in mind, we asked whether there is a compensation with changes in amino acid transporter expression and/or increased transport functions in the intestine that compensates for the loss of PEPT1. Mucosal samples of small intestine were therefore submitted to microarray based profiling. But surprisingly this did not reveal any evidence for significant changes in mRNA levels of any of the amino acid transporters in PEPT1deficient compared to wildtype animals. In addition proteome analysis of mucosal tissue and uptake studies using the everted gut sac technique were performed. By proteome analysis of mucosal tissue samples only 6 proteins with significant changes could be identified but those can not be brought into a context of altered transport function of the amino acid transporters. To assess on a functional level if amino acid transporters with increased activity compensate the lack of PEPT1 we determined the uptake of proline. Proline is known to be a primary substrate of the amino acid transporter PAT1 (SLC36A1), expressed in the small intestine, colon, kidney and other organs [153]. PAT1 mediates the uptake of proline and derivatives and like PEPT1 utilizes a transmembrane electrochemical $\mathrm{H}^{+}$gradient for uptake into cells $[154,155]$. The $\mathrm{H}^{+}$gradient is maintained by $\mathrm{NHE3}$, the apical $\mathrm{Na}^{+} / \mathrm{H}^{+}$antiporter [156], which is also essential for PEPT1. Besides PAT1, which is considered to be the major route for proline uptake, another transporter called SIT1/IMINO ${ }^{B}$ (SLC6A20) mediates uptake of Proline. SIT1 is expressed in various tissues, like kidney, intestine, brain and ovary [157]. In contrast to PAT1, the transport is $\mathrm{Na}^{+}$ dependent and $\mathrm{H}^{+}$independent and SIT1 shows a more restricted substrate specifitiy 
with alanine, GABA or other substrates of PAT1 not transported by SIT1 [158]. But the affinity of SIT1 for L-proline is approximately 10-fold higher than proline affinity for PAT1 [157], which indicates that SIT1 is the high-affinity and PAT1 the low-affinity transporter. Our functional studies, using the everted gut sac method, did not reveal differences in uptake of proline between Pept $1^{-/-}$and $P e p t 1^{+/+}$animals. Taken together any compensation mechanisms in which amino acid transporters compensate for the loss of PEPT1 by increased expression level or function could not be revealed.

However, when plasma amino acid levels were determined, Pept $1^{-/}$animals kept on a standard diet presented higher plasma amino acid levels when compared to wildtype animals. Although 24 out of 40 quantified amino acids and derivatives showed increased blood levels, most pronounced elevations were found for proline, arginine and citrulline. Since this could result from alterations in renal excretion of these amino acids, we also determined amino acid levels in spot urine samples and observed a huge increase in proline and a decrease in glycine and argininosuccinate excretion. As already mentioned, PEPT1 expression could not be detected here in mouse kidney and for PEPT2 we showed that it does not undergo adaptive changes in protein level by the loss of PEPT1. Furthermore, uptake studies in renal BBMV demonstrated that proline transport, like glucose transport, which served as control, remained unchanged in PEPT1-deficient animals. The differences in urinary levels of glycine and proline therefore seem to result predominantly from a different tubular load and a competition of these amino acids for renal reabsoption for common transporters with an overflow of proline as shown in other models [159].

Over-represented in the subset of altered plasma amino acids are amino acids and derivatives related to the urea cycle. Oxidation of amino acid requires the elimination of nitrogen by condensation of $\mathrm{NH}_{3}$ with $\mathrm{CO}_{2}$ for production of urea in liver and depending on dietary protein intake, urea production varies [160]. Urea levels in liver of $P$ ept $1^{-/}$animals displayed lower basal concentrations when compared to wild-type animals. Arginine and citrulline showed increased plasma levels and citrulline concentrations in liver were also elevated. Contrary, argininosuccinate was found with decreased levels in urine. In addition glutamate and alanine, which all contribute to interorgan transport of nitrogen and its delivery to liver for detoxification, showed 
increased plasma concentrations. Nevertheless, neither liver transaminase levels nor the urea cycle enzyme arginase, which serves as a marker enzyme of urea cycle capacity revealed any significant changes between genotypes. These findings in summary indicate that shuttling of amino acids into the urea cycle may be altered in Pept $1^{-1-}$ animals with increased plasma concentrations of almost all amino acids involved in nitrogen delivery and detoxification in liver. Further experiments are needed to determine the causality underlying these alterations in amino acid handling in Pept $1^{-/}$animals.

\subsection{PEPT1 in response to different protein contents}

Energy intake is strongly affected by diet composition and in mice lacking PEPT2 subtle but complex phenotypic changes were observed when mice were given diets with different protein contents $(10 \%, 20 \%$ or $30 \%$ energy of protein). Adaptations in food intake were visible as mice on low-protein diet showed higher consumption rates and mice on high-protein diet displayed lowered food intake rates when compared to control mice [119]. Therefore we also submitted PEPT1-deficient mice to feeding trials with diets of different protein contents. However, no changes, neither between diets nor genotypes, could be observed for Pept $1^{-/}$and Pept $1^{+/+}$mice on low-protein diet ( $8 \%$ of energy), when compared to a control diet with medium ( $21 \%$ of energy) protein content. This was surprising as we expected more pronounced effects, e.g. on weight gain when absorption of amino acids and in particular of essential amino acids may become limited by lack of PEPT1. However no changes in food intake rates, weight development or feces excretion were observed in mice on the lowprotein diet. Possible reasons for the lack of significant alterations might be the use of adult mice and a rather short period of feeding the diet for only 5 days. In studies with a similar low-protein diet it was shown that adult rats were able to maintain their bodyweight for at least 6 months without any obvious changes [161], suggesting that despite a low-protein content in the diet, the protein intake is still sufficient and no deficiency-symptoms arise. Goettsch determined the minimal protein concentration, which still supports growth, reproduction and lactation in rats and proposed a net protein concentration of $10.4 \%$ in the diet $[162,163]$. As protein intake is particularly important in growth further experiments should employ growing mice and then perhaps more severe effects might be observed. 
However, when Pept $1^{-1-}$ and wildtype mice were fed a high-protein (HP) diet, animals reduced food intake, possessed decreased feces excretion and this resulted in lowered body weight. Surprisingly, the response of Pept $1{ }^{-\%}$ animals to the HP diet was much more pronounced than in wildtype animals. This phenomenon was independent of gender, yet female mice responded even more pronounced with food intake more reduced than in male mice.

Reduced food intake rates are often related to higher satiety and in many studies it has been shown, that diets high in protein lead to greater satiety than diets with low or normal protein content [164-166]. Numerous mechanisms have been proposed for this satiation effect of a diet high in protein (for review see [167]) and in recent times two hypotheses have received considerable attention. One involves the hypothalamic sensing of increased leucine availability on high-protein diets. The other is based on an increased intestinal gluconeogenesis sensed in the portal system and transmitted via afferences of the vagus nerve to brain. As mentioned above, only in response to a HP diet animals lacking PEPT1 showed a much more pronounced reduction in food intake than wildtype animals. Although, after 5 days on the HP diet, Pept $1^{-/}$mice increased food intake again, showing a similar daily caloric intake as wildtype animals, PEPT1-deficient animals revealed a persisting body weight reduction. In contrast wildtype mice on the HP diet showed a decrease in food intake and body weight as well but after 4 to 5 days food intake and thus also body weight increased again.

Despite very similar food and therefore also caloric intake after the regain, a significantly increased energy loss in feces on all diets and in particular on the highprotein diet in PEPT1-deficient animals was observed. This suggests an impaired energy assimilation in the intestine and that the lack of a weight gain on the HP diet, despite normal food intake rates after 5 to 6 days, can be attributed to reduced extraction and absorption of food energy. However the data also indicated that $P e p t 1^{-1 /}$ mice are unable to regulate energy intake adequately to prevent weight loss or to increase body weight after the regain of food intake.

To assess whether these differences in energy assimilation and the lack of weight gain can be overcome by providing extra energy, a separate feeding trial was 
conducted in which animals on the HP diet were allowed to have extra carbohydrate (glucose) energy provided in drinking water with voluntary intake. Due to the glucose substitution, food intake was even more suppressed in PEPT1-deficient mice as compared to control mice over the entire 18 days of feeding. However Pept $1^{+/+}$and $P e p t 1^{-/-}$mice on the HP diet with glucose substitution had an almost identical mean energy intake $\left(95.92 \mathrm{~kJ} /\right.$ day in Pept $1^{+/+}$mice and $95.6 \mathrm{~kJ} /$ day in $P e p t 1^{-/-}$mice). The phenomenon of isocaloric food intake in rodents was first described in rats with changes in the energy density of food being compensated over time to achieve the same energy intake and thus reach always the same body weight [168]. Pept $1^{+/+}$and $P_{e p t} 1^{-1}$ mice also seem to have such a 'sensor', which allows them to eat isocalorically. But despite an almost identical mean energy intake, differences in food intake persisted, suggesting that this gene-specific diet effect is due to the lack of PEPT1 and that is best explained by the above mentioned impaired energy assimilation in the intestine.

The problems in regulating energy intake are further substantiated by the fact, that Pept $1^{-/}$mice seem only to be able to ingest approximately the same amount of protein as the control group. This becomes obvious when calculating the amount of protein, which is ingested by Pept $1^{-/-}$and Pept $1^{+/+}$mice on the HP diet. On the basis of their mean food intake during the experiment, the mean amount of ingested protein of Pept $1^{-/-}$and Pept $1^{+/+}$animals on control diet comes to $0.9 \mathrm{~g} / \mathrm{day}$, and for the HP diet $1.09 \mathrm{~g} /$ day for Pept $1^{-/-}$and Pept $1^{+/+}$animals respectively. In the long-term feeding trial (18 days) the same effect can be seen for the first 4 days on HP diet (C wt and ko: $0.9 \mathrm{~g}$ protein/day vs. HP wt: $1.7 \mathrm{~g}$ protein/day and HP ko: $1.1 \mathrm{~g}$ protein/day). However after 18 days $P e p t 1^{-/}$mice show an adaptation to the higher protein intake although levels of $P e p t 1^{+/+}$mice are not reached (HP wt: $1.6 \mathrm{~g}$ protein/day vs. HP ko: $1.4 \mathrm{~g}$ protein/day).

In the context of alterations in energy intake and reduced food consumption it is also important to address the plasma levels of satiety hormones. Although blood levels of ghrelin, which is the only known appetite stimulant, increase in response to body weight loss [169-172], no differences, neither between diets nor genotypes, were detectable in non-fasting and fasting plasma samples of the mice. The same was observed for insulin as levels did also not reveal any significant differences between 
diets and genotypes. Only leptin, known as a key signaling molecule in energy homeostasis and in regulation of food intake [173] decreased significantly in PEPT1deficient animals under fasting as well as non-fasting conditions. Leptin levels generally follow fat mass changes, suggesting that PEPT1-deficient animals not only have reduced body weight but also reduced fat depots. According to the paradigm of leptin effects on food intake control, reduced plasma leptin levels should translate into an increase in food intake. However animals lacking PEPT1 reduce food intake even more than wildtype animals on the HP diet. In this respect, PEPT1-deficiency seems to antagonize leptin actions to increase food intake when plasma leptin levels are low. Interestingly, leptin was shown to regulate PEPT1 expression and transport capacity in the intestine $[100,174,175]$, which suggests that control of amino acid absorption in the intestine involving PEPT1 may be part of the body's response to changes in leptin levels that participate in control of energy homeostasis.

Various studies have proposed that signalling processes initiated in the portal vein and transmitted from there via afferences of the vagus nerve to the brain may provide satiety signals [167, 176, 177]. Such a mechanims was also suggested for the hypophagic effects of protein-rich diets via an increased intestinal gluconeogenesis and elevated portal glucose concentrations in rats [178-180]. However, these findings have been challenged with lack of evidence for a significant intestinal gluconeogenesis from the stable-isotope labeled glucogenic amino acid glutamine in two strains of fasted rats [181]. Nevertheless this finding confirmed other studies in rats, which were fed high-protein diets, that could not demonstrate a significant glucose production in the intestine [182]. To assess whether alterations in absorption and intestinal amino acid metabolism in Pept $1^{-/}$mice occurs, we profiled portal blood for appearance of labeled amino acids after providing a ${ }^{15} \mathrm{~N}$-labeled yeast extract by gavage [64]. Alterations in the appearance rate of glucogenic amino acids in portal vein could have revealed evidence of such a gluconeogenesis effect influencing food intake. But, neither for the sum of all amino acids that could be detected and quantified in portal blood, nor the appearance rate of glucogenic amino acids any significant differences between genotypes were observed. Analyzing different tissue sections (duodenum, jejunum and ileum) however revealed different patterns of amino acids with jejunual samples as the prime site of absorption generally showing highest amino acid concentrations. Taken together that amino acid absorption in 
PEPT1-deficient mice may not be impaired [64], the administration of labeled protein did not reveal any evidence that intestinal utilisation with a production of glucose from glucogenic precursor amino acids can explain the differences in food intake between Pept $1^{-/}$and Pept $1^{+/+}$mice.

In addition to peptide uptake, mediated by PEPT1, a large number of basolateral and apical amino acid transporters contribute to the delivery of amino acids into systemic circulation (for reviews see $[117,131]$ ). After portal delivery, selective hepatic extraction of amino acids allows only some of the 20 proteinogenic amino acids to change in peripheral blood in the absorptive phase. Amongst them are the branched chain amino acids (BCAA) as well as the aromatic amino acids. Within the BCAA group, leucine has been proposed to contribute to satiety control. Leucine administered centrally into hypothalamic regions in rats was shown to increase mTOR signaling leading to a decrease in food intake and body weight. Thus it was suggested that low leucine levels in brain may initiate mechanisms that stimulate food intake whereas high leucine levels may cause increased satiety [183]. However, this finding contradicts with clinical experiences in various human diseases in which supplementing BCAA in patients was shown to generally increase food intake [184, 185]. Moreover, when given in a quantity as contained in a high-protein diet to C57BI/6 mice, fed a diet with normal protein content, leucine failed to show any effect on food intake or weight gain [186]. Studies supplying leucine in drinking water to mice on control or high-fat diet did also not reveal effects on food intake but improved some metabolic parameters in animals on high-fat diets [187]. In the present studies, plasma amino acid profiling in animals on HP or control diet after 5 or 18 days showed that plasma BCAA and in particular leucine levels increased significantly on the HP diet ( $p=0.02$ at day 5 , and $p=0.02$ at day 18$)$, but no genotype effects were found. This means that despite almost identical plasma leucine levels, Pept $1^{+/+}$and Pept $1^{-/}$mice did show marked differences in food intake in response to a HP diet, strongly suggesting that higher leucine plasma levels per se cannot account for these differences in satiety and weight management.

As a function of protein intake plasma amino acid levels are altered and especially BCAAs are elevated in direct proportion to the protein content of the diet $[188,189]$. When comparing only diets, independent of genotype, this effect was observed after 
5 days on the HP diet and the levels remained elevated until day 18. Anderson et al. [190] concluded that enzymes, responsible for the BCAA degradation respond more slowly to HP diets than do others. Therefore BCAA plasma levels remain elevated while other amino acids tend to decrease again. However Pept $1^{-}$mice display lowered levels for BCAAs and almost all other amino acids after 18 days on HP. In Pept $1^{-1}$ mice BCAA levels remain approximately at the level of mice on control diet. This was also evident after $24 \mathrm{~h}$ on the HP diet when amino acid levels rise as compared to control diet in wildtype mice, yet almost all amino acids displayed lowered levels in Pept1\% mice.

Diets with a high amount of protein require increased nitrogen elimination after amino acid oxidation which is achieved by an increased delivery of nitrogen to liver via glutamine, glutamate and alanine, an enhanced urea cycle flux and increased renal excretion of urea. As expected, blood urea concentrations increased in animals fed the HP diet but were significantly lower in Pept1 ${ }^{-\%}$ animals, while liver urea levels did not reveal any genotype effect, only a diet specific effect. A recent proteome analysis of hepatic proteins in mice fed a normal or HP diet [191] identified carbamoylphosphate synthetase 1 and ornithine aminotransferase with increased protein levels, suggesting that the increased ornithine demand is achieved from proline while ornithine-transcarbamoylase-activity may limit efficient urea cycle flux. We indeed observed that citrulline levels at day 18 in liver tissue declined while ornithine levels increased upon high-protein feeding, however without a genotype specific effect. Although liver arginine was below detection limit, Pept $1^{-1}$ mice displayed significantly increased plasma arginine levels on both, control as well as HP diet at days 5 and 18. Plasma citrulline levels were also significantly higher in PEPT1-deficient animals at day 5 but no longer at day 18. Although portal blood arginine and citrulline levels did not reveal any genotype-specific differences, arginine concentrations in portal blood were much lower than in peripheral blood. This suggests that the unusual high plasma levels of arginine in Pept $1^{-1}$ mice originate from an increased renal arginine production from citrulline. In this respect it is of interest that dietary L-arginine supplementation (but not D-arginine) was shown to reduce food intake in mice via altered nitric oxide (NO) levels in brain [192]. Since brain arginine concentrations were shown to change almost proportional to plasma arginine levels [193], it is suggested that $P e p t 1^{-/}$mice may have also an increased 
arginine level in brain. Most interestingly, delivery of arginine to brain was shown to antagonize the leptin effects on food intake in mice with a prominent regain of food consumption when co-administered centrally with leptin [194]. Moreover, this effect was abolished in NO-Synthase (nNOS) deficient mice and nNOS is shown to be down-regulated by leptin [195] and up-regulated by food deprivation [196]. A similar effect of leptin on brain NO production and food intake has also been shown in chicken [197, 198]. We observed low leptin levels (fasting as well as non-fasting) in Pept $^{-/}$mice only when animals received the HP diet and when food intake was markedly reduced (at day 5). While animals at that time had almost two-fold higher plasma arginine levels than wildtype animals, it is tempting to speculate that the leptin-NOS axis in brain contributes to changes in food intake on protein-rich diets. Low leptin levels in PEPT1-deficient mice on HP diet most likely arise from the very low food intake and the apparent "starvation condition". Plasma leptin levels are known to decrease radiply upon starvation, yet, low leptin levels should increase food intake and this response seems antagonized by high plasma arginine levels in Pept $1^{-/}$mice. Assuming that in analogy to previous reports, low leptin levels in $P e p t 1^{-/}$mice together with apparent food deprivation cause major changes in NOS levels [194, 196], then NO production may, in spite of high arginine levels, be reduced. This would be in line with the anorexic effects of inhibitors of NOS [199, 200]. Although we cannot provide conclusive evidence for this hypothesis, our findings call for future studies employing agonist and antagonists to alter brain NO pathways to assess whether high plasma arginine levels in mice lacking PEPT1 indeed prevent proper leptin signalling for an adaptive increase in food intake on protein-rich diets.

Changes in urea production are often related to changes in enzyme activities of urea cycle enzymes. After adaptation to the HP intake, a positive correlation between the quantity of excreted urea and the hepatic arginase activity, which often serves as marker of urea cycle capacity, was observed in rats [201]. Activities of hepatic transaminases were also shown to increase after HP intake [202, 203]. In addition changes in enzyme activities in rats with HP intake were assessed as a function of time, showing an increasing activity for several days, reaching its maximum between day 4 and 7 [204, 205]. After 24h on the HP diet we observed no changes for arginase levels. However in female mice, independent of genotype, an increase of 
$43 \%$ in arginase activity after 5 days on HP compared to control diet was found. This might indicate that excess amino acids are deaminated and the resulting nitrogen is shuttled into the urea cycle [206]. Again independent of genotype, at day 18, arginase showed decreased levels which may be attributed to adaptation mechanisms. Likewise, independent of genotype, AST levels were altered, showing highest activities after 5 days in female mice and a decrease after 18 days on the HP diet.

Enhanced liver gluconeogenesis is also a known adaptation mechanism to HP diets, and higher GDH activities are often linked to increased liver gluconeogenesis [207]. $\mathrm{GDH}$, commonly accepted as a major terminal deamination enzyme [208], converts glutamate to 2-oxoglutarate and vice versa. GDH levels in Pept $1^{-/-}$mice on HP diet showed elevated levels when compared to Pept $1^{+/+}$animals. Already after $24 \mathrm{~h}$ on HP diet, levels were increased and showed a slight decrease after 18 days, but only $\mathrm{Pept}^{+/+}$animals returned to control levels. In line with this are the elevated liver amino acid concentrations of glutamate in $P$ ept $1^{-/}$mice at days 5 and 18 .

To assess acute dietary protein effects on Pept $1^{-/}$animals a large intragastric protein load of $178 \mathrm{mg}$ per mouse was administered. After gavage, Pept $1^{-/}$animals displayed reduced plasma appearance rates of a subset of amino acids when compared to those in wild-type animals. Amongst these amino acids, proline followed by valine, leucine, aminobutyric acid, glutamate, aspartate and threonine showed the most pronounced differences. As we were able to demonstrate that proline absorption rate via the proline transport pathways represented by SIT1/IMINO ${ }^{B}$ (SLC6A20) and PAT1 (SLC36A1) transporters in the intestine [131] were not different between genotypes, the difference in proline plasma appearance may indicate that a larger quantity of proline is absorbed in peptide-bound form via PEPT1. This may not be surprising as proline-containing peptides are generally more resistant to enzymatic hydrolysis by brush border and intracellular peptidases then all other peptides. Moreover proline-containing peptides such as Ile-Pro-Pro and Leu-Pro-Pro were recently shown to be absorbed in intact form after oral administration in humans [90], yet with very low plasma appearance rates [209]. A remarkable feature of all proline-containing peptides is that the peptide bond can be presented in cis-or transconformation and PEPT1 was shown to transport only the trans peptide bond 
conformers [49]. Interestingly, by proteome analysis the enzyme peptidylprolyl isomerase A (Ppia) was identified with a two-fold increased protein level in Pept ${ }^{-/}$ animals. PPlases catalyze the cis-trans isomerization of proline imidic peptide bonds [210]. This finding suggests that there could be a co-regulation of Ppia and PEPT1 and that absorbed proline-peptides in intestinal cells may participate in regulation of the isomerase levels. The acute challenge test, where mice were provided with a high protein quantity, established that PEPT1 is most important for amino acid absorption at high dietary protein intakes and that peptides with a higher enzymatic resistance against hydrolysis gain a kinetic advantage for uptake via PEPT1. Despite the fact that the peptide transporter deficient C.elegans line showed retarded development with reduced body and brood size [146], mice lacking the peptide transporter did not possess any obvious phenotypic changes [71]. Only when animals were challenged with a high-protein load we were able to detect major alterations in plasma appearance of amino acids and an effect on food intake.

\subsection{Conclusion}

Based on our findings we may conclude that the contribution of PEPT1 to overall intestinal amino acid absorption is negligible when low or normal amounts of dietary protein are ingested. However, PEPT1 function becomes visible when a high amount of protein reaches the intestine. When the maximal capacity for peptide hydrolysis in the intestine and highest amino acid absorption capacity have been reached by the high protein intake, some amino acids presented in peptide form, appear to gain a kinetic advantage with higher absorption rates via PEPT1 - and this becomes detectable mainly with proline-rich peptides that are more resistant to hydrolysis. These findings also suggested that a high-protein diet administered to Pept1 ${ }^{-/}$mice may induce a stronger variant phenotype then under standard protein feeding in which animals obviously balance their amino acid homeostasis at its 'limits'. However, the feeding trials with protein-rich diets led to some unexpected findings. On a high-protein diet, mice lacking PEPT1, displayed a most pronounced reduction in food intake lasting for 5 to 6 days. Thereafter a regain in food intake was observed but despite very similar food intake rates, like control animals, Pept1 ${ }^{-/}$mice did not show any weight regain. 
A depression in food intake is generally observed with protein rich diets and this has been associated with altered plasma amino acid concentrations, especially of leucine. Yet, our collected data argues against a prominent role of leucine in being responsible for the effects of HP diets as almost identical plasma leucine levels were observed during the time of the largest differences in food intake between Pept $1^{-1-}$ and control mice on protein-rich diets. What was observed is a currently unexplained reduction in energy assimilation with an increased fecal energy loss that was most pronounced in animals on the HP diet. Despite the fact that intestinal morphology seems not impaired in PEPT1-deficient animals and no evidence for any functional changes in amino acid absorption was found, this reduced energy assimilation is obvious and deserves further studies on the digestive capacity and on gut ultrastructure changes at the levels assessible only by electron-microscopy. As a unique finding in animals lacking PEPT1, we observed plasma arginine levels being increased around two-fold even during the period of severe food intake suppression (day 5) and this is a defined genotype-dependent effect. Based on this finding and the reduced plasma leptin levels observed in PEPT1-deficient animals on a HP diet, a cross-talk of leptin with the arginine-dependent NO system in brain was proposed as a hypothesis to explain how hypothalamic control loops, that affect food intake, could be altered in PEPT1-deficient animals on a high-protein diet. This needs to be studied in further experiments employing agonist and antagonists of the NO-pathway. 




\section{Materials and Methods}

\subsection{Chemicals and consumables}

Unless otherwise specified all chemicals were purchased from Sigma (Taufkirchen, Germany), Merck (Darmstadt, Germany) or Roth (Karlsruhe, Germany) and of pro analysis quality. Oligonucleotides for PCR were bought from MWG (Ebersberg, Germany).

\subsection{Laboratory animals}

PEPT1-deficient mice have been generated by Deltagen (San Mateo, California, USA). Briefly, a genomic fragment of about $5.6 \mathrm{~kb}$, including protein coding regions of the Pept1 gene (Slc15a1), was isolated from a mouse genomic library and subcloned into the BamHI site of the pBluescript II SK(-) vector. Bases from +77 to +101 were deleted from a segment of the protein coding region and replaced with an IRES-lacZ reporter and neomycin (G418) resistance cassette of about $6.9 \mathrm{~kb}$. This mutation was designed to produce a loss of function mutation by deletion of amino acids 16 to 24 . IRES-lacZ-neo cassette was flanked by $2.8 \mathrm{~kb}$ of mouse genomic DNA at the $5^{\prime}$ arm and by $2.8 \mathrm{~kb}$ of genomic DNA at the $3^{\prime}$ arm. The targeting vector was then linearized and electroporated into ES cells derived from the 129P2/OlaHsd mouse substrain. The ES cells were selected for G418 resistance, and colonies that had integrated the IRES lacZneo DNA were identified by PCR amplification using 3 neo-specific primers paired with primers located outside the targeting homology arms of vector (i.e. AAGGCTCTTCTTGGCTGACTGTAGC for $5^{\prime}$ and TTAAGCATGGAATGGACATGGTCTC for 3', respectively). Male chimeric mice, generated by injection of the targeted ES cells into C57BL/6 blastocysts, were bred with C57BL/6 mice to produce F1 heterozygous (Pept $1^{+/}$) mice. F2 homozygous mutant mice were then produced by intercrossing $\mathrm{F} 1$ heterozygous males and females [71]. Mice were backcrossed to the genetic background of C57BL/6 for 10 generations.

\subsubsection{Mouse husbandry}

PEPT1-deficient mice were maintained at $22 \pm 2^{\circ} \mathrm{C}$ and a $12: 12 \mathrm{~h}$ light/dark cycle with access to tap water and a standard rodent diet (Ssniff, R/M-H, Soest, Germany) ad libitum unless stated otherwise. For determination of metabolic studies homozygous animals of $P e p t 1^{+/-}$were mated to litters of entirely $P e p t 1^{-/}$and $P e p t 1^{+/+}$animals. All procedures applied throughout this study were conducted according to the German guidelines for animal care and approved by the state ethics committee under reference number 55.2-1-54-2531-140-08.

\subsubsection{Genotyping}

Mice were genotyped by multiplex PCR screening with following three primers (62790 Pept1D Wt - 5'AGT GTG GGC TGG TGA GAC ACG TGT C-3', directed against the Pept1 D Neo Insert. And the forward primer 3195 Pept1D Neo 5'-GGG CCA GCT CAT TCC TCC CAC TCA T-3' and reverse primer 62791 P1D Neo/WT 5'-CAG GGG GAG AGA GAA ACA GAG TTA G-3'). 
Tail biopsies were digested at $65^{\circ} \mathrm{C}$ with proteinase $\mathrm{K}(0.5 \mathrm{mg} / \mathrm{ml}$ proteinase $\mathrm{K}$ (Roche Diagnostics, Mannheim, Germany), $50 \mathrm{mM} \mathrm{KCl}, 10 \mathrm{mM}$ Tris- $\mathrm{HCl}, 0.1 \mathrm{mg} / \mathrm{ml}$ gelatine, $0.45 \%$ Nonidet NP-40, $0.45 \%$ Tween-20, pH 8.3) overnight. After digestion proteinase $\mathrm{K}$ was inactivated at $95^{\circ} \mathrm{C}$ and PCR was performed with a $1 \mu \mathrm{l}$ aliquot of the digested sample containing genomic DNA. PCR products were separated on a $1.5 \%$ agarose gel. A band of 213 bps indicates the amplification product of the wildtype allele and a band of $360 \mathrm{bps}$ indicates the amplification product of the targeted allele.

\subsubsection{Data sampling for body weight}

Body weight was monitored weekly starting from birth up to the age of 20 weeks with 7-29 mice per genotype, age and sex.

\subsubsection{Bomb calorimetry of feces samples}

Gross energy content of feces was determined using a bomb calorimeter (Parr 6300 Calorimeter, Parr Instrument Co., Illinois, USA). Dried feces was grinded with a pebble mill (TissueLyser, Qiagen, Hilden, Germany) and approximately $1 \mathrm{~g}$ of powdered feces was pressed to a pellet and analyzed by a bomb calorimeter.

\subsection{Dietary intervention studies}

\subsubsection{Dietary intervention study with low, medium and high protein content for 5 days in male mice}

For each diet and genotype 10 adult male animals were studied. During the study mice received semisynthetic purified diets with high (45\% of energy; E15209, Ssniff Spezialdiäten GmbH, Germany), low (8\% of energy; E15202) or medium (21\% of energy; E15000) protein content as control diet. Mice were separated in individual cages and diet was put in food containers that allowed recording of food intake. Water consumption was recorded as well. Throughout the study mice had access to tap water ad libitum. To allow for adaptation all animals received the medium protein diet ad libitum for 3 days before starting the experiment. In the following 5 days, mice had free access to either control (C) or high protein (HP) diet. Body weight, food and water consumption were monitored daily between 8:00 and 9:00 A.M. Feces and spot urine samples were collected daily. Feces samples were dried at $60^{\circ} \mathrm{C}$ for 2 days and stored at RT until analysis. On the last day, blood was collected into Li-Heparin coated tubes (Sarstedt, Nuembrecht, Germany) by puncturing the retro-orbital sinus under isoflurane anaesthesia. Samples were centrifuged for 10 minutes at $3000 \mathrm{~g}, 4^{\circ} \mathrm{C}$ within $1 \mathrm{~h}$ of collection to prevent possible in vitro changes. 


\subsubsection{Dietary intervention study in female mice for 5 days}

Dietary intervention was also examined for female mice. During the study 10 adult females for each diet and genotype were studied, but due to the few results obtained on low-protein diet in male mice, female mice received semi-synthetic purified diets only with high (45\% of energy; E15209) or medium (21\% of energy; E15000) protein content as control diet. Metabolic parameters (body weight, food intake, water consumption, feces excretion) were determined daily and feces and urine samples were collected daily.

\subsubsection{Dietary intervention study for 18 days plus carbohydrate substitution}

To determine long-term effects of HP diets we performed a feeding trial lasting for 18 days. Male mice $(n=3)$ were kept on either control or HP diet. In prior experiments the differences in energy intake between mice on $\mathrm{C}$ and HP were determined. Due to these differences a third group was generated. Mice were given the HP diet and in addition they received water with glucose to have the ability to compensate the calculated energy difference. For all groups metabolic parameters (body weight, food and water consumption, feces excretion) were measured daily. Feces and urine were collected every 5 days and on day 18 plasma and tissue samples were taken.

\subsubsection{4 hour dietary intervention study}

To analyze acute effects of feeding HP diets, a short-term experiment was designed. Pept1/t+ and Pept $1^{-1-}$ mice $(n=6)$ were given the HP diet (45\% of energy) for $24 \mathrm{~h}$. Body weight, food intake, water consumption and feces excretion were determined. After $24 \mathrm{~h}$ plasma and tissue samples were taken.

\subsection{High protein load and administration of low $15 \mathrm{~N}$-labeled protein load by gastric gavage}

5-6 mice per group and genotype received either $178 \mathrm{mg}$ protein (Power System 90 Plus, Well Plus Trade $\mathrm{GmbH}$, Hamburg, Germany) or $8.83 \mathrm{mg}{ }^{15} \mathrm{~N}$-labeled protein by gavage. ${ }^{15} \mathrm{~N}$-labeled yeast protein (Saccharomyces cerevisiae) was provided by Dr. W. Eisenreich (TU München, Garching, Germany).

For high protein load, blood and tissue (small intestine, liver, kidney) samples were collected at 0, 10, 30 and 60 min after gavage. In studies with ${ }^{15} \mathrm{~N}$-labeled protein, 15 and $30 \mathrm{~min}$ after administration blood was collected from portal vein and heart. 


\subsection{Analysis of selected metabolites in body fluids and tissue}

\subsubsection{Clinical chemical parameters in plasma}

To analyze multiple analytes in plasma samples the Piccolo xpress $^{\mathrm{TM}}$ chemistry analyzer (Abaxis, California, USA) was used. Plasma samples were diluted with the same volume of deionized water. The Piccolo ${ }^{\circledR}$ General Chemistry 13 reagent discs (Abaxis, California, USA) were used for in vitro quantitative determination of following parameters: alanine aminotransferase (ALT), albumin, alkaline phosphatase (ALP), amylase, aspartate aminotransferase (AST), calcium, creatinine, gamma glutamyltransferase (GGT), glucose, total bilirubin, total protein, blood urea nitrogen (BUN) and uric acid.

\subsubsection{Amino acid analysis in plasma, urine and tissue}

In $40 \mu$ l urine or plasma amino acids and derivatives were labeled by the ITRAQ methodology using the AA45/32 Starter Kit according to the manufacturer's instructions (Applied Biosystems, USA) and analyzed via LC-MS/MS (3200QTRAP LC/MS/MS, Applied Biosystems, USA). The data were analyzed using the Analyst ${ }^{\circledR} 1.5$ Software.

For amino acid analysis of tissue, parts of duodenum, jejunum and ileum were homogenized and diluted in $\mathrm{MeOH} / \mathrm{H}_{2} \mathrm{O}$. After centrifugation amino acid analysis was performed as described in $40 \mu \mathrm{l}$ supernatant.

\subsubsection{Urine parameters}

Spot urine samples of $\mathrm{Pept}^{+/+}$and Pept $1^{-/}$mice were collected daily between 8 and 9 A.M. and pooled (per animal) for analysis. Creatinine concentrations were determined with the Creatinine Liquicolor Jaffè Test \#G205117 (Rolf Greiner BioChemica GmbH, Flacht, Germany) and urea levels were analyzed with the Urea Liquicolor Test \#10505 (Human Gesellschaft für Biochemica und Diagnostica, Wiesbaden, Germany) according to the manufacturer's instructions. Osmolarity in urine was determined with a semi-micro osmometer (Knauer, Berlin, Germany).

\subsubsection{Determination of hormone levels in plasma}

To determine basal hormone levels in fed and fasted state (fasting period: 6h), plasma samples of Pept $^{+/+}$and Pept ${ }^{-/}$animals $(n=10)$ were taken puncturing the retro-orbital sinus under isoflurane anaesthesia. Samples were taken between 8:00 and 9:00 A.M.. Blood was collected in either LiHeparin coated tubes for insulin and leptin measurements, or in EDTA-coated tubes (both Sarstedt, Nümbrecht, Germany) for ghrelin determination. For ghrelin measurement blood was treated with Pefabloc $^{\circledR}$ SC (Sigma-Aldrich, Steinheim, Germany) to a final concentration of $1 \mathrm{mg} / \mathrm{ml}$. All samples were centrifuged at $2000 \mathrm{~g}$ for 15 minutes at $4^{\circ} \mathrm{C}$. Insulin levels were determined using the Ultra Sensitive Mouse Insulin ELISA Kit and leptin levels using the Mouse Leptin ELISA Kit (both Crystal 
Chem Inc, Illinois, USA). Measurement of ghrelin levels was assayed by the Rat/Mouse Ghrelin (active) ELISA Kit (Millipore GmbH, Schwalbach, Germany).

\subsubsection{Measurement of enzyme activites in liver and kidney tissue}

In liver tissue samples of mice, aspartate aminotransferase (AST), alanine aminotransferase (ALT) and glutamate dehydrogenase $(\mathrm{GDH})$ enzyme activities were measured. Furthermore urea and arginase levels were determined. Arginase activity was also determined in kidney samples. Tissue samples were homogenized with $0.9 \% \mathrm{NaCl}$ and centrifuged for 15 minutes at $14000 \mathrm{~g}$. Supernatant was removed and stored at $-80^{\circ} \mathrm{C}$ until analysis. Supernatant was diluted 1:100 and enzyme activities were determined with the GPT (ALT) liquidUVTest \#12012 and GOT (AST) liquiUV Test \#12011 (both Human Gesellschaft für Biochemica und Diagnostica, Wiesbaden, Germany) and GLDH FS \#G82100 (Rolf Greiner BioChemica GmbH, Flacht, Germany) according to the manufacturer's instructions. Urea levels were analyzed from supernatant without dilution with the Urea Liquicolor Test \#10505 (Human Gesellschaft für Biochemica und Diagnostica, Wiesbaden, Germany) according to the manufacter's instructions. Arginase activity was measured by activation of the tissue supernatant in presence of glycine, incubation with L-arginine at $37^{\circ} \mathrm{C}$ for $10 \mathrm{~min}$, and termination of reaction by adding $20 \% \mathrm{TCA}$. Protein was removed by centrifugation and the supernatant was mixed with $9 \% \mathrm{H}_{2} \mathrm{SO}_{4}, 23 \% \mathrm{H}_{3} \mathrm{PO}_{4}$, $100 \mathrm{mM} \mathrm{FeCl}{ }_{3}$ and $3 \%$ isonitrosopropionphenone for urea determination (incubation: $100^{\circ} \mathrm{C}$ for 60 $\min )$.

\subsubsection{Oral glucose tolerance test (OGTT) and insulin measurement}

For the oral glucose tolerance test, $12 \mathrm{~h}$ fasted male wildtype and Pept $1^{-/}$mice ( $\mathrm{n}=4$ animals per group) received $2 \mathrm{~g} / \mathrm{kg}$ body weight of glucose in $500 \mu \mathrm{l}$ water with help of a syringe attached to a feeding needle (18G, FST, Heidelberg, Germany). Blood glucose concentrations were measured from tail vein samples (Accu-Chek Aviva, Roche, Germany), immediately before ( $t=0)$, and 15, 30, 60 and 120 min after gavage.

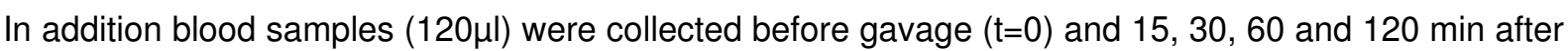
gavage for determination of insulin (Crystal Chem Inc. Downers Grove, USA) by ELISA.

\subsection{Characterization of tissue samples by profiling techniques}

\subsubsection{Proteome analysis of intestinal tissue by 2D-PAGE and MALDI-TOF-MS}

Protein extraction for two-dimensional-polyacrylamid gel electrophoresis (2D-PAGE): Scraped mucosa samples of $\mathrm{Pept}^{+/+}$and Pept1 $1^{-/}$mice were homogenized in a mortar under liquid nitrogen, $100 \mathrm{mg}$ of tissue were transferred into $1 \mathrm{ml}$ of lysis buffer (7 M Urea, $2 \mathrm{M}$ Thiourea, $40 \mathrm{mM}$ TrisHCl, $4 \%$ CHAPS, $20 \mathrm{mM}$ dithiothreitol (DTT), 2\% IPG Buffer, Complete Mini proteinase inhibitor), and homogenized using ultrasonification (30 strokes, low amplitude) on ice. After $1 \mathrm{~h}$ on ice, lysed tissue samples were 
centrifuged for $30 \mathrm{~min}$ at $15000 \mathrm{~g}$ at $4^{\circ} \mathrm{C}$ to collect the supernatant. Proteins were precipitated from the supernatant with 5 volumes of ice-cold acetone overnight at $-20^{\circ} \mathrm{C}$. The precipitated protein was pelleted for $15 \mathrm{~min}$ at $15000 \mathrm{~g}$ at $4^{\circ} \mathrm{C}$ and lysed again as described earlier. Protein concentration was determined using the Bradford method as described above.

2D-PAGE: 2D-PAGE was performed as described by Gorg et al. [211]. In brief, $300 \mu \mathrm{g}$ of protein were loaded by passive rehydration, and isoelectric focusing was performed on 18-cm immobilized $\mathrm{pH}$ gradient strips (pH 3-10, GE Healthcare, München, Germany) using the Ettan IPG Phor II Unit (GE Healthcare). In the second dimension $12.5 \%$ SDS-polyacrylamide gels were ran on the Ettan-Dalt II system (GE Healthcare). Gels were fixed and subsequently stained with Coomassie-Blue. Gels were scanned and analyzed using the Decodon Delta 2D software 4.0 (Decodon, Greifswald, Germany), which combines the spot detection with automatic background substraction and normalization of spot volumes. Spots differing significantly $(P<0.05$, double sided, unpaired Student's $t$-test) in density were picked for matrix-assisted laser desorption/ionization-time of flight-mass spectrometry (MALDITOF-MS) analysis.

Tryptic digestion of protein spots and peptide mass fingerprinting by MALDI-TOF-MS: All methods applied here have been described in detail by Winkelmann et al. [212]. In brief, Coomassie Bluestained spots were picked, destained and digested in gel with sequencing grade modified trypsin (Promega, Madison, USA). The resulting peptide fragment extracts were analyzed by MALDI-TOF-MS with an autoflex mass spectrometer (Bruker Daltonics, Leipzig, Germany). Proteins were identified with the Mascot Server 1.9.00 (Bruker Daltonics) based on mass searches with mouse sequences only. The criteria for positive identification of proteins were set as follows: (i) a minimum score of 63 , (ii) mass accuracy of $\pm 0.01 \%$, and (iii) at least twofold analysis from independent gels.

\subsubsection{Transcriptome analysis of mucosal samples by cDNA microarrays}

Scraped mucosa samples of male Pept $1^{+/+}$and Pept $1^{-/}$mice were homogenized in a mortar under liquid nitrogen. From $100 \mathrm{mg}$ of tissue total RNA was isolated using a combination of TRIZOLH (Invitrogen, Karlsruhe, Germany) till the ethanol precipitation step, followed by purification via the RNeasy Mini Kit (Qiagen, Hilden, Germany). After reverse transcription $15 \mu \mathrm{g}$ of the corresponding cRNA was biotinylated and fragmented following the original protocol of Affymetrix (Affymetrix, Santa Clara, USA). $10 \mu \mathrm{g}$ of the cDNA samples were hybridized over night for $16 \mathrm{~h}$ at $45^{\circ} \mathrm{C}$ on Affymetrix mouse whole-genome arrays. After that the arrays were washed and scanned following the instructions of the provider. Quality control and statistical analysis were performed by a bioconductor and $\mathrm{R}$ based method in the Nutrigenomics Organisation NuGO Array Pipeline (www.madmax.bioinformatics.nl). To calculate gene expression measures, the preprocessing method GCRMA was used [147], which is implemented in the package 'gcrma' of bioconductor (www.bioconductor.org). Bioconductor is an open source software project for the analysis and comprehension of genomic data based on a free statistical programming language $\mathrm{R}$. 


\subsubsection{Gene expression analysis by qPCR}

Changes in transcript levels were studied by quantitative real-time reverse transcription PCR (qPCR). Total RNA of tissue samples was isolated with the RNeasy Mini Kit (Quiagen, Hilden, Germany) according to the manufacturer's protocol. $1 \mu \mathrm{g}$ of total RNA was then transcribed into cDNA with MLVRT (Promega, Mannheim, Germany) and random hexamers (Fermentas, St.Leon-Rot, Germany). qPCR was performed on a LightCycler (Roche, Penzberg, Germany) with 3.3 ng cDNA per PCR reaction and the FastStart SYBR Green Kit (Roche, Mannheim, Germany). Cycle parameters were annealing at $62^{\circ} \mathrm{C}$ for $10 \mathrm{~s}$, elongation at $72^{\circ} \mathrm{C}$ for $10 \mathrm{~s}$ and melting at $95^{\circ} \mathrm{C}$ for $10 \mathrm{~s}$. Specifity of PCR products was controlled by melting curve analysis and by agarose gel electrophoresis. Primers were designed by LightCycler Probe Design sotware Version 3.5 (Roche, Penzber, Germany). For relative quantification the geometric mean of crossing point (CP) values of the three housekeeping genes GAPDH, SDHA and HPRT was calculated for each sample as described by Pfaffl et al. [213]. This Bestkeeper Index was used as CP of the reference gene to calculate mean normalized expression values for each sample and thus the ratio (fold change) between wild-type and Pept1 knockout animals.

\subsection{Western blot analysis and uptake studies in BBMV and everted gut sacs}

\subsubsection{Intestinal brush border membrane vesicles (BBMV)}

After male Pept $1^{+/+}$and Pept $1^{-/}$mice were killed, intestine was removed quickly, everted by a metal rod and mucosa was scraped off. Brush border membrane vesicles were prepared from mucosa tissue by $\mathrm{Mg}^{2+}$ aggregation in the presence of EGTA. Mucosa of each mouse was homogenized 1:10 (w/v) in ice-cold buffer 1 (100 mM Mannitol, $2 \mathrm{mM}$ HEPES/Tris, pH 7.1) using an Ultra-Thurrax (IKA Labortechnik, Staufen, Germany) at a speed of $17000 \mathrm{U} / \mathrm{min}$ for $45 \mathrm{~s}$. $1 \mathrm{M} \mathrm{MgCl}_{2}$ was added to give a final concentration of $10 \mathrm{mM}$. After stirring for $1 \mathrm{~min}$ the suspension was allowed to stand on ice for 20 min and then centrifuged at $3000 \mathrm{~g}$ for $10 \mathrm{~min}$ at $4^{\circ} \mathrm{C}$. The supernatant was then centrifuged at 30000 $g$ for $30 \mathrm{~min}$ at $4^{\circ} \mathrm{C}$. The pellets were suspended in ice-cold buffer $2(100 \mathrm{mM}$ Mannitol, $2 \mathrm{mM}$ HEPES/Tris, $0.1 \mathrm{mM} \mathrm{MgSO}_{4}, \mathrm{pH} 7.5$ ) using a 27-gauge needle and centrifuged at $30000 \mathrm{~g}$ for $45 \mathrm{~min}$ at $4{ }^{\circ} \mathrm{C}$. The final pellets containing the brush border membranes were suspended in buffer $3(300 \mathrm{mM}$ Mannitol, $20 \mathrm{mM} \mathrm{HEPES} /$ Tris, $0.1 \mathrm{mM} \mathrm{MgSO}_{4}, 0.02 \% \mathrm{NaN}_{3}$, pH 7.5) using a 27-gauge needle. Protein concentration was determined using the Bradford method with the BioRad Protein Assay, measuring extinction at OD 595. Vesicles were stored in liquid nitrogen until use for Western Blot analysis.

\subsubsection{Purity of brush border membrane vesicles}

The purity of brush border membrane preparation was assayed by the marker enzyme alkaline phophatase (EC 3.1.3.1). 


\subsubsection{Preparation of BBMV from kidney tissue and uptake studies}

Kidneys were removed quickly and only tissue of the cortex used for preparation. Vesicles were prepared from kidney tissue by $\mathrm{Mg}^{2+}$ aggregation in the presence of EGTA. Individual kidneys were homogenized 1:10 (w/v) in ice-cold homogenisation buffer (300 mM Mannitol, 5mM EGTA, 12mM Tris/HCl, pH7,1, 1mM PMSF) using a Polytron (Kinematica AG, Luzern, Suisse) at a speed of 20000 $\mathrm{U} / \mathrm{min}$ for $45 \mathrm{~s}$. $1 \mathrm{M} \mathrm{MgCl}_{2}$ was added to give a final concentration of $10 \mathrm{mM}$. After stirring for $1 \mathrm{~min}$ the suspension was allowed to stand on ice for $20 \mathrm{~min}$ and then centrifuged at $800 \mathrm{~g}$ for $15 \mathrm{~min}$ at $4{ }^{\circ} \mathrm{C}$. The supernatant was centrifuged at $12000 \mathrm{~g}$ for $15 \mathrm{~min}$ at $4^{\circ} \mathrm{C}$. For glucose uptake pellets were suspended in ice-cold membrane buffer (100 mM Mannitol, $2 \mathrm{mM} \mathrm{HEPES/Tris,} \mathrm{0,1} \mathrm{mM} \mathrm{MgSO} 4$, pH 7,5 ) using a 25 -gauge needle and centrifuged at $12000 \mathrm{~g}$ for $30 \mathrm{~min}$ at $4^{\circ} \mathrm{C}$. For proline uptake pellets were suspended in ice-cold THM buffer (1 $\mathrm{mM}$ Tris, 2mM HEPES, $100 \mathrm{mM}$ Mannitol, pH 7,4) using a 23-gauge needle and centrifuged at $12000 \mathrm{~g}$ for $30 \mathrm{~min}$ at $4^{\circ} \mathrm{C}$. The final pellets containing the brush border membranes were suspended in membrane buffer (for glucose) or THM buffer (for proline) using a 25-gauge needle. Protein concentration was determined using the Bradford method with the BioRad Protein Assay, measuring extinction at OD 595. Vesicles were used freshly on the same day and stored on ice until use.

D-glucose transport in renal BBMV was measured at $37^{\circ} \mathrm{C}$ in the presence of either NaSCN or KSCN gradients. The measurement of amino acid uptake was performed using the rapid filtration technique [214].

\subsubsection{Western blot analysis}

$25 \mu \mathrm{g}$ of BBMV proteins were separated by SDS-10\% PAGE, followed by transfer to a nitrocellulose membrane with a semi-dry blotter (Bio-Rad Laboratories $\mathrm{GmbH}$, München, Germany). After blocking, the primary antibody (rabbit anti PEPT1, 1:1000 or rabbit anti PEPT2, 1:1000; Pineda, Berlin, Germany) was added. After washing, the secondary antibody was added (SCD1, goat polyclonal IgG, 1:10000; Santa Cruz Biotechnology, California, USA or donkey anti rabbit IRDye680, 1:10000; LICOR, Bad Homburg, Germany). Chemiluminescence was detected with a radiographic film and fluorescence was detected by the Odyssey Infrared Imaging System (LI-COR, Germany).

\subsubsection{Uptake studies by the everted gut sac technique}

Jejunum segments of $P e p t 1^{+/}, P e p t 1^{+-}$and $P e p t 1^{-/-}(n=4)$ were everted with a metal rod. Sacs were filled with Carbogen gased Krebs buffer $\mathrm{pH} 7.4$ and transferred into Krebs buffer $\mathrm{pH} 6.0$ at $37^{\circ} \mathrm{C}$ with $10 \mu \mathrm{M}\left[{ }^{14} \mathrm{C}\right]$ Gly-Sar or $10 \mu \mathrm{M}\left[{ }^{3} \mathrm{H}\right]$ L-proline (GE Healthcare, München, Germany) and incubated for 10 min at $37^{\circ} \mathrm{C}$. After incubation, serosal fluid was drained into small tubes. Each sac was weighed before and after fluid collection to calculate serosal volume. Tissues were dried, weighed and lysed in $\mathrm{NaOH}$ for normalization of transport data. 


\subsection{Tissue preparation and immmunofluorescence}

After twice PBS washing, tissue samples were fixed in 4\% paraformaldehyde in PBS pH 7.4 over night. On the next day the tissue was dehydrated in ascending concentrations of ethanol in water and xylene at $40{ }^{\circ} \mathrm{C}(70 \%$ and $80 \% 30 \mathrm{~min}, 2 \times 95 \% 45 \mathrm{~min}, 3 \times 100 \% 45 \mathrm{~min}$ and $2 \times 100 \%$ xylene $45 \mathrm{~min})$ and embedded in paraffin (Paraplast embedding media, Sigma Aldrich, Steinheim, Germany). Tissue preparations were cut $(5-10 \mu \mathrm{m})$ and dried on Superfrost Plus microslides (Menzel $\mathrm{GmbH}$, Braunschweig, Germany) at $37^{\circ} \mathrm{C}$ for $2 \mathrm{~h}$. Subsequently, sections were dewaxed in xylene $(2 \times 5 \mathrm{~min})$, rehydrated in descending concentrations of ethanol in water $(2 \times 100 \%$ for $5 \mathrm{~min}, 1 \times 100 \%$ for $2 \mathrm{~min}, 2$ x 96\% for 2 min and, $1 \times 80 \%$ for $2 \mathrm{~min}$ ) and finally rinsed in water for $3 \mathrm{~min}$. For demasking of epitopes, the sections were incubated in $10 \mathrm{mM}$ citrate-buffer $(100 \mathrm{mM}$ citric acid and $100 \mathrm{mM}$ trisodiumcitrate-dihydrate), $\mathrm{pH} 6$ for $35 \mathrm{~min}$ at $95^{\circ} \mathrm{C}$. Tissue sections were then blocked in $3 \%$ goat seurm in TBS $(137 \mathrm{mM} \mathrm{NaCl}, 2.7 \mathrm{mM} \mathrm{KCl}, 24.8 \mathrm{mM}$ Tris-Base $\mathrm{pH} 7,4)$ for $30 \mathrm{~min}$ at room temperature and incubated with $100 \mu \mathrm{l}$ anti-PEPT1 antibody, (Rabbit anti PEPT1 produced against the synthetic peptide VGKENPYSSLEPVSQTNM, corresponding to the amino acids 693-710 of the rat PEPT1 Cterminus (Pineda, Berlin, Germany), 1:1000 [215]), in an antibody dilution solution with background reducing components (DAKO, S3022, Carpinteria, USA) overnight at room temperature and in a humidified chamber. After washing in TBS $(2 \times 5 \mathrm{~min})$, sections were incubated with the secondary antibodies (Donkey anti rabbit-CY5 and donkey anti goat-CY3, 1:250, Jackson Laboratories Immuno Research, West Grove) in the antibody dilution solution with background reducing component for 30 minutes in the dark at room temperature and in a humidified chamber. Then sections were mounted and examined by confocal microscopy (Leica TCS SP2, spectral confocal and multiphoton system).

\subsection{Detection of B-galactosidase activity via X-gal staining}

After washing in PBS (2x) tissue samples were fixed in LacZ fixing solution for $1 \mathrm{~h}$. To minimize cell damage samples were washed in PBS (2x) and then incubated in $20 \%$ sucrose over night. On the next day tissue samples were frozen in dry ice and stored at $-80^{\circ} \mathrm{C}$ until processing.

After cutting, frozen sections $(10-20 \mu \mathrm{m})$ were transferred to Superfrost Plus microslides (Menzel $\mathrm{GmbH}$, Braunschweig, Germany) and dried for $2 \mathrm{~h}$ at room temperature.

Sections were washed for $1 \mathrm{~min}$ in LacZ wash buffer and then incubated for $12 \mathrm{~h}$ at $37^{\circ} \mathrm{C}$ in LacZ staining solution. After that sections were washed with PBS (2x5 min) and dehydrated in ascending concentrations of ethanol in water and xylene $(70 \% \mathrm{EtOH}, 80 \% \mathrm{EtOH}, 96 \% \mathrm{EtOH}, 100 \% \mathrm{EtOH}$ for 3 min and $100 \%$ xylene for $2 \times 7 \mathrm{~min})$. Subsequently tissue sections were mounted and analyzed.

\subsection{Statistical analysis}

Statistical analysis was performed using R 2.8 (R Foundation of Statistical Computing [216]) and GraphPad Prism 4.01 (GraphPad Software, California, USA). Unless stated otherwise one-way or twoway ANOVA and Tukey-test or unpaired Students $t$-test were used to test for statistical significance. Data are presented as mean \pm SD unless stated otherwise. 



\section{Appendix}

\section{List of abbreviations}

\begin{tabular}{|c|c|}
\hline 2D & two-dimensional \\
\hline${ }^{\circ} \mathrm{C}$ & degree celcius \\
\hline$\mu \mathrm{l}$ & microliter \\
\hline$\mu \mathrm{M}$ & micromolar \\
\hline aa & amino $\operatorname{acid}(\mathrm{s})$ \\
\hline Ala & alanine \\
\hline Arg & arginine \\
\hline Asn & asparagines \\
\hline Asp & aspartate \\
\hline ATP & adenosine triphosphate \\
\hline bp & base pair(s) \\
\hline bw & body weight \\
\hline CAMP & cyclic adenosine monophosphate \\
\hline CBB & coomassie brilliant blue \\
\hline cDNA & complementary deoxyribonucleic acid \\
\hline CHAPS & 3-[(3-cholamidopropyl)dimethyl-ammonio]-1-propanesulfonate \\
\hline C-terminus & carboxy-terminus \\
\hline Cys-Gly & cysteinyl-glycine \\
\hline D-Ala-Lys-AMCA & D-alanyl-lysyl-N- $\varepsilon-7$-amino-4-methylcoumarin-3-acetic acid \\
\hline dATP & deoxyadenosine triphosphate \\
\hline D-Phe-Ala & D-phenylalanyl-alanine \\
\hline DTT & dithiothreitol \\
\hline E.coli & Escherichia coli \\
\hline EDTA & ethylenediaminetetraacetic acid \\
\hline ENU & $\mathrm{N}$-nitroso-N-ethylurea \\
\hline ES cells & embryonic stem cells \\
\hline FDR & false discovery rate \\
\hline
\end{tabular}


Fig.

g

Gln

Glu

Gly-Sar

h

His

HPLC

Hyp

IEF

Ile

IPG

$\mathrm{kD}$

ko

LC

Leu

Lys

M

Met

$\min$

$\mathrm{ml}$

$\mathrm{mM}$

MNE

mRNA

MS

n

$\mathrm{N}$-terminus

PAGE

PCR

$\mathrm{pH}$

Phe figure

acceleration of gravity

glutamine

glutamate

glycyl-sarcosine

$\operatorname{hour}(\mathrm{s})$

histidine

high performance liquid chromatography

hydroxyproline

isoelectric focusing

isoleucine

immobilized $\mathrm{pH}$ gradient

kilo Dalton

knockout

liquid chromatography

leucine

lysine

$\operatorname{molar}(\mathrm{mol} / \mathrm{l})$

methionine

minutes(s)

mililiter

millimolar

mean normalized expression

messenger deoxyribonucleic acid

mass spectrometry

number of samples

amino-terminus

polyacrylamide gel electrophoresis

polymerase chain reaction

logarithm of the reciprocal of hydrogen-ion concentration

Phenylalanine 
POT

qPCR

rpm

RT-PCR

SD

SDS

SEM

TMD

TOF

Tyr

Val

wt

$\mathrm{V}_{\max }$ proton coupled oligopeptide transporter superfamily

quantitative real-time reverse transcription polymerase chain reaction rounds per minute

reverse transcription polymerase chain reaction

standard deviation

sodium dodecyl sulphate

standard error of the mean

transmembrane domaine

time of flight

tyrosine

valine

wild-type

maximum velocity 



\section{References}

1. Hediger, M.A., et al., The ABCs of solute carriers: physiological, pathological and therapeutic implications of human membrane transport proteinsIntroduction. Pflugers Arch, 2004. 447(5): p. 465-8.

2. Daniel, H., et al., From bacteria to man: archaic proton-dependent peptide transporters at work. Physiology (Bethesda), 2006. 21: p. 93-102.

3. He, L., K. Vasiliou, and D.W. Nebert, Analysis and update of the human solute carrier (SLC) gene superfamily. Hum Genomics, 2009. 3(2): p. 195-206.

4. Matthews, D.M., Protein absorption. Development and present state of the subject. 1991, New York: Wiley-Liss.

5. Kihara, H., W.G. McCullough, and E.E. Snell, Peptides and bacterial growth. I. Purification of a peptide factor required for growth of lactobacillus casei. J Biol Chem, 1952. 197(2): p. 783-9.

6. Snell, E.E., The Vitamin B6 group.VII. Replacement of vitamin B6 for some microorganisms by $\mathrm{d}(-)$-alanine and an unidentified factor from casein. J Biol Chem, 1945. 158: p. 497-503.

7. Adibi, S.A., Intestinal transport of dipeptides in man: relative importance of hydrolysis and intact absorption. J Clin Invest, 1971. 50(11): p. 2266-75.

8. Adibi, S.A. and M.R. Soleimanpour, Functional characterization of dipeptide transport system in human jejunum. J Clin Invest, 1974. 53(5): p. 1368-74.

9. Adibi, S.A. and E.L. Morse, The number of glycine residues which limits intact absorption of glycine oligopeptides in human jejunum. J Clin Invest, 1977. 60(5): p. 1008-16.

10. Adibi, S.A., et al., Evidence for two different modes of tripeptide disappearance in human intestine. Uptake by peptide carrier systems and hydrolysis by peptide hydrolases. J Clin Invest, 1975. 56(6): p. 1355-63.

11. Ganapathy, V., G. Burckhardt, and F.H. Leibach, Characteristics of glycylsarcosine transport in rabbit intestinal brush-border membrane vesicles. J Biol Chem, 1984. 259(14): p. 8954-9.

12. Ganapathy and F.H. Leibach, Is intestinal peptide transport energized by a proton gradient? Am J Physiol, 1985. 249(2 Pt 1): p. G153-60.

13. Ganapathy, V. and F.H. Leibach, Role of $\mathrm{pH}$ gradient and membrane potential in dipeptide transport in intestinal and renal brush-border membrane vesicles from the rabbit. Studies with L-carnosine and glycyl-L-proline. J Biol Chem, 1983. 258(23): p. 14189-92.

14. Silbernagl, S., V. Ganapathy, and F.H. Leibach, H+ gradient-driven dipeptide reabsorption in proximal tubule of rat kidney. Studies in vivo and in vitro. Am J Physiol, 1987. 253(3 Pt 2): p. F448-57.

15. Daniel, H., E.L. Morse, and S.A. Adibi, The high and low affinity transport systems for dipeptides in kidney brush border membrane respond differently to alterations in $\mathrm{pH}$ gradient and membrane potential. J Biol Chem, 1991. 266(30): p. 19917-24.

16. Daniel, H., E.L. Morse, and S.A. Adibi, Determinants of substrate affinity for the oligopeptide/H+ symporter in the renal brush border membrane. J Biol Chem, 1992. 267(14): p. 9565-73.

17. Daniel, H. and S.A. Adibi, Transport of beta-lactam antibiotics in kidney brush border membrane. Determinants of their affinity for the oligopeptide/ $\mathrm{H}+$ symporter. J Clin Invest, 1993. 92(5): p. 2215-23.

18. Fei, Y.J., et al., Expression cloning of a mammalian proton-coupled oligopeptide transporter. Nature, 1994. 368(6471): p. 563-6.

19. Boll, M., et al., Expression cloning of a cDNA from rabbit small intestine related to protoncoupled transport of peptides, beta-lactam antibiotics and ACE-inhibitors. Pflugers Arch, 1994. 429(1): p. 146-9.

20. Boll, M., et al., Expression cloning and functional characterization of the kidney cortex highaffinity proton-coupled peptide transporter. Proc Natl Acad Sci U S A, 1996. 93(1): p. 284-9.

21. Liu, W., et al., Molecular cloning of PEPT 2, a new member of the $\mathrm{H}+$ /peptide cotransporter family, from human kidney. Biochim Biophys Acta, 1995. 1235(2): p. 461-6.

22. Yamashita, T., et al., Cloning and functional expression of a brain peptide/histidine transporter. J Biol Chem, 1997. 272(15): p. 10205-11.

23. Sakata, K., et al., Cloning of a lymphatic peptide/histidine transporter. Biochem J, 2001. 356(Pt 1): p. 53-60. 
24. Ganapathy, V., G. Burckhardt, and F.H. Leibach, Peptide transport in rabbit intestinal brush-border membrane vesicles studied with a potential-sensitive dye. Biochim Biophys Acta, 1985. 816(2): p. 234-40.

25. Kennedy, D.J., et al., Optimal absorptive transport of the dipeptide glycylsarcosine is dependent on functional $\mathrm{Na}+/ \mathrm{H}+$ exchange activity. Pflugers Arch, 2002. 445(1): p. 139-46.

26. Kennedy, D.J., D. Raldua, and D.T. Thwaites, Dual modes of 5-(N-ethyl-Nisopropyl)amiloride modulation of apical dipeptide uptake in the human small intestinal epithelial cell line Caco-2. Cell Mol Life Sci, 2005. 62(14): p. 1621-31.

27. Anderson, C.M., et al., Inhibition of intestinal dipeptide transport by the neuropeptide VIP is an anti-absorptive effect via the VPAC1 receptor in a human enterocyte-like cell line (Caco-2). Br J Pharmacol, 2003. 138(4): p. 564-73.

28. Thwaites, D.T., et al., $\mathrm{H}(+)$ /solute-induced intracellular acidification leads to selective activation of apical $\mathrm{Na}(+) / \mathrm{H}(+)$ exchange in human intestinal epithelial cells. J Clin Invest, 1999. 104(5): p. 629-35.

29. Thwaites, D.T., et al., H/dipeptide absorption across the human intestinal epithelium is controlled indirectly via a functional $\mathrm{Na} / \mathrm{H}$ exchanger. Gastroenterology, 2002. 122(5): p. 132233.

30. Chen, M., et al., Gene ablation for PEPT1 in mice abolishes the effects of dipeptides on small intestinal fluid absorption, short circuit current and intracellular pH. Am J Physiol Gastrointest Liver Physiol, 2010.

31. Daniel, H., Molecular and integrative physiology of intestinal peptide transport. Annu Rev Physiol, 2004. 66: p. 361-84.

32. Liang, R., et al., Human intestinal $\mathrm{H}_{+}$/peptide cotransporter. Cloning, functional expression, and chromosomal localization. J Biol Chem, 1995. 270(12): p. 6456-63.

33. Fei, Y.J., et al., cDNA structure, genomic organization, and promoter analysis of the mouse intestinal peptide transporter PEPT1. Biochim Biophys Acta, 2000. 1492(1): p. 145-54.

34. Urtti, A., S.J. Johns, and W. Sadee, Genomic structure of proton-coupled oligopeptide transporter hPEPT1 and pH-sensing regulatory splice variant. AAPS PharmSci, 2001. 3(1): p. E6.

35. Shimakura, J., et al., Characterization of the human peptide transporter PEPT1 promoter: Sp1 functions as a basal transcriptional regulator of human PEPT1. Am J Physiol Gastrointest Liver Physiol, 2005. 289(3): p. G471-7.

36. Fei, Y.J., V. Ganapathy, and F.H. Leibach, Molecular and structural features of the protoncoupled oligopeptide transporter superfamily. Prog Nucleic Acid Res Mol Biol, 1998. 58: p. 239-61.

37. Doring, F., et al., Functional analysis of a chimeric mammalian peptide transporter derived from the intestinal and renal isoforms. J Physiol, 1996. 497 ( Pt 3): p. 773-9.

38. Fei, Y.J., et al., Identification of the histidyl residue obligatory for the catalytic activity of the human $\mathrm{H}+$ /peptide cotransporters PEPT1 and PEPT2. Biochemistry, 1997. 36(2): p. 452-60.

39. Terada, T., et al., Identification of the histidine residues involved in substrate recognition by a rat $\mathrm{H}+$ /peptide cotransporter, PEPT1. FEBS Lett, 1996. 394(2): p. 196-200.

40. Chen, X.Z., A. Steel, and M.A. Hediger, Functional roles of histidine and tyrosine residues in the $\mathrm{H}(+)$-peptide transporter PepT1. Biochem Biophys Res Commun, 2000. 272(3): p. 726-30.

41. Bolger, M.B., et al., Structure, function, and molecular modeling approaches to the study of the intestinal dipeptide transporter PepT1. J Pharm Sci, 1998. 87(11): p. 1286-91.

42. Yeung, A.K., et al., Molecular identification of a role for tyrosine 167 in the function of the human intestinal proton- coupled dipeptide transporter (hPepT1). Biochem Biophys Res Commun, 1998. 250(1): p. 103-7.

43. Lee, V.H., et al., Biopharmaceutics of transmucosal peptide and protein drug administration: role of transport mechanisms with a focus on the involvement of PepT1. J Control Release, 1999. 62(1-2): p. 129-40.

44. Meredith, D. and R.A. Price, Molecular modeling of PepT1--towards a structure. J Membr Biol, 2006. 213(2): p. 79-88.

45. Pedretti, A., et al., Modeling of the intestinal peptide transporter hPepT1 and analysis of its transport capacities by docking and pharmacophore mapping. ChemMedChem, 2008. 3(12): p. 1913-21.

46. Daniel, H. and G. Kottra, The proton oligopeptide cotransporter family SLC15 in physiology and pharmacology. Pflugers Arch, 2004. 447(5): p. 610-8.

47. Doring, F., et al., Minimal molecular determinants of substrates for recognition by the intestinal peptide transporter. J Biol Chem, 1998. 273(36): p. 23211-8. 
48. Doring, F., et al., Delta-aminolevulinic acid transport by intestinal and renal peptide transporters and its physiological and clinical implications. J Clin Invest, 1998. 101(12): p. 2761-7.

49. Brandsch, M., et al., Evidence for the absolute conformational specificity of the intestinal H+/peptide symporter, PEPT1. J Biol Chem, 1998. 273(7): p. 3861-4.

50. Brandsch, M., et al., Decisive structural determinants for the interaction of proline derivatives with the intestinal $\mathrm{H}_{+}$/peptide symporter. Eur J Biochem, 1999. 266(2): p. 502-8.

51. Mazzei, T. and P. Dentico, The pharmacokinetics of oral cephalosporins. Clin Microbiol Infect, 2000. 6 Suppl 3: p. 53-4.

52. Zhang, H., J. Zhang, and J.B. Streisand, Oral mucosal drug delivery: clinical pharmacokinetics and therapeutic applications. Clin Pharmacokinet, 2002. 41(9): p. 661-80.

53. Landowski, C.P., et al., Targeted delivery to PEPT1-overexpressing cells: acidic, basic, and secondary floxuridine amino acid ester prodrugs. Mol Cancer Ther, 2005. 4(4): p. 659-67.

54. Tsuda, M., et al., Transport characteristics of a novel peptide transporter 1 substrate, antihypotensive drug midodrine, and its amino acid derivatives. J Pharmacol Exp Ther, 2006. 318(1): p. 455-60.

55. Biegel, A., et al., Three-dimensional quantitative structure-activity relationship analyses of beta-lactam antibiotics and tripeptides as substrates of the mammalian $\mathrm{H}+$ /peptide cotransporter PEPT1. J Med Chem, 2005. 48(13): p. 4410-9.

56. Gebauer, S., et al., Three-dimensional quantitative structure-activity relationship analyses of peptide substrates of the mammalian $\mathrm{H}+$ /peptide cotransporter PEPT1. J Med Chem, 2003. 46(26): p. 5725-34.

57. Lu, H. and C. Klaassen, Tissue distribution and thyroid hormone regulation of Pept1 and Pept2 mRNA in rodents. Peptides, 2006. 27(4): p. 850-7.

58. Ogihara, $\mathbf{H}_{\text {., }}$ et al., Immuno-localization of $\mathrm{H}+$ /peptide cotransporter in rat digestive tract. Biochem Biophys Res Commun, 1996. 220(3): p. 848-52.

59. Hilgendorf, C., et al., Expression of thirty-six drug transporter genes in human intestine, liver, kidney, and organotypic cell lines. Drug Metab Dispos, 2007. 35(8): p. 1333-40.

60. Fenselau, H., Charakterisierung von Peptidtransporter-defizienten Mäusen zur Untersuchung der physiologischen Bedeutung von PEPT1. 2008, TU München: Freising.

61. Ogihara, H., et al., Peptide transporter in the rat small intestine: ultrastructural localization and the effect of starvation and administration of amino acids. Histochem J, 1999. 31(3): p. 169-74.

62. Terada, T., et al., Expression profiles of various transporters for oligopeptides, amino acids and organic ions along the human digestive tract. Biochem Pharmacol, 2005. 70(12): p. 175663.

63. Knutter, l., et al., $\mathrm{H}+-$ peptide cotransport in the human bile duct epithelium cell line SK-ChA1. Am J Physiol Gastrointest Liver Physiol, 2002. 283(1): p. G222-9.

64. Nässl, A., et al., Amino acid absorption and homeostasis in mice lacking the intestinal peptide transporter PEPT1. Am J Physiol Gastrointest Liver Physiol, 2011. [Epub ahead of print].

65. Shen, H., D.E. Smith, and F.C. Brosius, 3rd, Developmental expression of PEPT1 and PEPT2 in rat small intestine, colon, and kidney. Pediatr Res, 2001. 49(6): p. 789-95.

66. Merlin, D., et al., Colonic epithelial hPepT1 expression occurs in inflammatory bowel disease: transport of bacterial peptides influences expression of MHC class 1 molecules. Gastroenterology, 2001. 120(7): p. 1666-79.

67. Shen, H., et al., Localization of PEPT1 and PEPT2 proton-coupled oligopeptide transporter mRNA and protein in rat kidney. Am J Physiol, 1999. 276(5 Pt 2): p. F658-65.

68. Tramonti, G., et al., Expression and functional characteristics of tubular transporters: Pglycoprotein, PEPT1, and PEPT2 in renal mass reduction and diabetes. Am J Physiol Renal Physiol, 2006. 291(5): p. F972-80.

69. Terada, T. and K. Inui, Gene expression and regulation of drug transporters in the intestine and kidney. Biochem Pharmacol, 2007. 73(3): p. 440-9.

70. Shimakura, J., et al., Induction of intestinal peptide transporter 1 expression during fasting is mediated via peroxisome proliferator-activated receptor alpha. Am J Physiol Gastrointest Liver Physiol, 2006. 291(5): p. G851-6.

71. Hu, Y., et al., Targeted disruption of peptide transporter Pept1 gene in mice significantly reduces dipeptide absorption in intestine. Mol Pharm, 2008. 5(6): p. 1122-30.

72. Ocheltree, S.M., et al., Role and relevance of peptide transporter 2 (PEPT2) in the kidney and choroid plexus: in vivo studies with glycylsarcosine in wild-type and PEPT2 knockout mice. J Pharmacol Exp Ther, 2005. 315(1): p. 240-7.

73. Rubio-Aliaga, I., et al., Targeted disruption of the peptide transporter Pept2 gene in mice defines its physiological role in the kidney. Mol Cell Biol, 2003. 23(9): p. 3247-52. 
74. Neumann, J. and M. Brandsch, Delta-aminolevulinic acid transport in cancer cells of the human extrahepatic biliary duct. J Pharmacol Exp Ther, 2003. 305(1): p. 219-24.

75. Herrera-Ruiz, D., et al., Spatial expression patterns of peptide transporters in the human and rat gastrointestinal tracts, Caco-2 in vitro cell culture model, and multiple human tissues. AAPS PharmSci, 2001. 3(1): p. E9.

76. Augustine, L.M., et al., Xenobiotic and endobiotic transporter mRNA expression in the bloodtestis barrier. Drug Metab Dispos, 2005. 33(1): p. 182-9.

77. Gaildrat, P., et al., A novel pineal-specific product of the oligopeptide transporter PepT1 gene: circadian expression mediated by cAMP activation of an intronic promoter. J Biol Chem, 2005. 280(17): p. 16851-60.

78. Thamotharan, M., et al., Mechanism of dipeptide stimulation of its own transport in a human intestinal cell line. Proc Assoc Am Physicians, 1998. 110(4): p. 361-8.

79. Walker, D., et al., Substrate upregulation of the human small intestinal peptide transporter, hPepT1. J Physiol, 1998. 507 ( Pt 3): p. 697-706.

80. Erickson, R.H., et al., Regional expression and dietary regulation of rat small intestinal peptide and amino acid transporter mRNAs. Biochem Biophys Res Commun, 1995. 216(1): p. 249-57.

81. Shiraga, T., et al., Cellular and molecular mechanisms of dietary regulation on rat intestinal H+/Peptide transporter PepT1. Gastroenterology, 1999. 116(2): p. 354-62.

82. Nguyen, T.V., D. Fleisher, and D.E. Smith, In vivo effects of glycyl-glutamate and glycylsarcosine on gabapentin oral absorption in rat. Pharm Res, 2007. 24(8): p. 1538-43.

83. Ferraris, R.P., J. Diamond, and W.W. Kwan, Dietary regulation of intestinal transport of the dipeptide carnosine. Am J Physiol, 1988. 255(2 Pt 1): p. G143-50.

84. Komori, Y., et al., Effects of capsaicin on intestinal cephalexin absorption in rats. Biol Pharm Bull, 2007. 30(3): p. 547-51.

85. Wenzel, U., et al., PEPT1-mediated cefixime uptake into human intestinal epithelial cells is increased by $\mathrm{Ca} 2+$ channel blockers. Antimicrob Agents Chemother, 2002. 46(5): p. 1375-80.

86. Wenzel, U., S. Kuntz, and H. Daniel, Flavonoids with epidermal growth factor-receptor tyrosine kinase inhibitory activity stimulate PEPT1-mediated cefixime uptake into human intestinal epithelial cells. J Pharmacol Exp Ther, 2001. 299(1): p. 351-7.

87. Anderson, C.M. and D.T. Thwaites, Regulation of intestinal hPepT1 (SLC15A1) activity by phosphodiesterase inhibitors is via inhibition of NHE3 (SLC9A3). Biochim Biophys Acta, 2007. 1768(7): p. 1822-9.

88. Fisher, S.J., et al., Evaluation of the effect of ethanol's toxic metabolite acetaldehyde on the gastrointestinal oligopeptide transporter, PEPT1: in vitro and in vivo studies. Alcohol Clin Exp Res, 2008. 32(1): p. 162-70.

89. Nielsen, C.U. and B. Brodin, Di/tri-peptide transporters as drug delivery targets: regulation of transport under physiological and patho-physiological conditions. Curr Drug Targets, 2003. 4(5): p. 373-88.

90. Habold, C., et al., Morphological changes of the rat intestinal lining in relation to body stores depletion during fasting and after refeeding. Pflugers Arch, 2007. 455(2): p. 323-32.

91. Thamotharan, M., et al., Functional and molecular expression of intestinal oligopeptide transporter (Pept-1) after a brief fast. Metabolism, 1999. 48(6): p. 681-4.

92. Doring, F., et al., Hypothyroidism induces expression of the peptide transporter PEPT2. Biol Chem, 2005. 386(8): p. 785-90.

93. Ashida, K., et al., Decreased activity and expression of intestinal oligopeptide transporter PEPT1 in rats with hyperthyroidism in vivo. Pharm Res, 2004. 21(6): p. 969-75.

94. Sun, B.W., et al., Hormonal regulation of dipeptide transporter (PepT1) in Caco-2 cells with normal and anoxia/reoxygenation management. World J Gastroenterol, 2003. 9(4): p. 808-12.

95. Alteheld, B., et al., Alanylglutamine dipeptide and growth hormone maintain PepT1-mediated transport in oxidatively stressed Caco-2 cells. J Nutr, 2005. 135(1): p. 19-26.

96. Cocchi, D., et al., Leptin regulates GH secretion in the rat by acting on GHRH and somatostatinergic functions. J Endocrinol, 1999. 162(1): p. 95-9.

97. Adibi, S.A., Regulation of expression of the intestinal oligopeptide transporter (Pept-1) in health and disease. Am J Physiol Gastrointest Liver Physiol, 2003. 285(5): p. G779-88.

98. Bikhazi, A.B., et al., Effect of diabetes mellitus and insulin on the regulation of the PepT 1 symporter in rat jejunum. Mol Pharm, 2004. 1(4): p. 300-8.

99. Watanabe, K., et al., Effect of insulin on cephalexin uptake and transepithelial transport in the human intestinal cell line Caco-2. Eur J Pharm Sci, 2004. 21(1): p. 87-95.

100. Hindlet, P., et al., Long-term effect of leptin on $\mathrm{H}_{+}$-coupled peptide cotransporter 1 activity and expression in vivo: evidence in leptin-deficient mice. J Pharmacol Exp Ther, 2007. 323(1): p. $192-201$. 
101. Nduati, V., et al., Leptin transcriptionally enhances peptide transporter (hPepT1) expression and activity via the cAMP-response element-binding protein and $\mathrm{Cdx} 2$ transcription factors. $\mathrm{J}$ Biol Chem, 2007. 282(2): p. 1359-73.

102. Nielsen, C.U., et al., Epidermal growth factor inhibits glycylsarcosine transport and hPepT1 expression in a human intestinal cell line. Am J Physiol Gastrointest Liver Physiol, 2001. 281(1): p. G191-9.

103. Hang, C.H., et al., Apoptosis and functional changes of dipeptide transporter (PepT1) in the rat small intestine after traumatic brain injury. J Surg Res, 2007. 137(1): p. 53-60.

104. Ziegler, T.R., et al., Distribution of the $\mathrm{H}_{+}$/peptide transporter PepT1 in human intestine: upregulated expression in the colonic mucosa of patients with short-bowel syndrome. Am J Clin Nutr, 2002. 75(5): p. 922-30.

105. Tachibana, K., et al., Analysis of PPAR alpha function in human kidney cell line using siRNA. Nucleic Acids Symp Ser (Oxf), 2006(50): p. 257-8.

106. Daniel, H. and I. Rubio-Aliaga, An update on renal peptide transporters. Am J Physiol Renal Physiol, 2003. 284(5): p. F885-92.

107. Rubio-Aliaga, I. and H. Daniel, Mammalian peptide transporters as targets for drug delivery. Trends Pharmacol Sci, 2002. 23(9): p. 434-40.

108. Rubio-Aliaga, I. and H. Daniel, Peptide transporters and their roles in physiological processes and drug disposition. Xenobiotica, 2008. 38(7-8): p. 1022-42.

109. Saito, $\mathbf{H}$., et al., Cloning and characterization of a $\mathrm{pH}$-sensing regulatory factor that modulates transport activity of the human $\mathrm{H}+$ /peptide cotransporter, PEPT1. Biochem Biophys Res Commun, 1997. 237(3): p. 577-82.

110. Ruhl, A., et al., Functional expression of the peptide transporter PEPT2 in the mammalian enteric nervous system. J Comp Neurol, 2005. 490(1): p. 1-11.

111. Groneberg, D.A., et al., Peptide transport in the mammary gland: expression and distribution of PEPT2 mRNA and protein. Am J Physiol Endocrinol Metab, 2002. 282(5): p. E1172-9.

112. Nickolaus, M., Nachweis und zelluläre Lokalisation des Peptistransporters (PepT2) in extrarenalen Geweben in Justus Liebig Universität Gießen. 2001.

113. Groneberg, D.A., et al., Localization of the peptide transporter PEPT2 in the lung: implications for pulmonary oligopeptide uptake. Am J Pathol, 2001. 158(2): p. 707-14.

114. Bahadduri, P.M., et al., Functional characterization of the peptide transporter PEPT2 in primary cultures of human upper airway epithelium. Am J Respir Cell Mol Biol, 2005. 32(4): p. 319-25.

115. Groneberg, D.A., H. Paul, and T. Welte, Novel strategies of aerosolic pharmacotherapy. Exp Toxicol Pathol, 2006. 57 Suppl 2: p. 49-53.

116. Adibi, S.A., Renal assimilation of oligopeptides: physiological mechanisms and metabolic importance. Am J Physiol, 1997. 272(5 Pt 1): p. E723-36.

117. Palacin, M., et al., Molecular biology of mammalian plasma membrane amino acid transporters. Physiol Rev, 1998. 78(4): p. 969-1054.

118. Rubio-Aliaga, I., M. Boll, and H. Daniel, Cloning and characterization of the gene encoding the mouse peptide transporter PEPT2. Biochem Biophys Res Commun, 2000. 276(2): p. 73441.

119. Frey, I.M., et al., Phenotype analysis of mice deficient in the peptide transporter PEPT2 in response to alterations in dietary protein intake. Pflugers Arch, 2006. 452(3): p. 300-6.

120. Ocheltree, S.M., et al., Preliminary investigation into the expression of proton-coupled oligopeptide transporters in neural retina and retinal pigment epithelium (RPE): lack of functional activity in RPE plasma membranes. Pharm Res, 2003. 20(9): p. 1364-72.

121. Marrs, T.C., et al., Changes in plasma amino acid concentrations in man after ingestion of an amino acid mixture simulating casein, and a tryptic hydrolysate of casein. $\mathrm{Br} \mathrm{J}$ Nutr, 1975. 34(2): p. 259-65.

122. Adibi, S.A., The oligopeptide transporter (Pept-1) in human intestine: biology and function. Gastroenterology, 1997. 113(1): p. 332-40.

123. Kania, R.K., N.A. Santiago, and G.M. Gray, Intestinal surface amino-oligopeptidases. II. Substrate kinetics and topography of the active site. J Biol Chem, 1977. 252(14): p. 4929-34.

124. Piggott, C.O., G. O'Cuinn, and P.F. Fottrell, Similarities between a dipeptide hydrolase from brush-border and cytosol fractions of guinea-pig intestinal mucosa. Biochem J, 1976. 159(3): p. 715-7.

125. Sterchi, E.E. and J.F. Woodley, Peptide hydrolases of the human small intestinal mucosa: distribution of activities between brush border membranes and cytosol. Clin Chim Acta, 1980. 102(1): p. 49-56.

126. Dantzig, A.H., et al., Association of intestinal peptide transport with a protein related to the cadherin superfamily. Science, 1994. 264(5157): p. 430-3. 
127. Irie, M., et al., Recognition and transport characteristics of nonpeptidic compounds by basolateral peptide transporter in Caco-2 cells. J Pharmacol Exp Ther, 2001. 298(2): p. 711-7.

128. Matsumoto, S., H. Saito, and K. Inui, Transcellular transport of oral cephalosporins in human intestinal epithelial cells, Caco-2: interaction with dipeptide transport systems in apical and basolateral membranes. J Pharmacol Exp Ther, 1994. 270(2): p. 498-504.

129. Saito, H. and K. Inui, Dipeptide transporters in apical and basolateral membranes of the human intestinal cell line Caco-2. Am J Physiol, 1993. 265(2 Pt 1): p. G289-94.

130. Takeda, M., et al., Human organic anion transporters and human organic cation transporters mediate renal antiviral transport. J Pharmacol Exp Ther, 2002. 300(3): p. 918-24.

131. Broer, S., Amino acid transport across mammalian intestinal and renal epithelia. Physiol Rev, 2008. 88(1): p. 249-86.

132. Christensen, H.N., Role of amino acid transport and countertransport in nutrition and metabolism. Physiol Rev, 1990. 70(1): p. 43-77.

133. Milne, M.D., Disorders of Amino-Acid Transport. Br Med J, 1964. 1(5379): p. 327-36.

134. Scriver, C.R., R.W. Chesney, and R.R. McInnes, Genetic aspects of renal tubular transport: diversity and topology of carriers. Kidney Int, 1976. 9(2): p. 149-71.

135. Thier, S.O. and D.H. Alpers, Disorders of intestinal transport of amino acids. Am J Dis Child, 1969. 117(1): p. 13-23.

136. Young, J.A. and B.S. Freedman, Renal tubular transport of amino acids. Clin Chem, 1971. 17(4): p. 245-66.

137. Kleta, R., et al., Mutations in SLC6A19, encoding B0AT1, cause Hartnup disorder. Nat Genet, 2004. 36(9): p. 999-1002.

138. Levy, L.L., Hartnup disorder, in The Metabolic and Molecular Bases of Inherited Diseases (8th ed.), C.R. Scriver, et al., Editors. 2001, McGraw-Hill: New York. p. 4957-4969.

139. Jonas, A.J. and I.J. Butler, Circumvention of defective neutral amino acid transport in Hartnup disease using tryptophan ethyl ester. J Clin Invest, 1989. 84(1): p. 200-4.

140. Palacin, M., G. Borsani, and G. Sebastio, The molecular bases of cystinuria and lysinuric protein intolerance. Curr Opin Genet Dev, 2001. 11(3): p. 328-35.

141. Seow, H.F., et al., Hartnup disorder is caused by mutations in the gene encoding the neutral amino acid transporter SLC6A19. Nat Genet, 2004. 36(9): p. 1003-7.

142. Palacin, M., et al., Cystinuria, in Metabolic and Molecular Basis of Inherited Diseases (8th ed.). . 2001a. p. 4909-4932.

143. Asatoor, A.M., et al., Intestinal absorption of carnosine and its constituent amino acids in man. Gut, 1970. 11(3): p. 250-4.

144. Hellier, M.D., et al., Absorption of dipeptides in normal and cystinuric subjects. Gut, 1971. 12(6): p. 496-7.

145. Leibach, F.H. and V. Ganapathy, Peptide transporters in the intestine and the kidney. Annu Rev Nutr, 1996. 16: p. 99-119.

146. Meissner, B., et al., Deletion of the intestinal peptide transporter affects insulin and TOR signaling in Caenorhabditis elegans. J Biol Chem, 2004. 279(35): p. 36739-45.

147. Wu, Z., et al., A Model-Based Background Adjustment for Oligonucleotide Expression Arrays. J American Statistical Association, 2004. 99: p. 909-917.

148. Adibi, S.A. and D.W. Mercer, Protein digestion in human intestine as reflected in luminal, mucosal, and plasma amino acid concentrations after meals. J Clin Invest, 1973. 52(7): p. 1586-94.

149. Ganapathy, V. and F.H. Leibach, Peptide transport in intestinal and renal brush border membrane vesicles. Life Sci, 1982. 30(25): p. 2137-46.

150. Thwaites, D.T. and C.M. Anderson, $\mathrm{H}_{+}$-coupled nutrient, micronutrient and drug transporters in the mammalian small intestine. Exp Physiol, 2007. 92(4): p. 603-19.

151. Naruhashi, K., et al., PepT1 mRNA expression is induced by starvation and its level correlates with absorptive transport of cefadroxil longitudinally in the rat intestine. Pharm Res, 2002. 19(10): p. 1417-23.

152. Spanier, B., et al., How the intestinal peptide transporter PEPT-1 contributes to an obesity phenotype in Caenorhabditits elegans. PLoS One, 2009. 4(7): p. e6279.

153. Boll, M., et al., Functional characterization of two novel mammalian electrogenic protondependent amino acid cotransporters. J Biol Chem, 2002. 277(25): p. 22966-73.

154. Chen, Z., et al., Structure, function and immunolocalization of a proton-coupled amino acid transporter (hPAT1) in the human intestinal cell line Caco-2. J Physiol, 2003. 546(Pt 2): p. 349-61.

155. Anderson, C.M., et al., $\mathrm{H}+$ /amino acid transporter 1 (PAT1) is the imino acid carrier: An intestinal nutrient/drug transporter in human and rat. Gastroenterology, 2004. 127(5): p. 141022. 
156. Anderson, C.M. and D.T. Thwaites, Indirect regulation of the intestinal $\mathrm{H}_{+}-$coupled amino acid transporter hPAT1 (SLC36A1). J Cell Physiol, 2005. 204(2): p. 604-13.

157. Takanaga, H., et al., Identification of mammalian proline transporter SIT1 (SLC6A20) with characteristics of classical system imino. J Biol Chem, 2005. 280(10): p. 8974-84.

158. Ristic, Z., et al., Neutral amino acid transport mediated by ortholog of imino acid transporter SIT1/SLC6A20 in opossum kidney cells. Am J Physiol Renal Physiol, 2006. 290(4): p. F880-7.

159. O'Mara, M., A. Oakley, and S. Broer, Mechanism and putative structure of $B(0)$-like neutral amino acid transporters. J Membr Biol, 2006. 213(2): p. 111-8.

160. Folin, O., The American Journal of Physiology Volume XIII: 117-138, 1905. A theory of protein metabolism. Nutr Rev, 1975. 33(5): p. 141-3.

161. Goettsch, M., Minimum protein requirement of the adult rat for 28-day periods of maintenance of body weight. J Nutr, 1951. 45(4): p. 609-20.

162. Goettsch, M., Minimal protein requirement for growth in the rat. Arch Biochem, 1948. 19(3): $p$. 349-58.

163. Goettsch, M., Minimal protein requirement of the rat for reproduction and lactation. Arch Biochem, 1949. 21(2): p. 289-300.

164. Bensaid, A., et al., Protein is more potent than carbohydrate for reducing appetite in rats. Physiol Behav, 2002. 75(4): p. 577-82.

165. Lejeune, M.P., et al., Ghrelin and glucagon-like peptide 1 concentrations, 24-h satiety, and energy and substrate metabolism during a high-protein diet and measured in a respiration chamber. Am J Clin Nutr, 2006. 83(1): p. 89-94.

166. Weigle, D.S., et al., A high-protein diet induces sustained reductions in appetite, ad libitum caloric intake, and body weight despite compensatory changes in diurnal plasma leptin and ghrelin concentrations. Am J Clin Nutr, 2005. 82(1): p. 41-8.

167. Tome, D., Protein, amino acids and the control of food intake. Br J Nutr, 2004. 92 Suppl 1: p. S27-30.

168. Adolph, E.F., Urges to eat and drink in rats. Am J Physiol, 1947. 151(1): p. 110-25.

169. Wren, A.M., et al., The novel hypothalamic peptide ghrelin stimulates food intake and growth hormone secretion. Endocrinology, 2000. 141(11): p. 4325-8.

170. Nakazato, M., et al., A role for ghrelin in the central regulation of feeding. Nature, 2001. 409(6817): p. 194-8.

171. Kojima, M., et al., Ghrelin is a growth-hormone-releasing acylated peptide from stomach. Nature, 1999. 402(6762): p. 656-60.

172. Cummings, D.E. and M.H. Shannon, Roles for ghrelin in the regulation of appetite and body weight. Arch Surg, 2003. 138(4): p. 389-96.

173. Schwartz, M.W., et al., Central nervous system control of food intake. Nature, 2000. 404(6778): p. 661-71.

174. Buyse, M., et al., PepT1-mediated epithelial transport of dipeptides and cephalexin is enhanced by luminal leptin in the small intestine. J Clin Invest, 2001. 108(10): p. 1483-94.

175. Hindlet, P., et al., Reduced intestinal absorption of dipeptides via PepT1 in mice with dietinduced obesity is associated with leptin receptor down-regulation. J Biol Chem, 2009. 284(11): p. 6801-8.

176. Tome, D., et al., Protein, amino acids, vagus nerve signaling, and the brain. Am J Clin Nutr, 2009. 90(3): p. 838S-843S.

177. Faipoux, R., et al., Proteins activate satiety-related neuronal pathways in the brainstem and hypothalamus of rats. J Nutr, 2008. 138(6): p. 1172-8.

178. Mithieux, G., et al., Portal sensing of intestinal gluconeogenesis is a mechanistic link in the diminution of food intake induced by diet protein. Cell Metab, 2005. 2(5): p. 321-9.

179. Mithieux, G., A novel function of intestinal gluconeogenesis: central signaling in glucose and energy homeostasis. Nutrition, 2009. 25(9): p. 881-4.

180. Mithieux, G., F. Andreelli, and C. Magnan, Intestinal gluconeogenesis: key signal of central control of energy and glucose homeostasis. Curr Opin Clin Nutr Metab Care, 2009. 12(4): p. 419-23.

181. Martin, G., et al., Glutamine gluconeogenesis in the small intestine of $72 \mathrm{~h}$-fasted adult rats is undetectable. Biochem J, 2007. 401(2): p. 465-73.

182. Remesey, C., C. Demigne, and J. Aufrere, Inter-organ relationships between glucose, lactate and amino acids in rats fed on high-carbohydrate or high-protein diets. Biochem $\mathrm{J}$, 1978. 170(2): p. 321-9.

183. Cota, D., et al., Hypothalamic mTOR signaling regulates food intake. Science, 2006. 312(5775): p. 927-30.

184. Le Bricon, T., Effects of administration of oral branched-chain amino acids on anorexia and caloric intake in cancer patients. Clin Nutr, 1996. 15(6): p. 337. 
185. Hiroshige, K., et al., Oral supplementation of branched-chain amino acid improves nutritional status in elderly patients on chronic haemodialysis. Nephrol Dial Transplant, 2001. 16(9): p. 1856-62.

186. Noatsch, A., et al., Body weight and energy homeostasis was not affected in C57BL/6 mice fed high whey protein or leucine-supplemented low-fat diets. Eur J Nutr.

187. Zhang, Y., et al., Increasing dietary leucine intake reduces diet-induced obesity and improves glucose and cholesterol metabolism in mice via multimechanisms. Diabetes, 2007. 56(6): p. 1647-54.

188. Peters, J.C. and A.E. Harper, Influence of dietary protein level on protein self-selection and plasma and brain amino acid concentrations. Physiol Behav, 1984. 33(5): p. 783-90.

189. Peters, J.C. and A.E. Harper, Adaptation of rats to diets containing different levels of protein: effects on food intake, plasma and brain amino acid concentrations and brain neurotransmitter metabolism. J Nutr, 1985. 115(3): p. 382-98.

190. Anderson, H.L., N.J. Benevenga, and A.E. Harper, Associations among food and protein intake, serine dehydratase, and plasma amino acids. Am J Physiol, 1968. 214(5): p. 1008-13.

191. Kuhla, B., et al., Effect of a high-protein diet on food intake and liver metabolism during pregnancy, lactation and after weaning in mice. Proteomics. 10(14): p. 2573-88.

192. Morley, J.E. and J.F. Flood, Evidence that nitric oxide modulates food intake in mice. Life Sci, 1991. 49(10): p. 707-11.

193. Buchmann, I., et al., Effect of arginine administration on plasma and brain levels of arginine and various related amino compounds in the rat. Pharmacology, 1996. 53(3): p. 133-42.

194. Calapai, G., et al., Leptin increases serotonin turnover by inhibition of brain nitric oxide synthesis. J Clin Invest, 1999. 104(7): p. 975-82.

195. van't Hof, R.J., et al., Regulation of bone mass and bone turnover by neuronal nitric oxide synthase. Endocrinology, 2004. 145(11): p. 5068-74.

196. Squadrito, F., et al., Food deprivation increases brain nitric oxide synthase and depresses brain serotonin levels in rats. Neuropharmacology, 1994. 33(1): p. 83-6.

197. Yang, S.J. and D.M. Denbow, Interaction of leptin and nitric oxide on food intake in broilers and Leghorns. Physiol Behav, 2007. 92(4): p. 651-7.

198. Denbow, D.M., et al., Leptin-induced decrease in food intake in chickens. Physiol Behav, 2000. 69(3): p. 359-62.

199. Squadrito, F., et al., Central serotoninergic system involvement in the anorexia induced by NG-nitro-L-arginine, an inhibitor of nitric oxide synthase. Eur J Pharmacol, 1994. 255(1-3): p. 51-5.

200. Squadrito, F., et al., Anorectic activity of NG-nitro-L-arginine, an inhibitor of brain nitric oxide synthase, in obese Zucker rats. Eur J Pharmacol, 1993. 230(1): p. 125-8.

201. Ashida, K. and A.E. Harper, Metabolic adaptations in higher animals. IV. Liver arginase activity during adaptation to high protein diet. Proc Soc Exp Biol Med, 1961. 107: p. 151-6.

202. Rosen, F., N.R. Roberts, and C.A. Nichol, Glucocorticosteroids and transaminase activity. I. Increased activity of glutamicpyruvic transaminase in four conditions associated with gluconeogenesis. J Biol Chem, 1959. 234(3): p. 476-80.

203. Schimke, R.T., Adaptive characteristics of urea cycle enzymes in the rat. J Biol Chem, 1962. 237: p. 459-68.

204. Waldorf, M.A. and A.E. Harper, Metabolic adaptations in higher animals. VIII. Effect of diet on ornithine-alpha-ketoglutarate transaminase. Proc Soc Exp Biol Med, 1963. 112: p. 955-8.

205. Waldorf, M.A., et al., Metabolic adaptations in higher animals. VII. Responses of glutamateoxalacetate and glutamate-pyruvate transaminases to diet. Proc Soc Exp Biol Med, 1963. 112: p. 764-8.

206. Jean, C., et al., Metabolic evidence for adaptation to a high protein diet in rats. J Nutr, 2001. 131(1): p. 91-8.

207. Sanchez-Muros, M.J., et al., Long-term nutritional effects on the primary liver and kidney metabolism in rainbow trout. Adaptive response to starvation and a high-protein, carbohydrate-free diet on glutamate dehydrogenase and alanine aminotransferase kinetics. Int J Biochem Cell Biol, 1998. 30(1): p. 55-63.

208. Al-Awadi, F.M., Activity of adenylate deaminase and glutamate dehydrogenase in the liver: species and dietary variation. Comp Biochem Physiol B, 1982. 71(4): p. 605-9.

209. Foltz, M., P.C. van der Pijl, and G.S. Duchateau, Current in vitro testing of bioactive peptides is not valuable. J Nutr, 2010. 140(1): p. 117-8.

210. Galat, A., Peptidylproline cis-trans-isomerases: immunophilins. Eur J Biochem, 1993. 216(3): p. 689-707.

211. Gorg, A., et al., The current state of two-dimensional electrophoresis with immobilized $\mathrm{pH}$ gradients. Electrophoresis, 2000. 21(6): p. 1037-53. 
212. Winkelmann, I., et al., Proteome response in HT-29 human colorectal cancer cells to two apoptosis-inducing compounds with different mode of action. Int J Cancer, 2008. 122(10): p. 2223-32.

213. Pfaffl, M.W., et al., Determination of stable housekeeping genes, differentially regulated target genes and sample integrity: BestKeeper--Excel-based tool using pair-wise correlations. Biotechnol Lett, 2004. 26(6): p. 509-15.

214. McNamara, P.D., et al., Proline and glycine uptake by renal brushborder membrane vesicles. Proc Natl Acad Sci USA, 1976. 73(12): p. 4521-5.

215. Tanaka, H., et al., Regulation of the PepT1 peptide transporter in the rat small intestine in response to 5-fluorouracil-induced injury. Gastroenterology, 1998. 114(4): p. 714-23.

216. Team, R.D.C. R: A language and environment for statistical computing. 2009 [cited; Available from: http://www.R-project.org. 


\section{Erklärung}

Hiermit versichere ich, dass die vorliegende Arbeit

Amino acid absorption and homeostasis in mice lacking the intestinal peptide transporter PEPT1

selbständig verfasst und keine anderen als die angegebenen Quellen und Hilfsmittel benutzt habe. Die den benutzten Quellen wörtlich und inhaltlich entnommenen Stellen sind als solche kenntlich gemacht.

Diese Arbeit hat in gleicher oder ähnlicher Form noch keiner anderen Prüfungsbehörde vorgelegen.

Arget, den 17.08.2011

Anna-Maria NäßI 
Teile dieser Arbeit wurden bereits vorab veröffentlicht:

NässI AM, Rubio-Aliaga I, Fenselau H, Marth MK, Kottra G, Daniel H.

Amino acid absorption and homeostasis in mice lacking the intestinal peptide transporter PEPT1. Am J Physiol Gastrointest Liver Physiol. 2011 Feb 24. [Epub ahead of print]

Manuskript in Vorbereitung

NässI AM, Rubio-Aliaga I, Sailer M, Daniel H.

The intestinal peptide transporter PEPT1 is involved in food intake regulation in mice fed a highprotein diet 


\section{Curriculum vitae}

\section{Personal details}

Anna-Maria Näßl

Address

Zum Lang 1

82054 Sauerlach

Nationality

German

\section{School Education}

$1991-2000$

High School - Gymnasium Erding

$1987-1991$

Primary School Oberding

\section{University Education}

Since 05/2006

PhD in Nutrition Physiology in the group of Prof. Dr. Hannelore Daniel, Molecular Nutrition Unit, Technische Universität München/Weihenstephan, Germany „Amino acid absorption and homeostasis in mice lacking the intestinal peptide transporter PEPT1"

2000-2006

Nutrition science and home economics (Ökotrophologie), TU München/Weihenstephan

WS $2004 / 2005$

Study abroad - Anglia Polytechnic University in Cambridge (England)

\section{Selected Oral Presentations and Poster Contributions}

2009

NuGO Week - Montecatini Terme, Italy

2008

DFG Kongress - Bonn, Germany

2008

Transporters 2008 - Murten, Switzerland

2007

NuGO Week - Oslo, Norway 


\section{List of Scientific Publications}

2011 Nässl AM, Rubio-Aliaga I, Fenselau H, Marth MK, Kottra G, Daniel H.

Amino acid absorption and homeostasis in mice lacking the intestinal peptide transporter PEPT1.

Am J Physiol Gastrointest Liver Physiol. 2011 Feb 24. [Epub ahead of print]

2010

Chen M, Singh A, Xiao F, Dringenberg U, Wang J, Engelhardt R, Yeruva S, Rubio-

Aliaga I, NässI AM, Kottra G, Daniel H, Seidler U.

Gene ablation for PEPT1 in mice abolishes the effects of dipeptides on small intestinal fluid absorption, short-circuit current, and intracellular $\mathrm{pH}$.

American Journal of Physiology - Gastrointestinal and Liver Physiology. 299(1):G26574 (2010).

Rexhepaj R, Rotte A, Kempe DS, Sopjani M, Föller M, Gehring EM, Bhandaru M,

Gruner I, Mack AF, Rubio-Aliaga I, NässI AM, Daniel H, KuhI D, Lang F. Stimulation of electrogenic intestinal dipeptide transport by the glucocorticoid dexamethasone.

Pflügers Archive.459(1):191-202 (2009).

Winkelmann I, NässI AM, Daniel H, Wenzel U.

Proteome response in HT-29 human colorectal cancer cells to two apoptosis-inducing compounds with different mode of action.

International Journal of Cancer.122(10):2223-32 (2008). 



\section{Danksagung}

An dieser Stelle möchte ich mich bei allen, die auf verschiedenste Weise zum Gelingen dieser Arbeit beigetragen haben, ganz herzlich bedanken:

Frau Prof. Hannelore Daniel, weil Sie mir überhaupt erst diese Doktorarbeit ermöglicht haben. Diese Arbeit stets mit kritischem Auge „überwacht“ haben und in vielfältiger Weise zum Gelingen beigetragen haben. Vielen Dank auch an Herrn Prof. Haller und Herrn Prof. Klingenspor für die Beurteilung dieser Arbeit.

Dr. Isabel Rubio-Aliaga, weil du einfach die beste Betreuerin bist, die man sich wünschen kann und ich von dir so viel lernen konnte/durfte. Du hast mich immer unterstützt und weiter angetrieben und mit deinen Ideen und Anregungen dazu beigetragen, dass diese Arbeit so geworden ist, wie sie ist.

Dr. Isabelle Frey, weil du mich in der Anfangsphase bestens betreut und mir so ungemein viel über Mäuse beigebracht hast.

Henning Fenselau, danke für deine Arbeit.

Ronny Scheundel, für die Betreuung der Mäuse und weil du mir stets eine große Hilfe bei der Durchführung meiner Experimente warst.

Johanna Welzhofer und Barbara Gelhaus, die mich bei den Enzymassays und Proteom-Experimenten unterstützt haben und immer ein offenes Ohr hatten.

Sabine Mocek, die mir auf der „anderen Seite“ immer eine große Hilfe war.

Allen, die beim Lesen und Korrigieren der Manuskripte tatkräftig mitgewirkt haben und mit ihrer Kritik, ihren Ideen und Anregungen neue Impulse gesetzt haben.

Der ganzen Wurmgruppe, deren Tür für mich immer offen stand.

Allen Mitarbeitern der AG Daniel - ihr habt die Zeit in Freising noch schöner gemacht.

Manuela Sailer, weil du die beste Bürokollegin bist, mir jederzeit mit Rat und Tat zur Seite warst und auch bei den schwierigsten Unterfangen geholfen hast. Was hätte ich nur ohne unsere „R“-SkypeSessions gemacht?

Jacqueline Benner, weil du mit mir einfach durch „Dick und Dünn“ gegangen bist und mir in all den Jahren eine so gute Freundin geworden bist, die ich nicht mehr missen möchte.

Johann Eberl, weil du immer an meiner Seite bist.

Meiner Familie, ohne die das alles nicht möglich gewesen wäre und die mich immer unterstützt hat. Danke! 